\title{
(ब)
}

AUTARQUIA ASSOCIADA À UNIVERSIDADE DE SÃO PAULO

\section{ANÁLISE DO COMPORTAMENTO DA CONTENÇÃO DO REATOR ANGRA 2 DURANTE UM ACIDENTE DE BASE DE PROJETO}

DAYANE FARIA SILVA

Dissertação apresentada como parte dos requisitos para obtenção do Grau de Mestre em Ciências na Área de Tecnologia Nuclear - Reatores

Orientadora:

Profa. Dra. Gaianê Sabundjian 
INSTITUTO DE PESQUISAS ENERGÉTICAS E NUCLEARES

Autarquia associada à Universidade de São Paulo

\section{ANÁLISE DO COMPORTAMENTO DA CONTENÇÃO DO REATOR ANGRA 2 DURANTE UM ACIDENTE DE BASE DE PROJETO}

DAYANE FARIA SILVA

Dissertação apresentada como parte dos requisitos para obtenção do Grau de Mestre em Ciências na Área de Tecnologia Nuclear - Reatores

Orientadora:

Profa. Dra. Gaianê Sabundjian 


\section{AGRADECIMENTOS}

À Profa. Dra. Gaianê Sabundjian, pela valiosa orientação, amizade e ensinamentos, sem os quais não seria possível realizar este trabalho.

À Profa. Dra. Ana de Sousa Lima, pela ajuda e pelo companheirismo em todo o processo.

Ao Instituto de Pesquisas Energéticas e Nucleares, pela oportunidade do desenvolvimento deste trabalho.

Aos professores do mestrado e funcionários do IPEN que, de alguma forma, contribuíram para a minha formação.

Für Walter Klein Heßling, vielen Dank für die Hilfe beim Erlernen des COCOSYS Code. Viele Grüße aus der Ferne.

Ao meu pai, Lourenço, pelos ensinamentos que vão além do acadêmico. Por seu amor, carinho e pelo respeito à minha liberdade de escolher o meu caminho.

À minha irmã Lilian e meu cunhado Bruno, por tamanho amor, incentivo e companheirismo. Vocês são os exemplos que me inspiram.

À minha amada companheira, Bruna Trevenzoli, por estar sempre ao meu lado me fazendo acreditar que posso mais do que imagino. Graças à sua paciência, compreensão, apoio, alegria, amor e a várias doses do seu café, este trabalho pôde ser concretizado. Obrigada por ter feito do meu sonho o nosso sonho!

À Eunice Trevenzoli, amiga e parceira que a vida me trouxe como presente.

Aos amigos e colegas do IPEN, em especial à Paula Cristina Guimarães Antunes e Talita Salles, por toda ajuda, parceria e incentivo neste processo.

Aos meus alunos e ex-alunos, que são uma fonte de inspiração para o meu aperfeiçoamento.

E, acima de tudo, a Deus, por toda sabedoria, paciência e por ter colocado pessoas tão especiais em minha jornada. 
"Para ser grande, sê inteiro: nada

Teu exagera ou exclui.

Sê todo em cada coisa. Põe quanto és

No mínimo que fazes.

Assim em cada lago a Lua toda

Brilha, porque alta vive."

Fernando Pessoa 


\title{
ANÁLISE DO COMPORTAMENTO DA CONTENÇÃO DO REATOR ANGRA 2 DURANTE UM ACIDENTE DE BASE DE PROJETO
}

\author{
Dayane Faria Silva
}

\begin{abstract}
RESUMO
Este trabalho visa verificar a integridade da contenção do reator de Angra 2, com uma abordagem mais realista, da possibilidade de conter todos os radionuclídeos gerados durante Acidentes de Perda de Refrigerante Primário por Grande Ruptura (Large Break Loss of Coolant Accident - LBLOCA). Além disso, essas informações são utilizadas para o cálculo mais realista do Pico de Temperatura do Encamisamento (PTE) da vareta mais realista do núcleo deste reator durante esse acidente. Os resultados desse estudo possibilitarão verificar a integridade da Planta após a ocorrência de acidentes considerados base de projeto. Alguns dos programas utilizados para analisar a contenção de uma usina nuclear são o RELAP5 e o COCOSYS. Esses códigos computacionais são ferramentas de análise que preveem as condições termohidráulicas dentro de um prédio de contenção de um reator refrigerado à água leve. A contenção da planta tipo Pressurized Water Reactor (PWR) é um edifício de concreto revestido internamente por metal e tem limites de pressão que devem ser respeitados durante a ocorrência de um acidente. Os dados de entradas necessários para esta simulação são: adição de massa e energia geradas do estudo de um acidente do tipo LBLOCA com o código RELAP5 da planta em questão. Os resultados da análise do comportamento da contenção da planta nuclear Angra 2 durante os acidentes base de projetos estudados - rupturas do tipo guilhotina do circuito primário nas pernas fria e quente - foram satisfatórios quando comparados com os apresentados no Relatório de Análise de Segurança (RFAS/A2) da planta e as distribuições de pressão ficaram bem abaixo do valor de pressão de projeto da contenção (6,3bar).
\end{abstract}




\title{
ANALYSIS OF THE BEHAVIOR OF THE ANGRA 2 REACTOR CONTAINMENT DURING A DESIGN BASIS ACCIDENT
}

\author{
Dayane Faria Silva
}

\begin{abstract}
This work aims to verify the integrity of Angra 2 reactor containment by using a more realistic approach for the possibility of containing all radionuclides generated during a Large Break Loss of Coolant Accident (LBLOCA). In addition, this information is used for a more realistic calculation of the Peak Cladding Temperature (PCT) of the hottest area in the reactor during this accident. This study will contribute to the safety of the population from the surrounding areas after the occurrence of a design basis accident. Some of the programs used to analyze the containment of a nuclear plant are RELAP5 and COCOSYS. These computers codes are tools for analysis used for predicting the physical conditions and distributions of radionuclides inside a containment building following the release of material from the primary system in a light-water reactor accident. The containment of the type PWR plant is a concrete building coated internally with metal and has pressure limits to be respected during the occurrence of an accident. The simulation should be performed to ensure that the radionuclides originating from accidents in the plant are not released into the environment. The input data required for this simulation are: mass addition and energy generated from the simulation of an accident of the type Loss of Coolant Accident (LOCA) using RELAP5 code. The results of the analysis of the containment behavior of the Angra 2 nuclear plant during the design basis accidents studied guillotine-type ruptures of the primary circuit in the cold and hot legs - were satisfactory when compared to those presented in the Final Safety Analysis Report (FSAR) of the plant; moreover, the pressure distributions were below the contention design pressure value (6.3bar).
\end{abstract}




\section{SUMÁRIO}

Página

1. INTRODUÇÃO............................................................................................ 1

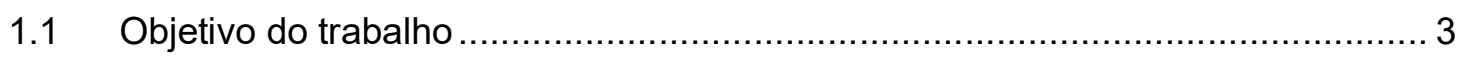

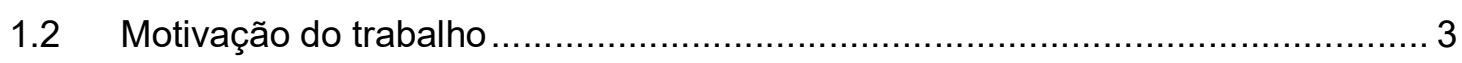

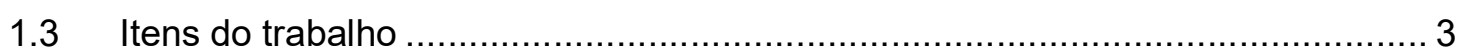

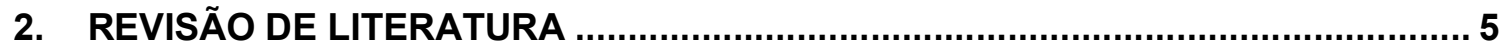

2.1 Aspectos gerais de segurança em plantas nucleares.................................... 6

2.1.1 Acidentes Base de Projeto ................................................................ 7

2.1.2 Descrição e consequências do LOCA …................................................. 9

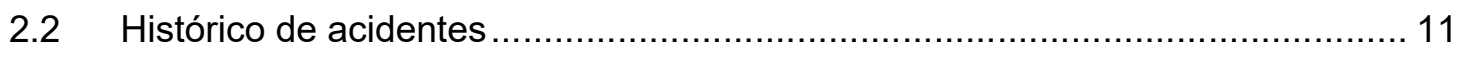

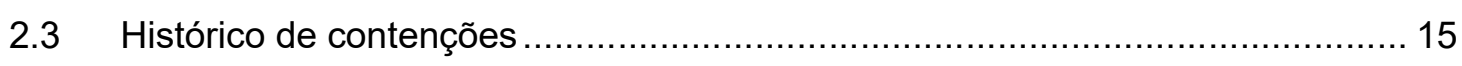

2.3.1 Tipos de contenção da primeira geração ............................................... 15

2.3.2 Tipos de contenção da segunda geração................................................... 17

2.3.3 Tipos de contenção da terceira geração ................................................ 24

2.3.4 Tipos de contenção da quarta geração .................................................. 30

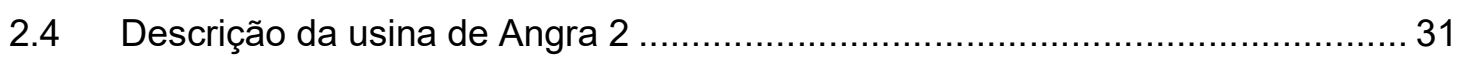

2.5 Evolução dos códigos computacionais de análise da contenção....................... 33

2.5.1 Containment Code (COCO) …........................................................ 34

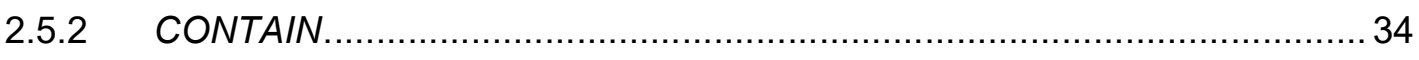

2.5.3 Containment Temperature Pressure Transient -Long Term (CONTEMPTLT)

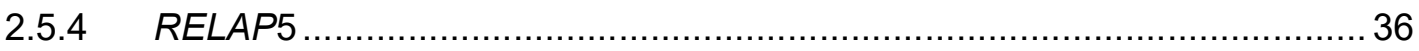

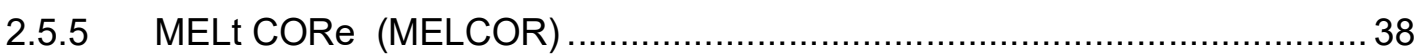

2.5.6 Containment Code System (COCOSYS) ......................................... 39

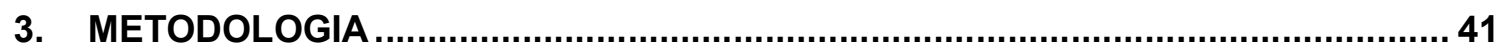

3.1 Simulação dos acidentes base de projeto com o código RELAP5 ...................... 42

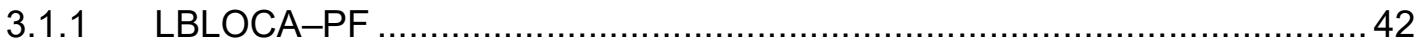

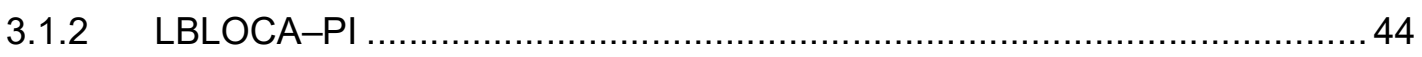

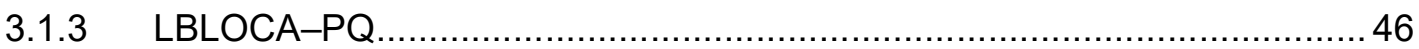




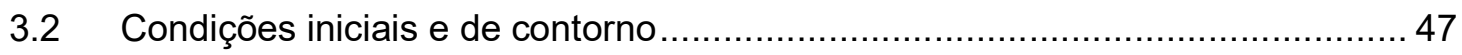

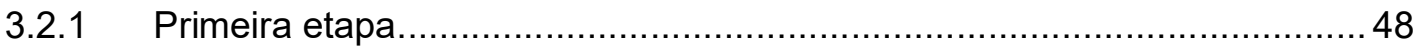

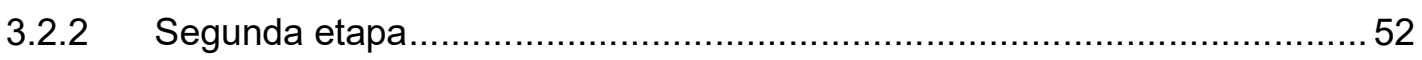

3.3 Modelagem da simulação da planta inteira de Angra 2 ................................ 53

3.4 Modelagem da contenção de Angra 2 com o código RELAP5 …...................... 54

3.5 Modelagem da contenção de Angra 2 com o código COCOSYS ...................... 56

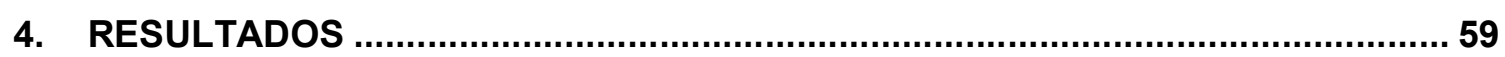

4.1 Resultados obtidos com o código RELAP5 …............................................... 59

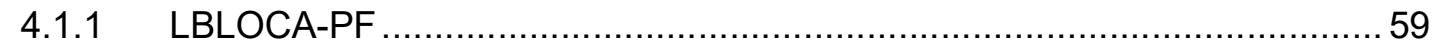

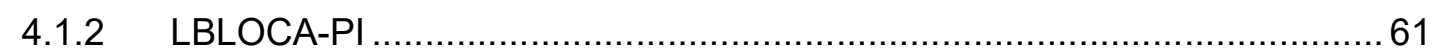

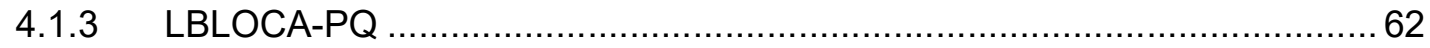

4.2 Resultados obtidos com o código COCOSYS ............................................... 64

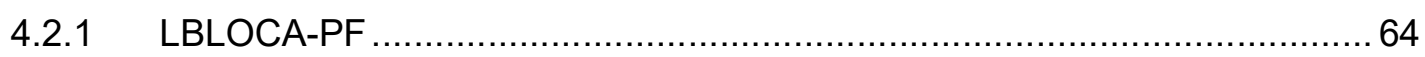

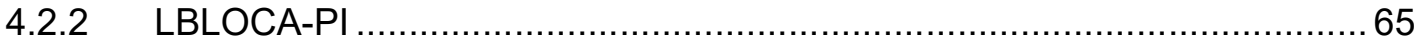

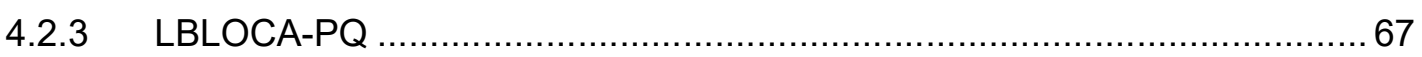

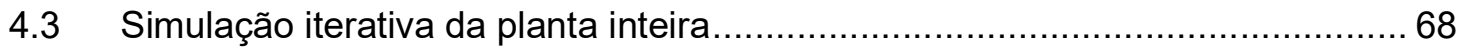

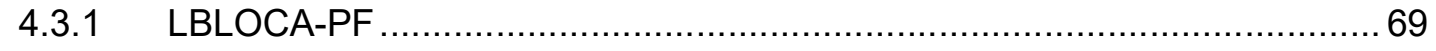

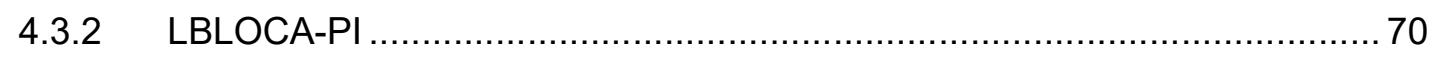

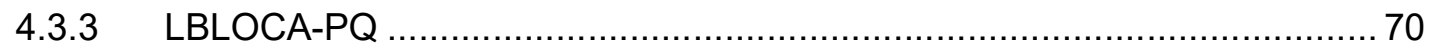

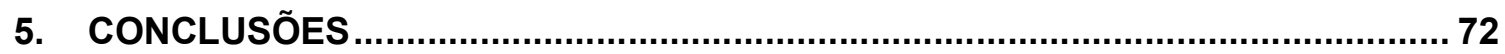

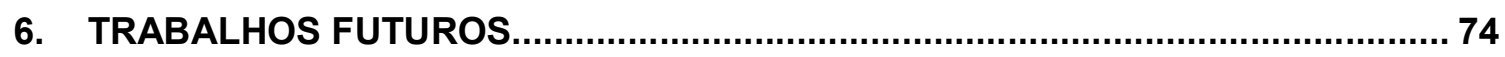

APÊNDICE A - Dados geométricos para a modelagem com o RELAP5 …................ 76

APÊNDICE B - Dados geométricos para a modelagem com o COCOSYS ............... 79

APÊNDICE C - Resultados de temperatura da vareta mais realista do núcleo para o processo iterativo ............................................................................................ 82

ANEXO A - Propriedades do Aço Austenítico WSTE 51 .......................................... 95

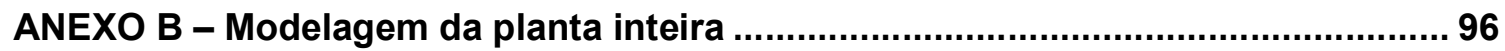

ANEXO C - Resultados da simulação da planta inteira ............................................ 102

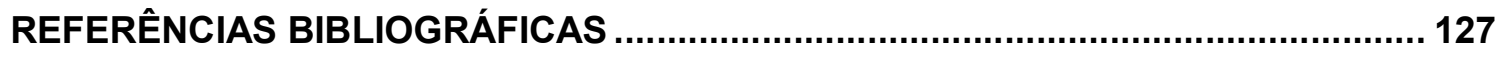




\section{LISTA DE TABELAS}

Tabela 1- Opções para combinação de códigos computacionais e dados de entrada

Tabela 2 - Disponibilidade dos componentes do SREN, LBLOCA-PF

Tabela 3 - Disponibilidade dos componentes do SREN, LBLOCA-PI .45

Tabela 4 - Disponibilidade dos componentes do SREN, LBLOCA-PQ .46

Tabela 5 - Condições iniciais da usina de Angra 2 .51

Tabela 6 - Condições geométricas e operacionais descritas no RFAS/A2 .52

Tabela 7 - Volumes definidos para cada abordagem utilizados para a simulação dos LBLOCA

Tabela 8 - Nodalização da Contenção de Angra 2: correspondência entre os componentes do código e as zonas hidráulicas.

Tabela 9 - Nodalização da Contenção de Angra 2: correspondência entre os componentes do código e as zonas hidráulicas. 


\section{LISTA DE FIGURAS}

Figura 1- Categorias dos Padrões de Segurança ......................................... 7

Figura 2 - Estrutura da contenção Mark I ................................................ 13

Figura 3 - Gerações de reatores ......................................................... 15

Figura 4 - Estrutura da contenção e sistemas internos da Usina de Shippingport 17

Figura 5 - Tipos de Contenção de BWR - Mark I, II e III.................................... 18

Figura 6 - Estrutura da Contenção Ice Condenser ......................................... 19

Figura 7- Estrutura da Contenção Dry Containmet ..........................................20

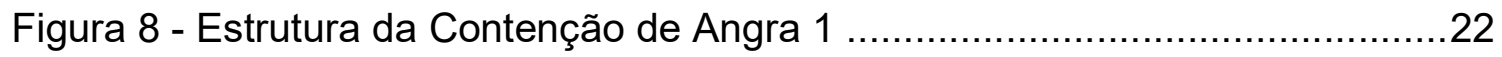

Figura 9 - Estrutura da Contenção de um Reator CANDU................................23

Figura 10 - Contenção e sistemas internos dos reatores AP600 e AP1000 .........25

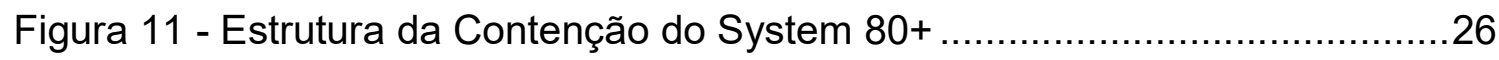

Figura 12 - Estrutura da Contenção do EC6 ............................................28

Figura 13 - Estrutura da Contenção e Compartimentos do Reator ABWR-GE ....29

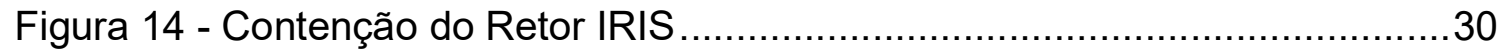

Figura 15 - Modelo do Prédio da Contenção de Angra 2 ....................................33

Figura 16 - Localização da quebra na tubulação da perna fria do circuito primário de Angra 2 (LBLOCA-PF) ................................................................. 44

Figura 17 - Localização da quebra na tubulação da perna fria do circuito primário de Angra2 (LBLOCA-PI)

Figura 18 - Localização da quebra na tubulação da perna quente do circuito primário (entrada do vaso) de Angra 2 (LBLOCA-PQ).

Figura 19 - Metodologia utilizada na análise da contenção, segundo o RFAS/A2 48 Figura 20 - Metodologia utilizada na análise da contenção com o código RELAP5

Figura 21 - Modelagem da contenção para o RELAP5

Figura 22 - Metodologia utilizada na análise da contenção com o código COCOSYS .57

Figura 23 - Modelagem da contenção para o COCOSYS .58

Figura 24 - Distribuição temporal da pressão na contenção dos casos simulados com o RELAP5 (LBLOCA-PF) 
Figura 25- Evolução temporal da temperatura na contenção dos casos simulados com o RELAP5 (LBLOCA-PF) 60

Figura 26 - Distribuição temporal da pressão na contenção dos casos simulados com o RELAP5 (LBLOCA-PI).

Figura 27 - Evolução temporal da temperatura na contenção dos casos simulados com o RELAP5 (LOCA-PI)

Figura 28 - Distribuição temporal da pressão na contenção dos casos simulados com o RELAP5 (LBLOCA-PQ)

Figura 29 - Evolução temporal da temperatura na contenção dos casos simulados com o RELAP5 (LBLOCA-PQ).

Figura 30 - Distribuição temporal da pressão na contenção dos casos simulados com o COCOSYS (LBLOCA-PF)

Figura 31 - Evolução temporal da temperatura na contenção dos casos simulados com o COCOSYS (LBLOCA-PF) .65

Figura 32 - Distribuição temporal da pressão na contenção dos casos simulados com o COCOSYS (LBLOCA-PI) .66

Figura 33 - Evolução temporal da temperatura na contenção dos casos simulado com o COCOSYS (LBLOCA-PI)

Figura 34 - Distribuição temporal da pressão na contenção dos casos simulados com o COCOSYS (LBLOCA-PQ).

Figura 35 - Evolução temporal da temperatura na contenção dos casos simulados com o COCOSYS (LBLOCA-PQ).

Figura 36 - Evolução temporal da temperatura do encamisamento na vareta mais realista do núcleo simulado com o RELAP5 (LBLOCA-PF). 69 Figura 37 - Evolução temporal da temperatura do encamisamento na vareta mais realista do núcleo simulado com o RELAP5 (LBLOCA-PI) .70 Figura 38 - Evolução temporal da temperatura do encamisamento na vareta mais realista do núcleo simulado com o RELAP5 (LBLOCA-PQ) .71 Figura 39 - Processo iterativo para o LBLOCA-PQ com o código COCOSYS .....74 


\section{LISTA DE SIGLAS E ABREVIAÇÕES}

BWR - Boiling Water Reactor

CNAAA - Central Nuclear Almirante Álvaro Alberto

CNEN - Comissão Nacional de Energia Nuclear

PI - Gerador de Vapor e Bomba (denominação para localização da quebra)

LOCA - Loss of Coolant Accident

LWR - Light-Water Reactor

IAEA - International Atomic Energy Agency

ICRP - International Commission on Radiological Protection

IPEN - Instituto de Pesquisas Energéticas e Nucleares

NISA - Nuclear and Industrial Safety Agency

NRC - Nuclear Regulatory Commission

PWR - Pressurized Water Reactor

$P Q$ - Perna Quente

PF - Perna Fria

PTE - Pico de Temperatura do Encamisamento

RBMK - Reaktor Bolshoy Moshchnosti Kanalnyy

RFAS/A2 - Relatório Final de Análise de Segurança de Angra 2

SREN - Sistema de Resfriamento de Emergência do Núcleo 


\section{INTRODUÇÃO}

A Agência Internacional de Energia Atômica (International Atomic Energy Agency - IAEA) preocupa-se que a segurança da população em torno de plantas nucleares seja garantida e, por isso, tem atuado fortemente neste sentido junto aos órgãos licenciadores dos países que possuem alguma instalação deste tipo. Essa preocupação intensifica-se diante de qualquer acidente que ocorra em reatores nucleares no mundo. Foi assim com os acidentes de Three Mile Island (US National Regulatory Commission, 1980), de Chernobyl (International Atomic Energy Agency, 1996) e de Fukushima (Tokyo Electric Power Company, 2012). Este último ocasionou graves consequências à população em torno das usinas nucleares e às cidades próximas, gerando insegurança com relação às instalações nucleares atualmente em operação. Portanto, a IAEA e a Comissão Nacional de Energia Nuclear (CNEN) têm realizado esforços na prevenção de acidentes e transientes em instalações nucleares para assegurar a integridade da população em geral.

Os órgãos reguladores do mundo incluíram nos seus relatórios de análise de segurança de reatores nucleares os estudos teóricos dos acidentes considerados como base de projeto (acidentes de perda de refrigerante primário) e, atualmente, estão sendo estudados os acidentes de condição estendida de projeto (fusão do núcleo), como os ocorridos em Chernobyl e Fukushima.

$\mathrm{Na}$ área termohidráulica, a análise de acidentes e transientes em reatores nucleares é feita com o uso de ferramentas computacionais sofisticadas, ou seja, códigos computacionais, tais como: Reactor Excursion and Leak Analysis Program (RELAP5) (ISL, 1994), Transient Reactor Analysis Code (TRAC) (Spore, 1993), Analysis of THermal-hydraulics of LEaks and Transients (ATHLET) (Wolfer et al., 1988) e Code for Analysis of THermalhydraulics during an Accident of Reactor and safety Evaluation (CATHARE) (Micaell; Bestuib, 1988).

A maioria desses programas possui uma filosofia realista (best estimate). Todos foram desenvolvidos para simular acidentes e transientes em reatores, principalmente, refrigerados a água leve do tipo Pressurized Water Reactor (PWR) e Boiling Water Reactor (BWR) e sistemas associados. No entanto, com o objetivo de atender à demanda de trabalhos na área de licenciamento de instalações nucleares 
no país, a ferramenta selecionada pelo órgão licenciador brasileiro, CNEN, é o código RELAP5, que tem um papel bastante importante nesse estudo.

O código RELAP5 tem a capacidade de simular Acidentes de Perda de Refrigerante (LOCA - Loss of Coolant Accident) por pequena ou grande ruptura e transientes operacionais. O primeiro passo para a simulação de uma planta com o RELAP5 é a nodalização dos circuitos em componentes hidrodinâmicos. Na modelagem, procura-se fazer a representação geométrica mais realista possível.

O desenvolvimento da nodalização da planta nuclear Angra 2 para o RELAP5 foi realizada num esforço conjunto entre os institutos da CNEN (IPEN Instituto de Pesquisas Energéticas e Nucleares de São Paulo e CDTN - Centro de Desenvolvimento da Tecnologia Nuclear) e os integrantes do Serviço de Avaliação de Segurança (SEAS) da sede (Andrade et al., 2003). Esse estudo teve a finalidade de dar suporte ao processo de qualificação de Angra 2 em caso de transientes e acidentes.

De posse dos dados de adição de massa e energia gerados quando da simulação de um acidente de perda de refrigerante primário com RELAP5 é possível verificar a integridade da planta.

O RELAP5 também pode ser utilizado para a análise da contenção de uma planta nuclear, que é um prédio de concreto revestido internamente por metal e possui limites de pressão de projeto que deverão ser respeitados durante a ocorrência de um acidente.

Além do RELAP5, há outros códigos computacionais que realizam a análise da contenção em caso de acidentes, tais como: CONTAIN (Murata et al. 1997), Containment Code (COCO) (Rickard, 1978), Containment Code System (COCOSYS), entre outros (Klein-Hessling et al., 2000).

Esse estudo deve ser realizado para verificar a integridade da contenção e para que todos os radionuclídeos oriundos dos acidentes ocorridos na planta não sejam liberados para o meio ambiente. 


\subsection{Objetivo do trabalho}

O objetivo deste trabalho é a análise mais realista do comportamento da contenção de Angra 2 com os códigos RELAP5 e COCOSYS durante um LOCA. Ademais, estas informações são utilizadas para o cálculo mais realista do Pico de Temperatura do Encamisamento (PTE) da vareta mais realista do núcleo do reator durante esse acidente.

Os acidentes estudados nesse trabalho são os de perda de refrigerante primário por grande ruptura (LBLOCA - Large Break LOCA) da tubulação do circuito primário de Angra 2, simulados com o RELAP5. Esses acidentes estão descritos no Relatório Final de Análise de Segurança de Angra 2 (RFAS/A2) (Eletronuclear, 2010), a saber:

- Ruptura na perna quente, entre o vaso do reator e o gerador de vapor;

- Ruptura na seção da bomba, entre o gerador de vapor e a bomba do primário;

- Ruptura na perna fria, entre a bomba do primário e o vaso de pressão.

As rupturas descritas são todas as consideradas como LBLOCA no RFAS/A2.

\subsection{Motivação do trabalho}

A primeira motivação desse trabalho é garantir a integridade da contenção de Angra 2 e conter todos os radionuclídeos gerados durante os LBLOCA nessa instalação. A outra motivação é a de estabelecer uma metodologia baseada no RFAS/A2 para o cálculo mais realista do comportamento da contenção utilizando dois códigos: o RELAP5 e o COCOSYS. No Brasil, o COCOSYS foi utilizado pela primeira vez.

\subsection{Itens do trabalho}

No capítulo 2 serão apresentados a revisão bibliográfica dos aspectos gerais de segurança em plantas nucleares, um breve histórico dos principais acidentes 
nucleares, os tipos de contenção nos projetos nucleares no mundo e os programas computacionais utilizados no estudo termohidráulico das mesmas.

O capítulo 3 contempla a metodologia utilizada, descrevendo os tipos de acidentes analisados nesse trabalho e a modelagem proposta para cada software em cada etapa.

No capítulo 4, são apresentados os resultados das simulações realizadas com os códigos RELAP5 e COCOSYS.

O capítulo 5 apresenta as discussões dos resultados obtidos e as conclusõs.

No capítulo 6, estão as sugestões para trabalhos futuros.

Finalmente, são fornecidas as referências bibliográficas utilizadas no trabalho.

Os APÊNDICES A e B contêm as condições de contorno utilizadas para a simulação da contenção com o RELAP5 e COCOSYS, respectivamente.

O APÉNDICE $C$ apresenta os principais resultados de temperatura do núcleo.

No ANEXO A estão definidas as propriedades do aço que constitui a contenção de Angra 2.

O ANEXO B apresenta a modelagem da planta de Angra 2.

No ANEXO C estão os resultados da planta inteira sem o processo iterativo. 


\section{REVISÃO DE LITERATURA}

Em uma planta nuclear, o confinamento do material radioativo é uma função fundamental de segurança a ser garantida, tanto em operação normal quanto em caso de ocorrências operacionais previstas (transientes operacionais), acidentes base de projeto e, na medida do possível, acidentes de condição estendida de projeto (International Atomic Energy Agency, 2000).

Em conformidade com esse conceito de defesa em profundidade, um dos níveis de defesa adotado no projeto das plantas nucleares é uma estrutura que envolve o reator, denominada contenção. Além de proteger o reator de eventos externos, a contenção fornece blindagem da radiação em operação normal e também em caso de transientes e acidentes.

A IAEA é o organismo internacional que recomenda e define características fundamentais no projeto de sistemas da contenção nos padrões de segurança das plantas nucleares no mundo. Cinco categorias de eventos internos que podem ocorrer nas plantas são considerados e, para esses casos, o desempenho do sistema da contenção e suas funções devem (International Atomic Energy Agency, 2004):

- suportar altas pressões e temperaturas, assim como os impactos devido ao chicoteamento e aos jatos de fluidos nas tubulações;

- ser capaz de confinar o material radioativo;

- suportar as cargas de pressão ou temperatura provenientes de transientes ocorridos na planta;

- suportar as cargas advindas de acidentes do tipo LOCA ou devido a rupturas nos tubos do gerador de vapor;

- suportar outros tipos de riscos internos, como mísseis internos, que não prejudiquem as funções da contenção.

A contenção também deverá suportar os eventos externos, devido a falhas humanas (por exemplo, queda de aviões), atentados terroristas e acidentes naturais (terremotos, furacões, ciclones, erupções vulcânicas, temperaturas extremas, tsunamis, enchentes, entre outros) (International Atomic Energy Agency, 2004). 


\subsection{Aspectos gerais de segurança em plantas nucleares}

A cultura de qualquer organização nuclear está centrada em segurança. A Nuclear Regulatory Commission (NRC) define:

"Uma boa cultura de segurança em uma instalação nuclear é um reflexo dos valores que são compartilhados em todos os níveis da organização e que se baseiam na crença de que a segurança é importante e que é responsabilidade de todos (International Atomic Energy Agency, 2006)."

Essa filosofia foi desenvolvida com o início do funcionamento do órgão regulador, a IAEA, e conforme as centrais nucleares foram sendo implantadas em todo o mundo.

A IAEA tem como missão promover o uso pacífico da energia nuclear, prevenir a proliferação de armas nucleares e, especialmente, após o acidente de Chernobyl ${ }^{1}$, promover padrões elevados de segurança.

As Séries de Normas de Segurança (Safety Standards Series), definidas pela agência, expressam o que é um alto nível de segurança para proteger a população e o meio ambiente dos efeitos deletérios da radiação ionizante e os classifica em três categorias (International Atomic Energy Agency, 2006):

- Fundamentos de Segurança

- Requerimentos de Segurança

- Guias de Segurança

Os Fundamentos de Segurança apresentam os objetivos e princípios de proteção considerados fundamentais na segurança. Esses servem de base para os Requerimentos de Segurança, um conjunto de requisitos a serem cumpridos por uma instalação a fim de garantir a proteção dos indivíduos e do meio ambiente no entorno da planta. Os Guias de Segurança orientam sobre como cumprir tais requerimentos e práticas recomendados de consenso internacional (International Atomic Energy Agency, 2006).

\footnotetext{
${ }^{1}$ Chernobyl cumpria toda a regulamentação imposta pela IAEA. Após o acidente, as diretrizes do órgão se tornaram mais severas.
} 
A FIG. 1 apresenta a estrutura desses padrões.

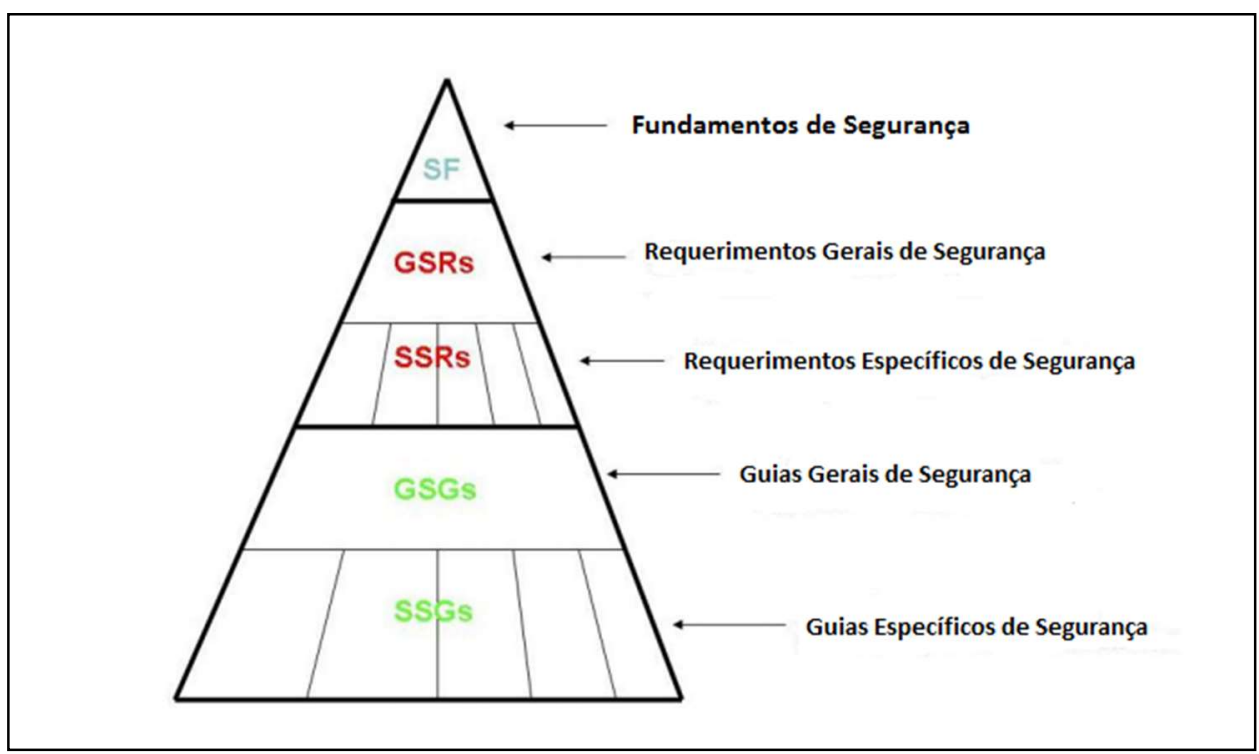

Fonte: IAEA, 2016

FIGURA 1- Categorias dos Padrões de Segurança

O Guia Específico de Segurança NS-G-1.10, intitulado "Projeto de Sistema de Contenção de Reatores para Centrais Nucleares", estabelece recomendações aos Estados membros da IAEA para concepção, fabricação, construção e operação do sistema de contenção de reatores nucleares (International Atomic Energy Agency, 2004).

\subsubsection{Acidentes Base de Projeto}

Os acidentes base de projeto para o sistema de contenção são o conjunto de possíveis sequências de eventos considerados para se avaliar a integridade da contenção e as consequências radiológicas para os trabalhadores, civis e para o meio ambiente.

Os acidentes base de projeto relevantes para o sistema de contenção são os que têm potencial de causar um excessivo carregamento mecânico nas estruturas e/ou no sistema da contenção, como também de prejudicar a função de limitar a fuga de material radioativo para o meio ambiente (International Atomic Energy Agency, 2014).

Nas avaliações desse tipo de acidente, os códigos computacionais e os métodos escolhidos para verificação das consequências de um evento iniciador 
(postulado) devem garantir margem ${ }^{2}$ de segurança suficiente para toda a sequência de eventos dentro dos limites estabelecidos pelo órgão regulador (International Atomic Energy Agency, 2004). Todas as avaliações devem ser adequadamente documentadas com indicação dos parâmetros analisados, códigos computacionais adotados e critérios de aceitação usados (International Atomic Energy Agency, 2014).

Existem diferentes opções de cálculo na área de acidentes, combinando a utilização de códigos computacionais e dados de entrada para fins de licenciamento. Quatro opções podem ser identificadas (Fiori, 2009):

- abordagem muito conservativa, demonstrada no Apêndice K do 10 Code of Federal Regulations (CFR) 50.46 (USNRC, 1974), para análise no caso de Loss of Coolant Accident (LOCA);

- abordagem conservativa realista, sendo esta similar à primeira, com exceção ao fato de que são utilizados códigos computacionais Best Estimate (BE) ou realistas, no lugar de códigos conservativos;

- condições inicias e de contorno tomadas como realistas, considerando suas incertezas (Best Estimate Plus Uncertainty - BEPU);

- abordagem realista considerando as condições reais de operação da instalação e o uso de códigos BE.

Essas opções encontram-se na TAB. 1, sendo que a opção 2 é a adotada neste trabalho.

\footnotetext{
${ }^{2}$ As margens consideradas são relacionadas a incertezas físicas, incertezas de projeto (como de envelhecimento de estruturas) e margens de operação (incluindo falha do operador).
} 
TABELA 1- Opções para combinação de códigos computacionais e dados de entrada

\begin{tabular}{l|l|l|l|l}
\hline $\mathbf{N}^{\circ}$ & Opção & $\begin{array}{l}\text { Código } \\
\text { computacional }\end{array}$ & $\begin{array}{l}\text { Disponibilidade de } \\
\text { sistemas }\end{array}$ & $\begin{array}{l}\text { Condições iniciais e de } \\
\text { contorno }\end{array}$ \\
\hline 1 & Conservativa & Conservativo & $\begin{array}{l}\text { Premissas } \\
\text { conservativas }\end{array}$ & $\begin{array}{l}\text { Dados de entrada } \\
\text { conservativos }\end{array}$ \\
\hline $\mathbf{2}$ & Combinada & Best estimate & $\begin{array}{l}\text { Premissas } \\
\text { conservativas }\end{array}$ & $\begin{array}{l}\text { Dados de entrada } \\
\text { conservativos }\end{array}$ \\
\hline 3 & $\begin{array}{l}\text { Best estimate } \\
\text { (BEPU) }\end{array}$ & Best estimate & $\begin{array}{l}\text { Premissas } \\
\text { conservativas }\end{array}$ & Realista mais incertezas \\
\hline 4 & $\begin{array}{l}\text { Risco } \\
\text { Informado } \\
\text { (BEPU } \\
\text { estendido) }\end{array}$ & Best estimate & Derivada da APS & $\begin{array}{l}\text { Dados de entrada realistas } \\
\text { mais análise de incertezas }\end{array}$ \\
\hline
\end{tabular}

\subsubsection{Descrição e consequências do LOCA}

O LOCA é definido como um acidente que resulta na perda do refrigerante que vai além da capacidade de restauração do sistema de controle volumétrico de refrigeração (United States Nuclear Regulatory Commission, 1980). O tamanho da ruptura resultante no acidente define se é um grande (de $1100 \mathrm{~cm}^{2}$ à $2 A$-guilhotina), médio (de $3 \mathrm{~cm}^{2}$ à $1100 \mathrm{~cm}^{2}$ ) ou pequeno (menor que $3 \mathrm{~cm}^{2}$ ) LOCA.

A sequência de um LOCA pode ser dividida em três fases (Eletronuclear, 2010):

- Despressurização (Blowdown): período entre o início do acidente e o instante em que a pressão do sistema de refrigeração do reator atinge o equilíbrio com a pressão do confinamento (contenção). Uma grande quantidade de massa e energia do refrigerante é lançada para a região do sump ${ }^{3}$ e se propaga pela contenção. Dura aproximadamente 17,5s;

- Reenchimento (Refill): período após o término da despressurização até o instante em que o pleno inferior do vaso do reator esteja preenchido por meio da água do Sistema de Refrigeração de Emergência do Núcleo (SREN). Nessa

\footnotetext{
${ }^{3}$ O sump é parte do Sistema de Refrigeração de Emergência do Núcleo (ECCS). No caso de um LOCA, é para a região do sump que o refrigerante escoa, servindo assim como fonte de água de recirculação, remoção de calor residual e resfriamento de emergência do núcleo.
} 
fase ocorre ainda a troca de calor do circuito secundário para o primário dentro do gerador de vapor;

- Reinundação (Reflood): período de refrigeração em longo prazo do núcleo. A água do sump, após recircular até o tempo de cerca de 1200s, cai rapidamente diminuindo, assim, a pressão dentro da contenção.

O acidente considerado mais grave para a integridade da contenção é o LOCA tipo guilhotina, devido aos picos de pressão e temperatura que podem atingir níveis muito altos em pouco tempo. Um dos requisitos no projeto de uma usina é que o prédio da contenção suporte as pressões e temperaturas resultantes desses acidentes (United States Nuclear Regulatory Commission, 1980).

As três localizações do circuito primário onde pode ocorrer este tipo de quebra são:

- Perna Fria - no circuito primário entre a bomba e o vaso de pressão (PF).

- Perna Intermediária - ruptura entre a saída do gerador de vapor e uma bomba do circuito primário $(\mathrm{PI})$.

- Perna Quente - ruptura entre a saída do vaso de pressão e a entrada de um gerador de vapor (PQ).

Iniciado o acidente, as temperaturas das estruturas internas da contenção são menores que as da atmosfera no seu interior, e o principal processo de remoção de energia do vapor ocorre por meio da transferência de calor (a condensação do vapor) para as estruturas e paredes internas da contenção. Após a abrupta despressurização do primário, ainda há liberação de vapor produzido pela refrigeração de emergência na remoção de calor residual do combustível.

A pressão na contenção diminui à medida que a taxa de remoção de calor pelas estruturas e sistemas de segurança excedem a taxa de adição de energia pelo primário.

Segundo a CNEN, para os cálculos dos valores de projeto da pressão e temperatura na contenção em caso desse tipo de acidente, deve-se considerar a usina em condições nominais de operação (100\% de carga). 


\subsection{Histórico de acidentes}

As consequências de um acidente em uma usina nuclear dependem das características de segurança da contenção e de seu desempenho em conter os radionuclídeos liberados durante $\mathrm{o}$ acidente. Se as condições estruturais da contenção se mantiverem, mesmo no caso de um acidente considerado severo (denominado acidente com condição estendida de projeto), as consequências radiológicas são minimizadas. Entretanto, se a integridade da contenção for comprometida, o tempo entre o acidente e a falha estrutural é um fator importante a ser considerado. Quanto maior o tempo que a barreira física se mantiver intacta, maior o tempo para que os dispositivos de segurança instalados eliminem o material radioativo dentro do confinamento da contenção (United States Nuclear Regulatory Commission, 1990).

Neste item são abordados os principais acidentes mais graves ocorridos no mundo e o desempenho da contenção/confinamento em meio aos acidentes.

Em 28 de março de 1979 ocorreu, na unidade 2 do reator da usina nuclear de Three Mile Island (TMI-2), o acidente considerado mais grave em central nuclear comercial dos Estados Unidos. Esta usina, do tipo PWR, projetada pela Babcock \& Wilcox e operada pela Metropolitan Edson Co., situa-se na ilha Three Mile Island no Rio Susquehanna, no Estado da Pennsylvania (United States Nuclear Regulatory Commission, 1980).

O acidente iniciou-se com uma falha no circuito secundário, que não permitiu que as bombas fornecessem água para os geradores de vapor, responsáveis por eliminar o calor residual do núcleo. Assim, a pressão no circuito primário aumentou, acionando automaticamente a válvula de alívio do pressurizador. Entretanto, a válvula não fechou após a despressurização. A partir desse momento, por seguidas falhas mecânicas, elétricas e, até humanas, o nível de água dentro do vaso do reator começou a cair devido à despressurização do refrigerante do primário, iniciando um superaquecimento do núcleo (Corey, 1979).

Mais tarde, o sistema de isolamento do prédio da contenção do reator foi acionado automaticamente. Pelo projeto da planta, o isolamento da contenção é automaticamente acionado quando a pressão no interior do prédio ultrapassa a 4,0psig. Em poucas horas, a pressão passou de 4,5psig para $28 p s i g$ dentro do 
confinamento da contenção (Oliveira, 1982). Esse pico de pressão foi resultado de combustão de hidrogênio gerado pela reação zircaloy-água, que passou para a contenção por meio da válvula de alívio do pressurizador aberta.

Pode-se afirmar que as consequências radiológicas desse acidente teriam proporções alarmantes caso as condições físicas e estruturais da contenção tivessem sido comprometidas, o que não aconteceu.

Outro acidente, considerado pela IAEA "uma das maiores catástrofes da história da humanidade", foi o da usina nuclear de Chernobyl, na Ucrânia (Kinly, 2006). O acidente teve início em 26 de abril de 1986 durante um teste na unidade 4 do reator RBMK-1000. O reator foi operado por um longo período a uma potência muito abaixo do limite inferior de segurança, o que acarretou o aumento de reatividade e superaquecimento do núcleo. Ocorreu, então, uma explosão que destruiu o vaso do reator, assim como a fina camada de concreto do prédio do reator (Kortov; Ustyantsev, 2013).

A nuvem formada por essa queima continha vários tipos de materiais radioativos, entre eles o lodo-131 - significante para doses da tireoide - e o césio-137 que, devido ao seu período de meia-vida (em média, 30 anos), ainda pode ser mensurado no solo e na vegetação em algumas regiões da Europa.

Caso a usina tivesse um prédio de contenção apropriado, dentro das normas de segurança atuais, o impacto do acidente teria sido minimizado.

A IAEA apontou que a primeira geração de plantas RBMK foi projetada de acordo com os princípios e normas de segurança estipulados para a década de 60 (International Atomic Energy Agency, 1996). Com o avanço tecnológico e o maior rigor nas normas de segurança, várias características do design original, como a falta de um sistema de contenção eficiente, ficam aquém dos requisitos de segurança em vigor.

Em 11 de março de 2011, um tsunami causado pelo abalo sísmico de magnitude 9 (escala Richter) na costa nordeste do Japão foi o desencadeador do acidente na central nuclear Fukushima Daiichi. A usina, com seis reatores do tipo BWR, é operada pela Tokyo Electric Power Company (Marques, 2011). A contenção dessa planta, para as unidades 1 a 5, foi projetada pelo modelo Mark I (FIG. 2).

Nesse modelo, o vaso de pressão e as bombas de recirculação ficam dentro de uma estrutura de aço em forma de ampola, denominada drywell. Essa se 
apoia em uma estrutura de anel, designada wetwell, que contém uma grande quantidade de água para suprimir picos de pressão que possam ocorrer no reator. As duas estruturas juntas funcionam para um reator BWR, assim como o prédio da contenção, para um reator PWR. Nesse projeto, o edifício serve apenas como uma contenção secundária (Marques, 2011).

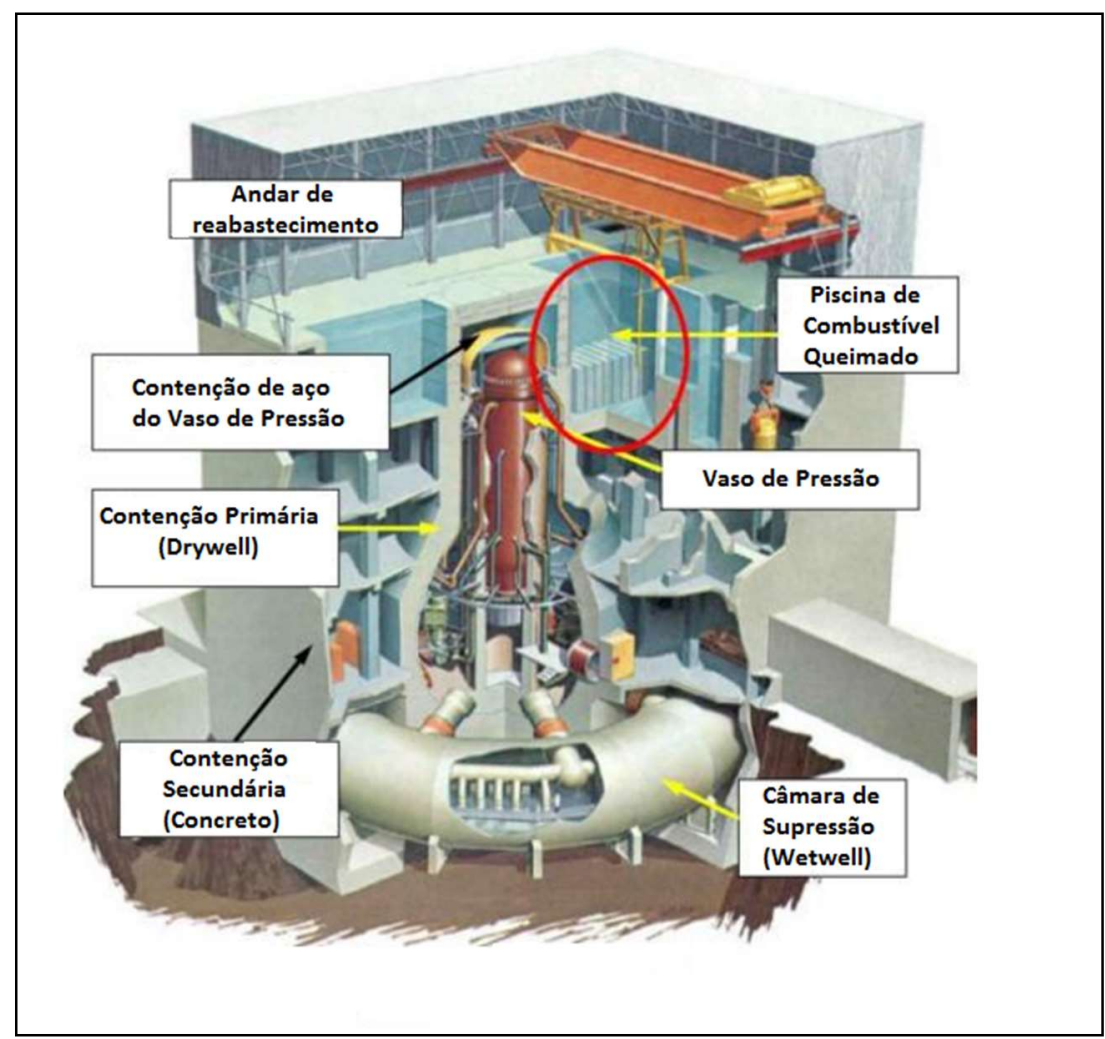

Fonte: Marques, 2011.

FIGURA 2 - Estrutura da contenção Mark I

No momento do abalo sísmico, ocorreu o scram 4 automático nas unidades 1, 2 e 3 da usina. As unidades 4, 5 e 6 não estavam em operação (Tokyo Electric Power Company, 2012). Porém, com a chegada do tsunami, os edifícios e os meios de fornecimento de emergência (geradores a diesel) da central foram inundados, e a instalação ficou seriamente danificada. Com a falta de fornecimento de eletricidade contínua, os mecanismos de refrigeração do núcleo se desligaram e o aumento da temperatura no núcleo acelerou a reação de oxidação do revestimento das varetas

\footnotetext{
${ }^{4}$ Scram ou SCRAM é um desligamento de emergência de um reator nuclear.
} 
combustíveis, constituídas de zircaloy, liberando hidrogênio (Tokyo Electric Power Company, 2012).

Com o aumento da pressão na Unidade 1, às $14 \mathrm{~h} 30$ do dia 12 de março, a ventilação dentro da contenção (abertura da válvula de alívio) foi autorizada, devido ao receio de ruptura desta pela alta pressão. Às 15h36, ocorreu uma explosão do hidrogênio disperso no prédio do reator. O teto da contenção secundária foi danificado, mas a contenção primária da Unidade 1 permaneceu intacta (Marques, 2011). Às $11 \mathrm{~h} 01$ do dia 14 de março, ocorreu uma nova explosão, na unidade 3 , que destruiu a parte superior do prédio, liberando detritos radioativos. A unidade 2 foi afetada devido às duas explosões. Em 15 de março, mais uma explosão ocorreu, dessa vez na unidade 4, possivelmente devido à entrada de hidrogênio liberado na ventilação da unidade 3 (Tokyo Electric Power Company, 2012). Os geradores e as piscinas das unidades 5 e 6 não sofreram danos.

Embora a exposição da população tenha sido abaixo dos limites que causam efeito na saúde de um indivíduo (20mSv/ano) e, mesmo sem ocorrência de mortes devido à radiação, os trabalhadores dessa central nuclear sofreram uma considerável exposição à radiação (Sagi, 2013).

Uma ordem de evacuação para o raio de $30 \mathrm{~km}$ da central foi emitida pelo governo quando o órgão regulador japonês, Nuclear and Industrial Safety Agency (NISA), confirmou a presença relevante de concentração de lodo-131 e de Césio-137 nas imediações do reator. O Comitê Internacional de Proteção Radiológica (International Comitee Radiologic Protection - ICRP) considera que levará anos para que a população evacuada possa retornar ao local (Sagi, 2013).

No ano de 2014, durante uma seção especial na $6^{\circ}$ Reunião de Revisão das Partes Contratantes da Convenção sobre Segurança Nuclear, foram discutidas possíveis melhorias no setor de segurança nuclear (International Atomic Energy Agency, 2015). As Partes Contratantes reportaram algumas medidas para a melhoria da segurança como, por exemplo, assegurar a implementação de métodos eficazes para preservar a integridade da contenção e sua funcionalidade (International Atomic Energy Agency, 2014). O relatório define a integridade da barreira da contenção como fundamental para a proteção da população e do ambiente no caso de um acidente. 


\subsection{Histórico de contenções}

Embora existam vários projetos distintos de contenções para os diferentes modelos de plantas nucleares em todo o mundo, pode-se distingui-los devido a algumas de suas características principais, como o tipo de reator.

Atributos, como segurança e eficiência, definem a evolução das quatro gerações de reatores de potência, como mostra a FIG. 3 (United States Department of Energy, 2002).

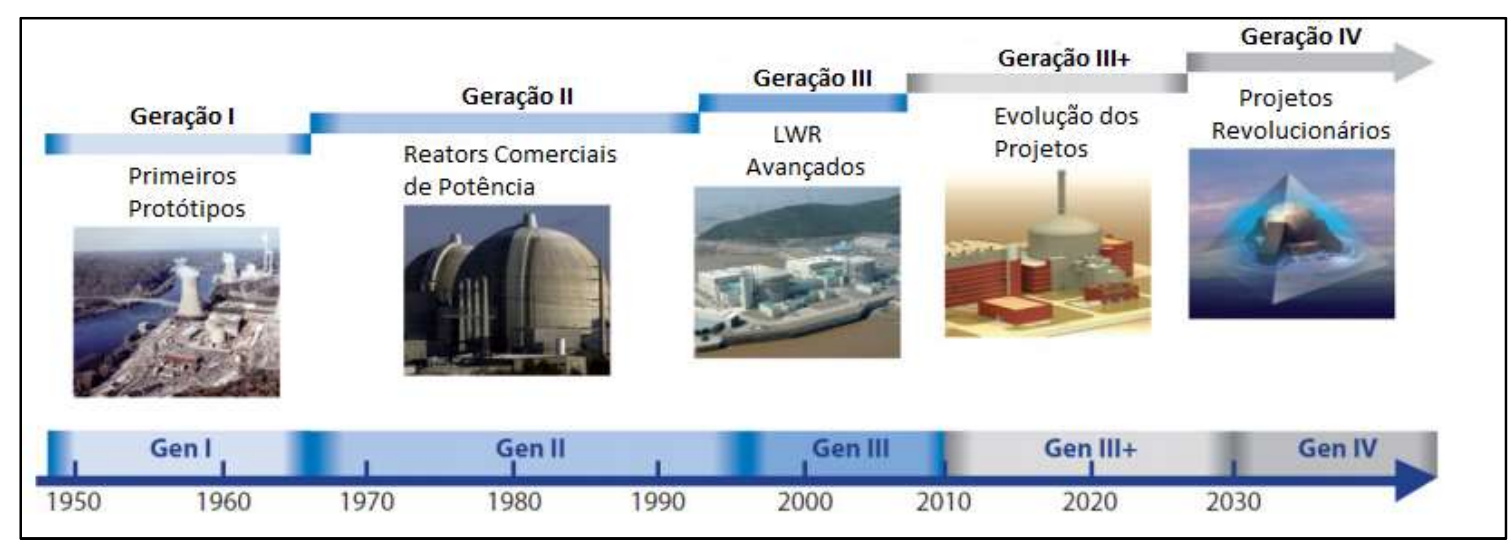

Fonte: US-DOE, 2002.

FIGURA 3 - Gerações de reatores

No item a seguir, será apresentada uma descrição das contenções de alguns dos projetos de reatores mais relevantes classificados por geração.

\subsubsection{Tipos de contenção da primeira geração}

Os reatores de Geração I, como o Shippingport (1957-1982), nos Estados Unidos, e o Calder Hall-1 (1956-2003), no Reino Unido, foram desenvolvidos entre 1950 e 1960. Atualmente, não há mais nenhum reator dessa geração em funcionamento.

A primeira planta nuclear do mundo, Calder Hall, usava um Reator Refrigerado a Gás (Gas-Cooled Reactor - GCR), conhecido também como Magnox, por ser o revestimento do combustível (urânio natural metálico) uma liga de magnésio. Esse modelo de reator não possuía a quarta barreira de proteção, ou seja, uma estrutura de contenção que abrigaria o reator e seus componentes. O vaso de pressão era a última barreira de proteção no Magnox (Jensen; Nobol, 1998). 
A usina de Shippingport foi a primeira planta equipada com um reator do tipo PWR. Construído no estado da Pennsylvania, nos Estados Unidos, é considerado o primeiro reator de potência em larga escala do país (United States Nuclear Regulatory Commission, 2016). Seu projeto trouxe grandes contribuições técnicas ao setor civil de energia nuclear, pois alguns dos componentes fundamentais, como bombas de refrigerante, válvulas e geradores de vapor foram projetados e fabricados pela primeira vez. Também foi pioneiro no uso de dióxido de urânio em pastilhas como combustível e varetas de encamisamento feitas de zircaloy (Duncan; Holl, 1983).

$\mathrm{Na}$ época, por ser um projeto sem precedentes, utilizou-se uma filosofia conservadora: a segurança foi o primeiro requisito estabelecido. $O$ refrigerante ficaria contido em um sistema selado e resistente à corrosão. A fim de manter o nível seguro de água dentro do vaso do reator, mesmo no caso de um LOCA (acidente potencial mais severo projetado até então), todas as tubulações ligadas ao vaso possuíam válvulas de isolamento, operadas automaticamente ou remotamente. Embora fossem necessários apenas três circuitos para a plena operação do reator, considerou-se adicionar um quarto circuito por questões de segurança, permitindo também manutenção em um dos circuitos sem necessidade do desligamento do reator (Duncan; Holl, 1983).

A filosofia conservadora de segurança também definiu inicialmente algumas barreiras de separação entre o combustível radioativo e o meio ambiente. A primeira barreira seria a vareta de zircaloy que envolve as pastilhas de combustível; a segunda, as paredes do sistema primário de refrigeração; a terceira, dois compartimentos blindados localizados ao lado do vaso do reator que abrigavam, cada um, dois circuitos do primário separados por uma parede de concreto.

Em seu projeto final, pela primeira vez na história, Shippinport contava com uma contenção que era subdividida em uma estrutura esférica e subterrânea de concreto para comportar o vaso do reator; duas câmaras laterais e mais uma câmara para equipamentos auxiliares (Duncan; Holl, 1983).

Os compartimentos, indicados na FIG. 4, tinham volumes projetados para conter todo o vapor resultante da liberação do refrigerante em caso de acidente. Feita de concreto, a estrutura da contenção tinha a espessura de aproximadamente $1,5 \mathrm{~m}$ de base e paredes e altura de aproximadamente $16 \mathrm{~m}$, coberta por laje. 


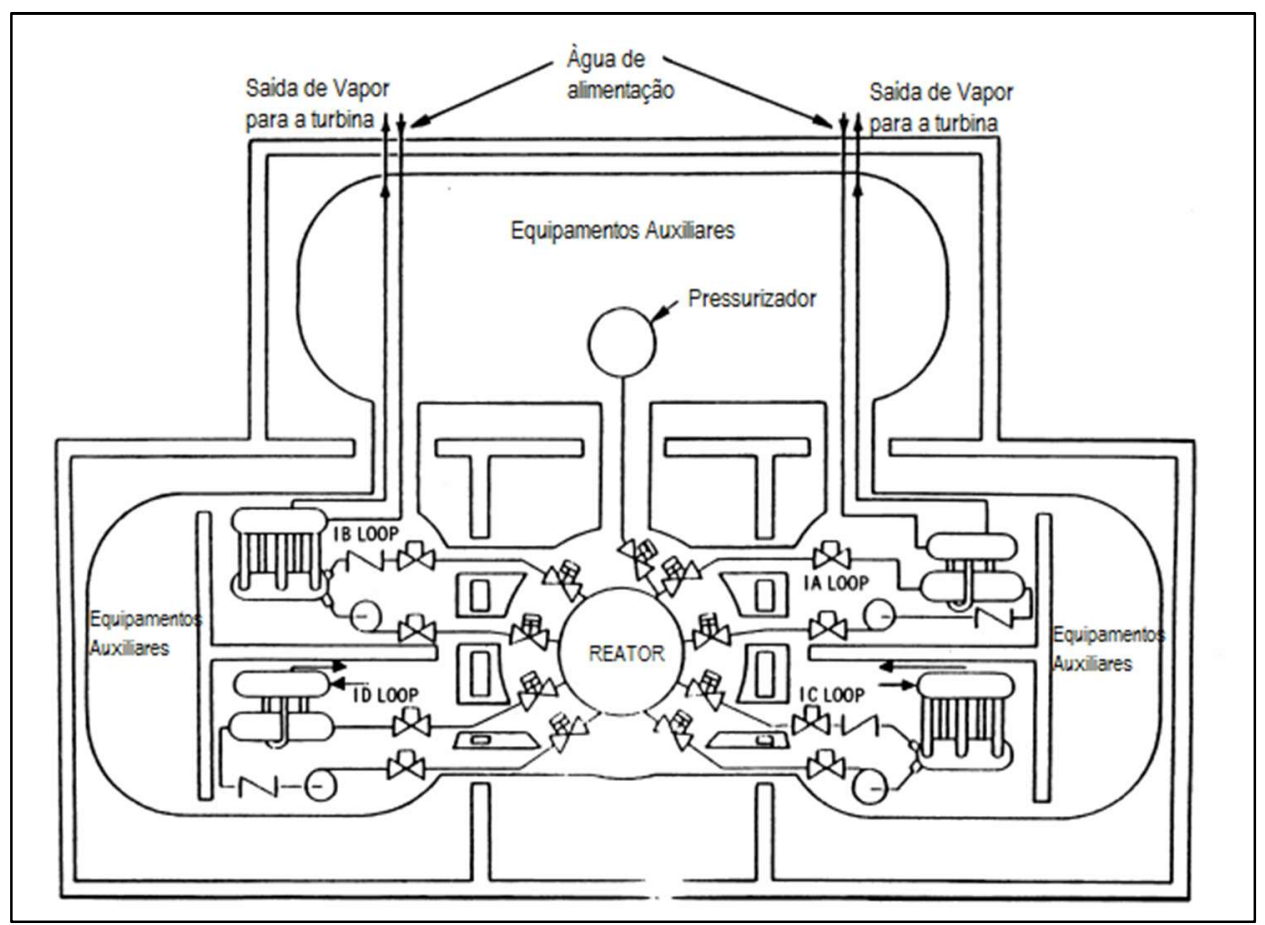

Fonte: Duncan e Holl, 1983.

FIGURA 4 - Estrutura da contenção e sistemas internos da Usina de Shippingport

\subsubsection{Tipos de contenção da segunda geração}

A Geração II engloba os reatores comerciais projetados para serem econômicos, de maior segurança e com vida operacional, em média, de 40 anos. Esses reatores podem ser, de maneira geral, dos tipos Boiling Water Reactor (BWR), Pressurized Water Reactor (PWR), Canadian Deuterium-Uranium (CANDU), WaterWater Energetic Reactor ${ }^{5}$ (VVER) e Advanced Gas-cooled Reactors (AGR). As plantas dessa geração iniciaram seu funcionamento no fim dos anos 60 e constituem a maior parte dos reatores atualmente em funcionamento.

Os reatores BWR não possuem geradores de vapor, o que permite um sistema de refrigeração mais compacto e, assim, um prédio de contenção correspondentemente menor. Entretanto, os BWR comportam dissipadores de calor no interior do edifício da contenção para a remoção de calor residual, já que esse excesso de calor é devido ao vapor ligeiramente radioativo formado que não pode ser liberado para a atmosfera (Ragheb, 2011).

\footnotetext{
5 Vodo-Vodyanoi Energetichesky Reaktor (Transliteração do russo para: Водо-водяной энергетический реактор). Como tradução literal: Reator de Potência Água-Água.
} 
A contenção de reatores do tipo BWR consiste basicamente de 2 partes: o drywell, que abriga o sistema de refrigeração do reator, e o wetwell, também chamado de piscina de supressão, que armazena grande quantidade de água. O objetivo dessas estruturas é diminuir a pressão na contenção no caso de um LOCA.

Os principais projetos de contenção para os BWR são o Mark I, Mark I/ e Mark III, detalhados na FIG. 5.

Aproximadamente $60 \%$ dos BWR americanos são do tipo Mark I (General Eletric Company - 1960) (Ragheb, 2011).

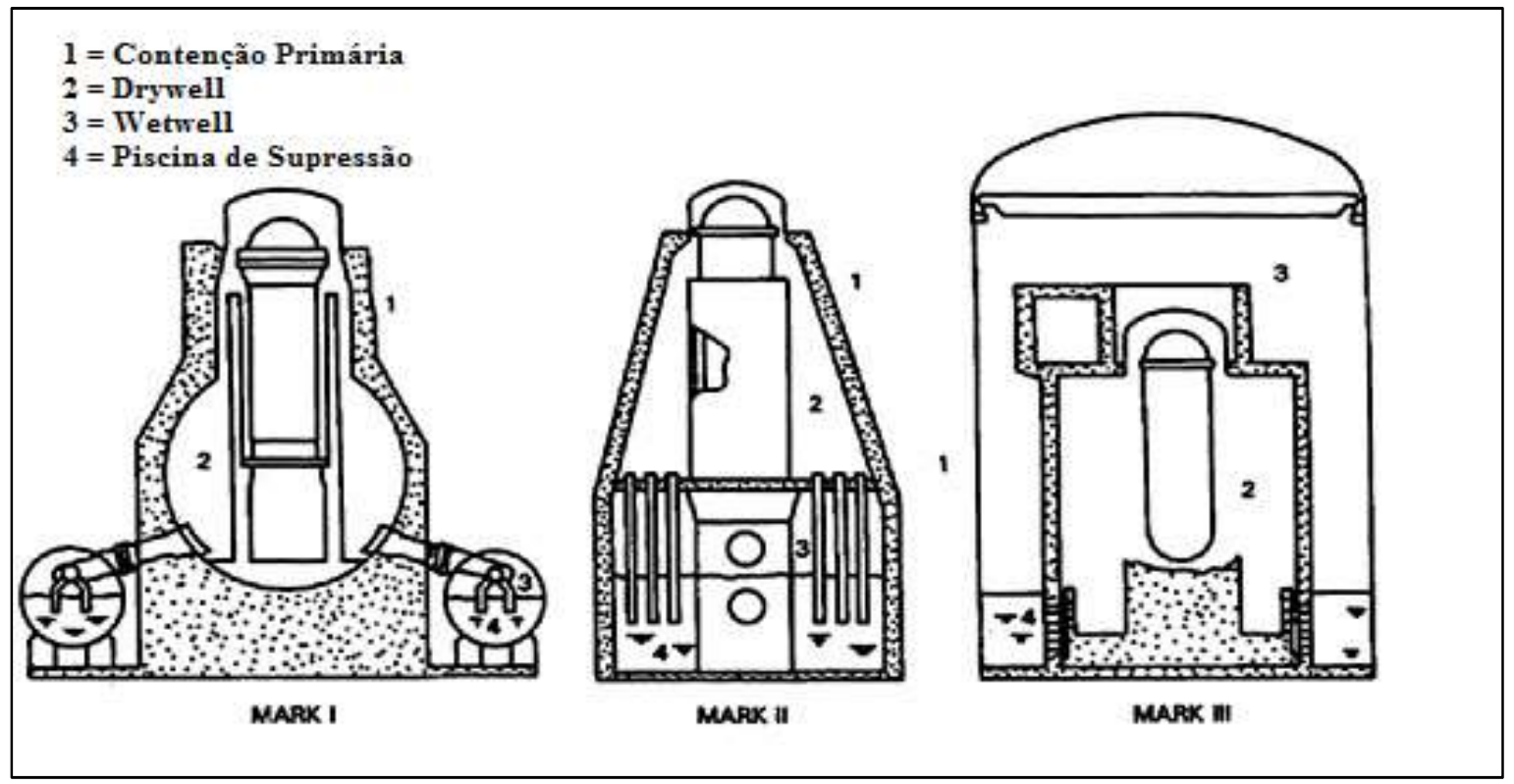

Fonte: Lahey e Moody, 1993.

FIGURA 5 - Tipos de Contenção de BWR - Mark I, II e III

A contenção do Mark II é semelhante à do Mark I, exceto pelo seu cônico drywell localizado acima do wetwell cilíndrico. Já no Mark III, o wetwell é cilíndrico, circunda o drywell e todo o sistema fica contido dentro da contenção de aço e do edifício.

Em um PWR, o confinamento da contenção também inclui os geradores de vapor e o pressurizador, além de todo o sistema de refrigeração do reator. O edifício da contenção é tipicamente um cilíndrico alto ou edifício semiesférico. Contenções de um PWR são geralmente grandes, atingindo até 10 vezes o tamanho de um modelo BWR (Ragheb, 2011). 
O Ice Condenser Containment é um tipo usado nos primeiros PWR como, por exemplo, no projeto do reator americano Sequoia-Unidade 1, localizado no Tennesse, Estados Unidos.

A estrutura do prédio, ilustrada na FIG. 6, possui câmaras de gelo mantidas em níveis altos que condensam o vapor no caso de um LOCA, reduzindo a pressão interna. Uma variante avaliada pelo Sandia National Laboratory foi substituir o gelo por filtros de areia e cascalho que formam um dissipador de calor passivo (Benjamin, 1979).

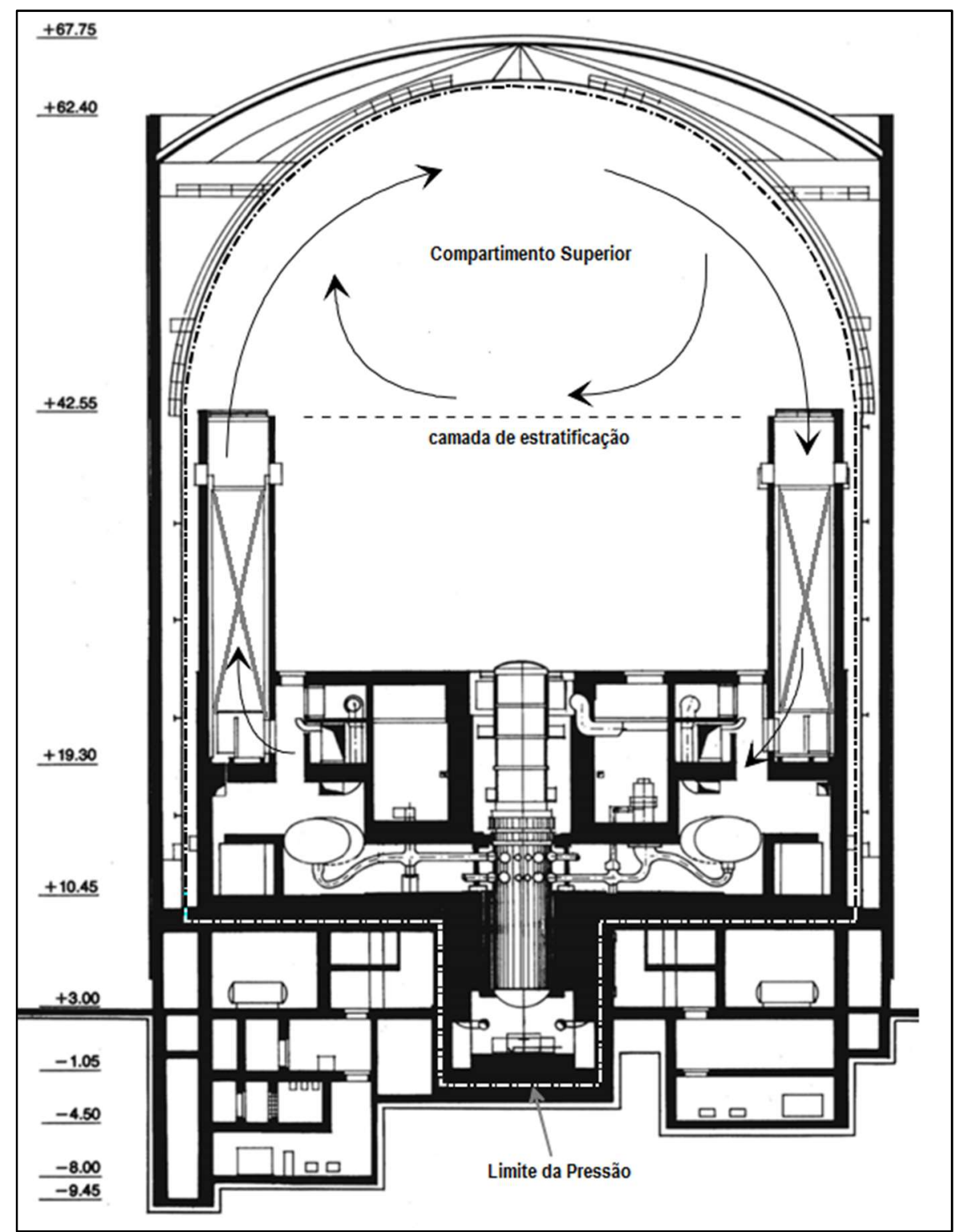

Fonte: RAGHEB, 2011.

FIGURA 6 - Estrutura da Contenção Ice Condenser 
Nos projetos de Dry Containment construidos por Siemens, Westinghouse e Combustion Engineering, a parte externa é constituida de concreto, já que este possui uma boa resistência estrutural (FIG. 7).

Como os modelos de reatores têm evoluído, muitos projetos de contenção esférica para PWR também foram construídos. Dependendo do material utilizado, este projeto é o mais adequado, pois uma esfera é a melhor forma para conter grandes pressões. A maioria dos modelos PWR atuais envolvem nessa estrutura uma parte inferior cilíndrica e uma parte superior semiesférica. A piscina com combustível irradiado está fora do prédio de contenção na maioria dos PWR (Ragheb, 2011).

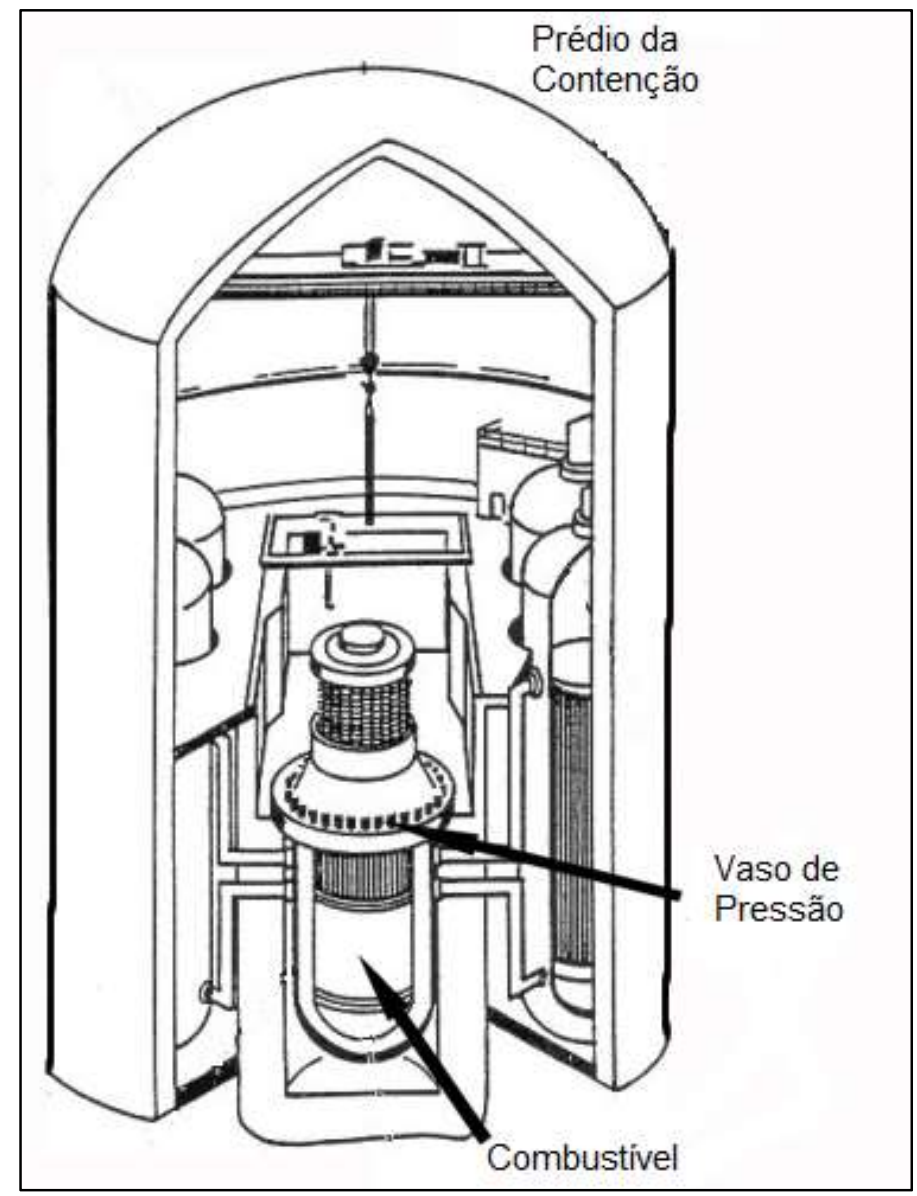

Fonte: $N R C^{6}$

FIGURA 7- Estrutura da Contenção Dry Containmet

Projetos mais modernos, denominados Double Wall Containment ou Dual Dry Containment, utilizam duas barreiras sendo, uma delas, uma estrutura de aço.

\footnotetext{
${ }^{6}$ Disponível em https://www.nrc.gov/images/reading-rm/photo-gallery/20071115-064.jpg
} 
Nesse caso, o aço é utilizado para forrar o interior do concreto contribuindo, assim, para a resistência no caso hipotético em que a contenção se torna altamente pressurizada.

Pertence, também, à geração II a Central Nuclear Almirante Álvaro Alberto (CNAAA), que faz parte do projeto nuclear brasileiro composto, até o momento, por dois reatores PWR, únicos no país. Além da Usina de Angra 2 (objeto de estudo, detalhado no item 2.4 deste trabalho), conta também com a Usina de Angra 1, que entrou em operação comercial em 1985.

O edifício da contenção metálica de Angra 1 é um vaso cilíndrico de aço, com uma cúpula hemisférica e um fundo elipsoidal esférico, apoiado em uma base de concreto armado. O vaso da contenção está totalmente contido dentro do edifício de blindagem (estrutura de concreto), existindo um espaço anular entre esse edifício e a contenção metálica (Silva et al., 1979). A contenção metálica envolve todas as estruturas que servem de suporte ao vaso do reator, às tubulações do refrigerante do reator, aos geradores de vapor, aos acumuladores e ao Sistema de Resfriamento de Emergência do Núcleo (SREN). Acima do nível de sua base, a contenção metálica é estruturalmente independente das estruturas adjacentes, interiores e exteriores, e existe espaço suficiente para que não haja contato entre elas, sob todas as condições previstas de carga (Silva et al., 1979). O esquema da contenção de Angra 1 é mostrado na FIG. 8. 


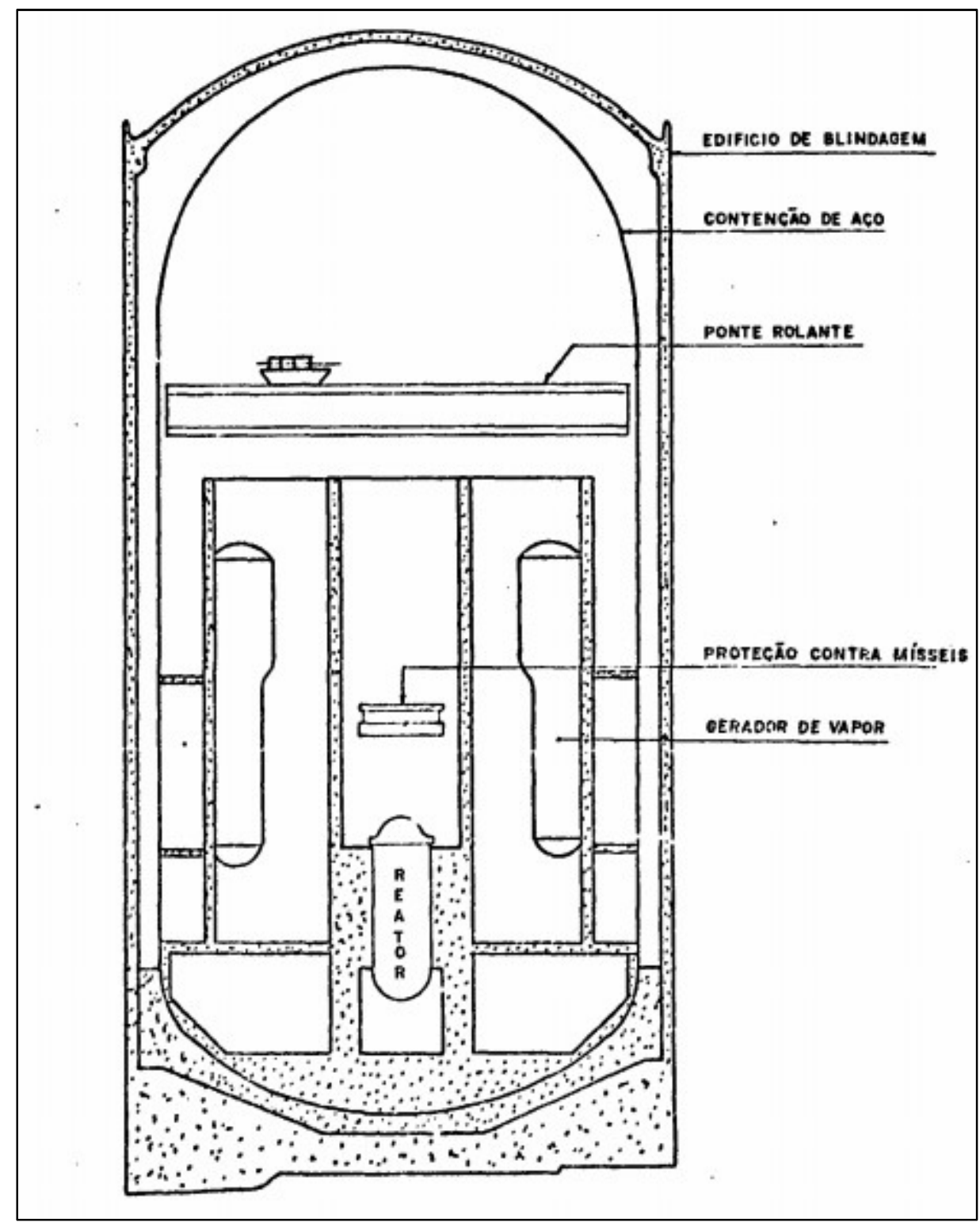

Fonte: Silva et al., 1979.

FIGURA 8 - Estrutura da Contenção de Angra 1

O Canadian Deuterium-Uranium (CANDU), também denominado Pressurized Heavy-Water Reactor (PHWR), é um reator que utiliza dióxido de urânio natural como combustível e água pesada como refrigerante.

Existem basicamente dois tipos desses reatores: o CANDU 6 single-unit e as estações CANDU multi-unit, em que cada estação tem de quatro até oito unidades (Chin et al., 2014).

A estrutura do CANDU multi-unit é mais complexa, utilizando um edifício a vácuo que liga as estações de multi-unidade e é mantido a uma pressão absoluta 
muito baixa e projetado com uma válvula de descarga filtrada para conter qualquer liberação de vapor e para retornar rapidamente o volume interno da contenção para uma pressão subatmosférica. Os edifícios de contenção para um CANDU são geralmente maiores do que um PWR ou BWR de semelhante capacidade de geração de energia (Chin et al., 2014).

Alguns dos sistemas de segurança em comum (relacionados à contenção) para os reatores do tipo CANDU são: refrigeradores de ar local, sistemas passivos que realizam a recombinação de hidrogênio, sistema de injeção de refrigerante (Emergency Core Cooling System - ECCS) e sistema de descarga de ar filtrado (Chin et al., 2014). Alguns dos sistemas descritos estão indicados na FIG. 9.

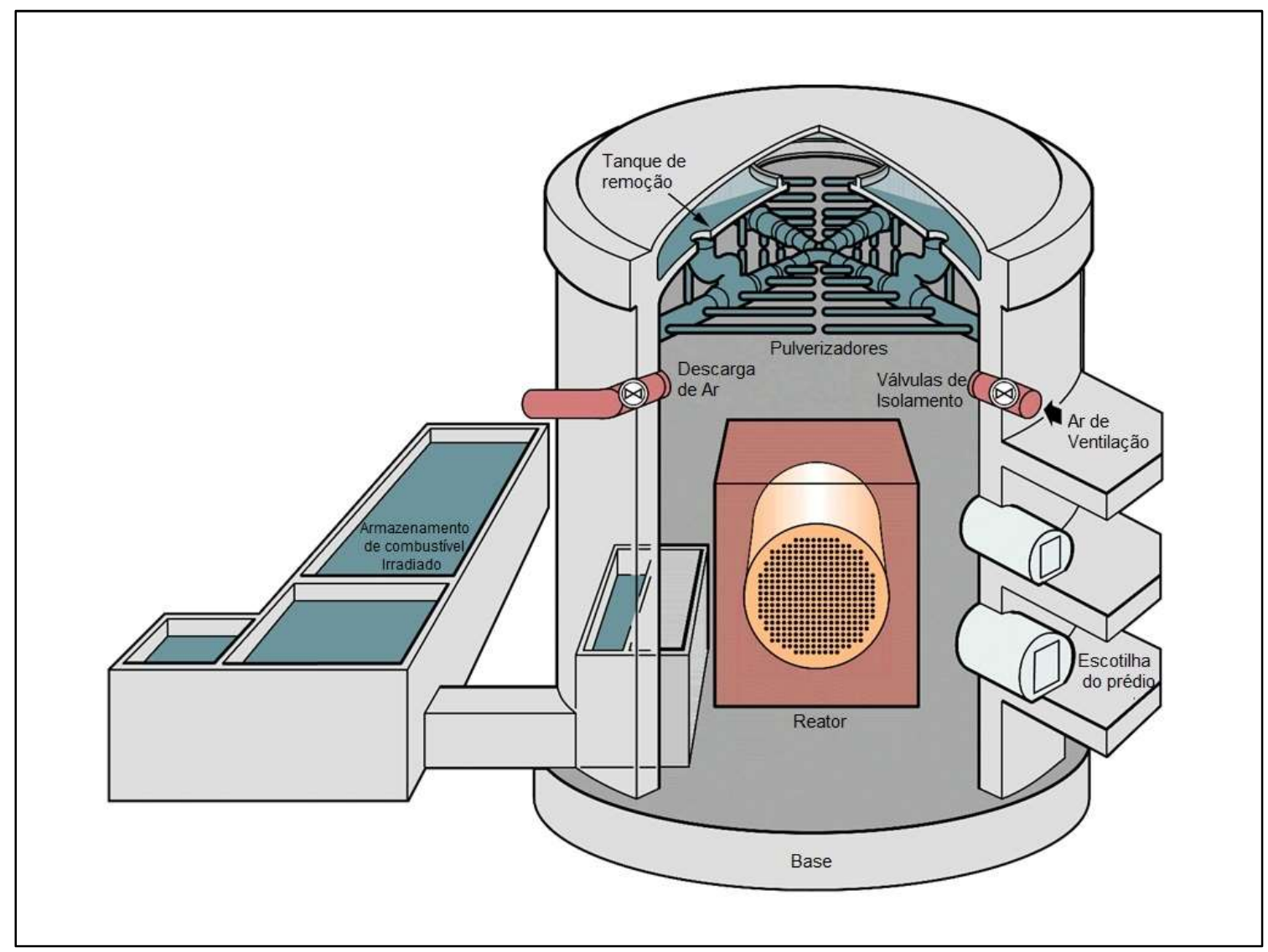

Fonte: Chin et al., 2014.

FIGURA 9 - Estrutura da Contenção de um Reator CANDU

O projeto soviético de reatores Reaktor Bolshoy Moshchnosti Kanalnyy (RBMK), também conhecido como Light Water Graphite Reactor (LWGR), usa dióxido de urânio como combustível, moderado com grafite e refrigerado a água pressurizada. 
Como demonstrado pelo acidente de Chernobyl, várias características em seu projeto não eram seguras como, por exemplo, as barras de controle, a fração de vazio positiva e a inexistência de prédio de contenção.

Após o acidente, a União Soviética implementou mudanças em todos os RBMK ainda em operação (Strupczewski, 2003). Em documento oficial, a IAEA (1992) afirmou que a filosofia de segurança de plantas nucleares baseada no princípio de defesa em profundidade foi ignorada no projeto, já que a filosofia define que a quarta barreira de segurança é a contenção.

Outro projeto soviético é o VVER, refrigerado e moderado à agua pressurizada. O reator VVER-1000, desenvolvido em 1975, possui uma contenção dupla. A parte exterior é um edifício de concreto e sua parte interna é esférica e de aço com pressão subatmosférica, que evita a emissão de gases para fora da contenção em caso de acidente (Noori-Kalkhoran et al., 2014). Entre os sistemas passivos de segurança, esse possui Sistema Passivo de Remoção de Calor Residual (SPRCR) sob condições de convecção natural.

O reator AGR, assim como seu precursor, o Gas Reactor Colum (GRC), não possui um edifício de contenção. O vaso de pressão do reator é a última barreira de contenção. Entretanto, seu vaso de pressão blindado contém todo o sistema primário de refrigeração (Nonbol, 1996).

\subsubsection{Tipos de contenção da terceira geração}

Os reatores de potência da geração III possuem um projeto de sistemas modulares, menos complexos que os da geração anterior, a fim de reduzir os custos, o tempo de construção e de licenciamento e também facilitar sua operação. Entretanto, são mais robustos, eficientes e menos vulneráveis a transientes operacionais, reduzindo a possibilidade de acidentes (Goldberg; Rosner, 2011). Possuem, ainda, maior vida operacional que os de geração II - cerca de 60 anos - e incorporam características de segurança passivas ou inerentes (por gravidade, convecção natural ou resistência a altas temperaturas), que não necessitam de controles ativos ou intervenção operacional para evitar acidentes em caso de avaria (Goldberg; Rosner, 2011). 
Fazem parte dessa geração os Advanced Boiling Water Reactors (ABWR) e os Advanced Pressurized Water Reactors (APWR).

Um dos primeiros projetos de reatores dessa categoria, desenvolvido pela Westinghouse, é o PWR avançado AP-600. Seu sucessor, o AP-1000 (geração III+), manteve o design e suas principais características estruturais, mas melhorou sua eficiência e o custo foi minimizado. O sistema de refrigeração é constituído por dois circuitos de transferência de calor, cada um deles contendo um gerador de vapor, uma perna quente e duas pernas frias. O sistema também inclui um único pressurizador (Schulz, 2006).

Ambas as plantas têm uma contenção de 39,6 metros de diâmetro. A pressão do confinamento do AP-600 é 3,10bar, enquanto que do AP-1000 é de 4,07bar, devido a uma parede ligeiramente mais espessa de liga de aço mais forte e por sua altura (Schulz, 2006).

Os sistemas de refrigeração passivos da contenção permitem que a pressão não exceda a pressão de projeto dentro do confinamento em caso de acidente. A sua estrutura de aço permite a transferência de calor da parte interna para a atmosfera, e os reservatórios localizados no topo do edifício drenam a água por gravidade, refrigerando o ar interno e estimulando a convecção natural dentro da contenção. O desenho das plantas é apresentado na FIG.10.

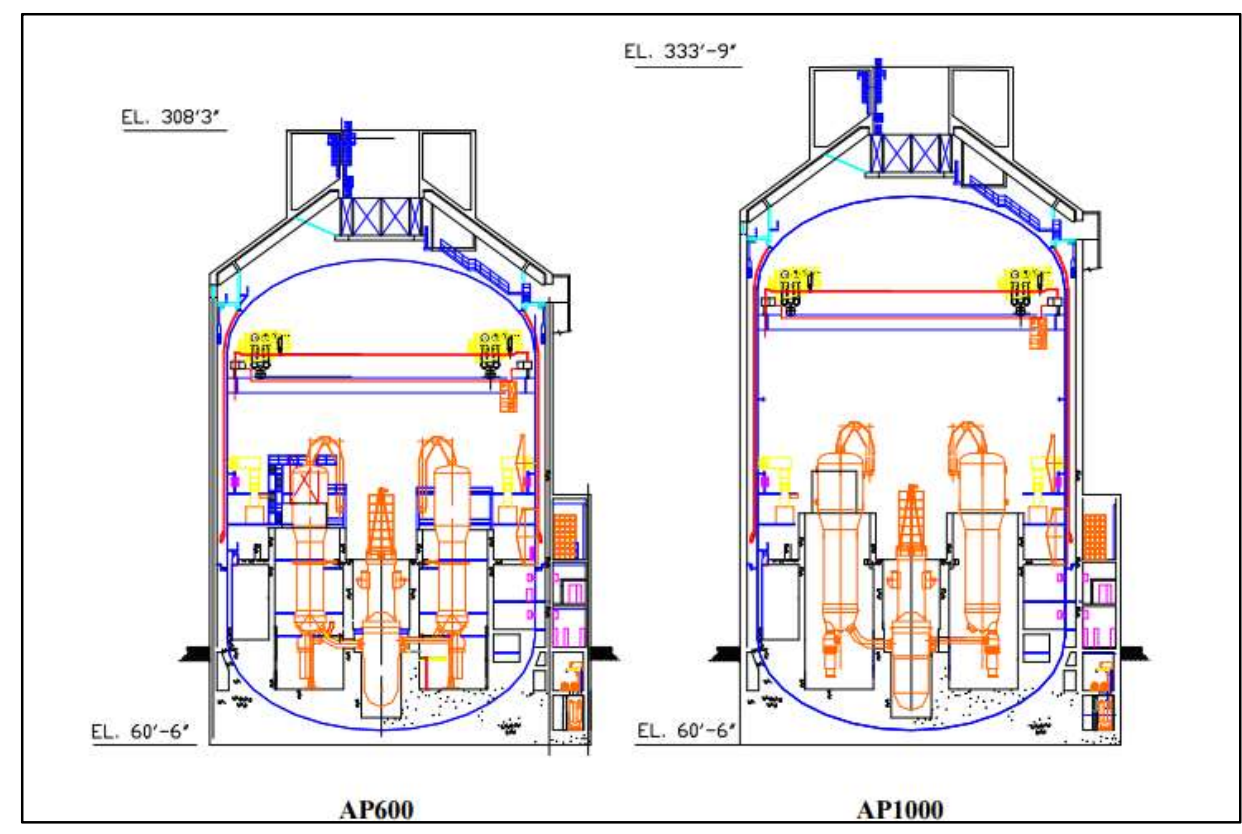

Fonte: SCHULZ, 2006.

FIGURA 10 - Contenção e sistemas internos dos reatores AP600 e AP1000 
Outro PWR avançado, desenvolvido pela ABB Combustion Engineering (adquirida pela Westinghouse), é o System 80+. Entre as melhorias oferecidas nesse projeto, estão (Matzie; Ritterbuschsyst, 1999):

- Sistema de Despressurização de Segurança (SDS) adicionado para proporcionar uma rápida despressurização no caso de um acidente com condição estendida de projeto;

- Tanque de Reabastecimento de Água (TRA) dentro da contenção, que fornece água aos Sistemas de Injeção de Segurança (SIS) e aos sistemas de spray da contenção, sem a necessidade de ativação por um operador;

- Maior volume livre interno na contenção, que fornece uma margem maior contra o excesso de pressurização e garante menor concentração de hidrogênio durante um acidente;

- Sistema de Ignição de Hidrogênio que, em conjunto com os recombinadores de hidrogênio, garantem o controle sem deflagração;

- Redundância mecânica adicional.

Alguns desses sistemas descritos, entre outros, estão em destaque na FIG.11.

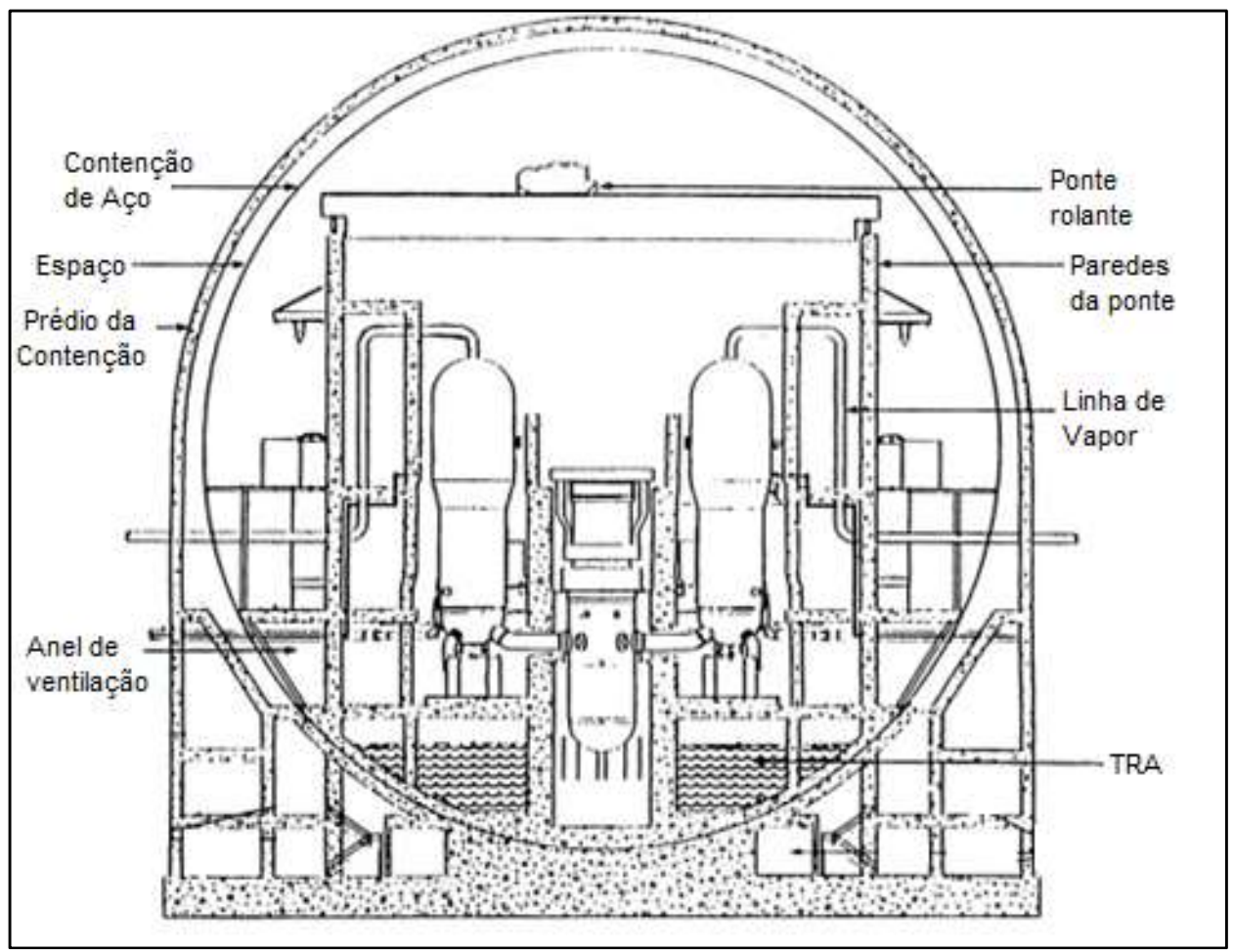

Fonte: Matzie e Ritterbuschsyst, 1999.

FIGURA 11 - Estrutura da Contenção do System 80+ 
O EC6 é um projeto de reator de potência baseado no CANDU 6, refrigerado e moderado à agua pesada, que usa como combustível o urânio natural. Possui desempenho de segurança superior, maior economia e adequação para pequenas e médias redes elétricas. Foi projetado pela CANDU Energy Inc. com o objetivo de atingir um fator de operabilidade entre $92 \%$ e $94 \%$ durante a sua vida útil, que é de 60 anos.

É equipado com sistemas de segurança passivos para a remoção de calor de decaimento (tanque de água superelevado) e para a remoção do calor do vaso de pressão (convecção de ar). A combinação desses sistemas de segurança passivos com sistemas ativos de injeção de refrigerante no núcleo (redundância e diversificação) minimiza a possibilidade de um acidente com condição estendida de projeto (Energy, 2012).

Os projetos CANDU possibilitam a troca dos combustíveis sem a necessidade de desligamento do reator, favorecendo a disponibilidade dos mesmos. Os principais recursos de segurança passiva são:

- dois sistemas de desligamento passivos independentes e cada um desses é capaz de desligar de forma segura o reator;

- um bom moderador de baixa pressão que, em situações de acidente grave, serve como um dissipador de calor de forma passiva, absorvendo o calor gerado pelo decaimento dos combustíveis;

- a grande contenção de concreto que circunda o núcleo do reator; a contenção, que contém um grande volume de água leve com a finalidade de retardar ou parar a progressão do dano ao núcleo em caso de acidente, fornecendo um segundo dissipador passivo de calor ao núcleo e;

- um tanque de água elevado localizado no piso superior do edifício do reator que foi projetado para oferecer passivamente, por gravidade, refrigeração aos sistemas removendo calor.

Isto atrasa a progressão de graves acidentes e fornece tempo adicional para que ações sejam tomadas.

O robusto prédio tem como segurança a estrutura espessa de concreto projetada para suportar o impacto da queda de aeronave, o revestimento interno 
estanque de aço para reduzir potenciais vazamentos durante e após acidentes e o sistema passivo de pulverização a partir do tanque de água elevado para reduzir a pressão no prédio do reator em caso de acidente grave, como mostra a FIG.12 (Energy, 2012).

Essas melhorias no projeto, juntamente com os avanços da engenharia, técnicas de fabricação e construção, resultam em uma redução do custo, em um cronograma de construção mais ágil e em melhora das características de segurança do projeto (Energy, 2012).

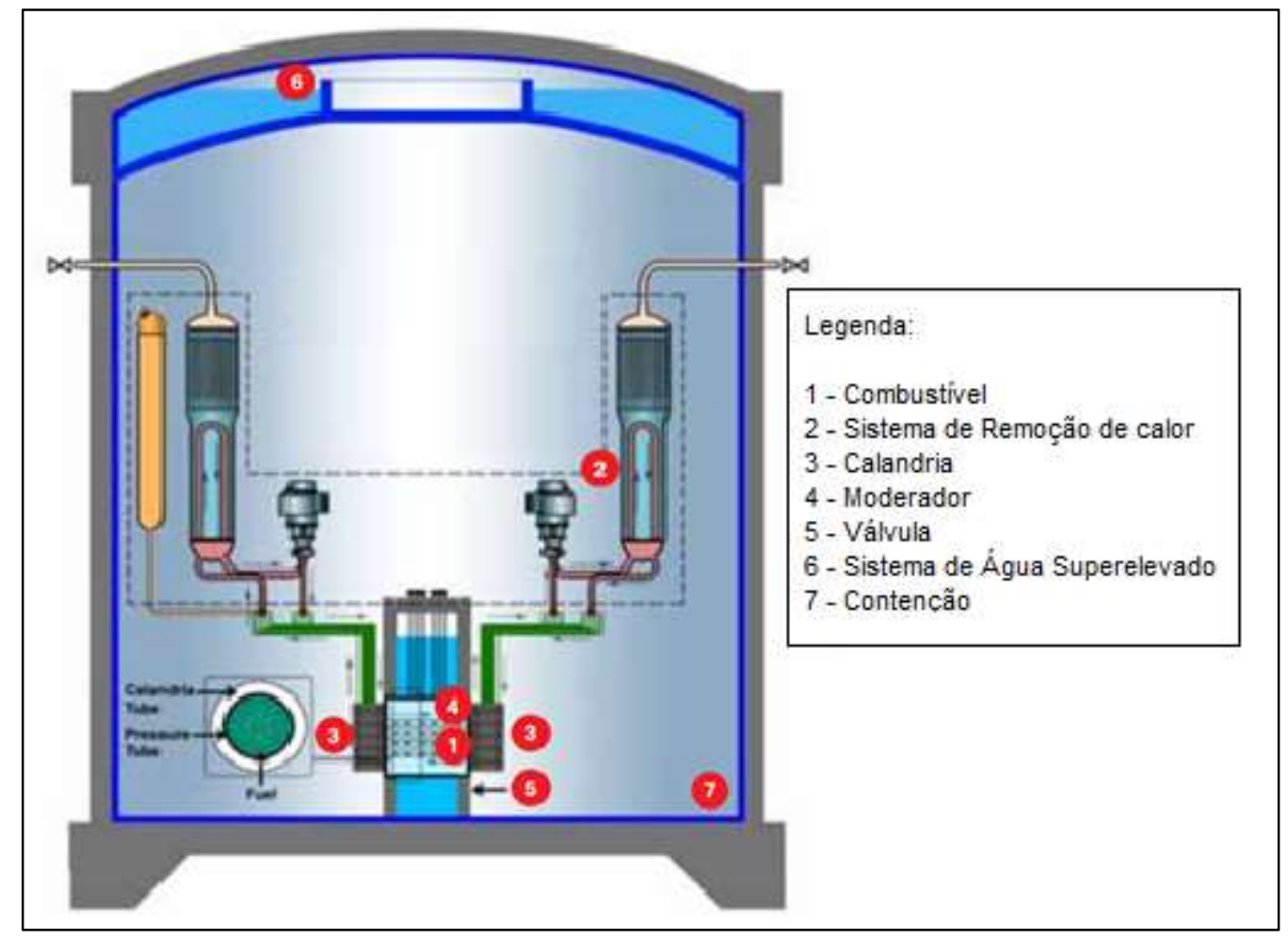

Fonte: Energy, 2012.

FIGURA 12 - Estrutura da Contenção do EC6

O modelo ABWR, projetado pela GE Nuclear Energy e colaboradores, é parte da geração III+. Comparado com o BWR da geração anterior, o ABWR possui maior eficiência, maior economia, e a refrigeração do reator é realizada por bombas internas. Esse reator possui um Vaso de Contenção de Concreto Reforçado (VCCR), que contém a pressão dentro do vaso do reator e evita vazamentos. Esse é dividido em duas partes: o drywell e a câmara de supressão. 
A câmara de supressão possui uma piscina e uma área livre com ar. Em caso de um LOCA, o vapor escoa do drywell para a piscina da câmara de supressão por tubos de ventilação embutidos na base do vaso do reator. Isso diminui a pressão dentro do VCCR. Na FIG. 13, os compartimentos citados são mostrados.

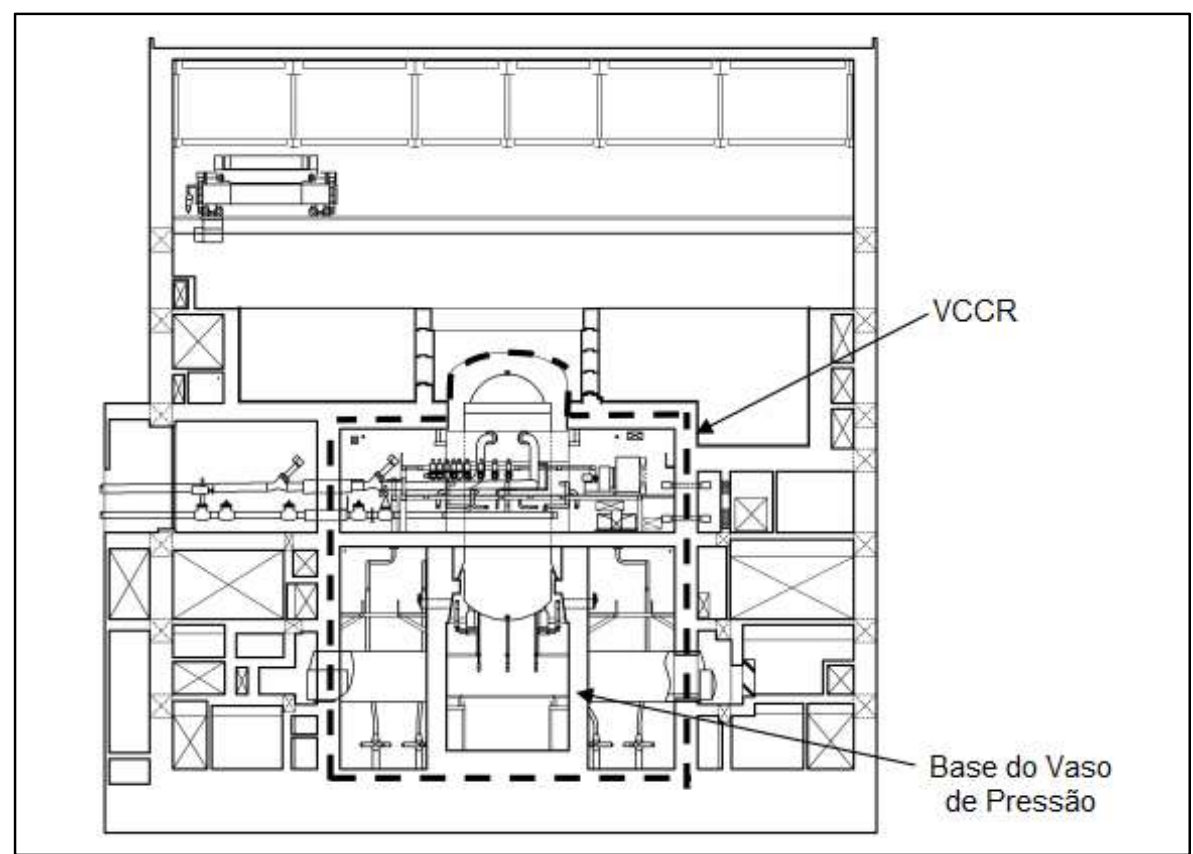

Fonte: Ge-Hitachi Inc., $2016 .^{7}$

FIGURA 13 - Estrutura da Contenção e Compartimentos do Reator ABWR-GE

O reator denominado International Reactor Innovative and Secure (IRIS), de água leve pressurizada, é um projeto de parceria entre alguns laboratórios, indústrias e universidades, coordenado pela Westinghouse. É categorizado como geração III+.

Embora seu vaso de pressão seja maior, quando comparado aos tradicionais PWR - já que abriga, além do combustível, a maior parte dos componentes do circuito primário que constituem o sistema de refrigeração (como bombas, geradores de vapor, mecanismos de barra de controle e o refletor de nêutrons) -, as dimensões da sua contenção são bem menores, o que resulta na redução do tamanho global da instalação (Westinghouse, 2003).

O pressurizador, localizado no topo do vaso de pressão (e não separadamente do circuito primário como nos PWR), possui dimensões maiores que

\footnotetext{
7 Disponível em http://www.hitachi-hgne-uk-abwr.co.uk/gda_library.html
} 
os das plantas atuais, o que ajuda a manter a pressão no vaso mesmo em caso de acidentes. A contenção esférica possui entre 22 a 27 metros de diâmetro, tem pressão de projeto de 1,4bar e dois terços de sua construção é subterrânea (Carelli et al., 2003).

O projeto do reator é integrado e, praticamente, inexiste a ocorrência de um LOCA, uma vez que não há grandes circuitos de tubulação. Além disso, esta configuração, aliada à geometria esférica, possibilita à contenção suportar pressões três vezes maiores que os sistemas convencionais cilíndricos que utilizam a mesma espessura de metal (FIG. 14).

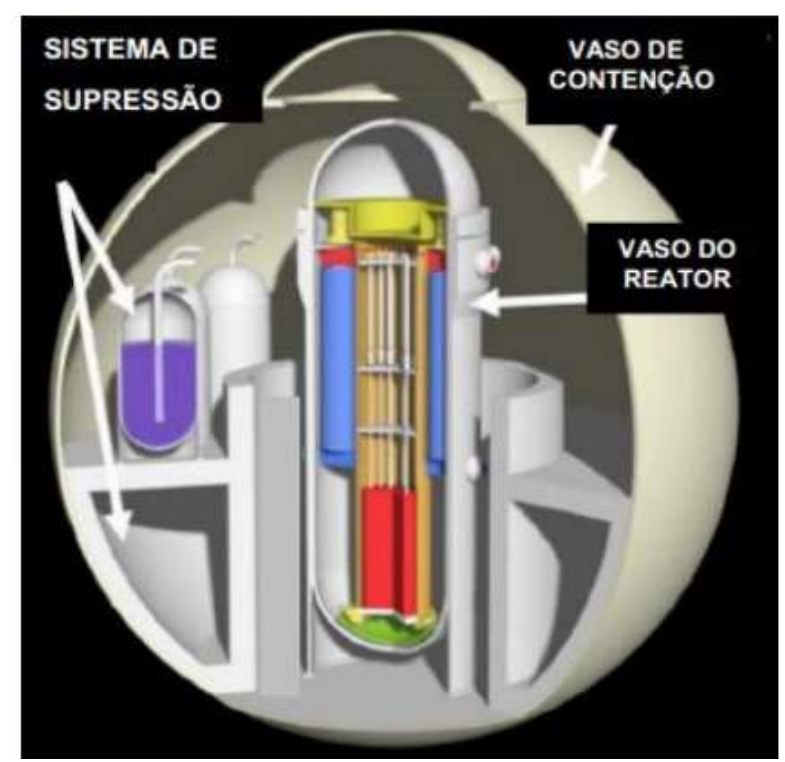

Fonte: Carelli et al., 2003.

FIGURA 14 - Contenção do Retor IRIS

\subsubsection{Tipos de contenção da quarta geração}

Em um simpósio organizado pela Organização das Nações Unidas (Grimston; Beck, 2000), posteriormente endossado pela IAEA, surgiu uma nova proposta de reatores de potência, denominados reatores de geração IV. O desenvolvimento desses reatores é um esforço iniciado pelo United States Department of Energy (US-DOE) com a participação de 13 membros que estabeleceram um acordo formal denominado Generation IV International Forum (GIF). 
O padrão para os novos projetos de reatores exige segurança inerente dos sistemas, exclusão de acidente com condição estendida de projeto com evacuação da população, utilização de urânio empobrecido ou natural como combustível, ausência de rejeitos de longo prazo e competitividade econômica (Bastos, 2002).

Nos reatores de geração IV (Generation IV - GEN-IV), em fase de desenvolvimento para uso após 2030, predomina a tecnologia de reatores rápidos, com altas temperaturas de saída para melhorar a eficiência de conversão termoelétrica e aplicações do calor gerado em processos industriais (Nascimento et al., 2015).

Entre os principais projetos de reatores dessa geração estão:

- GFR (Reator Rápido Resfriado a Gás);

- LFR (Reator Rápido Resfriado a Chumbo);

- MSR (Reator Resfriado a Sal Fundido);

- SCWR (Reator Resfriado a Água Supercrítica);

- SFR (Reator Rápido Resfriado a Sódio);

- VHTR (Very High Temperature Reactor).

Dentre esses, apenas os reatores refrigerados a sódio, até então, possuem tecnologia comprovada (Bastos, 2002). A maioria desses reatores é compacta, como os de terceira geração. Não foram encontradas informações específicas dos projetos de contenção dos reatores desta geração.

\subsection{Descrição da usina de Angra 2}

A Central Nuclear Almirante Álvaro Alberto - Unidade 2 está localizada no estado do Rio de Janeiro, entre a Serra do Mar e a baia de Ilha Grande, na região da cidade de Angra dos Reis, na costa do oceano Atlântico. Projetada pela German Siemens / KWU e operada pela Eletronuclear, a usina possui licenciamento nuclear do órgão regulador nacional (CNEN) para funcionamento.

A usina opera com um reator tipo PWR, amplamente utilizado nas usinas nucleares do mundo e possui sistemas de segurança redundantes e independentes para a prevenção de acidentes, além de sistemas de segurança passivos, como a contenção (Eletronuclear, 2010). Inclusive, após Fukushima, foram instalados 
recombinadores de hidrogênio dentro da contenção, para o caso de acidentes de condição estendida de base de projeto.

Em um caso remoto de liberação de material radioativo, o reator, o circuito primário e as piscinas de armazenamento de elementos combustíveis são envolvidos pela contenção, que é uma esfera de aço austenítico WStE 51, com diâmetro interno de $56 \mathrm{~m}$, espessura de $30 \mathrm{~mm}$ e massa de 2.600ton. Tal estrutura é protegida e completamente envolta pela contenção secundária, um edifício de concreto de forma cilíndrica e com uma cúpula de concreto, com diâmetro de $60 \mathrm{~m}$, espessura de $60 \mathrm{~cm}$ e altura de 60m (FIG.15).

Os critérios de segurança para plantas nucleares impostos pelo $\mathrm{BMI}^{8}$, que devem estar em conformidade, são (Eletronuclear, 2010):

- a planta nuclear deve possuir uma contenção capaz de desempenhar seus sistemas de segurança em caso de acidentes, contendo todos os prováveis radionuclídeos liberados dentro do seu confinamento;

- a contenção, incluindo seus compartimentos interiores, os acessos, as penetrações e os sistemas auxiliares devem garantir que as condições não violem os limites de projeto, com uma margem segura em casos de picos de temperatura e pressão que possam ocorrer em caso de acidente;

- os sistemas da contenção devem ser projetados e construídos para permitirem testes de vazamento durante a vida operacional da planta;

- as tubulações que penetram na contenção devem ser isoladas por meio de válvulas de segurança: uma por dentro e outra por fora da contenção, que possam ser controladas remotamente;

- um sistema confiável de redundância deve prover a remoção de calor residual dentro da contenção. Este deve ser concebido de tal modo que, mesmo em caso de falha no sistema, a pressão e temperatura dentro da contenção sejam reduzidas durante o acidente.

\footnotetext{
${ }^{8}$ Ministério Federal do Interior, tradução do alemão para Bundes Ministerium des Innern.
} 


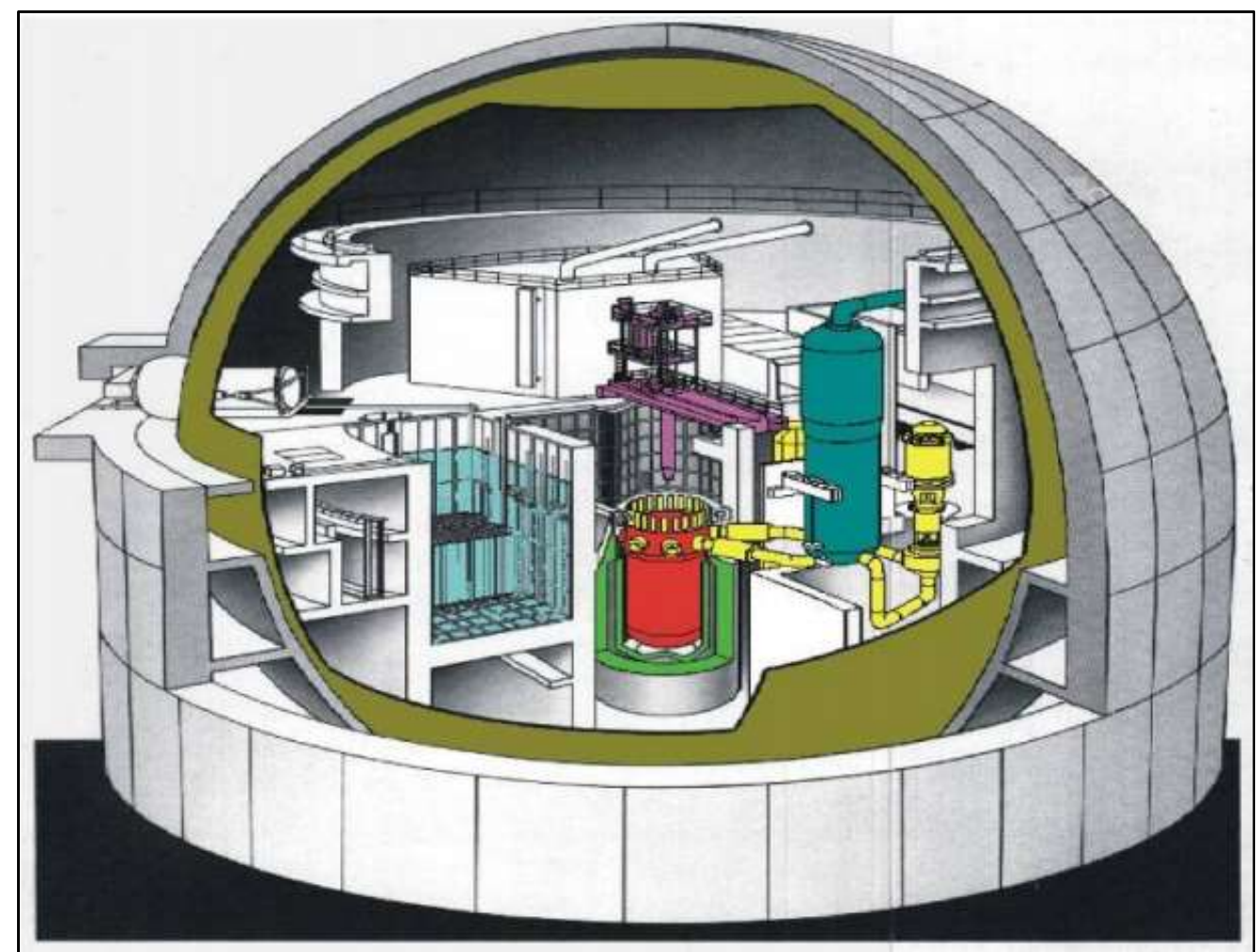

Fonte: Eletronuclear, $2016^{9}$

FIGURA 15 - Modelo do Prédio da Contenção de Angra 2

\subsection{Evolução dos códigos computacionais de análise da contenção}

Os códigos de análise de contenção têm sido tradicionalmente desenvolvidos como códigos que utilizam a técnica da divisão da contenção em volumes de controle e que modelam o comportamento termohidráulico e a condução de calor entre os compartimentos da contenção (International Atomic Energy Agency, 2003). Cada um dos compartimentos de volume modelados possui valores de pressão e temperatura, sendo que o fluxo entre os volumes se dá pela diferença de pressão entre eles.

Os códigos de contenção são usados em várias áreas, tais como: análise de máxima pressão e temperatura durante um acidente tipo LOCA; análise de pressão diferencial das estruturas internas da contenção durante um acidente tipo LOCA; comportamento em longo prazo da pressão e temperatura da contenção durante um acidente base do projeto como apoio para o cálculo das emissões radioativas (International Atomic Energy Agency, 2003).

\footnotetext{
${ }_{9}^{9}$ Disponível em http://www.eletronuclear.gov.br/hotsites/eia/v01_02_caracterizacao.html
} 
A aplicação desses códigos se estendeu até o domínio de acidentes de condição estendida de projeto em que são considerados: pressão, temperatura, produtos de fissão, emissão e distribuição do hidrogênio.

\subsubsection{Containment Code (COCO)}

O COCO é o programa de cálculo de acidentes usado pela Westinghouse e Kraftwerk Union (KWU) nos anos 80 e que simula os resultados descritos no Relatório de Segurança de Angra 1 e 2 (RFAS) (Eletronuclear, 2010).

A partir dos dados da adição de massa e energia durante um acidente, o programa analisa as mudanças do estado termodinâmico dentro da contenção (Eletronuclear, 2010). Os processos calculados pelo programa são:

- emissão de calor da reação entre a água e o zircaloy, devido à energia dos produtos de fissão.

- injeção de água no vaso de pressão pelos acumuladores e sistemas de remoção de calor.

- transporte de massa e calor dentro da contenção e para o meio ambiente.

O programa possui um modelo unidimensional, contendo três sistemas sob mesma pressão, mas com temperaturas distintas. Os três sistemas são o sump, a atmosfera da contenção e o circuito primário.

O COCO faz um histórico de tempo para as condições de cada um dos sistemas e do fluxo de massa e energia. Fornece, também, uma distribuição de pressão e temperatura da atmosfera interna da contenção.

\subsubsection{CONTAIN}

O código CONTAIN, desenvolvido pela Sandia National Laboratories, sob o patrocínio da USNRC, é uma ferramenta que analisa as condições físicas e químicas e a distribuição de material radioativo dentro da contenção de um reator nuclear em caso de acidente (Murata et al., 1997). Teve sua primeira versão lançada em 1984 (Boyack, 1995). 
Este programa prevê a resposta do comportamento termohidráulico dentro da contenção e a liberação de radionuclídeos para o meio ambiente em caso de ruptura na contenção. Também leva em consideração o comportamento do aerossol, o comportamento dos produtos de fissão e as interações entre os fenômenos termohidráulicos (Murata et al., 1997).

O código inclui vários modelos para executar problemas dos mais simples aos mais complexos. Este realiza escoamento entre as células, condensação e evaporação nas estruturas, comportamento dos aerossóis, combustão de gases, condução de calor entre as estruturas, decaimento e transporte dos produtos de fissão, entre outros (Murata et al., 1997).

Considerando ainda a significativa incerteza sobre inúmeros fenômenos ao se tratar de análise de acidentes, o CONTAIN possibilita a entrada de parâmetros que podem ser especificados pelo usuário. Ainda assim, possui uma grande quantidade de modelos disponíveis que tratam de acidentes mais graves para a contenção.

\subsubsection{Containment Temperature Pressure Transient -Long Term (CONTEMPTLT)}

Desenvolvido para descrever o sistema termohidráulico da contenção de reatores de água leve (LWR), o Containment Temperature Pressure Transient - Long Term (CONTEMPT-LT) calcula a variação com o tempo das pressões e temperaturas e adição de massa e energia em quatro compartimentos da contenção, que são: sistema do reator; wetwell; drywell e espaço anular (gap).

O programa permite que cada uma dessas divisões possua duas regiões de temperatura uniforme e apresenta modelos para o cálculo de ebulição, condensação ou evaporação de uma região para a outra e transferência de calor entre as estruturas (Wagner; West, 1973).

A sua versão mais recente, CONTEMPT4/MOD5, foi usada para modelar os Sistemas Passivos de Refrigeração da Contenção (SPRC) para o reator de geração III, AP600 (Kang; Park, 2000). Entretanto, devido à ausência de condições de contorno apropriadas para a parte externa da contenção, a simulação descrita na referência não é exata, mas mostra valores de pressão e temperatura suficientemente baixos para que se mantenha a integridade da contenção (Kang; Park, 2000). 


\subsubsection{RELAP5}

O RELAP5 é um código desenvolvido para a análise de segurança. Diferentes versões surgiram ao longo de sua evolução, algumas com hipóteses conservativas e outras que usam a filosofia realista (best estimate).

A versão RELAP5 (1999) tem sido a mais utilizada no Brasil na última década para a certificação de reatores nucleares no processo de licenciamento, pois sua filosofia best estimate reduz os custos de projetos, tornando-os competitivos comercialmente.

Esse código tem a capacidade de simular acidentes de perda de refrigerante primário (LOCA) por pequena, média ou grande ruptura. Além disso, pode simular transientes de perda de potência elétrica, perda de água de alimentação, perda de vazão, entre outros. A análise do comportamento termohidráulico durante um desses acidentes ou transientes se aplica tanto para o circuito primário como para o secundário de uma instalação nuclear.

Nos últimos anos, o código RELAP5 tem sido utilizado para a análise de segurança de reatores de pesquisa, pois os órgãos licenciadores exigem esse tipo de estudo para o licenciamento dessas instalações.

O processo de licenciamento de uma planta nuclear, tanto de potência como de pesquisa, envolve não apenas a simulação numérica de acidentes e transientes termohidráulicos, mas também a qualificação de sua modelagem, do código utilizado e de seus usuários. Em outras palavras, todo o processo requer que os usuários sejam treinados e que tenham uma boa experiência na nodalização e simulação de experimentos nacionais e internacionais, por meio dos quais tanto o usuário quanto o código são qualificados.

Com relação à qualificação da nodalização da planta em estudo, o usuário deverá simulá-la em regime permanente e compará-la com os dados fornecidos pela própria usina nestas condições. Quando os resultados experimentais e teóricos são comparados e os erros são menores do que 10\%, a nodalização é considerada qualificada.

No entanto, quando houver a simulação de acidentes e transientes termohidráulicos da planta nuclear em questão com o código RELAP5, há a necessidade da aplicação de cálculos de incerteza a fim de validar os resultados. 
Existem na literatura algumas metodologias de cálculo de incerteza, como: Best Estimate Plus Uncertainty - BEPU - desenvolvido pela Universidade de Pisa (D'auria et al., 2012) e o Software for Uncertainty and Sensitivity - SUSA - desenvolvido pela Global Research for Safety (GRS) (Koss, 2015), entre outros.

A modelagem de uma instalação nuclear com o código RELAP5 (1999) é feita separadamente para cada um dos componentes do reator, tais como: bombas, tubulações, trocadores de calor, acumuladores, válvulas e outros. A maior parte dos componentes é considerada como cilindros e, mesmo que alguns deles apresentem geometrias diferentes, o usuário deverá trabalhar com um diâmetro equivalente ao do cilindro, mantendo o mesmo volume do componente original.

A transferência de calor gerada no interior do núcleo é conduzida pelas estruturas metálicas que constituem a instalação, modeladas como estruturas de troca de calor, e é feita entre a estrutura e o fluido refrigerante.

O modelo hidrodinâmico é baseado no modelo de volumes de controle. Esses volumes de controle podem ser considerados como tubos com junções de entrada e saída. Propriedades escalares como pressão, temperatura, densidade e fração de vazio são representadas pela média dentro do volume de controle e estão localizadas no ponto central do mesmo. Por outro lado, propriedades vetoriais, tais como, as velocidades e vazões mássicas são localizadas nas junções entre os volumes de controle.

O modelo de escoamento do RELAP5 utiliza um modelo bifásico, não homogêneo e unidimensional. O modelo de transferência de calor também é baseado numa aproximação unidimensional para o cálculo das temperaturas e fluxos de calor.

O RELAP5 (1999) possui seis equações de conservação: de massa, de energia e de quantidade de movimento para cada uma das fases, liquida e vapor; possui, também, duas equações adicionais para gases não condensáveis e para o boro solúvel. O programa conta com uma aproximação da equação de conservação de movimento para fluxo transversal e um modelo de fluxo reverso. Esse último utiliza uma solução de condução bidimensional. O método numérico utilizado nesse código é o de diferenças finitas.

O primeiro passo para a simulação de um acidente ou transiente com o RELAP5 é a elaboração da nodalização dos componentes hidrodinâmicos do reator em estudo, que deverão ser modelados por meio da representação geométrica mais 
próxima da realidade. Alguns componentes existentes no RELAP5 são: PIPE para tubulações, BRANCH para bifurcações ou T's, VALVE para válvulas, ACCUM para acumuladores, PUMP para bombas, SEPARATOR para separadores de vapor, entre outros. Além dos dados geométricos da planta, que fazem parte dos dados de entrada do código RELAP5, também são modelados as estruturas de troca de calor e os sistemas de controle da planta.

As propriedades dos materiais que constituem o reator e os dados operacionais da planta também são fornecidas como dados de entrada para o RELAP5.

A versão utilizada neste trabalho é o RELAP5/MOD3.2Gamma. No RFAS/A2 é utilizado o S-RELAP5, uma versão que incorpora recursos das versões RELAP5/MOD2 e RELAP5/MOD3, com algumas melhorias específicas adotadas pela Siemens/KWU (Eletronuclear, 2010).

\subsubsection{MELt CORe (MELCOR)}

O código MELt CORe (MELCOR), também desenvolvido pela Sandia National Laboratories, é um código computacional integrado, desenvolvido na área de engenharia de reatores, cujo objetivo principal é modelar e analisar acidentes com condição estendida de projeto em reatores nucleares a água leve (Gauntt; Cole, 2000).

Esse programa retrata a fenomenologia de acidentes severos em reatores do tipo PWR, BWR e instalações nucleares de pesquisa. O programa fornece as respostas termohidráulicas no sistema de refrigeração do reator relativas à parte inferior do vaso de pressão da contenção, aquecimento do núcleo, degradação e realocação do núcleo do reator, interação do núcleo derretido com o concreto, produção, transporte e combustão de hidrogênio e liberação e transporte dos produtos de fissão.

O MELCOR é um programa do tipo determinístico ou realista: efetua os cálculos de uma simulação com grande detalhamento no tratamento dos fenômenos envolvidos no acidente e permite o estudo do comportamento da planta nuclear, com 
precisão, durante todo o desenvolvimento de um acidente com condição estendida de projeto.

A representação dos fenômenos no programa MELCOR é baseada em dados obtidos de experimentos onde é simulado o derretimento de um núcleo, como, por exemplo, o projeto PHEBUS, projeto experimental de simulação de degradação do combustível em diferentes condições de temperatura e taxas de oxidação do encamisamento. Além do mais, calcula as condições da contenção em vários cenários de acidentes.

\subsubsection{Containment Code System (COCOSYS)}

A simulação de acidentes com condição estendida de projeto em compartimentos de usinas nucleares necessita de uma análise das possíveis consequências destes acidentes em condições mais realistas. Portanto, a GRS desenvolveu o código COCOSYS para a análise da contenção de reatores nucleares de potência em caso de acidentes.

O objetivo principal desse código é realizar uma simulação completa da contenção de plantas nucleares em caso de acidentes base de projeto e acidentes com condição estendida de projeto para reatores à água leve.

Os modelos do COCOSYS são utilizados para a análise termohidráulica, combustão de hidrogênio, bem como dos produtos de fissão e do comportamento dos aerossóis. Com tal abordagem, o COCOSYS não se restringe aos fenômenos de acidentes com condição estendida de projeto, mas possibilita também demonstrar as interações entre estes fenômenos, bem como o comportamento global do confinamento.

O COCOSYS é dividido em vários módulos. Cada módulo é um programa separado executável, dedicado a uma área específica do problema analisado. A comunicação entre os módulos é feita através de Parallel Virtual Machine (PVM) (Geist, 1994), que organiza e controla a sequência de cálculos. A troca de dados só é permitida entre os principais módulos e o COCOSYS para que se mantenha a complexidade dentro de limites razoáveis. O PVM é utilizado entre os códigos COCOSYS e ATHLET. 
Devido ao fato de os módulos serem programas independentes, efeitos colaterais indesejáveis entre os módulos devem ser evitados, tornando, assim, a manutenção do sistema global consideravelmente mais fácil. O uso do PVM é uma base adequada para a paralelização no principal nível modular. Além dos três módulos principais, Thermal HYdraulic (THY), Aerosol Fission Products (AFP) e Core Melt $(\mathrm{CCl})$, que fazem parte do COCOSYS, outros programas são também acoplados ao código, como o ATHLETIC-CD, para a simulação do sistema primário de reatores nucleares e o código LAVA, desenvolvido para a simulação do processo de fusão (Klein-Hessling et al., 2000). 


\section{METODOLOGIA}

A metodologia utilizada neste trabalho envolve a simulação de três LBLOCA no circuito primário de refrigeração de Angra 2.

Nessa metodologia, são utilizados dois programas computacionais: RELAP5/MOD3. 2Gamma e o COCOSYS V2.4.

Inicialmente, serão feitas algumas considerações a respeito do acidente que foi simulado nesse trabalho.

Quando ocorre um LBLOCA, o refrigerante que inicialmente está subresfriado sofre uma rápida despressurização até atingir a temperatura de saturação que, para esse tipo de ruptura, ocorre em até 2 segundos.

Os três LBLOCA considerados nesse trabalho são:

- ruptura na PF do circuito primário entre a bomba e o vaso de pressão, circuito 20 onde se encontra o Pressurizador (LBLOCA-PF);

- ruptura na PI do circuito primário entre o gerador de vapor e a bomba, circuito 20 (LBLOCA-PI);

- ruptura na $P Q$ do circuito primário entre a saída do vaso de pressão e a entrada do gerador de vapor circuito 20, (LBLOCA-PQ).

A ruptura na PF, entre a bomba e o vaso de pressão, é considerada o pior caso para o reator, pois a água de refrigeração do núcleo é perdida, o que compromete a integridade do mesmo. Entretanto, a ruptura na perna quente é o pior caso para a contenção, pois há uma maior liberação de energia para o ambiente interno da contenção, quando comparada com os outros casos.

A primeira etapa do trabalho consiste na obtenção das condições de contorno geradas pelos três LBLOCA no circuito primário de refrigeração do reator utilizando, para isto, o código RELAP5. As simulações, com as suas respectivas hipóteses, obtidas do relatório técnico do Centro de Engenharia Nuclear, serão detalhadamente descritas a seguir (Sabundjian, 2016). 


\subsection{Simulação dos acidentes base de projeto com o código RELAP5}

Com o objetivo de obter as pressões na contenção de Angra 2 nos casos de LBLOCA nas pernas frias e na perna quente do circuito primário, foram utilizados alguns resultados da simulação do relatório técnico de Sabundjian (2016).

Para a simulação de tais acidentes, foi utilizado o input básico desenvolvido pelo grupo de trabalho da CNEN (2000), cuja modelagem é mencionada no item 3.3 deste trabalho (Andrade et al., 2001).

De forma geral, a simulação LBLOCA no circuito primário de Angra 2 visa verificar qual é o Pico de Temperatura no Encamisamento (PTE) da vareta mais realista do núcleo do reator. No caso de Angra 2, o material do encamisamento é o M5 (liga de Zircônio) que, segundo normas ${ }^{10}$ da CNEN, não deve exceder à temperatura de $1200^{\circ} \mathrm{C}$. Verifica-se também o bom desempenho do Sistema de Resfriamento de Emergência do Núcleo (SREN), ou seja, a transição confiável e segura da fase da injeção dos acumuladores para a fase de injeção de remoção de calor residual (injeção de baixa pressão). Além disso, são adotados critérios de falha e reparo para componentes do SREN a fim de verificar, de modo conservativo, se o sistema desempenha sua função como previsto no projeto, para preservar a integridade do núcleo do reator e garantir o seu resfriamento.

$\mathrm{Na}$ sequência, são apresentadas as descrições dos acidentes considerados neste trabalho.

\subsubsection{LBLOCA-PF}

O acidente base de projeto, neste caso, é o de perda de refrigerante primário por grande ruptura na tubulação na Perna Fria, entre a bomba e vaso de pressão do circuito primário da usina Angra 2 (LBLOCA-PF), circuito 20. Esse acidente está descrito no item 15.6.4.2.3.1.111 do capítulo de análise de acidentes do RFAS/A2 (Eletronuclear, 2010).

\footnotetext{
10 Norma CNEN NE-1.20 "Aceitação de Sistemas de Resfriamento de Emergência do Núcleo de Reatores a Água Leve" de novembro de 1985.

11 Item denominado Double-Ended Cold-Leg in Loop 20.
} 
As condições iniciais e de contorno adotadas nesta simulação seguem às especificadas no item 3.2.1 desse trabalho, incluindo as condições apresentadas na TAB. 2 e obtidas da Tabela 15.6.4.2-8 do RFAS/A2 (Eletronuclear, 2010).

TABELA 2 - Disponibilidade dos componentes do SREN, LBLOCA-PF

\begin{tabular}{|c|c|c|c|c|c|c|c|c|}
\hline Componentes do SREN & \multicolumn{8}{|c|}{ Injeção } \\
\hline Circuito & \multicolumn{2}{|c|}{10} & \multicolumn{2}{|r|}{20} & \multicolumn{2}{|c|}{30} & \multicolumn{2}{|c|}{40} \\
\hline Local de injeção & Hot & Cold & Hot & Cold & Hot & Cold & Hot & Cold \\
\hline Bomba de injeção de segurança & 1 & - & SF & - & 1 & - & 1 & - \\
\hline Acumuladores & 1 & 1 & SF & Break & $\mathrm{RC}$ & 1 & 1 & 1 \\
\hline $\begin{array}{c}\text { Bomba de remoção de calor } \\
\text { residual }\end{array}$ & \multicolumn{2}{|c|}{1} & \multicolumn{2}{|c|}{ SF/Break } & \multicolumn{2}{|c|}{1} & \multicolumn{2}{|c|}{1} \\
\hline
\end{tabular}

$\mathrm{Na}$ FIG. 16, encontra-se indicada a localização da ruptura na PF, LBLOCA-PF, entre a bomba e o vaso de pressão - no trecho indicado no circuito primário da planta (circuito 20).

As seguintes hipóteses foram assumidas nesse item:

- critério de reparo do acumulador da PQ do circuito 30;

- perda dos seguintes sistemas: acumulador PQ e PF, sistema de injeção de segurança e sistema de remoção de calor residual para o circuito 20 . 


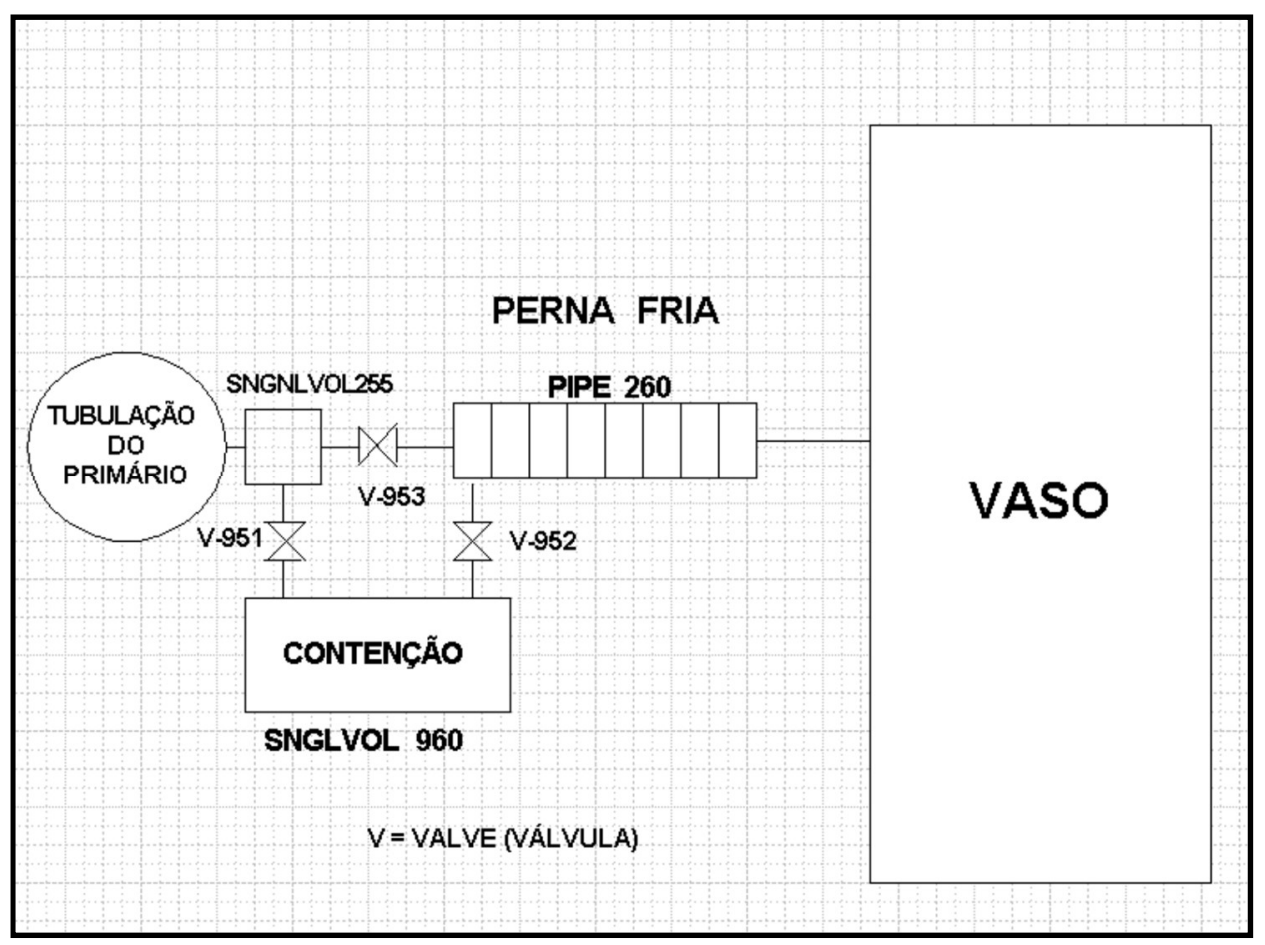

FIGURA 16 - Localização da quebra na tubulação da perna fria do circuito primário de Angra 2 (LBLOCA-PF)

\subsubsection{LBLOCA-PI}

Outro acidente base de projeto é o de perda de refrigerante primário por grande ruptura na tubulação da PF do circuito primário da usina nuclear Angra 2, LBLOCA-PI, entre o gerador de vapor e a bomba. Esse acidente está descrito no item 15.6.4.2.3.1.4 $4^{12}$ do capítulo de análise de acidentes do RFAS/A2 (Eletronuclear, 2010).

As condições iniciais e de contorno adotadas nessa simulação seguem às especificadas no item 3.2.1 desse trabalho, incluindo, porém, as condições apresentadas na TAB. 3 obtidas da Tabela 15.6.4.2-10 do RFAS/A2 (Eletronuclear, 2010).

12 Item denominado Double-Ended Crossover-Leg Break. 
TABELA 3 - Disponibilidade dos componentes do SREN, LBLOCA-PI

\begin{tabular}{|c|c|c|c|c|c|c|c|c|}
\hline Componentes do SREN & \multicolumn{8}{|c|}{ Injeção } \\
\hline Circuito & \multicolumn{2}{|c|}{10} & \multicolumn{2}{|c|}{20} & \multicolumn{2}{|c|}{30} & \multicolumn{2}{|c|}{40} \\
\hline Local de injeção & Hot & Cold & Hot & Cold & Hot & Cold & Hot & Cold \\
\hline $\begin{array}{l}\text { Bomba de injeção de } \\
\text { segurança }\end{array}$ & 1 & - & SF & - & 1 & - & 1 & - \\
\hline Acumuladores & 1 & 1 & SF & 1 & $\mathrm{RC}$ & 1 & 1 & 1 \\
\hline $\begin{array}{c}\text { Bomba de remoção de calor } \\
\text { residual }\end{array}$ & \multicolumn{2}{|c|}{1} & 1 & 1 & \multicolumn{2}{|c|}{1} & \multicolumn{2}{|c|}{1} \\
\hline
\end{tabular}

Cold - Perna Fria

Hot - Perna Quente

Break - injeção direta na quebra
SF - falha simples na válvula de isolamento $\mathrm{RC}$ - reparo

As seguintes hipóteses foram assumidas nesse item:

- critério de falha do acumulador da PQ do circuito 30;

- perda dos seguintes sistemas: acumulador PQ e sistema de injeção de segurança para o circuito 20 .

A FIG. 17 apresenta a localização do LBLOCA-PI para a nodalização proposta.

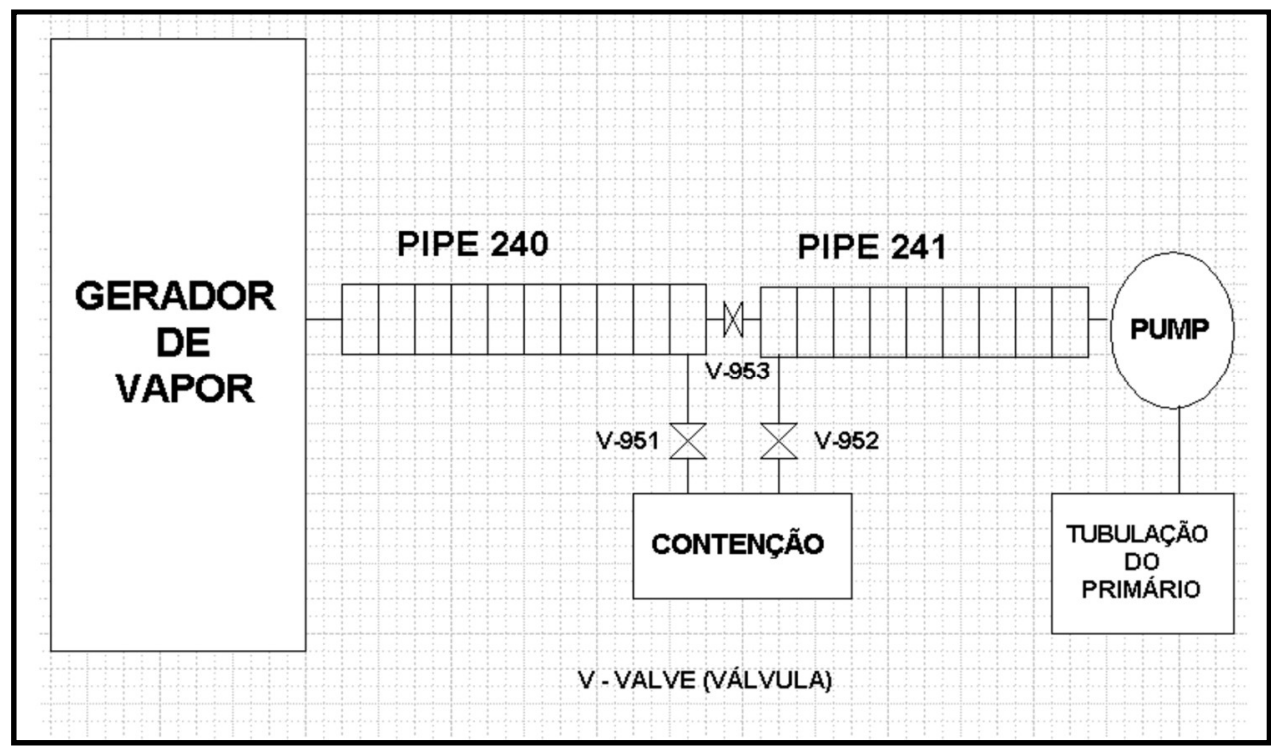

FIGURA 17 - Localização da quebra na tubulação da perna fria do circuito primário de Angra2 (LBLOCA-PI) 


\subsubsection{LBLOCA-PQ}

Finalmente, outro acidente base de projeto considerado é o de perda de refrigerante primário por grande ruptura na tubulação, $P Q$ do circuito primário da usina nuclear Angra 2 (LBLOCA-PQ). Esse acidente está descrito no item 15.6.4.2.3.1.313 do capítulo de análise de acidentes do RFAS/A2 (Eletronuclear, 2010).

As condições iniciais e de contorno adotadas nessa simulação seguem às especificadas no item 3.2.1 desse trabalho, juntamente com as condições apresentadas na TAB. 4, obtidas da Tabela 15.6.4.2-9 do RFAS/A2 (Eletronuclear, 2010).

TABELA 4 - Disponibilidade dos componentes do SREN, LBLOCA-PQ

\begin{tabular}{|c|c|c|c|c|c|c|c|c|}
\hline \multirow{3}{*}{$\begin{array}{c}\text { Componentes do SREN } \\
\text { Circuito } \\
\text { Local de injeção }\end{array}$} & \multicolumn{8}{|c|}{ Injeção } \\
\hline & \multicolumn{2}{|c|}{10} & \multicolumn{2}{|c|}{20} & \multicolumn{2}{|c|}{30} & \multicolumn{2}{|c|}{40} \\
\hline & Hot & Cold & Hot & Cold & Hot & Cold & Hot & Cold \\
\hline Bomba de injeção de segurança & 1 & - & Break & - & 1 & - & 1 & - \\
\hline Acumuladores & 1 & 1 & Break & SF & $\mathrm{RC}$ & 1 & 1 & 1 \\
\hline $\begin{array}{c}\text { Bomba de remoção de calor } \\
\text { residual }\end{array}$ & \multicolumn{2}{|c|}{1} & Break & SF & \multicolumn{2}{|c|}{1} & \multicolumn{2}{|c|}{1} \\
\hline
\end{tabular}

Cold - Perna Fria

Hot - Perna Quente

Break - injeção direta na quebra
SF - falha simples na válvula de isolamento $\mathrm{RC}$ - reparo

As seguintes hipóteses foram assumidas nesse trabalho:

- critério de falha do acumulador de PQ e do circuito 30;

- perda dos seguintes sistemas: acumulador de PQ e PF, sistema de injeção de segurança e sistema de remoção de calor residual para o circuito 20 .

A FIG.18 apresenta a localização do LBLOCA-PQ para a nodalização proposta.

13 Item denominado Double-Ended Cold-Leg Hot-Leg Break. 


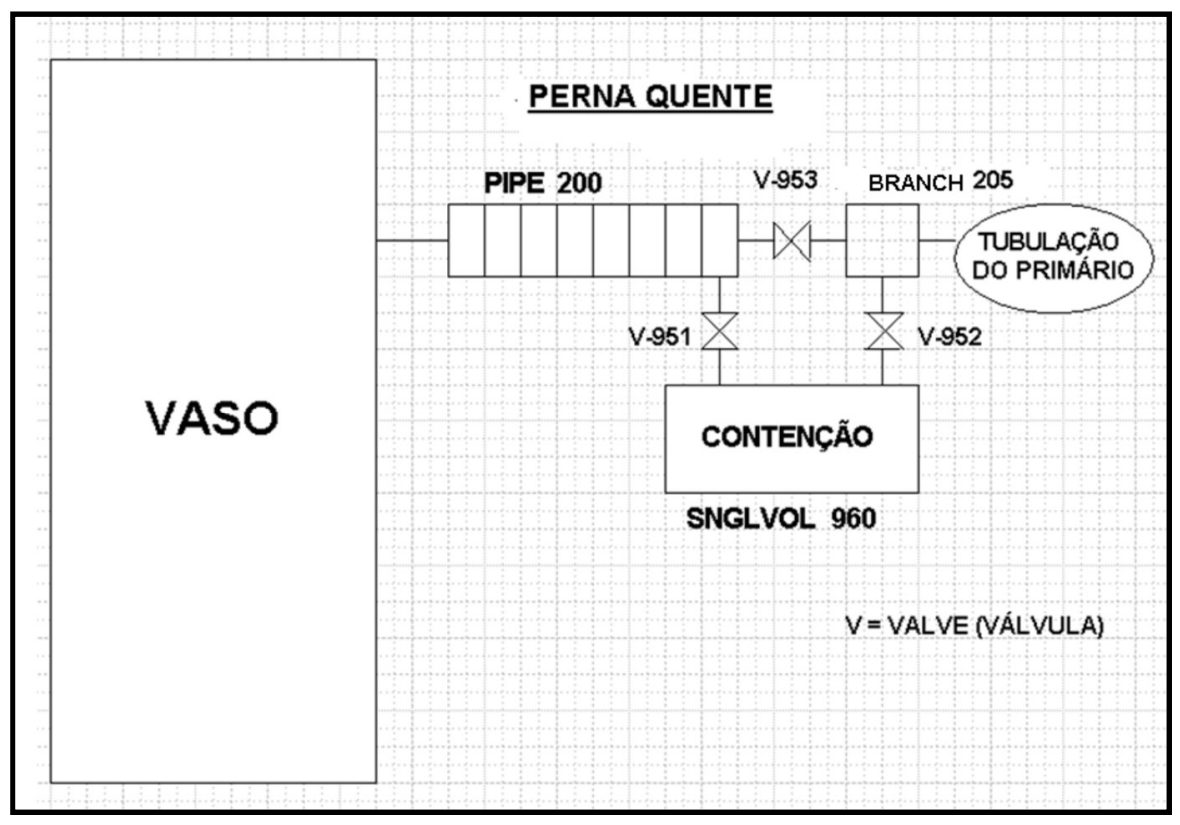

FIGURA 18 - Localização da quebra na tubulação da perna quente do circuito primário (entrada do vaso) de Angra 2 (LBLOCA-PQ)

\subsection{Condições iniciais e de contorno}

A seguir, serão descritas as condições de contorno utilizadas para:

- a primeira etapa: simulação dos três LBLOCA para o circuito primário de Angra 2 com o código RELAP5;

- a segunda etapa: simulação da contenção com os códigos RELAP5 e COCOSYS, utilizando as condições de contorno geradas na primeira etapa.

Na segunda etapa, o código RELAP5 foi inicialmente utilizado, pois o acordo firmado entre a CNEN e a GRS dependia da ministração de um curso para que o código COCOSYS fosse cedido ao Brasil. Esse processo se estendeu por um ano, sendo concluído em outubro de 2016. Durante tal processo, realizou-se um estudo da contenção de Angra 2 com o código RELAP5 a fim de obter resultados preliminares para testar a segunda etapa da metodologia. Embora este código não seja especifico para um estudo completo da contenção, possui modelos que a descrevem adequadamente. 
Ao final da segunda etapa, realizou-se ainda um processo iterativo (uma única iteração), em que os resultados do comportamento da contenção, referentes à segunda etapa, foram definidos como condição de contorno para uma nova simulação da planta inteira.

Este procedimento é adotado para se obter resultados mais realistas da distribuição de temperatura do encamisamento na vareta mais realista do núcleo do reator para os três casos de LBLOCA descritos nesse trabalho. Essa metodologia ${ }^{14}$ é indicada no RFAS/A2 para o estudo de acidentes base de projeto, no qual são utilizados o código S-RELAP5 para simulação da planta inteira de Angra 2 e o código COCO para a simulação da contenção desta planta (FIG. 19).

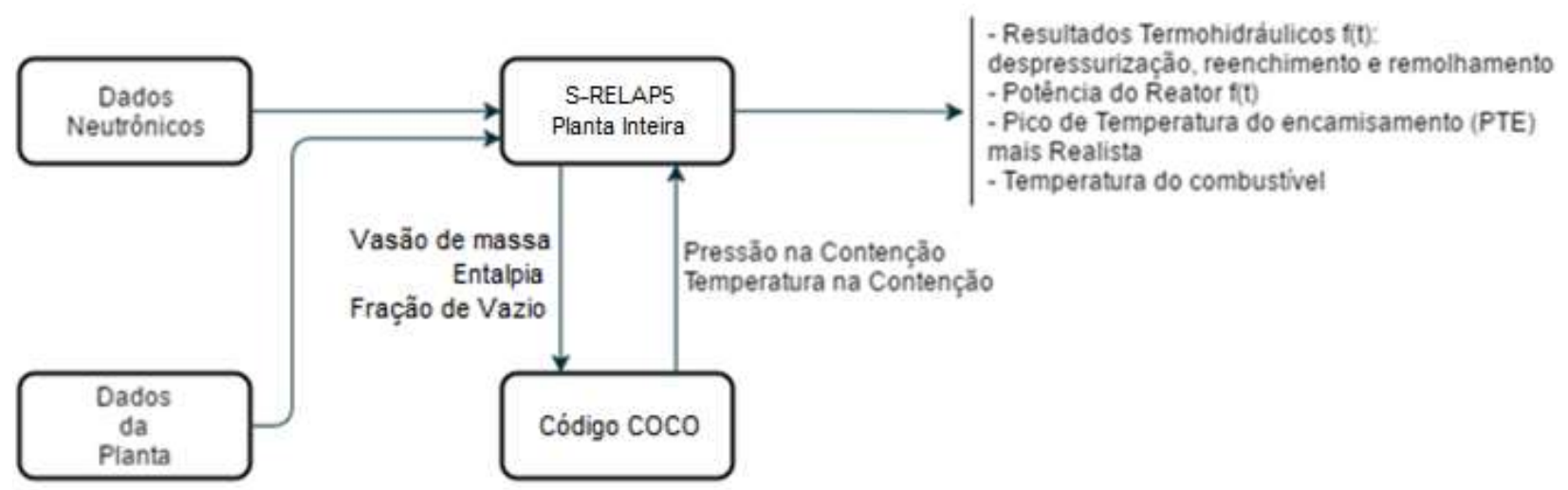

FIGURA 19 - Metodologia utilizada na análise da contenção, segundo o RFAS/A2

O código S-RELAP5 é uma versão modificada do RELAP5/MOD2 que incorpora alguns aspectos de portabilidade computacional do RELAP5/MOD3 (ELETRONUCLEAR, 2010).

O fato de ter se realizado apenas uma iteração nesse trabalho se deve ao atraso no envio do código COCOSYS, que limitou a realização das demais iterações, pois há um prazo limite para a defesa dessa dissertação.

\subsubsection{Primeira etapa}

Basicamente, as condições iniciais e de contorno adotadas na simulação dos acidentes aqui descritos seguem as que são especificadas no RFAS/A2 ${ }^{15}$. Essas

\footnotetext{
14 Descrita em detalhes no capítulo 15.6.4.0 - Code and Methodology Description

15 Essas condições estão descritas no capítulo 15.6.4.2 - Large-Break Loss-of-Coolant Accidents.
} 
condições são gerais para todos os casos de LOCA do RFAS/A2 (Eletronuclear, 2010).

As condições particulares de cada acidente estão descritas no item 3.1. O Sistema de Proteção do Reator e o SREN estão com suas lógicas de atuação incorporadas aos dados de entrada da nodalização:

- reator operando a $100 \%$ de potência - condições iniciais descritas na Tab. 5 (no RFAS/A2 todas as análises de LOCA foram realizadas a 100\% de potência);

- núcleo do reator na condição de início de ciclo, para o ciclo de equilíbrio (i.e., 6 dias de equilíbrio com operação a plena potência e queima de 0,2MWd/Kg);

- perfil axial da potência do tipo top skewed (potência maior no topo);

- calor de decaimento seguindo a Tabela ANS79-1, com um fator multiplicativo de 1,08;

- sinal de desligamento (scram) do reator: conservativamente considerado o segundo sinal de desligamento, desprezando-se o $1^{\circ}$ sinal;

- reatividade de scram (para desligamento do reator): reatividade equivalente de todas as barras com exceção da barra mais reativa. Adicionalmente, está sendo considerado um atraso de $0,2 \mathrm{~s}$ para início da queda das barras e $2 \mathrm{~s}$ de tempo de queda das barras;

- assumida a condição de MPE, i.e., indisponibilidade de potência externa, ocorrendo no mesmo instante do desligamento do reator e do isolamento da turbina;

- consideração do critério de falha e reparo para o gerador diesel dos circuitos 30 e 40, o que provoca a indisponibilidade das bombas de injeção de alta pressão e de remoção de calor residual do SREN conectado a esses circuitos;

- desligamento (coastdown) das bombas de refrigeração do reator concomitante com a perda da potência externa;

- considerado o resfriamento do secundário a uma taxa de $-100 \mathrm{~K} / \mathrm{h}$, quando a pressão do primário $\left(\mathrm{p}_{\mathrm{RCS}}\right)$ < 13,2MPa e a da contenção $\mathrm{p}_{\mathrm{cont}}>0,103 \mathrm{Mpa}$; 
- critério de atuação do SREN: 2 de 3 sinais; $p_{\text {cont }}>$ 0,103MPa; $p_{R c s}<11,0 \mathrm{MPa}$; nível do pressurizador (LPZR) $<2,28 \mathrm{~m}$;

- critério para a bomba de injeção de alta pressão (SIP): critério do SREN atingido, +32s de atraso devido ao MPE, +5s de atraso para a partida da bomba;

- critério para a bomba de remoção de calor residual (SIPB): pRcs < 1,0MPa, +37s de atraso devido ao MPE, +5 s de atraso para a partida da bomba;

- critério para a injeção de água de alimentação auxiliar: nível do gerador de vapor $(\mathrm{Lgv})<5 \mathrm{~m}$.

A disponibilidade do SREN foi feita de acordo com o local da quebra no circuito primário de Angra 2, como mostrado nas TAB. 2, 3 e 4, seguindo as considerações feitas pelo RFAS/A2. Na TAB. 5, são apresentadas as condições de contorno da usina operando a $100 \%$ de potência. 
TABELA 5 - Condições iniciais da usina de Angra 2

\begin{tabular}{|c|c|c|c|c|c|}
\hline \multirow[b]{2}{*}{ PARÂMETRO } & \multirow[b]{2}{*}{ UNIDADE } & \multirow[b]{2}{*}{$\begin{array}{l}\text { NOMINAL } \\
\text { [RFAS/A2] }\end{array}$} & \multirow[b]{2}{*}{$\begin{array}{c}\text { RELAP5 } \\
\text { Mod 3.2gama }\end{array}$} & \multicolumn{2}{|c|}{ ERRO (\%) ${ }^{16}$} \\
\hline & & & & $\begin{array}{c}\text { CALCULA } \\
\text { DO }\end{array}$ & $\begin{array}{l}\text { ACEITÁV } \\
\text { EL }\end{array}$ \\
\hline \multicolumn{6}{|c|}{ Reator } \\
\hline Potência térmica & MW & 3765 & 3768,4 & 0,09 & 2,0 \\
\hline Perda de pressão no vaso & bar & 2,93 & 2,815 & $-3,92$ & 10 \\
\hline Perda de pressão no núcleo & bar & 1,34 & 1,345 & 0,37 & 10 \\
\hline Temperatura na saída do núcleo & $\mathrm{K}$ & 601,25 & 601,18 & $-0,01$ & 0,5 \\
\hline $\begin{array}{l}\text { Temperatura na entrada do } \\
\text { núcleo }\end{array}$ & $\mathrm{K}$ & 564,45 & 566,29 & 0,33 & 0,5 \\
\hline $\begin{array}{l}\text { Aumento de temperatura no } \\
\text { núcleo }\end{array}$ & $\mathrm{K}$ & 36,80 & 34,89 & $-5,19$ & - \\
\hline Temperatura de saída no vaso & $\mathrm{K}$ & 599,25 & 600,70 & 0,24 & 0,5 \\
\hline Temperatura de entrada no vaso & $\mathrm{K}$ & 564,45 & 566,29 & 0,33 & 0,5 \\
\hline Aumento de temperatura no vaso & $\mathrm{K}$ & 34,8 & 34,41 & $-1,12$ & - \\
\hline Vazão de refrigerante no núcleo & $\mathrm{kg} / \mathrm{s}$ & 17672,0 & 17671,00 & $-0,01$ & 2,0 \\
\hline Vazão de desvio do núcleo & $\mathrm{kg} / \mathrm{s}$ & 846,00 & 845,69 & $-0,04$ & 10,0 \\
\hline $\begin{array}{l}\text { Vazão de desvio pernas fria- } \\
\text { quente }\end{array}$ & $\mathrm{kg} / \mathrm{s}$ & 188,00 & 188,21 & 0,11 & 10,0 \\
\hline Vazão na cabeça do vaso & $\mathrm{kg} / \mathrm{s}$ & 94,00 & 93,98 & $-0,02$ & 10,0 \\
\hline \multicolumn{6}{|c|}{ Gerador de Vapor } \\
\hline Pressão de vapor na saída & bar & 64,5 & 64,50 & 0,0 & 0,1 \\
\hline Perda de pressão no primário & bar & 2,33 & 2,63 & 12,88 & 10,0 \\
\hline $\begin{array}{l}\text { Temperatura da água de } \\
\text { alimentação }\end{array}$ & $\mathrm{K}$ & 491,15 & 491,15 & 0,0 & 0,5 \\
\hline $\begin{array}{l}\text { Vazão mássica da água de } \\
\text { alimentação }\end{array}$ & $\mathrm{kg} / \mathrm{s}$ & 513,9 & 513,90 & 0,0 & 2,0 \\
\hline Vazão mássica de vapor & $\mathrm{kg} / \mathrm{s}$ & 513,9 & 512,34 & $-0,30$ & 2,0 \\
\hline Vazão mássica de recirculação & $\mathrm{kg} / \mathrm{s}$ & 1541,7 & 1541,3 & $-0,03$ & 10,0 \\
\hline Nível de líquido & $\mathrm{m}$ & 12,2 & 12,34 & $0,14 \mathrm{~m}$ & $0,1 \mathrm{~m}$ \\
\hline Energia térmica transferida & MW & 945,5 & 944,99 & $-0,05$ & 2,0 \\
\hline \multicolumn{6}{|c|}{ Pressurizador } \\
\hline Pressão & bar & - & 158,41 & & 0,1 \\
\hline Nível de líquido & $\mathrm{m}$ & 7,95 & 7,96 & $0,01 \mathrm{~m}$ & $0,05 \mathrm{~m}$ \\
\hline \multicolumn{6}{|c|}{ Circuito Primário } \\
\hline Pressão na Perna Quente & bar & 158,0 & 158,11 & 0,07 & 0,1 \\
\hline Temperatura na Perna Quente & $\mathrm{K}$ & 599,25 & 600,72 & 0,25 & 0,5 \\
\hline Temperatura na Perna Fria & $\mathrm{K}$ & 564,45 & 566,29 & 0,33 & 0,5 \\
\hline Vazão mássica do circuito & $\mathrm{kg} / \mathrm{s}$ & 4700,0 & 4699,70 & $-0,01$ & 2,0 \\
\hline Perda de pressão total & bar & 6,5 & 6,37 & $-2,00$ & 10,0 \\
\hline
\end{tabular}

${ }^{16}$ D'Auria, F., Galassi, G. M., Belsito, S., Gatta, P., Ingegneri, M., UMAE Application: Contribution to the OECD/CSNI UMS Vol. 2, Uncertainty Methods Study for Advanced Best Estimate Thermal Hydraulic Code Applications. Vol. 2, NEA/CSNI/R(97)35, França, pp.2.I-2.114, 1998. 


\subsubsection{Segunda etapa}

As condições geométricas e operacionais da contenção de Angra 2 consideradas, segundo o RFAS/A2, estão listadas na TAB. 6.

TABELA 6 - Condições geométricas e operacionais descritas no RFAS/A2 ${ }^{17}$

\begin{tabular}{c|c|c}
\hline Item & Unidade & Valor \\
\hline Diâmetro Interno & $\mathrm{m}$ & 56,0 \\
\hline Volume Livre de Projeto & $\mathrm{m}^{3}$ & $7,1 \times 10^{4}$ \\
\hline Espessura da Contenção de Aço & $\mathrm{mm}$ & 30,0 \\
\hline Pressão Manométrica de Projeto & bar & 5,3 \\
\hline Superfície da Contenção de aço & $\mathrm{m}^{2}$ & $7,66 \times 10^{3}$ \\
\hline
\end{tabular}

Se a pressão manométrica de projeto de 5,3 bar $^{18}$ for atingida, será aberta parcialmente a válvula de alívio da contenção de Angra 2 em $5 \%$ de sua área total de abertura. Com isto, será liberada parte da pressão da contenção para o meio ambiente. No entanto, se a pressão na contenção continuar aumentando e atingir a máxima pressão manométrica de $8,5 \operatorname{bar}^{19}$, a mesma válvula de alívio será aberta totalmente - $100 \%$ de sua área de abertura - liberando para o meio ambiente não apenas a pressão como também, de maneira controlada, os rejeitos oriundos das fissões nucleares ocorridas no reator (RFAS/A2, 2010).

A metodologia realista do LOCA possui dois cálculos adicionais de sensibilidade que estão definidos no capítulo 15.6.4 ${ }^{20}$ do RFAS/A2 para determinar a maior e a menor pressão na contenção, além do caso base (Base Case), que considera o volume livre de projeto da contenção para cada uma das quebras. Esses se diferenciam pelo volume livre que é considerado dentro da contenção. Ao considerar um volume interno maior que o dado no caso base, o pico de pressão interno tende a ser menor. Essa abordagem é denominada Low Case (volume maior em $5 \%$ em relação ao Base Case). Já para o High Case, o volume interno é menor

\footnotetext{
17 Informações retiradas do capítulo 3.8.2.1 do RFAS/A2, denominado Description of the Containment

18 Pressão manométrica de 5,3bar e pressão absoluta de 6,3bar.

19 Pressão manométrica de 8,5bar e pressão absoluta de 9,5bar.

${ }^{20}$ Capítulo denominado Loss-of-Coolant Accidents Resulting from a Spectrum of Postulated Piping

Breaks within the Reactor Coolant Pressure Boundary.
} 
em $5 \%$ em relação ao caso base, e espera-se que os valores de pressão para um mesmo acidente sejam maiores.

A TAB. 7 indica os valores de volumes livres considerados em cada uma das abordagens, segundo o RFAS/A2.

TABELA 7 - Volumes definidos para cada abordagem utilizados para a simulação dos LBLOCA

\begin{tabular}{c|c}
\hline Abordagem $^{\mathbf{2 1}}$ & Volume da Contenção $\left.\mathbf{( m}^{\mathbf{3}}\right)$ \\
\hline High Case & 67.840 \\
\hline Base Case & 70.980 \\
\hline Low Case & 74.275 \\
\hline
\end{tabular}

As propriedades do material da contenção de Angra 2 são as do aço austenítico WStE 51, detalhadas no ANEXO A.

A capacidade térmica e a condutividade térmica do aço em relação à temperatura definem as propriedades de troca de calor da estrutura e são inseridas por meio de uma tabela no RELAP5.

\subsection{Modelagem da simulação da planta inteira de Angra 2}

Essa modelagem, que corresponde à primeira etapa, foi baseada na nodalização básica desenvolvida pelo grupo de trabalho da CNEN e institutos (Grupo de Trabalho, 2000; Andrade et al., 2001).

Foi feita uma modelagem para cada um dos quatro circuitos primários, mas apenas um circuito (20) é apresentado, conforme ANEXO B. Isso porque é neste circuito que ocorrem as quebras estudadas nesse trabalho e, devido ao fato do pressurizador se encontrar neste circuito, esse é o pior cenário nos casos dos LBLOCA, devido a drenagem mais rápida da linha de surto e do pressurizador.

O núcleo foi dividido em regiões, tomando como exemplo a modelagem descrita no RFAS/A2, sendo uma região mais quente que é a parte central do núcleo, uma região vizinha a esta, uma região mais periférica do núcleo e quatro regiões chamadas de breakthrough channel, que correspondem às regiões próximas das

${ }^{21}$ Termos utilizados no RFAS/A2 e usuais da área. 
saídas e entradas do fluido refrigerante, descrito no ANEXO B. Além disso, foram simuladas uma vareta mais realista e uma vareta conservativa, que estão localizadas na região mais quente do núcleo.

Os outros três circuitos são análogos ao circuito 20, com exceção da linha de surto do pressurizador e o próprio pressurizador, que são únicos e pertencem apenas ao circuito 20 .

Os resultados referentes à primeira etapa encontram-se no ANEXO C.

\subsection{Modelagem da contenção de Angra 2 com o código RELAP5}

A metodologia usada para análise das condições na contenção é apresentada no fluxograma descrito na FIG.20.

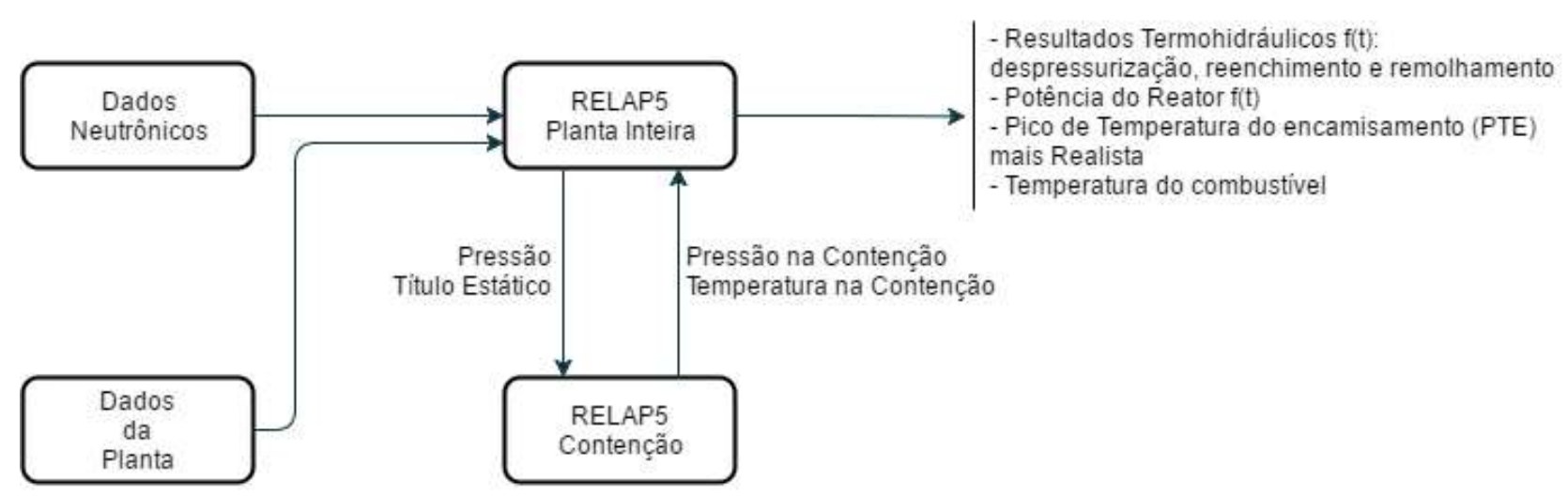

FIGURA 20 - Metodologia utilizada na análise da contenção com o código RELAP5

Além das condições detalhadas no item 3.2 desse trabalho, os dados de pressão e título estático em função do tempo fornecidos pela simulação dos LBLOCA foram considerados nessa simulação como condições de contorno para o cálculo da pressão e da temperatura na contenção.

Os resultados obtidos da simulação da contenção foram utilizados em um processo iterativo numa nova simulação do LBLOCA da planta inteira (uma única iteração), a fim de se obter valores mais realistas dos picos de temperatura do encamisamento na vareta mais realista do núcleo.

A modelagem da contenção foi elaborada com base nos volumes livres definidos (TAB. 7) e suas dimensões, de acordo com o RFAS/A2 (Eletronuclear, 
2010). A partir destas informações componentes foram criados e as condições de contorno oriundas do circuito primário para a contenção nos três casos simulados de LBLOCA, com o RELAP5 foram fornecidas, conforme FIG. 21.

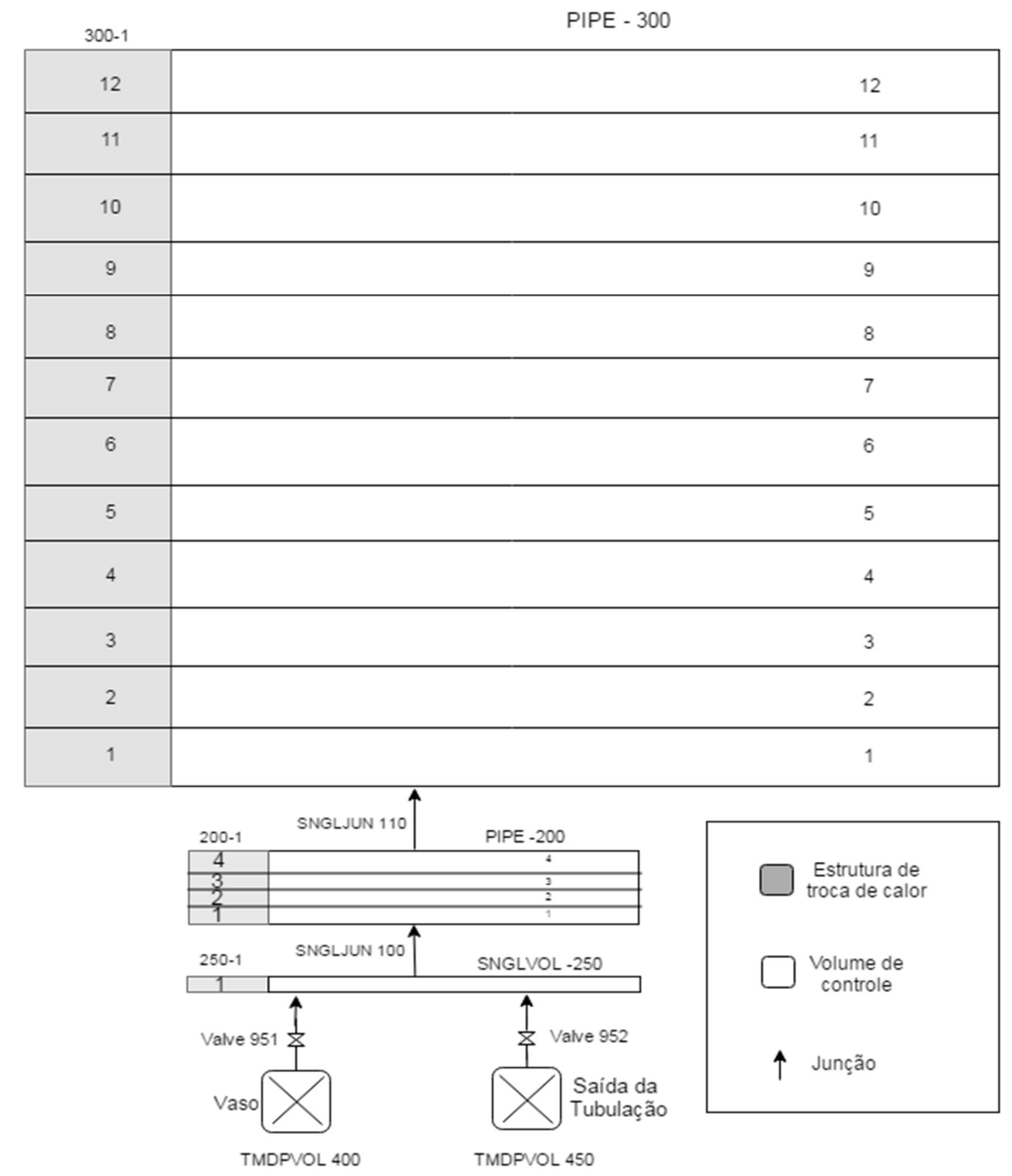

FIGURA 21 - Modelagem da contenção para o RELAP5

No caso de uma ruptura tipo guilhotina no circuito primário, existem três possibilidades de LBLOCA, como descritas anteriormente. Assim, para cada uma das 
rupturas, há vazão mássica da mistura bifásica em cada um dos lados rompidos, que, nesse trabalho estão sendo simulados como componentes dependentes do tempo (time-dependent volume component-TMDPVOL).

As junções entre o primário e a contenção são feitas por meio de válvulas que simulam teoricamente a quebra tipo guilhotina. A descrição de cada um dos componentes modelados se encontra na TAB. 8, e os dados geométricos definidos na modelagem estão no APÊNDICE A.

TABELA 8 - Nodalização da Contenção de Angra 2: correspondência entre os componentes do código e as zonas hidráulicas

\begin{tabular}{|c|c|c|c|}
\hline \multicolumn{2}{|c|}{ Região Hidráulica } & \multirow{2}{*}{$\begin{array}{c}\begin{array}{c}\mathbf{N}^{\circ} \text { do } \\
\text { Componente }\end{array} \\
400\end{array}$} & \multirow{2}{*}{ 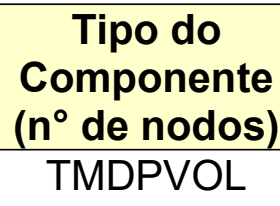 } \\
\hline \multirow{4}{*}{$\begin{array}{l}\text { Circuito } \\
\text { Primário }\end{array}$} & Vaso de Pressão & & \\
\hline & Tubulação & 450 & TMDPVOL \\
\hline & $\begin{array}{c}\text { Junção de Quebra } \\
\text { (Guilhotina) }\end{array}$ & 950 & VALVE \\
\hline & $\begin{array}{c}\text { Junção de Quebra } \\
\text { (Guilhotina) }\end{array}$ & 951 & VALVE \\
\hline \multirow{4}{*}{ Sump } & Primeiro volume & 250 & SNGLVOL \\
\hline & Demais volumes & 200 & PIPE \\
\hline & Junção (250 - 200) & 100 & SNGLJUN \\
\hline & Junção (200 - 300) & 110 & SNGLJUN \\
\hline Contenção & Contenção & 300 & PIPE \\
\hline
\end{tabular}

\subsection{Modelagem da contenção de Angra 2 com o código COCOSYS}

Para o cálculo das condições dentro da contenção pelo COCOSYS, quatro tabelas (com valores de vazão mássica e de entalpia em função do tempo para cada uma das fases, líquida e vapor, respectivamente, e para cada um dos lados da ruptura) compõem as adições de massa e energia provenientes da despressurização do circuito primário no caso dos três LBLOCA.

A metodologia usada para a análise das condições na contenção é apresentada no fluxograma descrito na FIG. 22. 


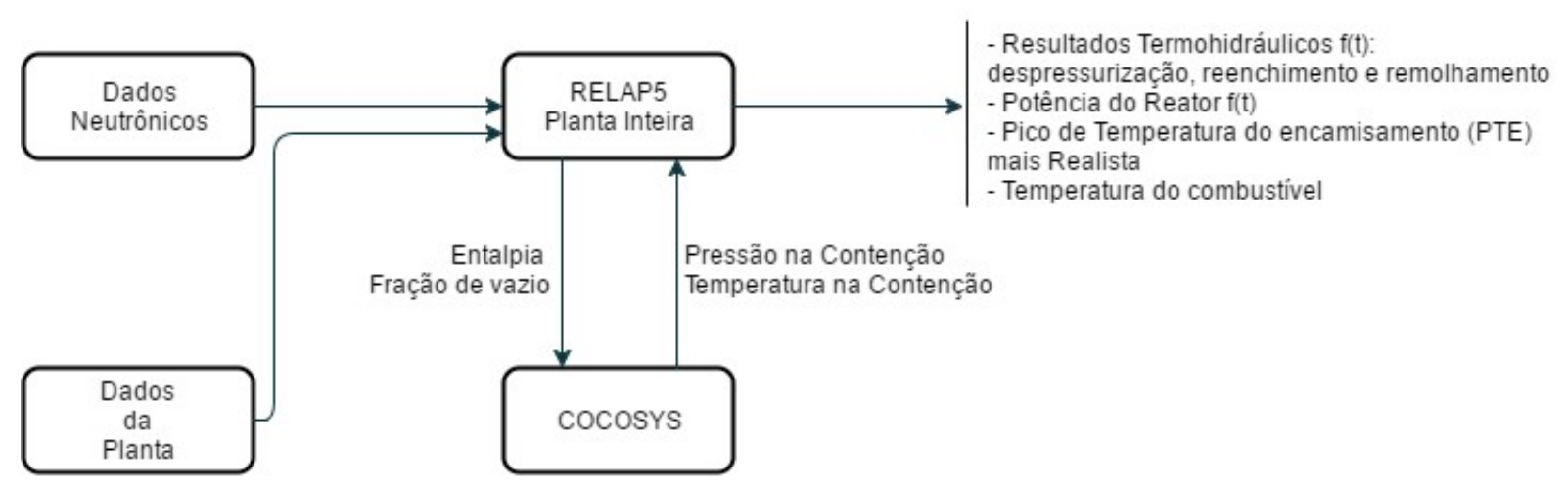

FIGURA 22 - Metodologia utilizada na análise da contenção com o código COCOSYS

As transferências de calor por meio das estruturas de troca de calor podem ser realizadas entre: dois compartimentos; internamente em um compartimento; ou entre um compartimento e o ambiente externo à contenção. Foram especificadas as conexões físicas e as condições de contorno, que consistem no fornecimento dos dados do coeficiente de transferência de calor e das dimensões geométricas para cada uma das regiões.

No desenvolvimento da modelagem do COCOSYS, observou-se que, para o caso de um LBLOCA, o detalhamento dos volumes de controle e das estruturas de troca de calor pouco interferiram no cálculo dos picos de pressão e temperatura no ambiente da contenção que ocorrem nos primeiros segundos dos acidentes considerados. Portanto, optou-se para uma modelagem mais simplificada, pois o tempo de processamento é bem menor. Este detalhamento é relevante no caso de um acidente com condições estendidas de projeto (acidente severo), já que esse tipo de acidente tem uma evolução por algumas horas, e até dias, permitindo assim uma maior transferência de calor por meio das estruturas de troca.

A FIG. 23 apresenta a modelagem da contenção de Angra 2 para a simulação dos LBLOCA proposta nesse trabalho com o código COCOSYS. Na TAB.9 estão discriminadas as zonas definidas na FIG. 23.

No APÊNDICE B são apresentados os dados geométricos e as áreas de troca de calor de cada uma das zonas deste modelo. 


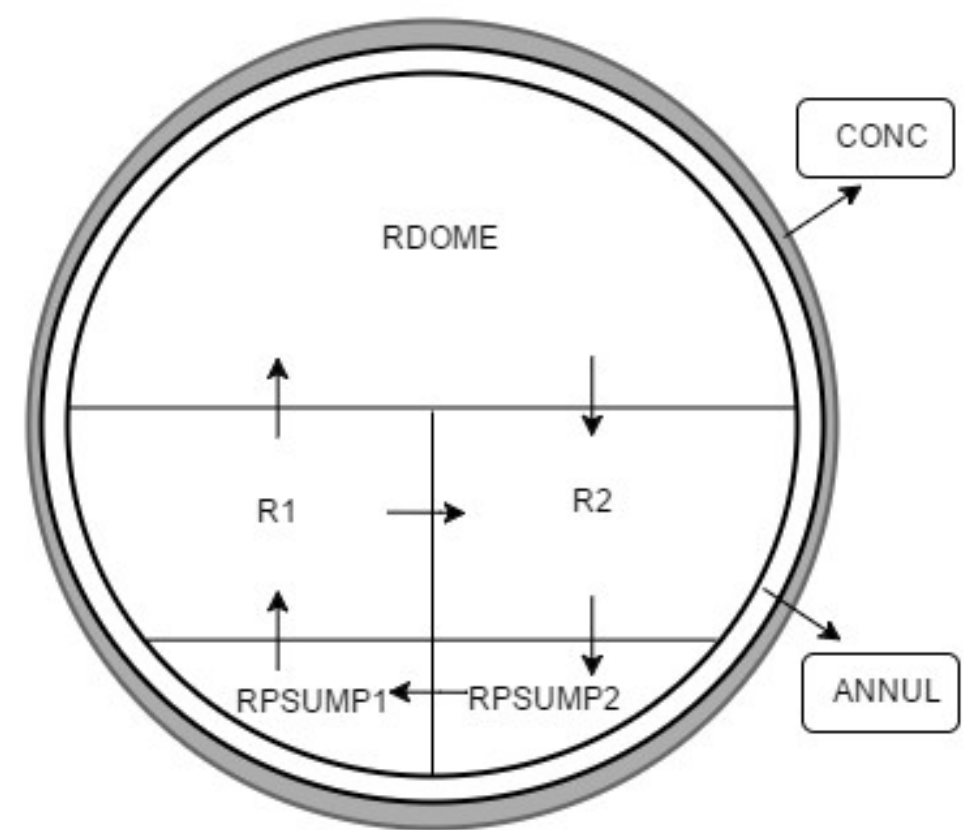

FIGURA 23 - Modelagem da contenção para o COCOSYS

TABELA 9 - Nodalização da Contenção de Angra 2: correspondência entre os componentes do código e as zonas hidráulicas

\begin{tabular}{c|c|c}
\hline \multicolumn{2}{c|}{ Região Hidráulica } & Componente Correspondente \\
\hline \multirow{4}{*}{ Contenção } & RPSUMP1 & Região do Sump \\
& RPSUMP2 & Região do Sump \\
& R1 & Contenção \\
& R2 & Contenção \\
& RDOME & Contenção \\
& ANNUL & Anel \\
& CONC & Contenção Secundária \\
\hline
\end{tabular}




\section{RESULTADOS}

A seguir, serão apresentados os resultados de pressão e temperatura na contenção de Angra 2 para ambos os códigos utilizados: RELAP5 e COCOSYS. Também serão apresentados os resultados dos PTE da vareta mais realista do núcleo de Angra 2, utilizando, para isto, a simulação da planta inteira com o RELAP5, após o processo de iteração, os dados de pressão e temperatura da contenção e condição de contorno.

\subsection{Resultados obtidos com o código RELAP5}

Neste caso, além do processo iterativo (uma única iteração), foi realizado um ajuste no coeficiente de descarga $\left(\mathrm{C}_{\mathrm{D}}\right)$ na válvula de quebra, pois é um parâmetro de incerteza que tem a possiblidade de ser ajustado dentro dos dados de entrada do código RELAP5.

Os resultados da simulação da contenção com o código RELAP5 para os casos analisados nesse trabalho serão apresentados a seguir.

\subsubsection{LBLOCA-PF}

Na FIG. 24, são mostradas as curvas de pressão na contenção nos primeiros 250 segundos de acidente obtidas com o código RELAP5 e comparadas com a do RFAS/A2 (que utiliza o código COCO) e, também, a curva da pressão de projeto da contenção (6,3bar).

Observa-se que a distribuição de pressão obtida para o Base Case é muito próxima à do High e Low Cases. Entretanto, os resultados obtidos nesta simulação são superiores aos do RFAS/A2. Essa diferença se deve ao fato de terem sido utilizadas condições de contorno mais conservativas na simulação da planta inteira, que levam a resultados que superestimam a pressão na contenção. Ainda assim, tanto as distribuições de pressão como o maior pico de pressão na contenção (de 4,1bar aos 30s), obtidos com o RELAP5, estão bem abaixo da pressão de projeto (6,3bar). 


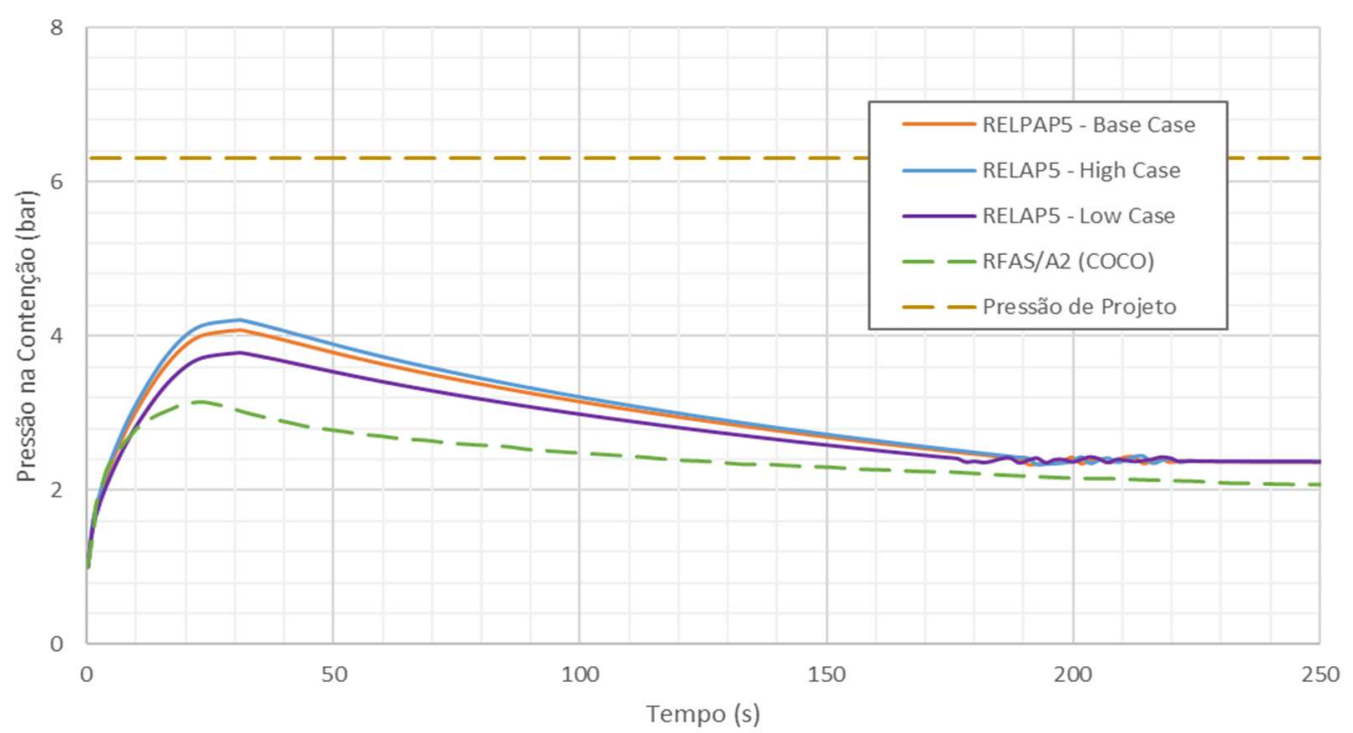

FIGURA 24 - Distribuição temporal da pressão na contenção dos casos simulados com o RELAP5 (LBLOCA-PF)

Conforme demonstrado na FIG. 25, a evolução temporal da temperatura na contenção segue o mesmo comportamento da pressão, sendo que o valor máximo obtido é de $146,2^{\circ} \mathrm{C}$, que é a temperatura de saturação da mistura bifásica. Neste caso, não há como comparar estes resultados com o do RFAS/A2, pois a distribuição de temperatura na contenção não é apresentada no relatório de análise de segurança da planta.

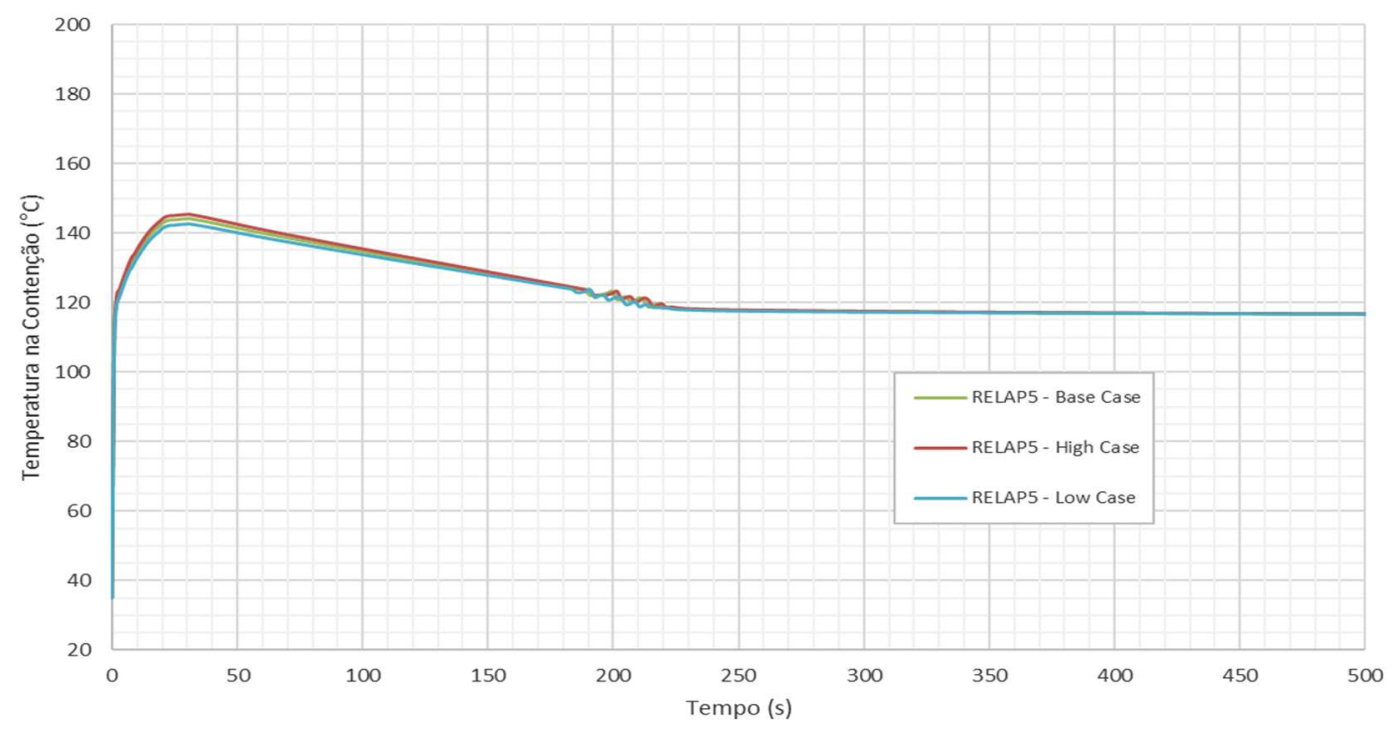

FIGURA 25- Evolução temporal da temperatura na contenção dos casos simulados com o RELAP5 (LBLOCA-PF) 


\subsubsection{LBLOCA-PI}

Na FIG. 26, são apresentados os valores de pressão dentro da contenção nos primeiros 250 segundos de acidente, em que os resultados obtidos com o RELAP5 são comparados com o apresentado no RFAS/A2 e também com o valor de pressão de projeto da contenção.

Observa-se que a distribuição de pressão obtida para o Base Case, assim como no caso anterior, é muito próxima à do High e Low Cases e estes, superiores a do RFAS/A2. Aqui também, tanto as distribuições de pressão quanto o pico de pressão na contenção (de 3,84bar aos 25s), obtidos com o RELAP5, estão bem abaixo da pressão de projeto.

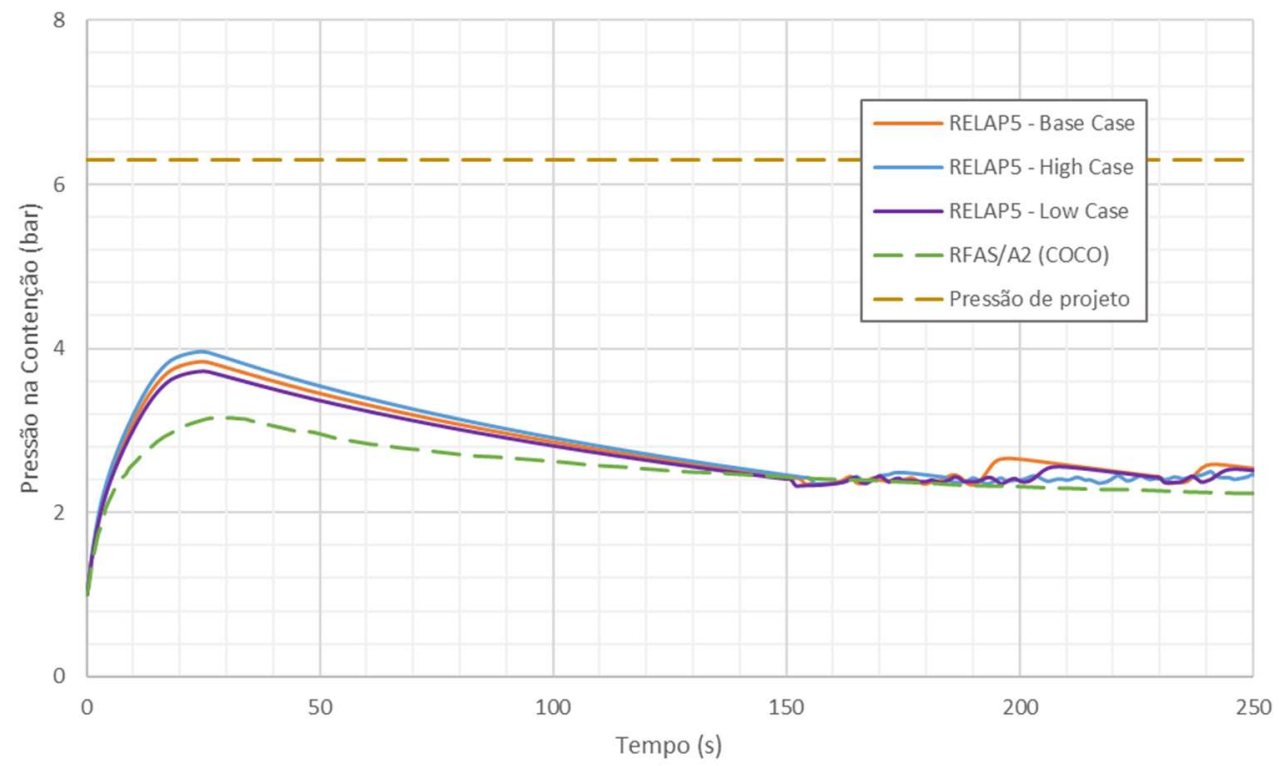

FIGURA 26 - Distribuição temporal da pressão na contenção dos casos simulados com o RELAP5 (LBLOCA-PI).

Na FIG. 27, é apresentada a evolução temporal da temperatura na contenção, que segue o mesmo comportamento da pressão, sendo que o valor máximo obtido é de $142,6^{\circ} \mathrm{C}$. Como a pressão, neste caso, é menor que a pressão no caso do LBLOCA-PF, é coerente obter-se uma distribuição ligeiramente menor de temperatura. Neste caso, analogamente ao caso anterior, não há como comparar 
esses resultados com o do RFAS/A2, pois a distribuição de temperatura na contenção não é apresentada no relatório de Angra 2.

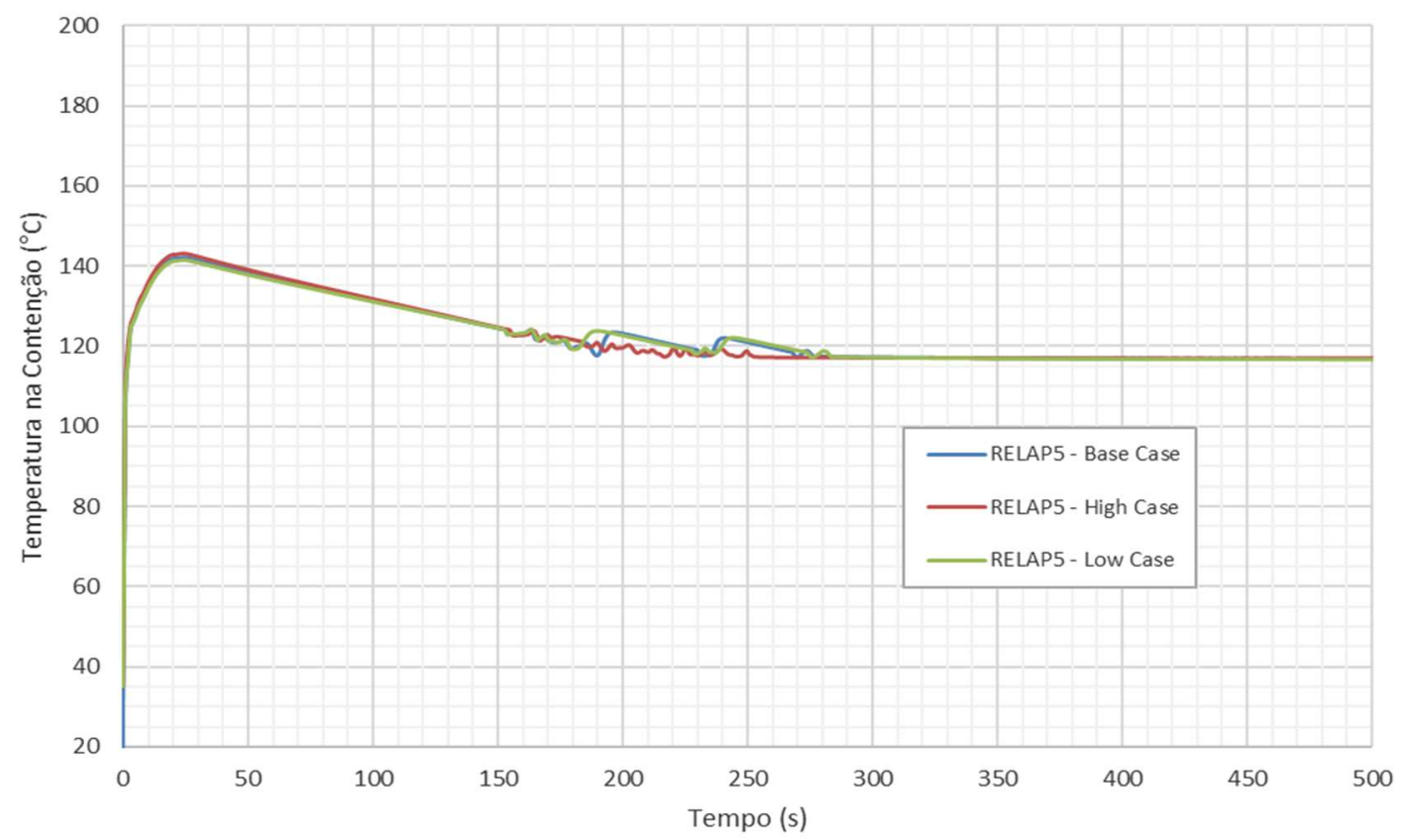

FIGURA 27 - Evolução temporal da temperatura na contenção dos casos simulados com o RELAP5 (LOCA-PI)

\subsubsection{LBLOCA-PQ}

Na FIG. 28, o valor máximo de pressão obtido dentro da contenção foi o maior, quando comparado com os outros casos analisados com o RELAP5 nesse trabalho. Isto ocorre quando a quebra é na saída do vaso do reator, já que a temperatura é maior e, portanto, a energia liberada para a contenção é maior que nas outras duas quebras. O pico de pressão calculado pelo RELAP5 é de aproximadamente 4,4bar aos 30 s de acidente. Ainda assim, a distribuição de pressão está bem abaixo da pressão de projeto. 


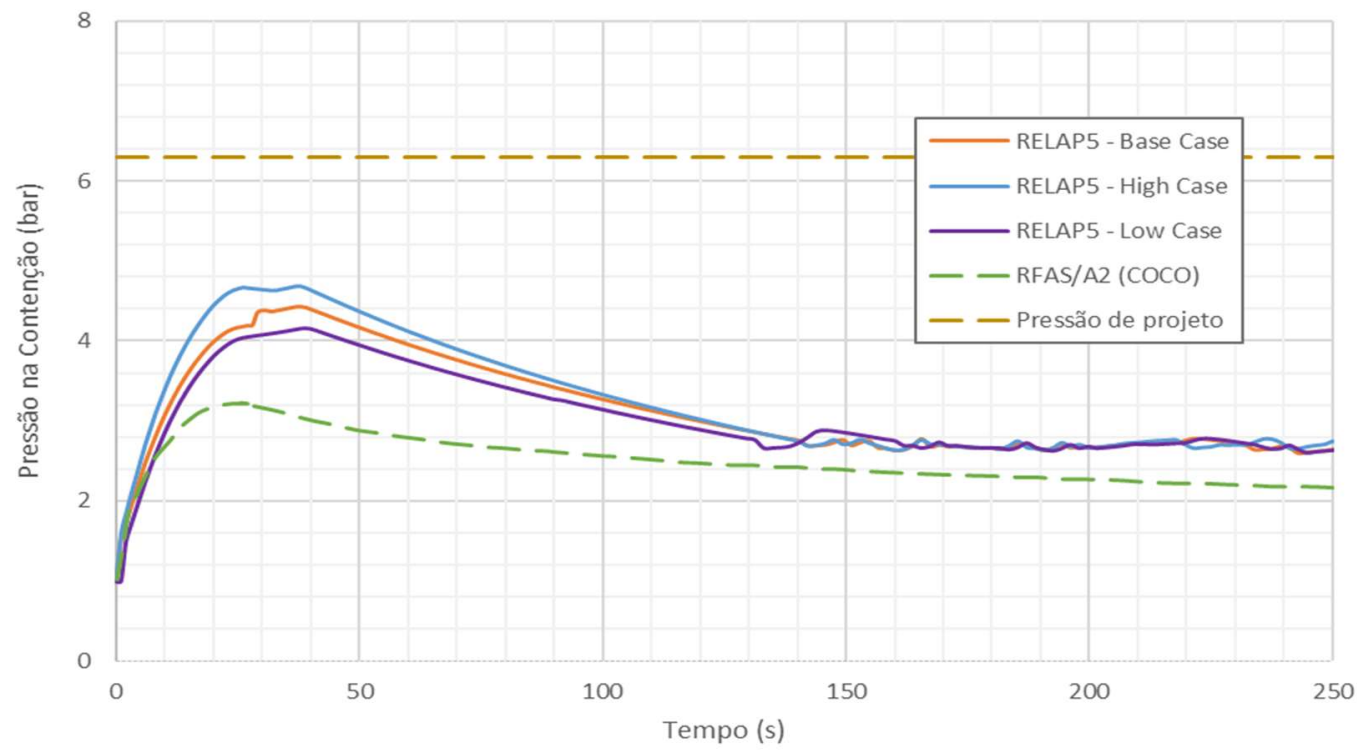

FIGURA 28 - Distribuição temporal da pressão na contenção dos casos simulados com o RELAP5 (LBLOCA-PQ)

Conforme demonstrado na FIG. 29, a distribuição de temperatura na contenção segue o mesmo comportamento da pressão, sendo que o valor máximo obtido é de $148,0^{\circ} \mathrm{C}$. Também é a maior temperatura entre os casos simulados com o RELAP5, já que possui o maior pico de pressão.

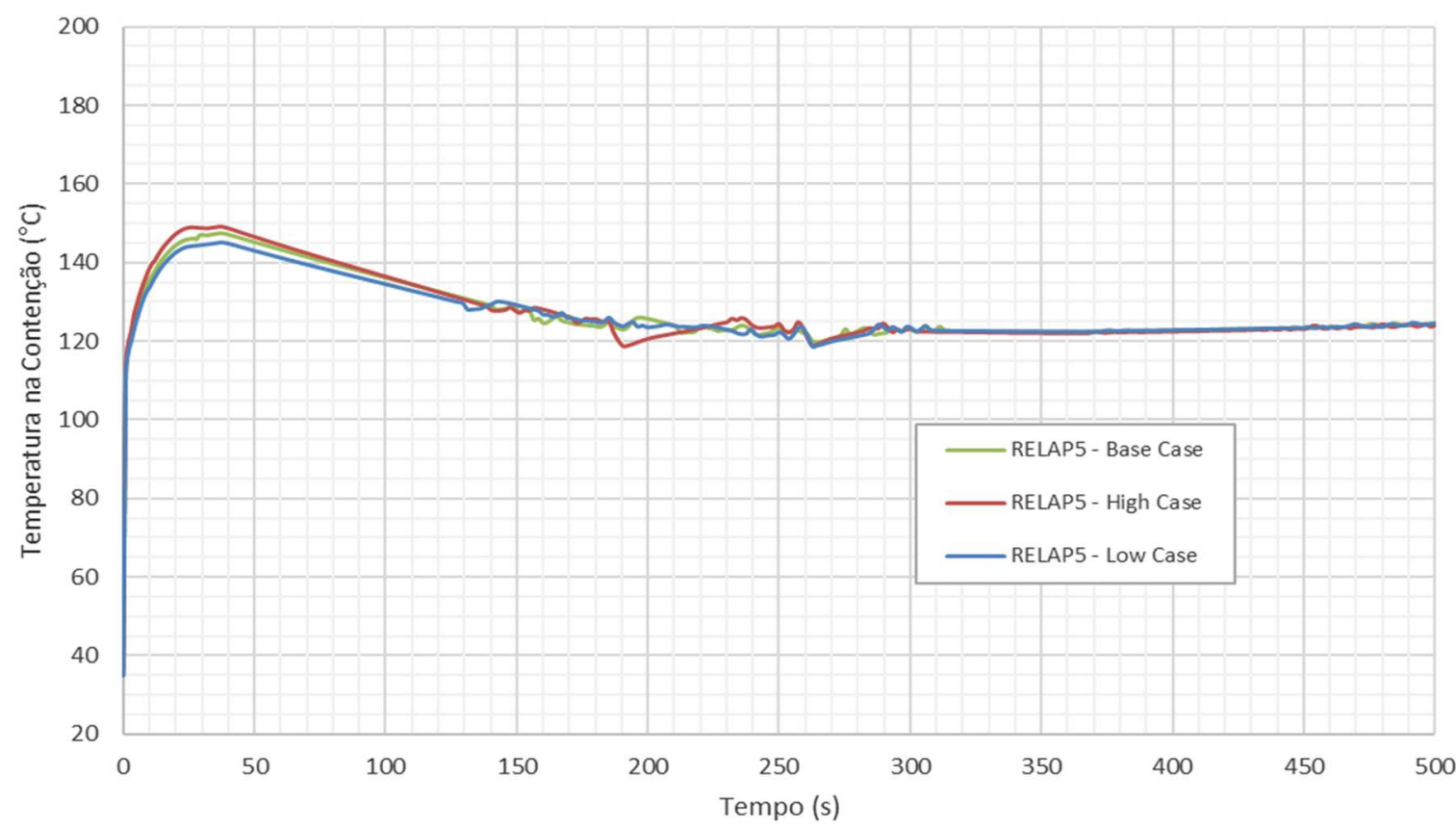

FIGURA 29 - Evolução temporal da temperatura na contenção dos casos simulados com o RELAP5 (LBLOCA-PQ) 
Verifica-se, portanto, que os três casos de LBLOCA simulados com o código RELAP5 nesse trabalho superestimaram os valores especificados no RFAS/A2. Mesmo assim, as pressões ficaram bem abaixo do valor máximo de segurança de 6,3bar.

\subsection{Resultados obtidos com o código COCOSYS}

A seguir, são apresentados os resultados da simulação da contenção com o código COCOSYS para os três casos de LBLOCA descritos neste trabalho.

\subsubsection{LBLOCA-PF}

Na FIG. 30, as distribuições de pressão dentro da contenção nos primeiros 250 segundos de acidente para os três casos descritos na TAB. 7 e simulados com o código COCOSYS são comparadas com a do RFAS/A2. É possível observar que as distribuições do Base, Low e High Cases são próximos e estão seguramente abaixo do valor de pressão de projeto (6,3bar). O pico de pressão para o Base Case é de 4,54bar aos 28s de evolução do acidente.

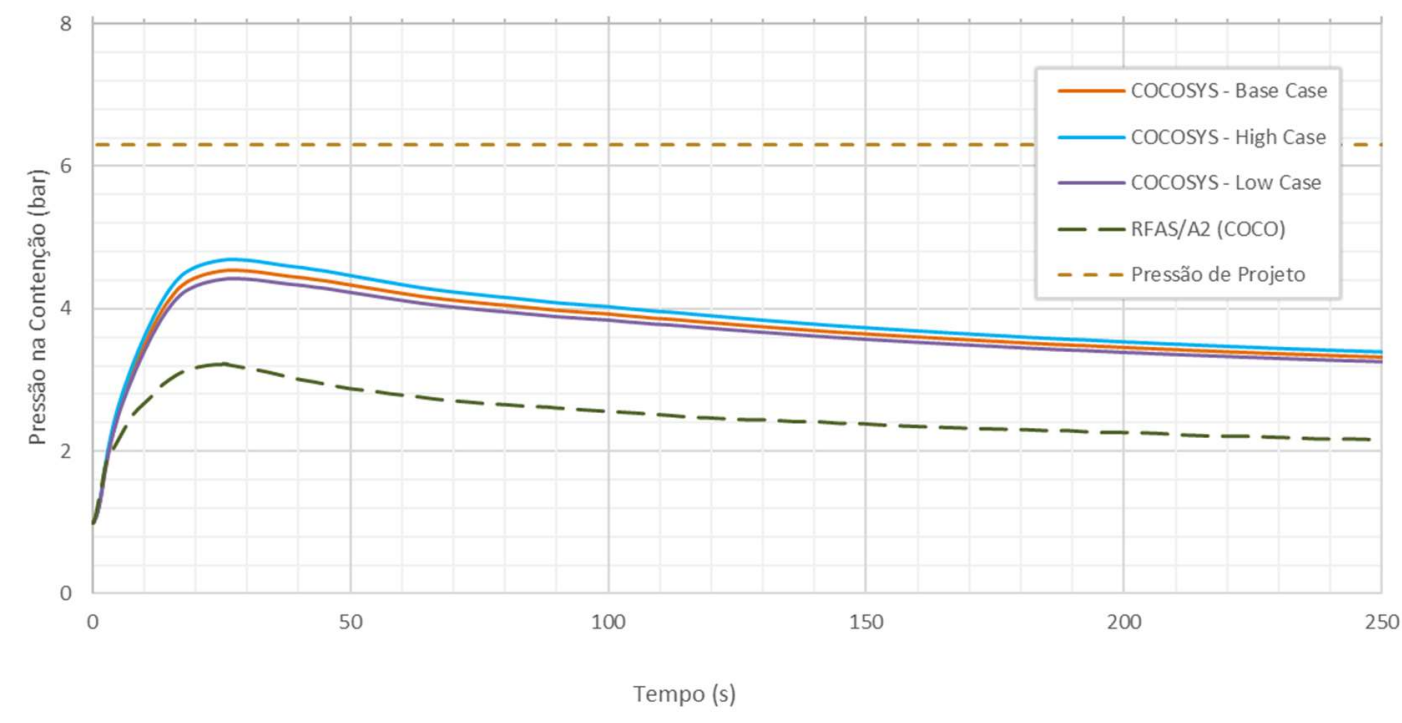

FIGURA 30 - Distribuição temporal da pressão na contenção dos casos simulados com o COCOSYS (LBLOCA-PF) 
$\mathrm{Na}$ FIG. 31, é apresentada a distribuição de temperatura obtida na contenção durante a simulação deste acidente com o COCOSYS, com o pico em torno de $185,8^{\circ} \mathrm{C}$.

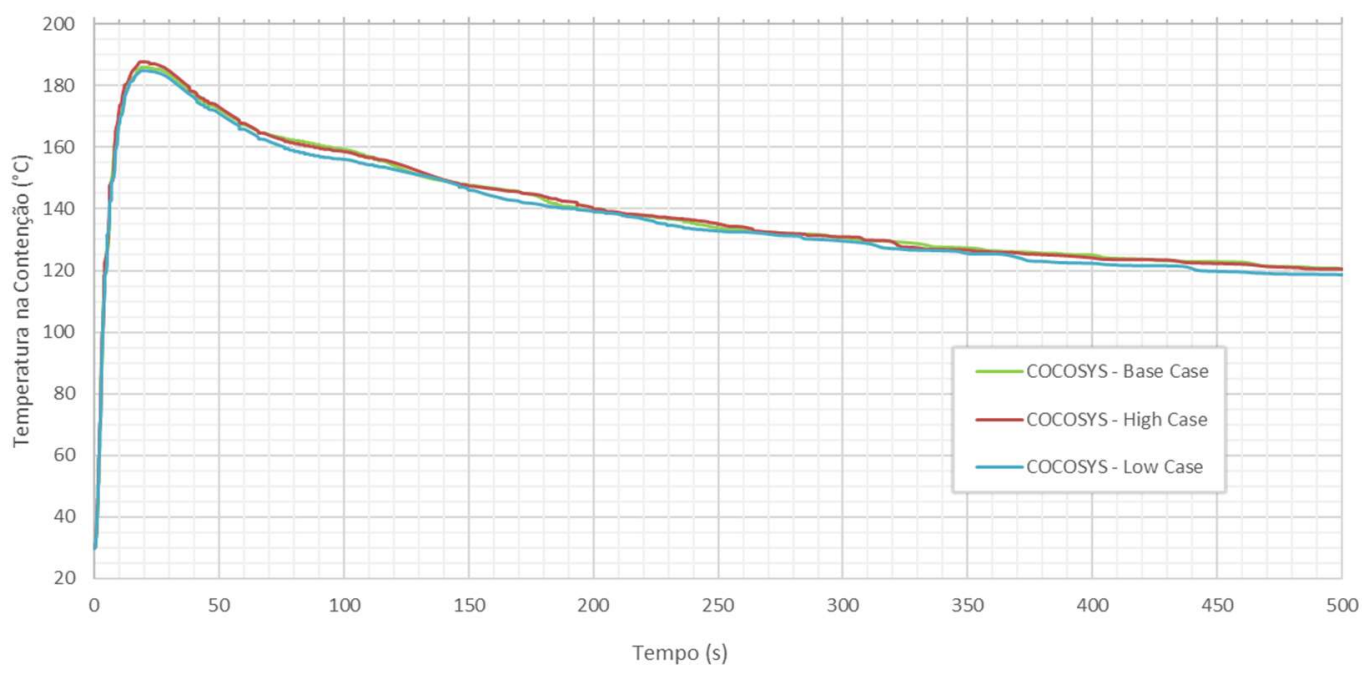

FIGURA 31 - Evolução temporal da temperatura na contenção dos casos simulados com o COCOSYS (LBLOCA-PF)

\subsubsection{LBLOCA-PI}

Na FIG. 32, os valores de pressão dentro da contenção nos primeiros 250 segundos de acidente, obtidos com o COCOSYS, são comparados com os apresentados no RFAS/A2 e também com o valor de pressão de projeto da contenção.

Observa-se que a distribuição de pressão obtida para o Base Case, assim como no LBLOCA-PF, é muito próxima à do High e Low Cases e estes, superiores ao do RFAS/A2. O maior pico de pressão na contenção (de 4,67bar aos 36s), obtido com o COCOSYS, embora seja ligeiramente maior que no caso LBLOCA-PF, está abaixo da pressão de projeto. 


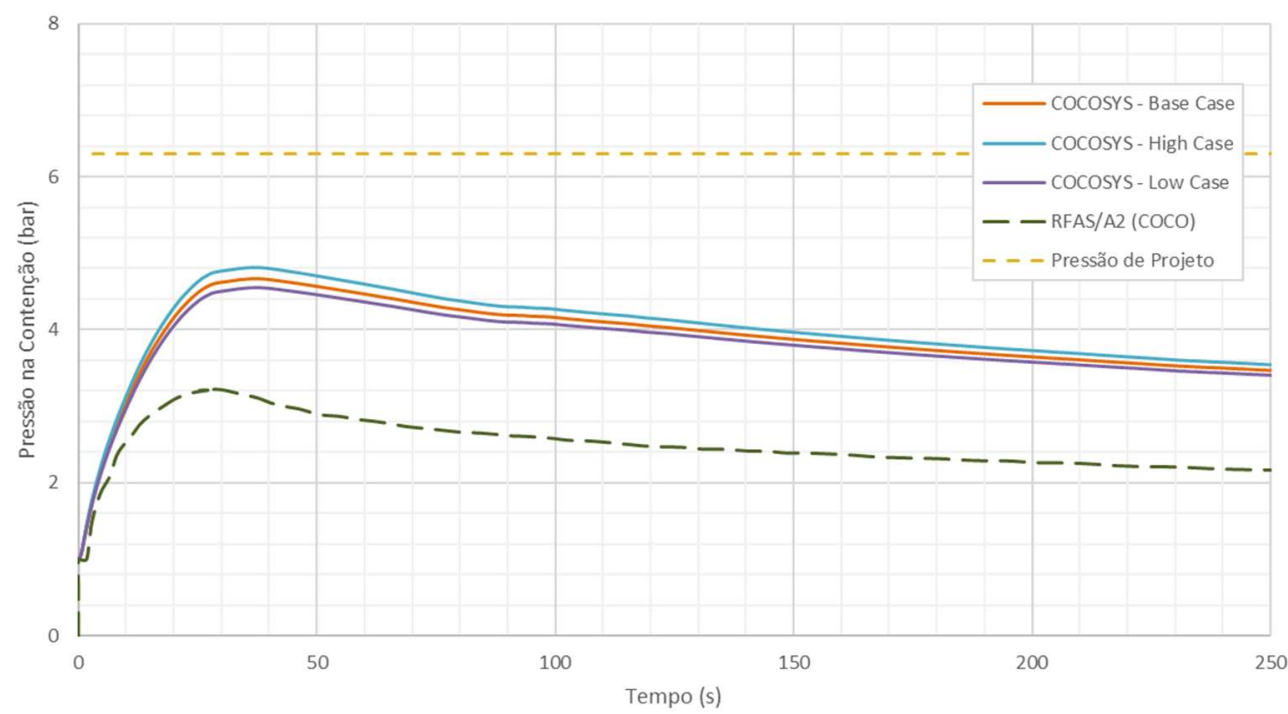

FIGURA 32 - Distribuição temporal da pressão na contenção dos casos simulados com o COCOSYS (LBLOCA-PI)

Na FIG. 33, é mostrada a evolução temporal de temperatura obtida na contenção durante a simulação desse acidente com o COCOSYS. O pico de temperatura de $186,8^{\circ} \mathrm{C}$ ocorre aos $26 \mathrm{~s}$.

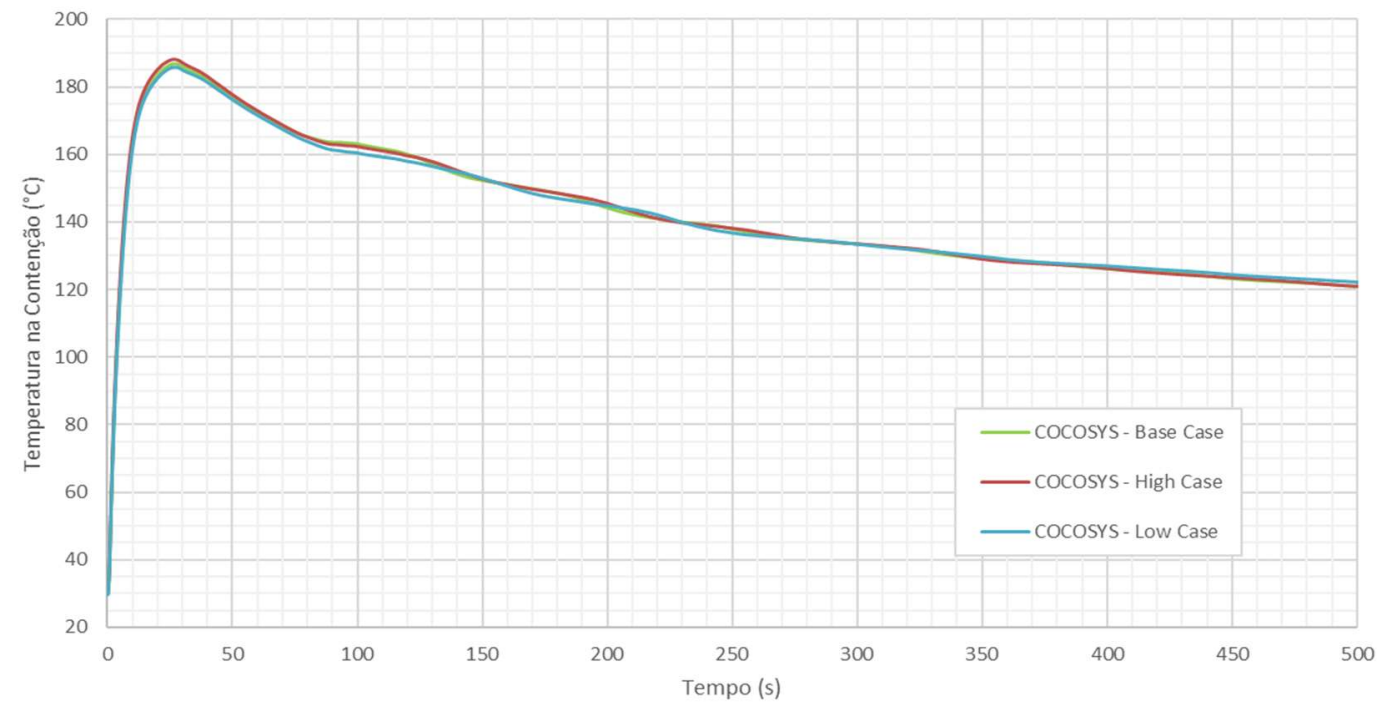

FIGURA 33 - Evolução temporal da temperatura na contenção dos casos simulado com o COCOSYS (LBLOCA-PI) 


\subsubsection{LBLOCA-PQ}

A FIG. 34 demonstra que, entre todos os casos analisados neste trabalho, o pico de pressão dentro da contenção foi o maior encontrado. Isto ocorre quando a quebra é na $P Q$, pois a energia liberada para a contenção é maior, quando comparada com as outras duas quebras. A pressão aumenta rapidamente aos primeiros $26 \mathrm{~s}$ de acidente, atingindo o valor de 4,71bar (Base Case). Entretanto, diferentemente dos outros casos, a pressão continua aumentando até os 78 s, atingindo um pico, calculado pelo COCOSYS, de 4,78bar, posterior ao que é definido pelo COCO. Ainda assim, está seguramente abaixo do valor de pressão de projeto.

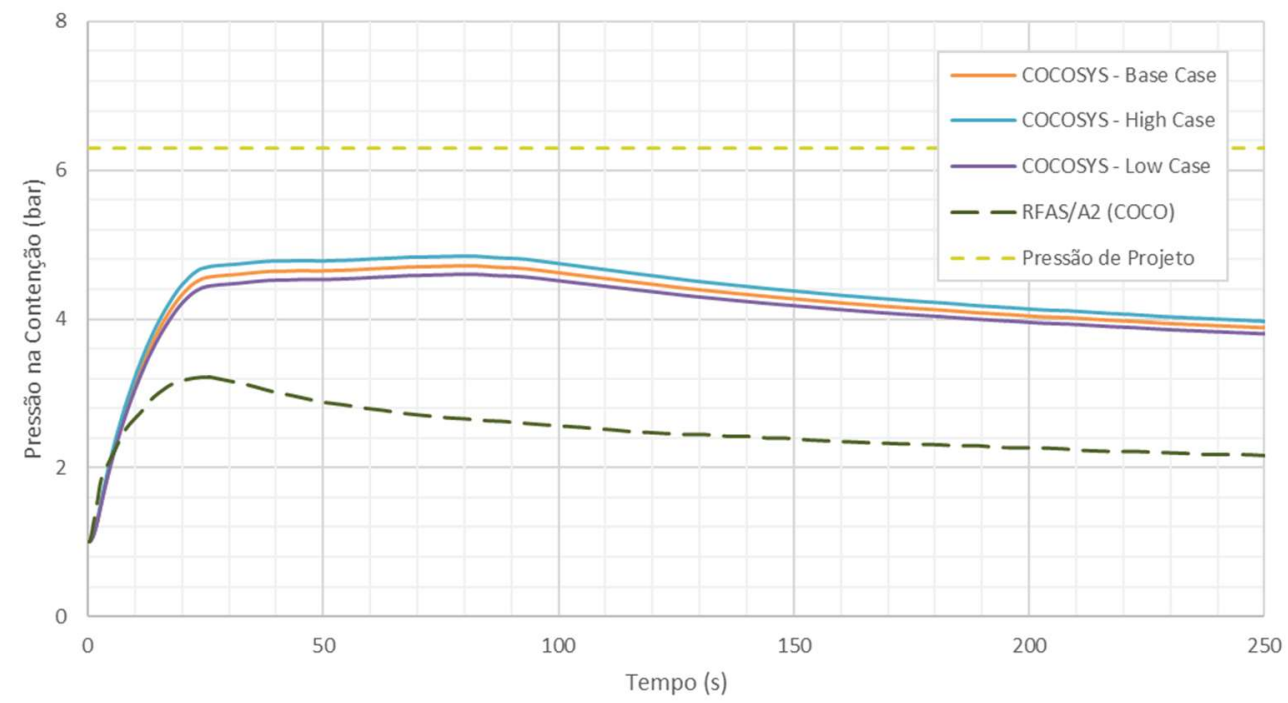

FIGURA 34 - Distribuição temporal da pressão na contenção dos casos simulados com o COCOSYS (LBLOCA-PQ)

A FIG. 35 apresenta a distribuição de temperatura obtida na contenção durante a simulação deste acidente com o COCOSYS. O pico de temperatura está em torno $189,2^{\circ} \mathrm{C}$ aos $24 \mathrm{~s}$ do acidente. 


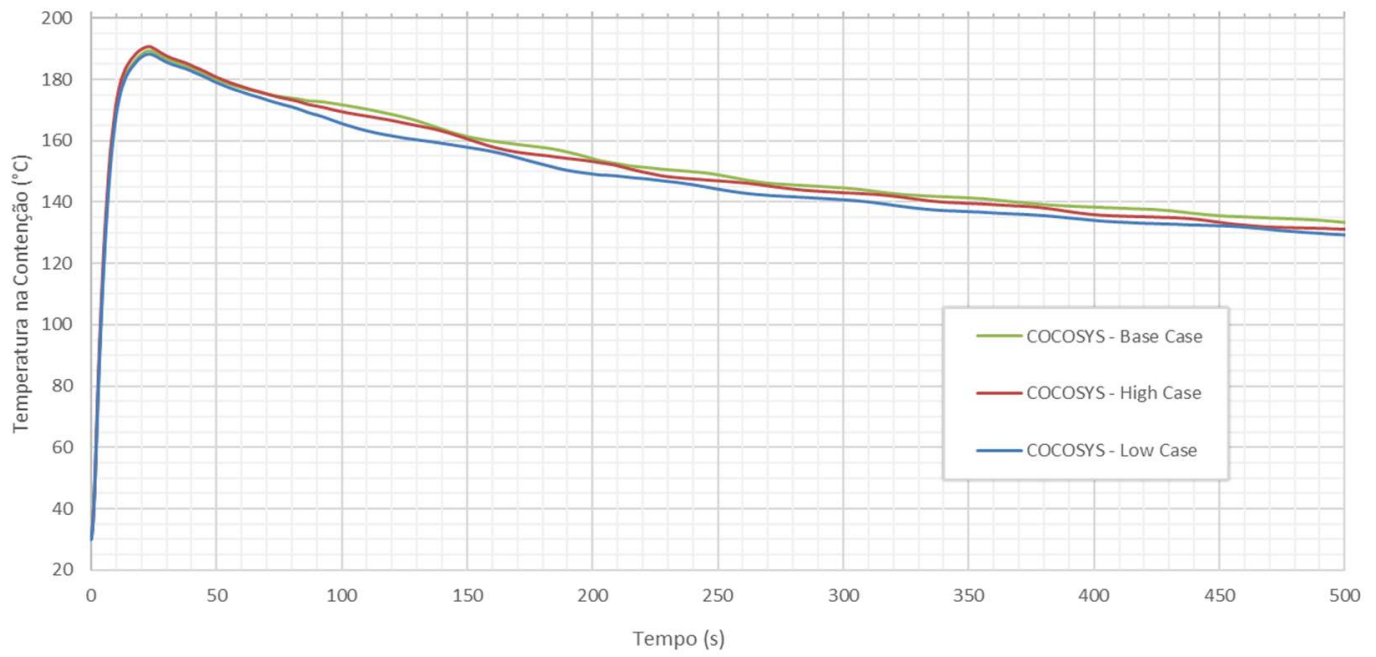

FIGURA 35 - Evolução temporal da temperatura na contenção dos casos simulados com o COCOSYS (LBLOCA-PQ)

Embora os três casos de LBLOCA simulados com o código COCOSYS nesse trabalho tenham superestimado os valores especificados no RFAS/A2, ainda assim as pressões ficaram abaixo do valor de projeto de 6,3bar.

\subsection{Simulação iterativa da planta inteira}

Após as simulações da contenção descritas nos itens 4.1 e 4.2, uma nova simulação da planta inteira foi efetuada de forma iterativa, conforme FIG. 20 e 22, com base no input original do grupo de trabalho da CNEN (Grupo de Trabalho, 2000 e Andrade et al., 2001).

As distribuições de pressão e temperatura na contenção, obtidas por meio dos códigos RELAP5 e COCOSYS, foram definidas como condição de contorno para cada uma das simulações iterativas (foi realizada uma única iteração por ruptura), a fim de obter resultados mais realistas do PTE para cada uma das quebras analisadas.

Segundo o RFAS/A2, o PTE ocorre na vareta mais quente do núcleo de Angra 2, logo foi comparada com a da temperatura da vareta mais realista do núcleo de Angra 2 obtida com o código RELAP5.

Todos os outros resultados de temperatura da vareta mais realista no núcleo de Angra 2 obtidos nesse trabalho e comparados com RFAS/A2 são apresentados no APÊNDICE C. 


\subsubsection{LBLOCA-PF}

Na FIG. 36, observa-se a evolução temporal da temperatura da vareta mais realista do núcleo do reator na região do nó 9 (RELAP5), apresenta na modelagem do vaso de Angra 2, conforme a FIG. AB4 (Anexo B). Os picos de temperatura ( $1^{\circ}$ pico) nessa região ocorrem simultaneamente para ambas as simulações, tanto com as condições de contorno da contenção dadas pelo RELAP5 (PTE de 961,8 $\mathrm{C}$ ), quanto com as fornecidas pelo COCOSYS (PTE de $964,8^{\circ} \mathrm{C}$ ), nos primeiros segundos do acidente.

Embora o PTE dado pelo RFAS/A2 ocorra alguns segundos depois, o valor de temperatura máxima das três curvas é praticamente o mesmo (aproximadamente $920^{\circ} \mathrm{C}$ ). Logo, a temperatura do encamisamento não atinge o valor de $1.200^{\circ} \mathrm{C}$ (limite de temperatura estipulado pela norma da CNEN).

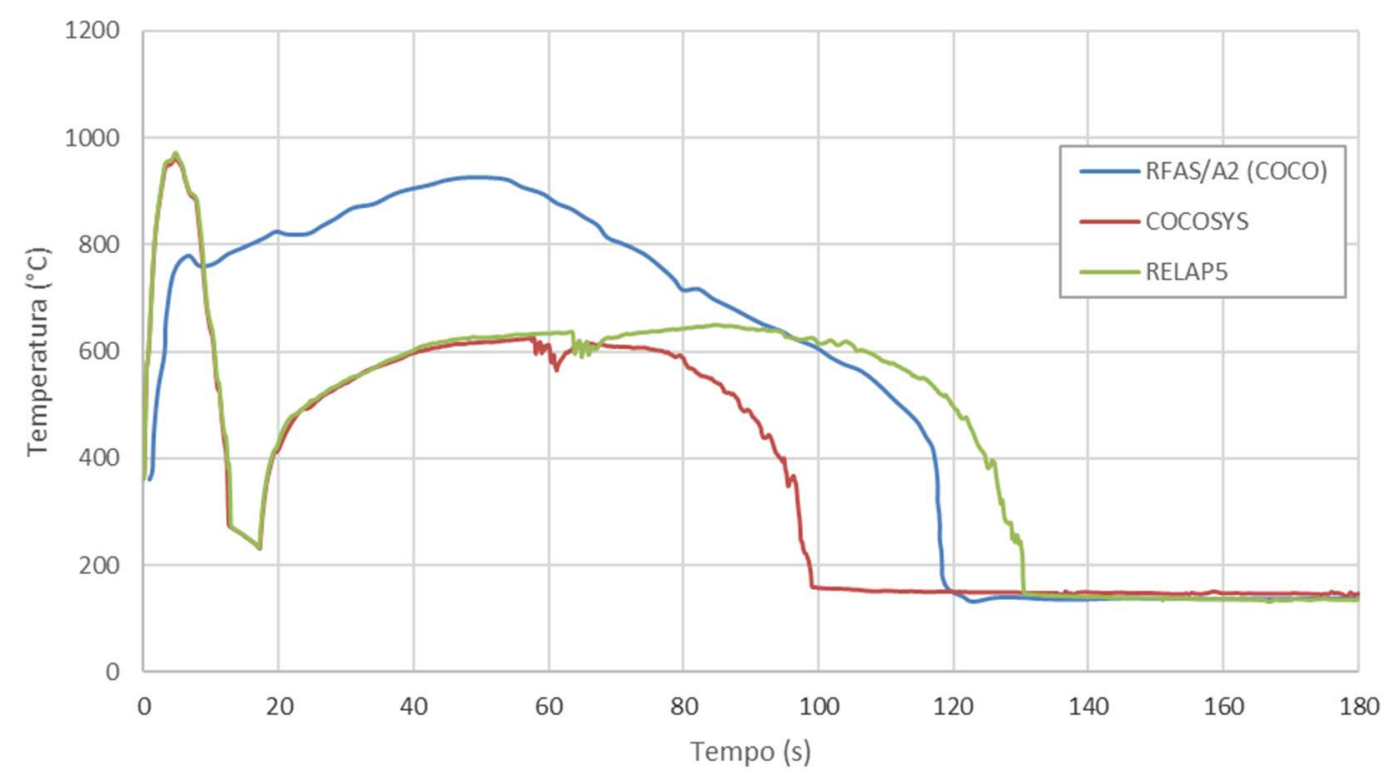

FIGURA 36 - Evolução temporal da temperatura do encamisamento na vareta mais realista do núcleo simulado com o RELAP5 (LBLOCA-PF)

Os maiores valores de PTE encontrados, tanto para esse trabalho quanto para o RFAS/A2, são no caso do LBLOCA-PF. Este é o pior cenário de acidente para o núcleo do reator, pois neste caso, como a quebra é na tubulação de entrada do 
vaso, a água de refrigeração do núcleo é perdida, o que pode comprometer a sua integridade.

\subsubsection{LBLOCA-PI}

Na FIG. 37, é apresentada a distribuição da temperatura na vareta mais realista do núcleo do reator na região do nó 9 para as simulações que utilizaram, como condição de contorno, a pressão e temperatura da contenção feitas com os códigos RELAP5 e COCOSYS (PTE de $460,2^{\circ} \mathrm{C}$ e $403,3^{\circ} \mathrm{C}$, respectivamente).

A temperatura da vareta mais realista definida pelo RFAS/A2 possui PTE de $578,4^{\circ} \mathrm{C}$ logo nos primeiros segundos do acidente. A distribuição da temperatura calculada pelos códigos é menor que a do RFAS/A2 e também não indica o primeiro pico (que para o RFAS/A2, ocorre no tempo 4s), provavelmente pelo fato de que a simulação desse trabalho não calcula uma vareta específica, como feita pelo RFAS/A2, mas sim uma média da vareta mais realista.

Neste caso, a temperatura do encamisamento está bem abaixo do valor do limite de temperatura estipulado pela $\operatorname{CNEN}\left(1.200^{\circ} \mathrm{C}\right)$.

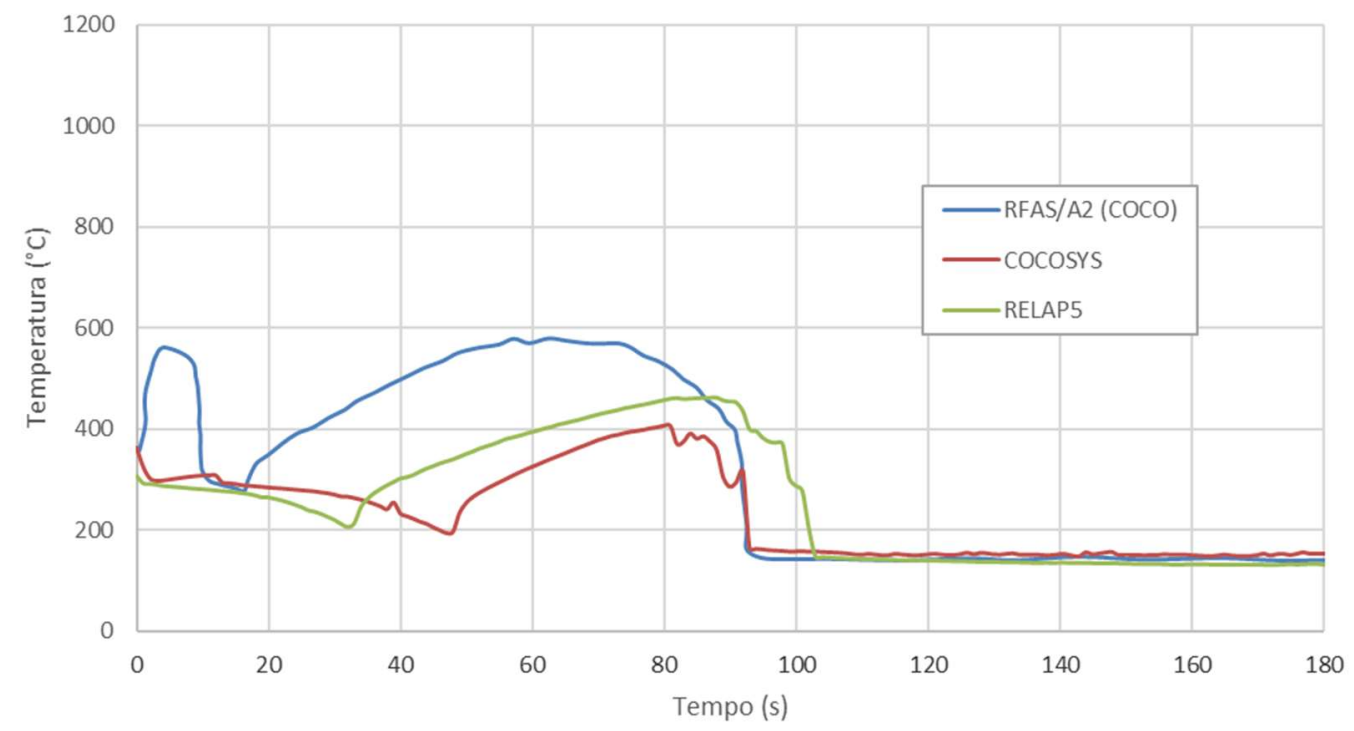

FIGURA 37 - Evolução temporal da temperatura do encamisamento na vareta mais realista do núcleo simulado com o RELAP5 (LBLOCA-PI)

\subsubsection{LBLOCA-PQ}


Na FIG. 38, observa-se a distribuição temporal da temperatura por tempo da vareta mais realista do núcleo do reator na região do nó 9 para o LBLOCA-PQ. As distribuições de temperatura, assim como os picos de temperatura na vareta mais realista do núcleo, são muito próximas para todos os casos analisados.

No caso em que a condição de contorno da contenção foi dada pelo código RELAP5, o PTE é de $411,4^{\circ} \mathrm{C}$; no caso do COCOSYS, o PTE é de $413,1^{\circ} \mathrm{C}$; e o PTE dado pelo RFAS/A2 é de $368,9^{\circ} \mathrm{C}$.

Tais picos de temperaturas estão seguramente abaixo do valor de $1.200^{\circ} \mathrm{C}$, que é o limite de temperatura estipulado pela CNEN.

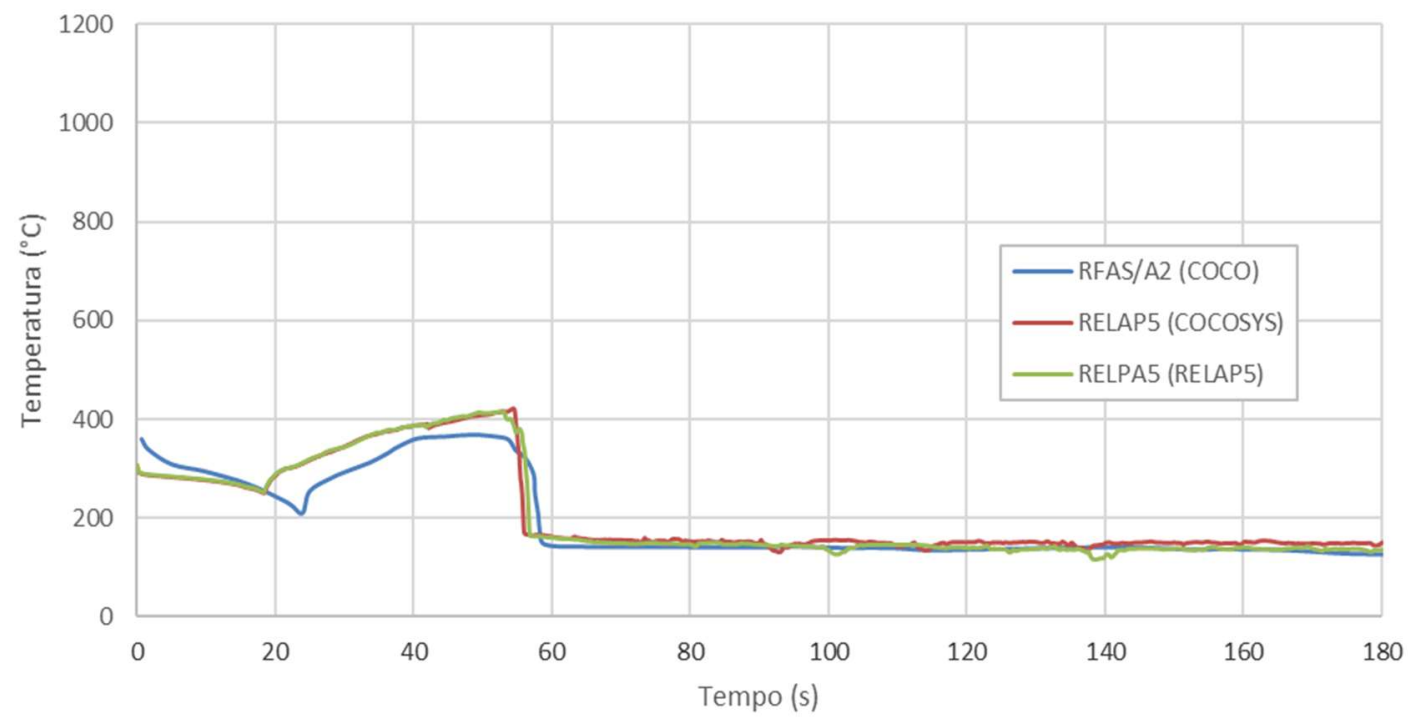

FIGURA 38 - Evolução temporal da temperatura do encamisamento na vareta mais realista do núcleo simulado com o RELAP5 (LBLOCA-PQ) 


\section{CONCLUSÕES}

A contribuição deste trabalho é o cálculo mais realista da pressão na contenção de Angra 2 e, consequentemente, a obtenção de valores de PTE mais realistas da vareta mais realista do núcleo de Angra 2 para os três casos de LBLOCA aqui analisados.

Os resultados de pressão obtidos com os códigos RELAP5 e COCOSYS da contenção de Angra 2 foram satisfatórios, já que foram próximos entre si e próximos quando comparados aos do RFAS/A2.

Os valores de pressão na contenção obtidos tanto com o RELAP5 quanto com o COCOSYS encontram-se abaixo da pressão de projeto definido pelo RFAS/A2. Como pôde ser observado, o maior pico de pressão na contenção ocorre para a ruptura na perna quente para os dois códigos devido à maior liberação de energia em função do tempo.

Em todos os casos, os picos de pressão foram maiores que os apresentados no RFAS/A2, pelo fato de os acidentes terem sido simulados com uma modelagem e algumas condições de contorno da planta inteira mais conservativas que os definidos no RFAS/A2, o que influenciou nos resultados de adição de massa e energia liberados para a contenção.

Os resultados obtidos do PTE foram satisfatórios quando comparados com os do RFAS/A2, já que uma única iteração entre os códigos permitiu que as distribuições de temperatura representassem uma situação mais realista da planta. Nos casos simulados, foram utilizadas as distribuições de temperatura e pressão da contenção obtidas com o RELAP5 e o COCOSYS, como condições de contorno durante os LBLOCA.

Os resultados de PTE obtidos por meio de uma iteração foram melhores que os originais apresentados nos LBLOCA da planta inteira simulados com o RELAP5 (ANEXO C), onde a contenção foi considerada como um volume dependente do tempo e não como um volume físico definido, com condições operacionais bem definidas.

Vários fenômenos podem ameaçar a integridade da contenção de um reator nuclear. Alguns dos mais significativos acidentes, descritos no item 2.2, indicam a importância da contenção em reter os radionuclídeos emitidos, evitando efeitos 
deletérios ao meio ambiente e à população em seu entorno. Por isso, torna-se necessário compreender e prever tais fenômenos e suas consequências, a fim de serem evitados ou minimizados nos diversos projetos de plantas existentes e em projetos futuros.

A abordagem adotada nesse trabalho também é importante para a viabilidade de novas plantas nucleares tipo PWR, pois foram adotadas ferramentas computacionais e hipóteses mais realistas (best estimate). Estudos deste tipo permitem projeções de menores custos de manutenção e de operação de novas plantas. 


\section{TRABALHOS FUTUROS}

A partir dos resultados obtidos, verificou-se a possibilidade das seguintes pesquisas futuras:

1) Para a obtenção de resultados ainda mais realistas de pressão e temperatura na contenção e do PTE, seria relevante realimentar, em cada um dos casos simulados para a contenção, valores obtidos no primeiro processo de iteração, e, assim, sucessivamente. Provavelmente, com o processo de realimentação entre os códigos (RELAP5/RELAP5 e RELAP5/COCOSYS) e com maior número de iterações, esses valores superestimados de pressão e temperatura convergiriam a um valor ainda mais realista, como propõe a abordagem realizada no RFAS/A2.

Na FIG. 39, pode-se observar que, após uma segunda iteração para o caso do LBLOCA-PQ, a distribuição de pressão na contenção se aproxima dos valores definidos no RFAS/A2;

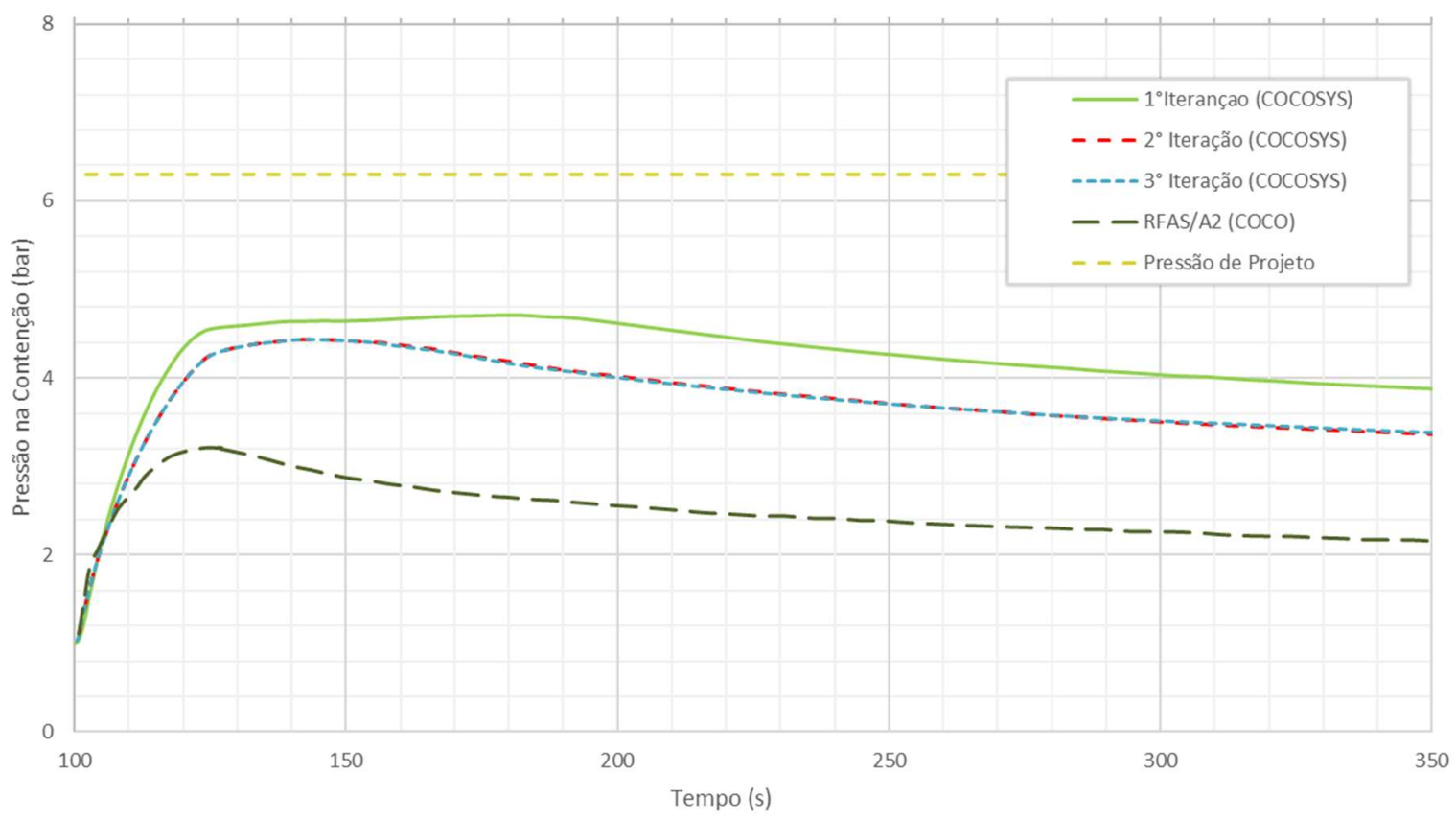

FIGURA 39 - Processo iterativo para o LBLOCA-PQ com o código COCOSYS 
2) A partir das modelagens da contenção de Angra 2 sugeridas nesse trabalho e com a utilização do código COCOSYS, outros acidentes podem ser estudados, como pequenos e médios LOCA;

3) Com uma modelagem da contenção mais detalhada para o código COCOSYS, verificar se há alteração dos resultados obtidos;

4) Elaborar um programa de interface entre os códigos RELAP5 (primeira etapa) e COCOSYS (segunda etapa);

5) Fazer uma verificação detalhada dos dados de entrada para a planta inteira de Angra 2 para ser simulada com o código RELAP5 e, se necessário, um detalhamento da modelagem da planta, a fim de se ter resultados mais próximos do RFAS/A2;

6) Realizar a avaliação de incertezas dos resultados obtidos com a finalidade de obter as margens de erros das variáveis desejadas. Para esse tipo de estudo, é viável o uso do código SUSA (Koss, 2015);

7) Para o cálculo do PTE mais realista, acoplar o código RELAP5 à um código neutrônico. Assim, a distribuição de potência no núcleo seria mais realista.

8) A metodologia de cálculo desse trabalho possibilita o estudo das condições da contenção da Unidade 3 da Central Nuclear Almirante Álvaro Alberto, atualmente em fase de desenvolvimento. 


\section{APÊNDICE A - Dados geométricos para a modelagem com o RELAP5}

A contenção de Angra 2 é uma esfera de $56 \mathrm{~m}$ de diâmetro e volume livre de $74.275 \mathrm{~m}^{3}$. Entretanto, para a simulação com o código RELAP5, os componentes utilizados foram do tipo PIPE, que considera a geometria como sendo cilíndrica, que é a opção disponível no código (FIG. A1).

Nos três casos analisados, o volume livre da contenção, originalmente esférica, foi considerada como cilíndrica. Os ajustes dos volumes do sump e da Contenção sem o sump estão detalhados a seguir para as três abordagens (Base, Low e High cases) em cada um dos casos estudados.

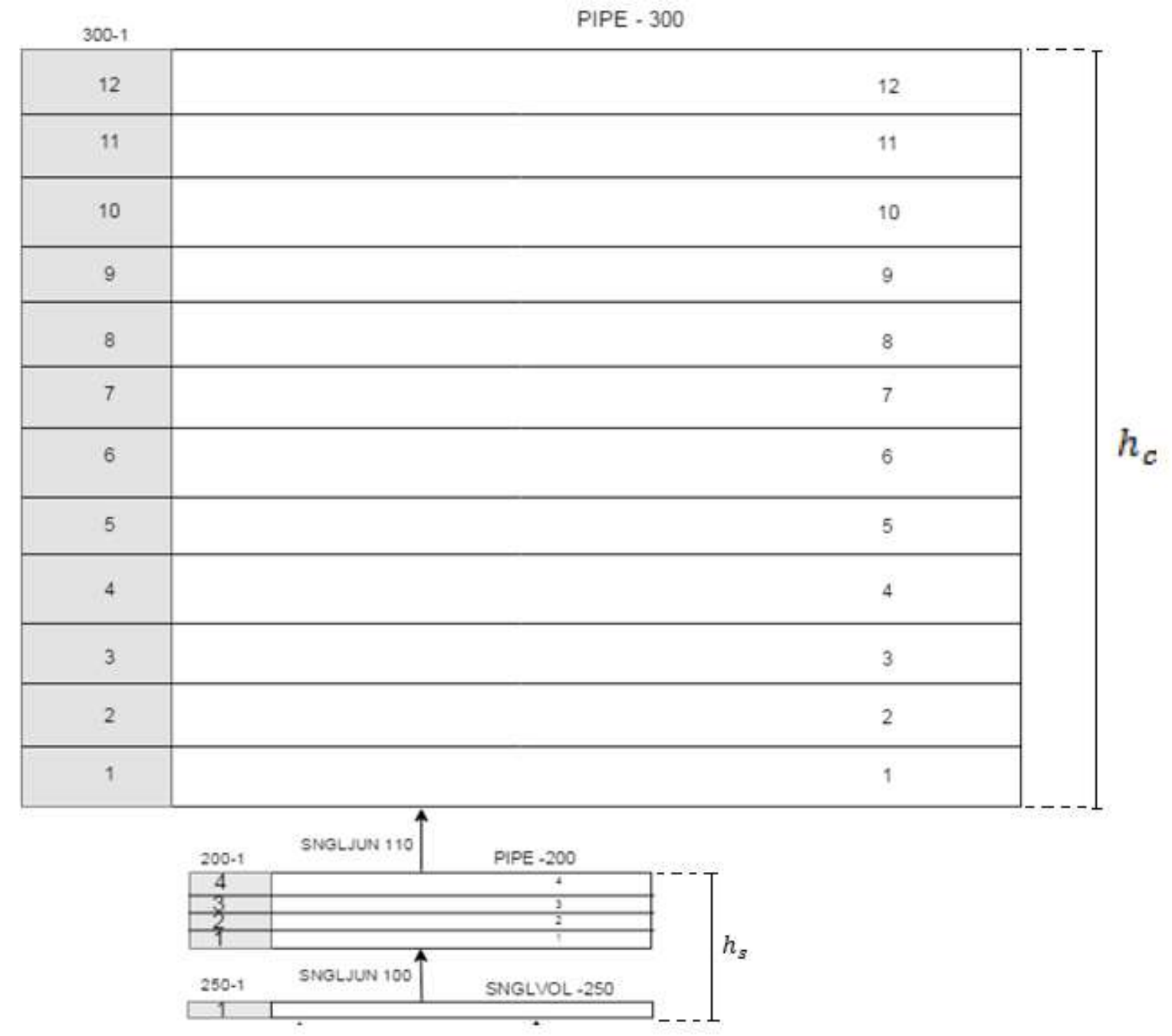

FIGURA A1 - Divisão dos volumes de controle 


\section{Caso Base (Base Case):}

Esta abordagem postulada no RFAS/A2 considera o volume livre da contenção de $V_{c}=70.985 \mathrm{~m}^{3}$. Assim, dividiu-se este volume em duas regiões principais (sump e contenção sem o sump) com valores especificados na TAB. A1.

TABELA A1 - Valores de cada zona para o Base Case

\begin{tabular}{c|c|c|c}
\hline Região Hidráulica & Altura $(\mathbf{m})$ & $\begin{array}{c}\text { Raio da Base } \\
(\mathbf{m})\end{array}$ & Volume $\left.\mathbf{( m}^{\mathbf{3}}\right)$ \\
\hline Sump & 10,02 & 5,50 & 602,14 \\
\hline Contenção sem sump & 28,60 & 28,00 & $70.382,86$ \\
\hline
\end{tabular}

A contenção cilíndrica de altura $h_{c}$ foi dividida em 12 volumes com altura de $2,38 \mathrm{~m}$ cada.

2. Low Case:

Esta abordagem adota o volume livre nominal da contenção segundo o RFAS/A2 $\left(V_{c}=74.275 \mathrm{~m}^{3}\right)$. O volume do sump foi definido como o mesmo do Case Base. Sendo assim, o volume livre da contenção sem o sump é o volume do cilindro, raio da base e altura, dados na TAB. A2.

TABELA A2 - Valores de cada zona para o Base Case

\begin{tabular}{c|c|c|c}
\hline Região Hidráulica & Altura $(\mathbf{m})$ & $\begin{array}{c}\text { Raio da Base } \\
(\mathbf{m})\end{array}$ & Volume $\left.\mathbf{( m}^{\mathbf{3}}\right)$ \\
\hline Sump & 10,02 & 5,50 & 602,14 \\
\hline Contenção sem sump & 29,93 & 28,00 & $73.672,86$ \\
\hline
\end{tabular}

Portanto, cada um dos 12 volumes da contenção possui altura de $2,49 \mathrm{~m}$.

3. High Case:

O volume livre da contenção adotado foi baseado no cálculo proporcional comparado com os volumes entre o Base Case e o Low Case: 


$$
\frac{V_{C B A S E}}{V_{C L O W}}=\frac{V_{C H I G H}}{V_{C B A S E}}
$$

Logo, as relações geométricas nesta abordagem estão indicadas na TAB. A3. Cada um dos 12 volumes da contenção possui altura de 2,28 m.

TABELA A3 - Valores de cada zona para o Base Case

\begin{tabular}{c|c|c|c}
\hline Região Hidráulica & Altura $(\mathbf{m})$ & $\begin{array}{c}\text { Raio da Base } \\
(\mathbf{m})\end{array}$ & Volume $\left(\mathbf{m}^{\mathbf{3}}\right)$ \\
\hline Sump & 10,02 & 5,50 & 602,14 \\
\hline Contenção sem sump & 27,36 & 28,00 & $66.907,86$ \\
\hline
\end{tabular}




\section{APÊNDICE B - Dados geométricos para a modelagem com o COCOSYS}

Para as simulações com o código COCOSYS, definiu-se uma esfera com 6 zonas (volumes), com valores de áreas e volumes específicos para cada uma das abordagens. As alturas de cada volume foram divididas, conforme mostra a FIG. B1.

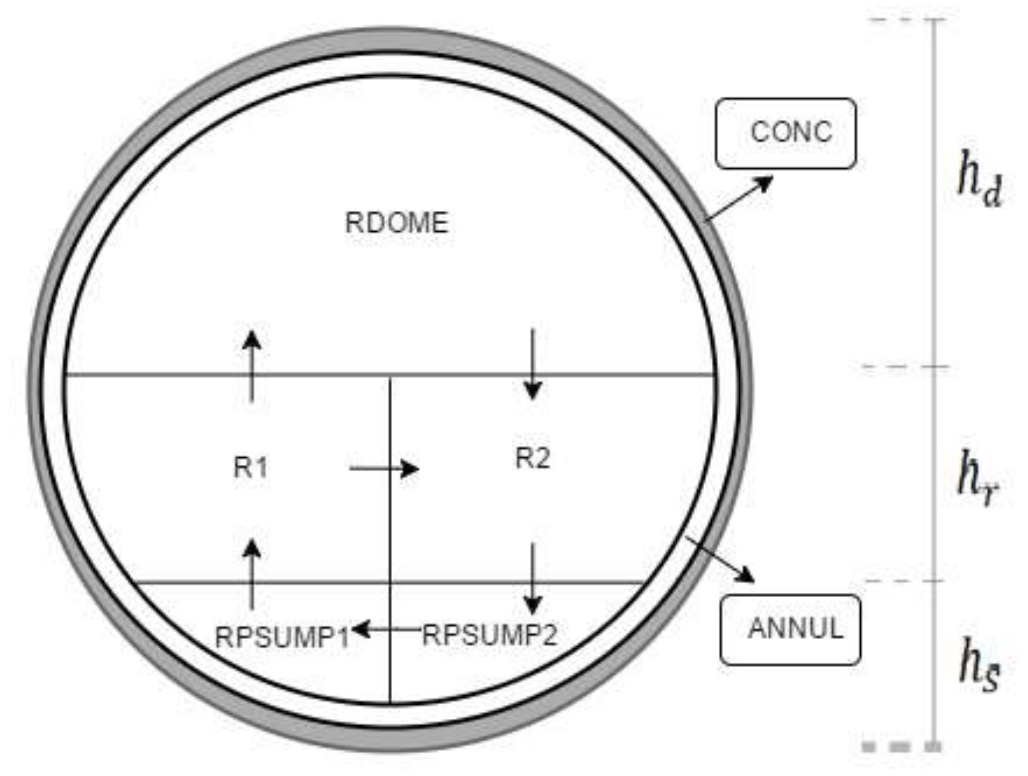

FIGURA B1 - Divisão dos volumes de controle (zonas).

Para as três abordagens, as alturas das regiões próximas ao sump (RPSUMP1 e RPSUMP2) e da cúpula (RDOME) foram iguais. A altura da zona intermediária (R1 e R2) é definido de acordo com o raio da esfera para cada abordagem.

\section{Caso Base (Base Case):}

O volume total da contenção para esta abordagem é de aproximadamente $70.985 \mathrm{~m}^{3}$. Os valores de altura, área e volume de cada zona estão definidos na TAB. B1. 
TABELA B1 - Valores de cada zona para o Base Case

\begin{tabular}{c|c|c|c}
\hline $\begin{array}{c}\text { Região } \\
\text { Hidráulica }\end{array}$ & Altura $(\mathbf{m})$ & $\begin{array}{c}\text { Área de } \\
\text { Transferência de } \\
\text { Calor }\left(\mathbf{m}^{\mathbf{2}}\right)\end{array}$ & Volume $\left.\mathbf{( m}^{\mathbf{3}}\right)$ \\
\hline RPSUMP1 & 9 & 723,82 & $2.874,51$ \\
\hline RPSUMP2 & 9 & 723,82 & $2.874,51$ \\
\hline R1 & 29,2 & $2.348,4$ & $26.966,82$ \\
\hline R2 & 29,2 & $2.348,4$ & $26.966,82$ \\
\hline RDOME & 13 & $2.091,04$ & $11.292,34$ \\
\hline
\end{tabular}

2. Low Case:

O volume total da contenção para esta abordagem é de aproximadamente $74.275 \mathrm{~m}^{3}$. Os valores de altura, área e volume de cada zona estão definidos na TAB. B2.

TABELA B2 - Valores de cada zona para o Low Case

\begin{tabular}{c|c|c|c}
\hline $\begin{array}{c}\text { Região } \\
\text { Hidráulica }\end{array}$ & Altura $(\mathbf{m})$ & $\begin{array}{c}\text { Área de } \\
\text { Transferência de } \\
\text { Calor }\left(\mathbf{m}^{\mathbf{2}}\right)\end{array}$ & Volume $\left.\mathbf{( m}^{\mathbf{3}}\right)$ \\
\hline RSUMP1 & 9 & 735,14 & $2.924,20$ \\
\hline RSUMP2 & 9 & 735,14 & $2.924,20$ \\
\hline R1 & 30 & $3.126,54$ & $28.138,00$ \\
\hline R2 & 30 & $3.126,54$ & $28.138,00$ \\
\hline RDOME & 13 & $2.123,7$ & $11.512,00$ \\
\hline
\end{tabular}

\section{High Case:}

O volume total da contenção para esta abordagem é de aproximadamente $67.510 \mathrm{~m}^{3}$. Os valores de altura, área e volume de cada zona estão definidos na TAB. B3. 
TABELA B3 - Valores de cada zona para o Base Case

\begin{tabular}{c|c|c|c}
\hline $\begin{array}{c}\text { Região } \\
\text { Hidráulica }\end{array}$ & Altura $(\mathbf{m})$ & $\begin{array}{c}\text { Área de } \\
\text { Transferência de } \\
\text { Calor }\left(\mathbf{m}^{\mathbf{2}}\right.\end{array}$ & Volume $\left.\mathbf{( m}^{\mathbf{3}}\right)$ \\
\hline RSUMP1 & 9,00 & 656,53 & $2.572,30$ \\
\hline RSUMP2 & 9,00 & 656,53 & $2.572,30$ \\
\hline R1 & 24,44 & $1.985,64$ & $26.166,57$ \\
\hline R2 & 24,44 & $1.985,64$ & $26.166,57$ \\
\hline RDOME & 13,00 & $1.491,05$ & $10.032,27$ \\
\hline
\end{tabular}




\section{APÊNDICE C - Resultados de temperatura da vareta mais realista do núcleo para o processo iterativo}

Os resultados a seguir apresentam as distribuições da temperatura da vareta mais realista do núcleo de Angra 2 simuladas com o RELAP5 - que utiliza como condição de contorno os valores de pressão e temperatura da contenção indicados nos itens 4.1 (RELAP5) e 4.2 (COCOSYS) desse trabalho - além dos resultados de temperatura correspondentes do RFAS/A2.

A região considerada e indicada nas legendas é a 42 (FIG. AB5 do ANEXO B), que corresponde à região mais quente do núcleo. No entanto, foi considerada a vareta mais realista (421), que embora esteja nesta região não está indicada na FIG. AB5.

\section{C.1 LBLOCA-PF}

Nas FIG. C1 e C2 são apresentadas as temperaturas do encamisamento na parte inferior (nodos 1 a 5) da vareta mais realista do reator Angra 2 no caso de LBLOCA-PF, COCOSYS e RELAP5, respectivamente. Comparando tais resultados com a FIG. C3 (RFAS/A2), que indica a temperatura da parte inferior para a vareta mais realista, observa-se que, para ambas as simulações desse trabalho, o primeiro pico é razoavelmente maior que os do RFAS/A2.

O segundo pico possui valores mais próximos ao do relatório de análise de segurança, embora o tempo de estabilização da temperatura ocorra num tempo posterior para as simulações RELAP5(COCOSYS) - 88s - e RELAP5(RELAP5) 114s. Ainda assim, ambas se estabilizam em um valor próximo ao dado no RFAS/A2, de aproximadamente $140^{\circ} \mathrm{C}$. 


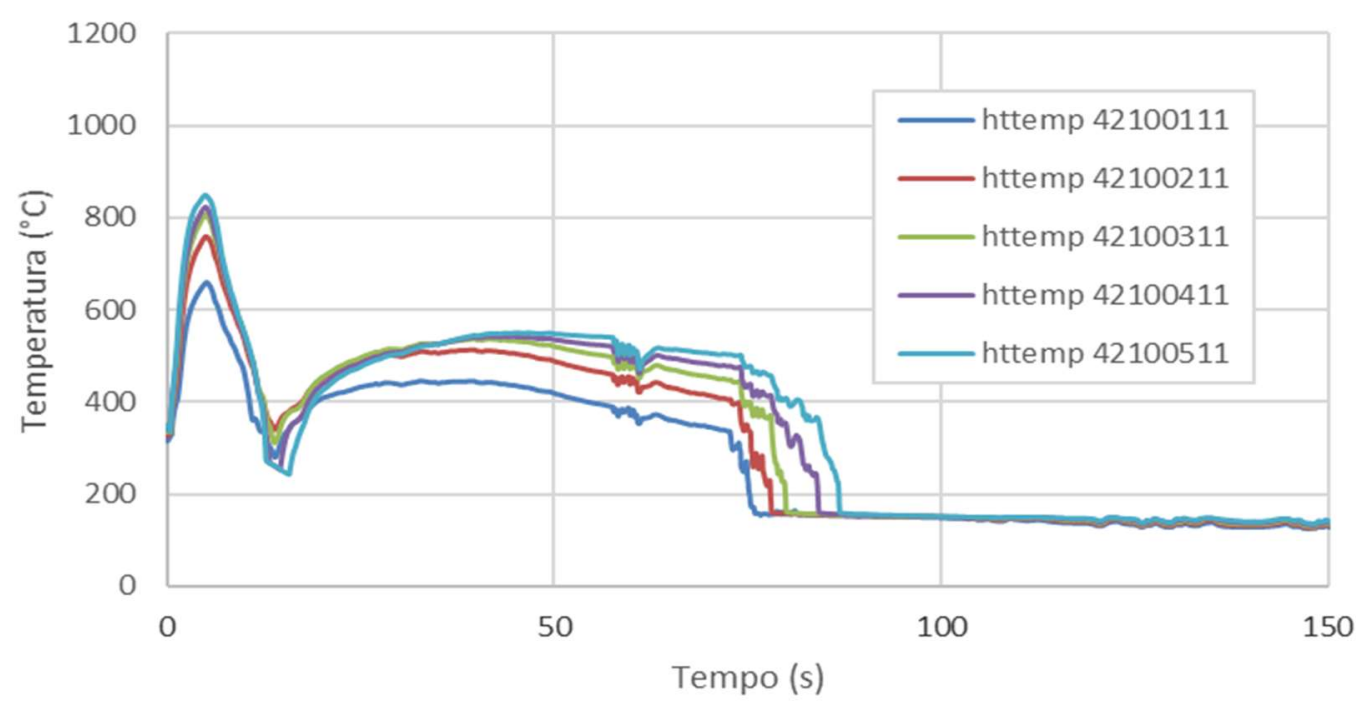

FIGURA C1 - Evolução temporal da temperatura do encamisamento na parte inferior da vareta mais realista do núcleo - LBLOCA-PF com RELAP5 (COCOSYS)

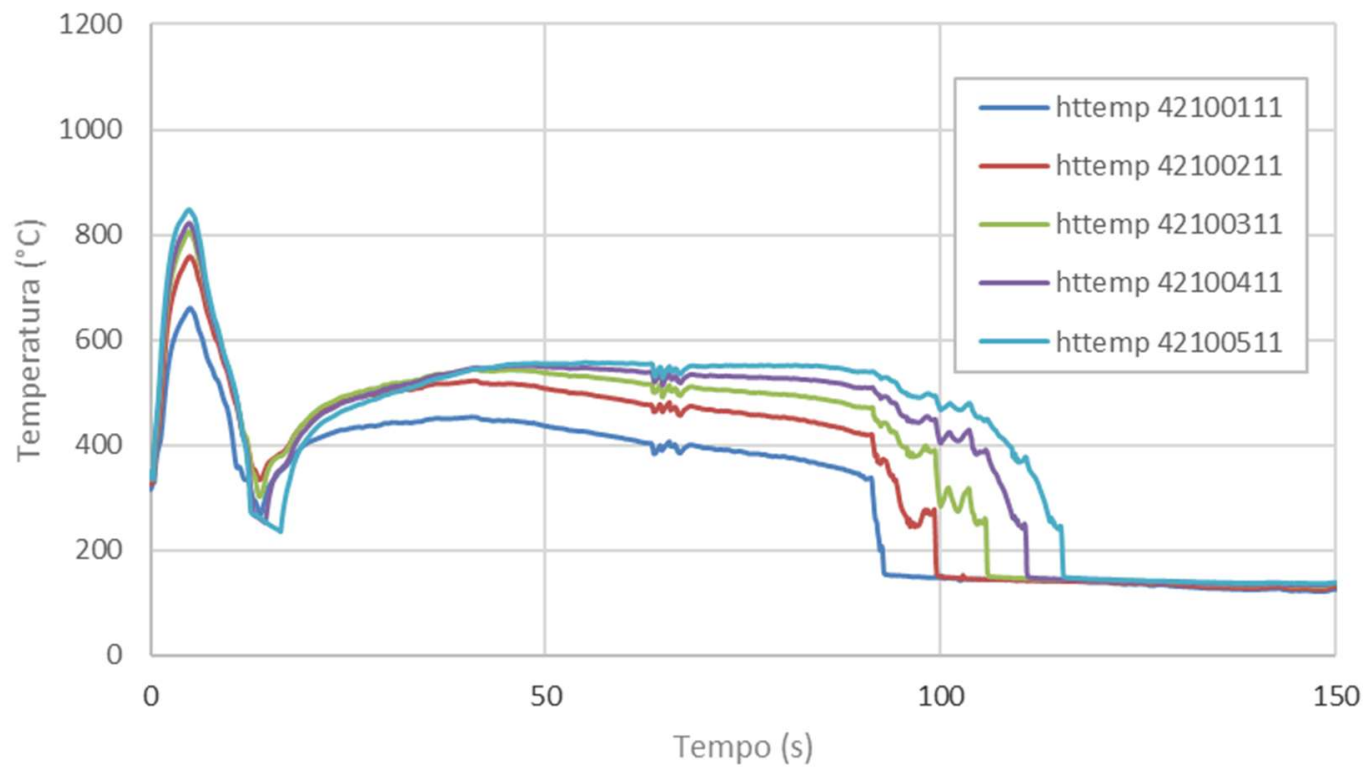

FIGURA C2 - Evolução temporal da temperatura do encamisamento na parte inferior da vareta mais realista do núcleo - LBLOCA-PF com RELAP5 (RELAP5) 


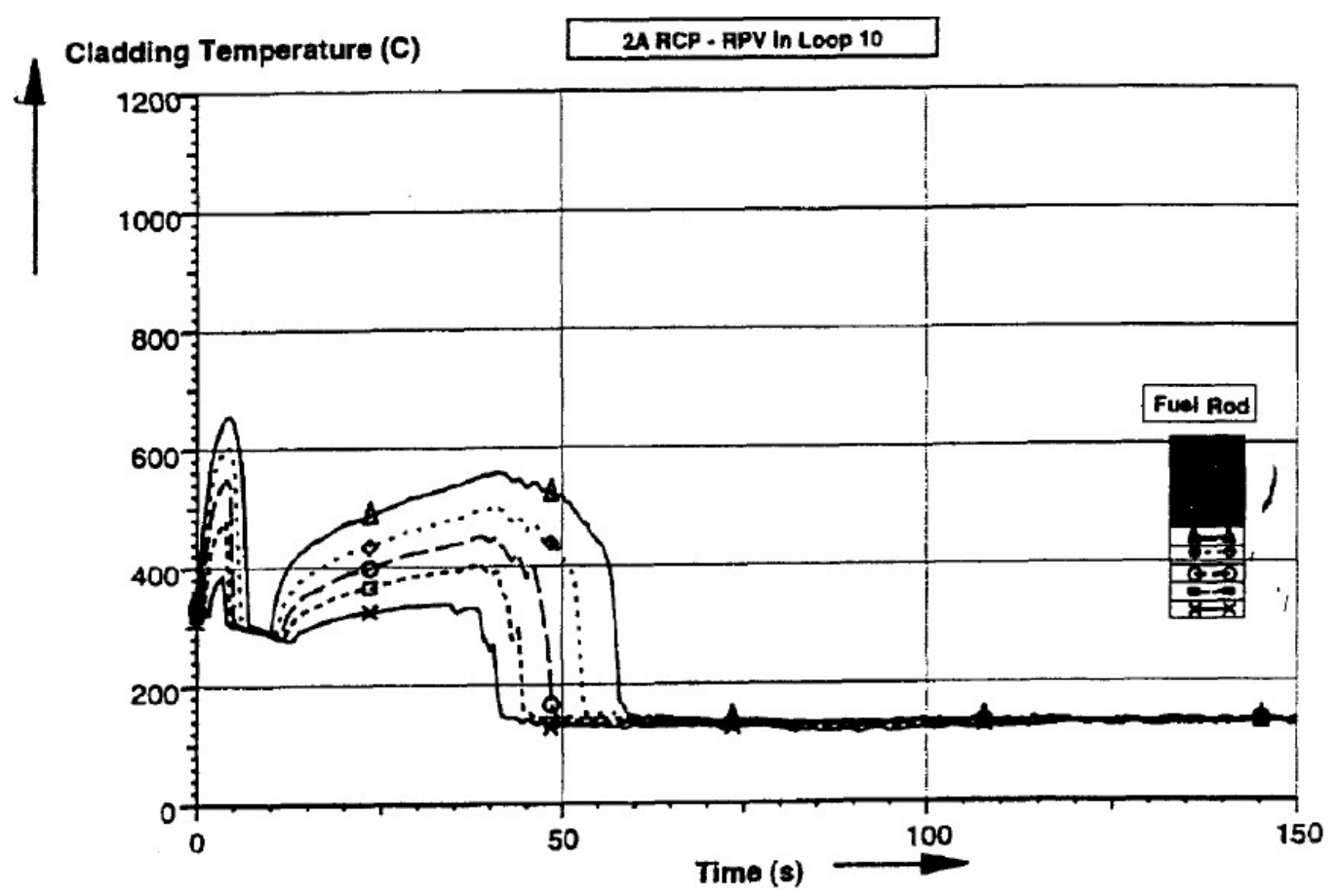

FIGURA C3 - Evolução temporal da temperatura do encamisamento na parte inferior da vareta mais realista do núcleo - LBLOCA-PF (RFAS/A2)

Nas FIG. C4 e C5 encontram-se também as distribuições de temperaturas do encamisamento para a parte superior (nodos 6 a 10) da vareta mais realista do reator Angra 2 para a mesma ruptura. Observa-se que o primeiro pico, para ambas as simulações, é maior que o segundo pico, antagonicamente ao que consta no RFAS/A2 (FIG. C6). Isso se deve ao fato da modelagem do núcleo ser para uma região e não para uma única vareta, a mais quente, como definido no RFAS/A2. Embora haja esta diferença, o tempo de início da estabilidade de temperatura assim como a temperatura de estabilidade são bem próximos. Também é importante ressaltar que as temperaturas máximas não ultrapassam $1200^{\circ} \mathrm{C}$, como as normas da $\mathrm{CNEN}$ definem. 


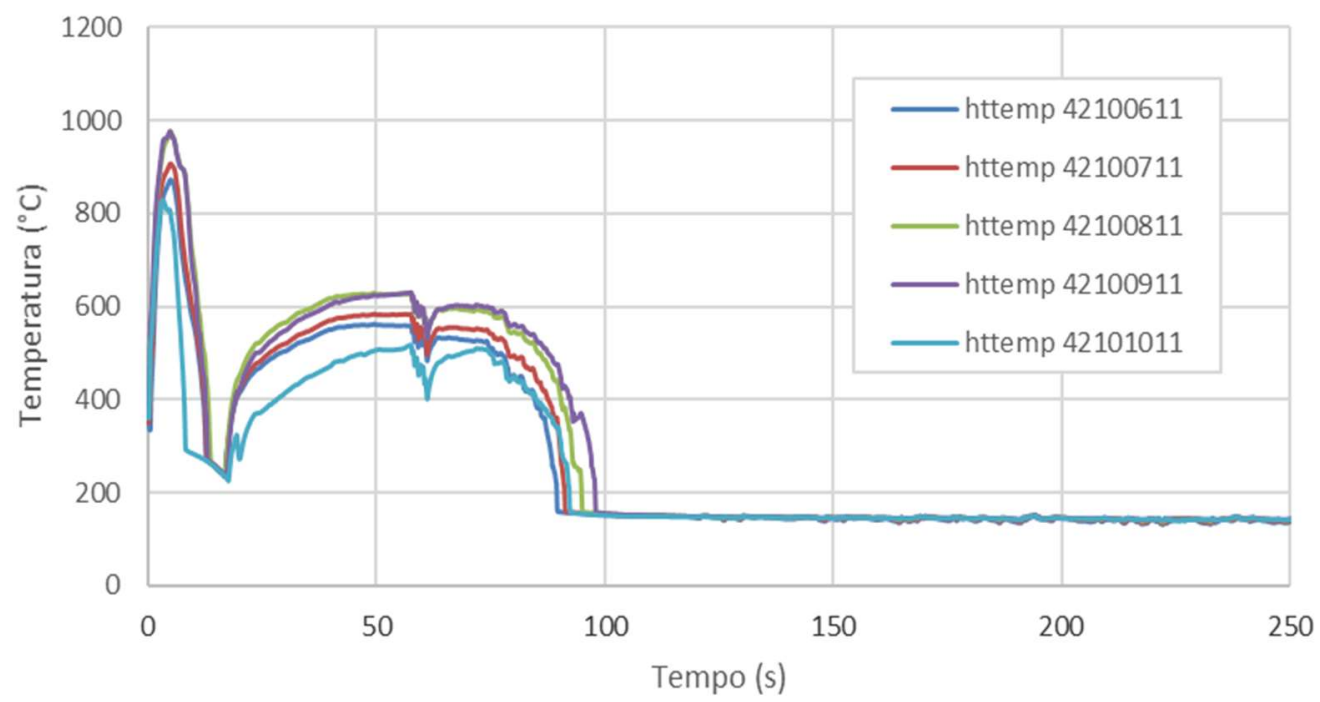

FIGURA C4 - Evolução temporal da temperatura do encamisamento na parte superior da vareta mais realista do núcleo - LBLOCA-PF com RELAP5 (COCOSYS)

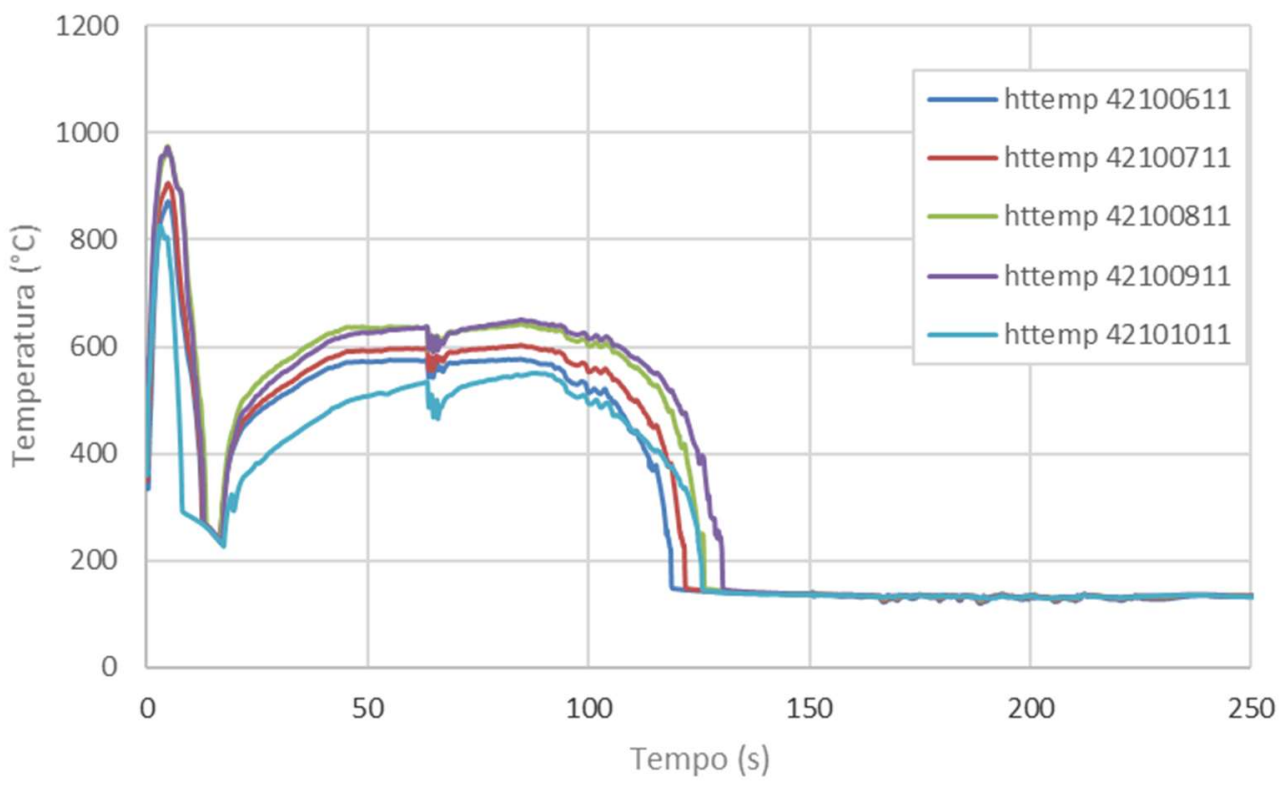

FIGURA C5 - Evolução temporal da temperatura do encamisamento na parte superior da vareta mais realista do núcleo - LBLOCA-PF com RELAP5 (RELAP5) 


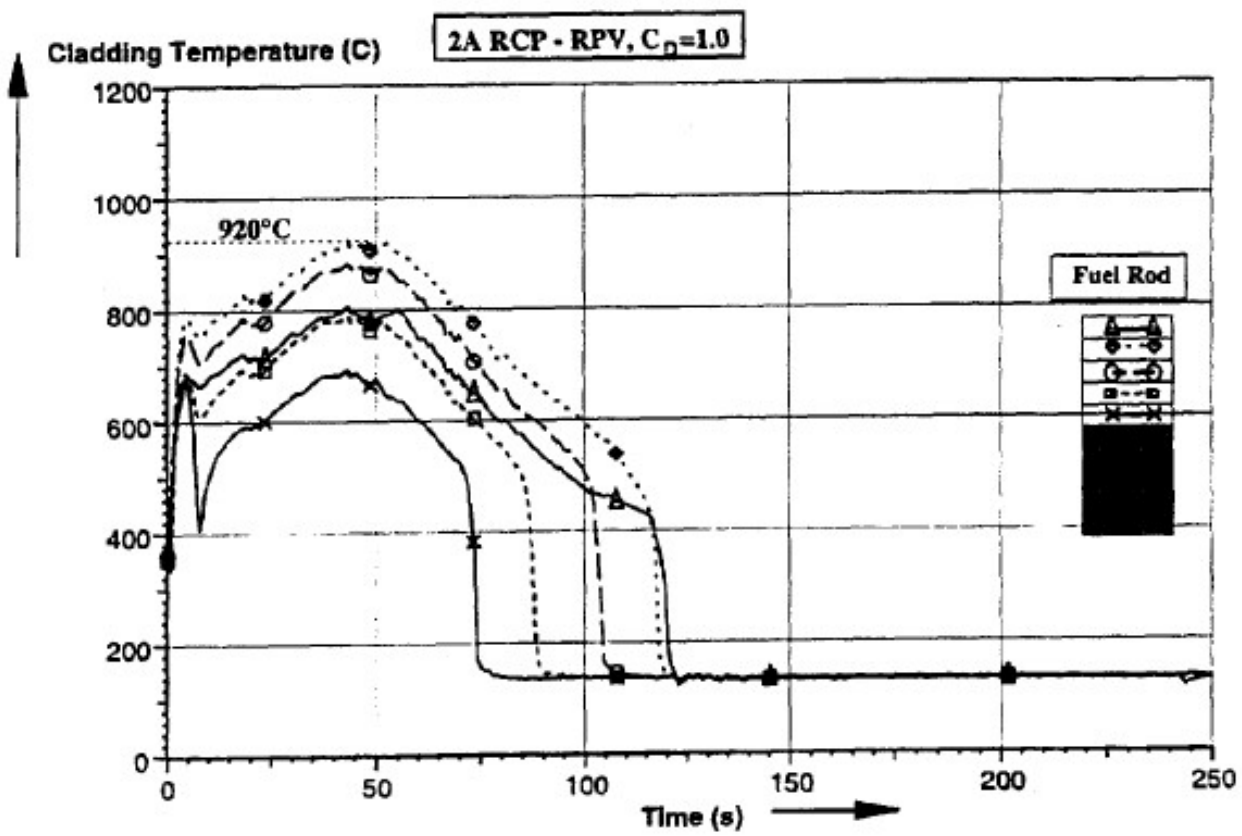

FIGURA C6 - Evolução temporal da temperatura do encamisamento na parte superior da vareta mais realista do núcleo - LBLOCA-PF (RFAS/A2)

\section{C.2 LBLOCA-PI}

Nas FIG. C7 e C8, são apresentadas as temperaturas do encamisamento na parte inferior da vareta mais realista do reator Angra 2 para o caso de LBLOCA PI. Os valores de temperatura do pico e de temperatura de estabilidade obtidos nas simulações são próximos aos valores do RFAS/A2 (FIG. C9), por volta de $400^{\circ} \mathrm{C}$ e $140^{\circ} \mathrm{C}$, respectivamente. 


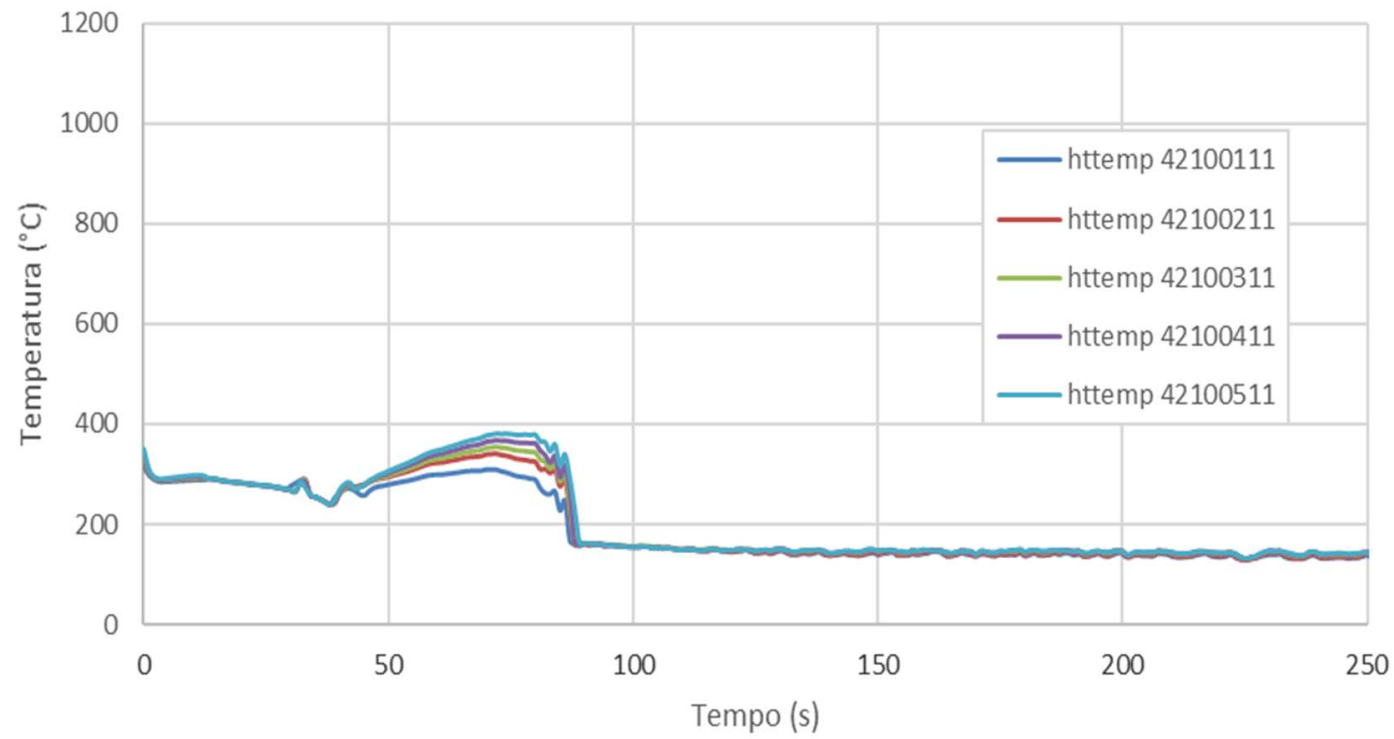

FIGURA C7 - Evolução temporal da temperatura do encamisamento na parte inferior da vareta mais realista do núcleo - LBLOCA-PI com RELAP5 (COCOSYS)

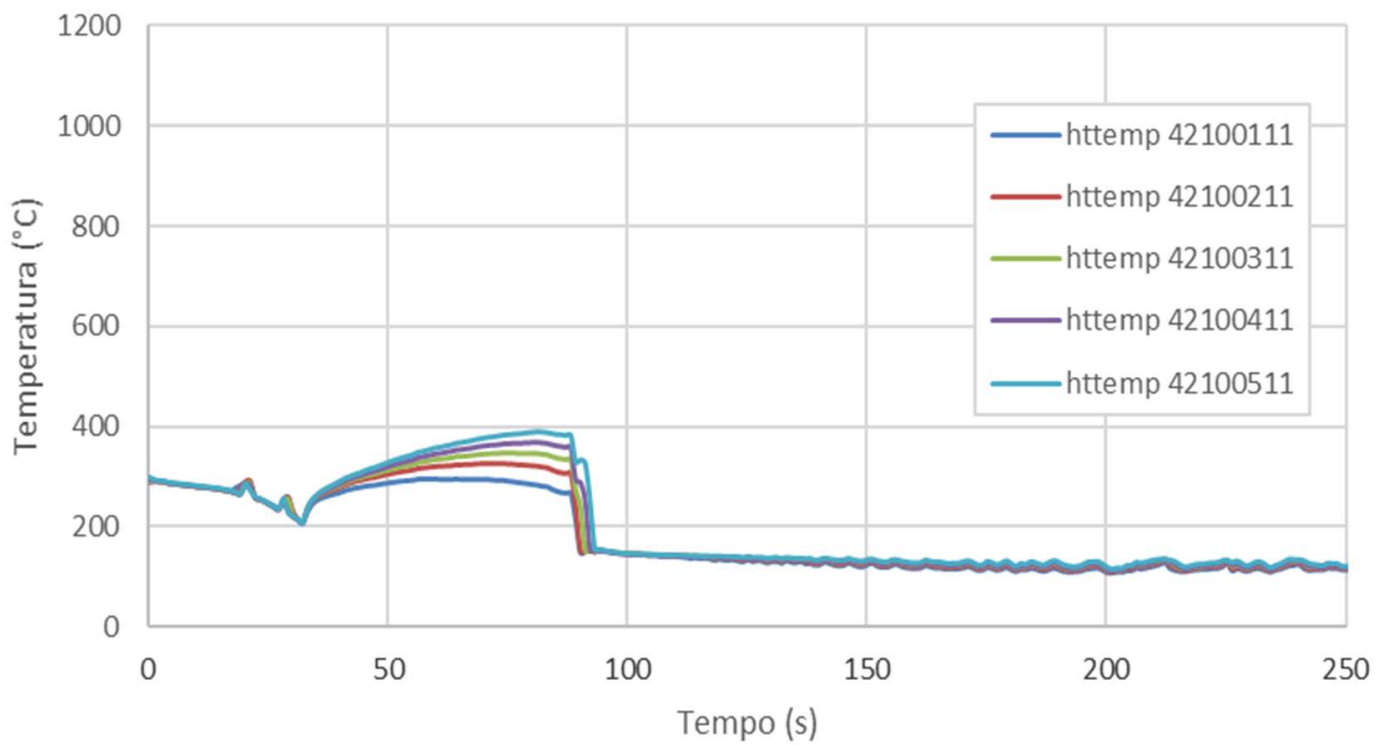

FIGURA C8 - Evolução temporal da temperatura do encamisamento na parte inferior da vareta mais realista do núcleo - LBLOCA-PI com RELAP5 (RELAP5) 


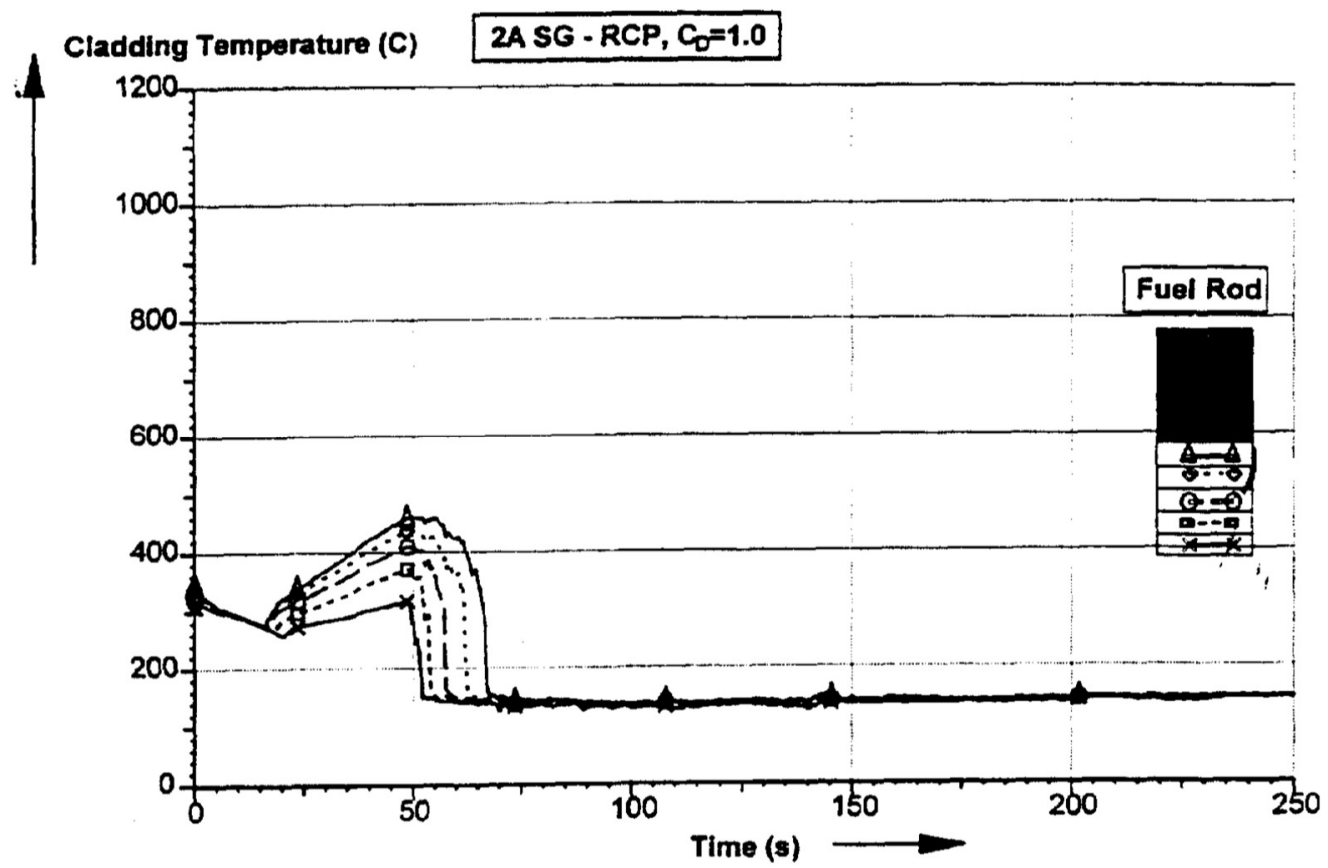

FIGURA C9 - Evolução temporal da temperatura do encamisamento na parte inferior da vareta mais realista do núcleo - LBLOCA-PI (RFAS/A2)

Nas FIG. C10 e C11, são apresentadas as temperaturas do encamisamento na parte superior da vareta mais realista do reator Angra 2, no caso de LBLOCA-PI, para as simulações da planta inteira com condições de contorno fornecidas pelo COCOSYS e RELAP5, respectivamente. Em comparação com o RFAS/A2, conforme a FIG. C12, que indica a temperatura da parte superior da vareta mais realista, observa-se que os valores do primeiro pico, para ambas as simulações, são ligeiramente menores que os do RFAS/A2. No entanto, a temperatura de estabilidade das simulações, além do tempo em que ocorre, é coerente, quando comparada com os dados no relatório (aproximadamente $140^{\circ}$ aos $75 \mathrm{~s}$ ). 


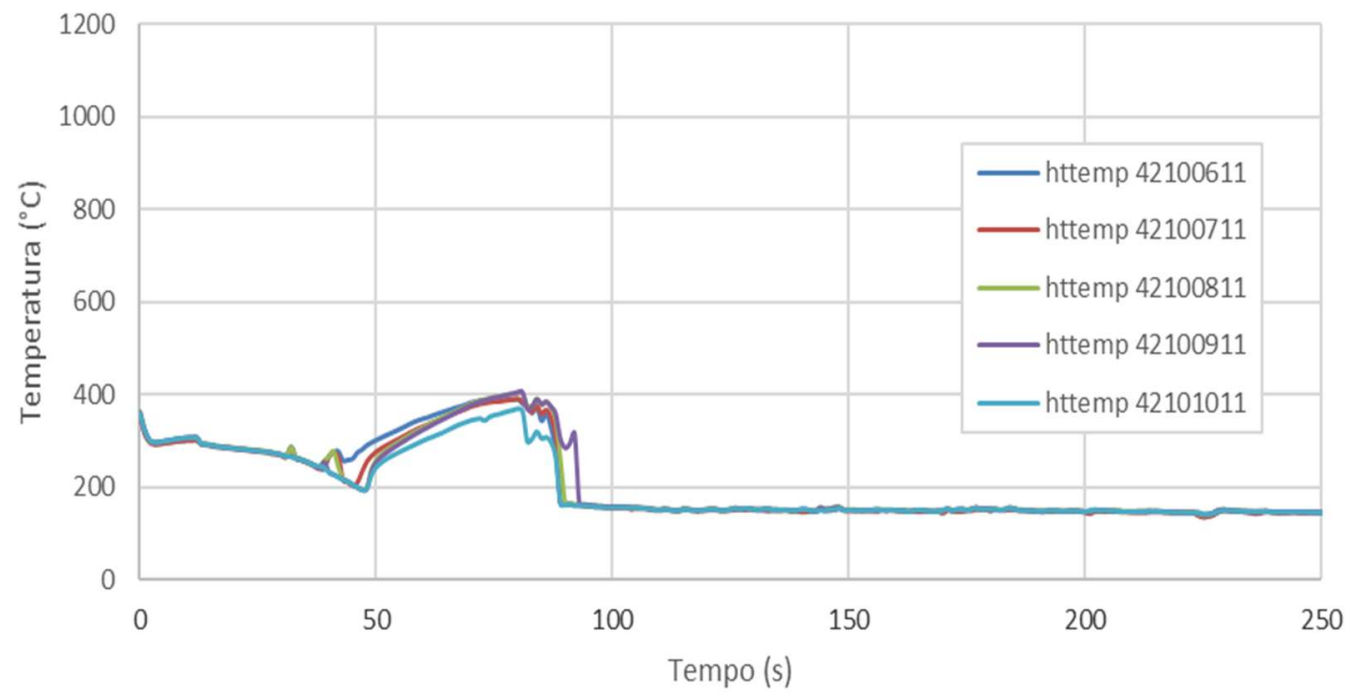

FIGURA C10 - Evolução temporal da temperatura do encamisamento na parte superior da vareta mais realista do núcleo - LBLOCA-PI com RELAP5 (COCOSYS)

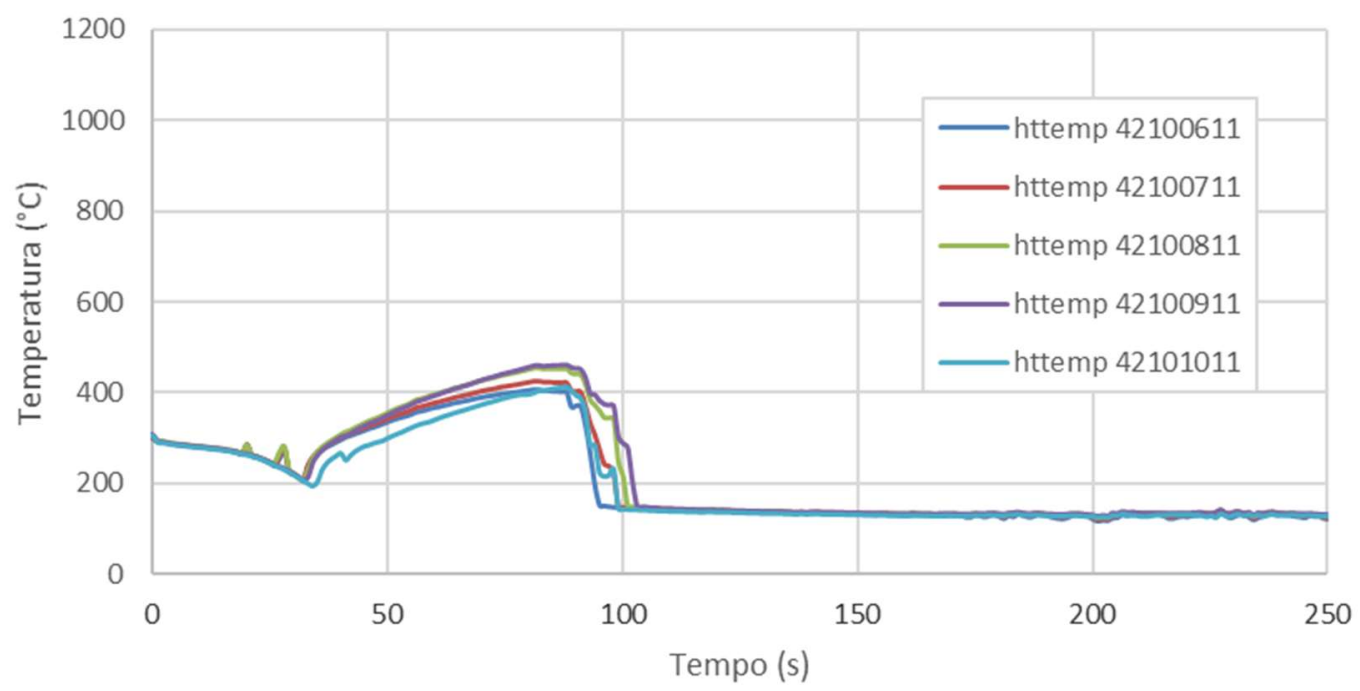

FIGURA C11 - Evolução temporal da temperatura do encamisamento na parte superior da vareta mais realista do núcleo - LBLOCA-PI com RELAP5 (RELAP5) 


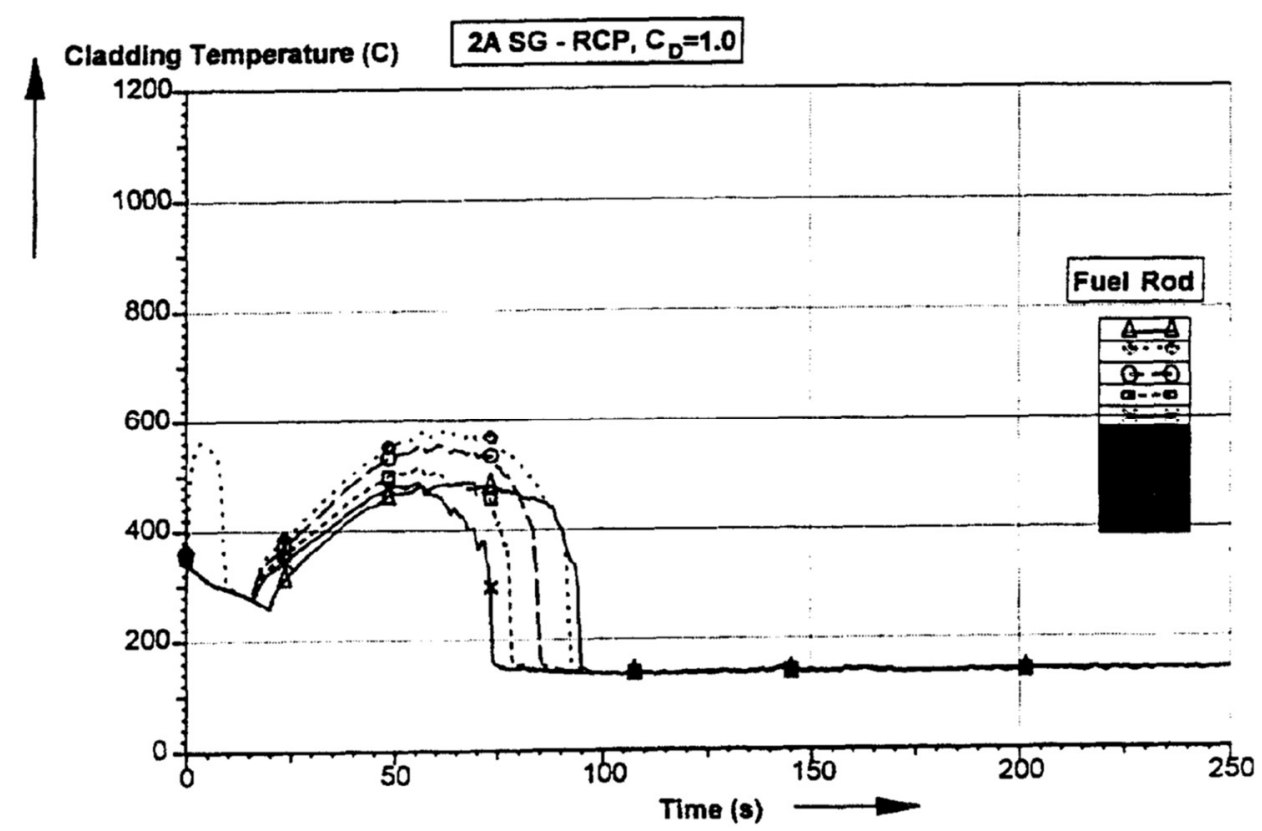

FIGURA C12 - Evolução temporal da temperatura do encamisamento na parte superior da vareta mais realista do núcleo - LBLOCA-PI (RFAS/A2)

\section{C.3 LBLOCA-PQ}

Nas FIG. C13 e C14, encontram-se as distribuições de temperaturas do encamisamento para a parte inferior da vareta mais realista do reator Angra 2 para o LBLOCA-PQ. Observa-se que, para cada uma das simulações, o pico possui valor de temperatura bem próximo ao que consta no RFAS/A2 (FIG. C15).

As temperaturas se estabilizam em $130^{\circ} \mathrm{C}$, aproximadamente, tanto para as simulações da planta inteira com condições de contorno fornecidas pelo COCOSYS e RELAP5 quanto para o RFAS/A2. 


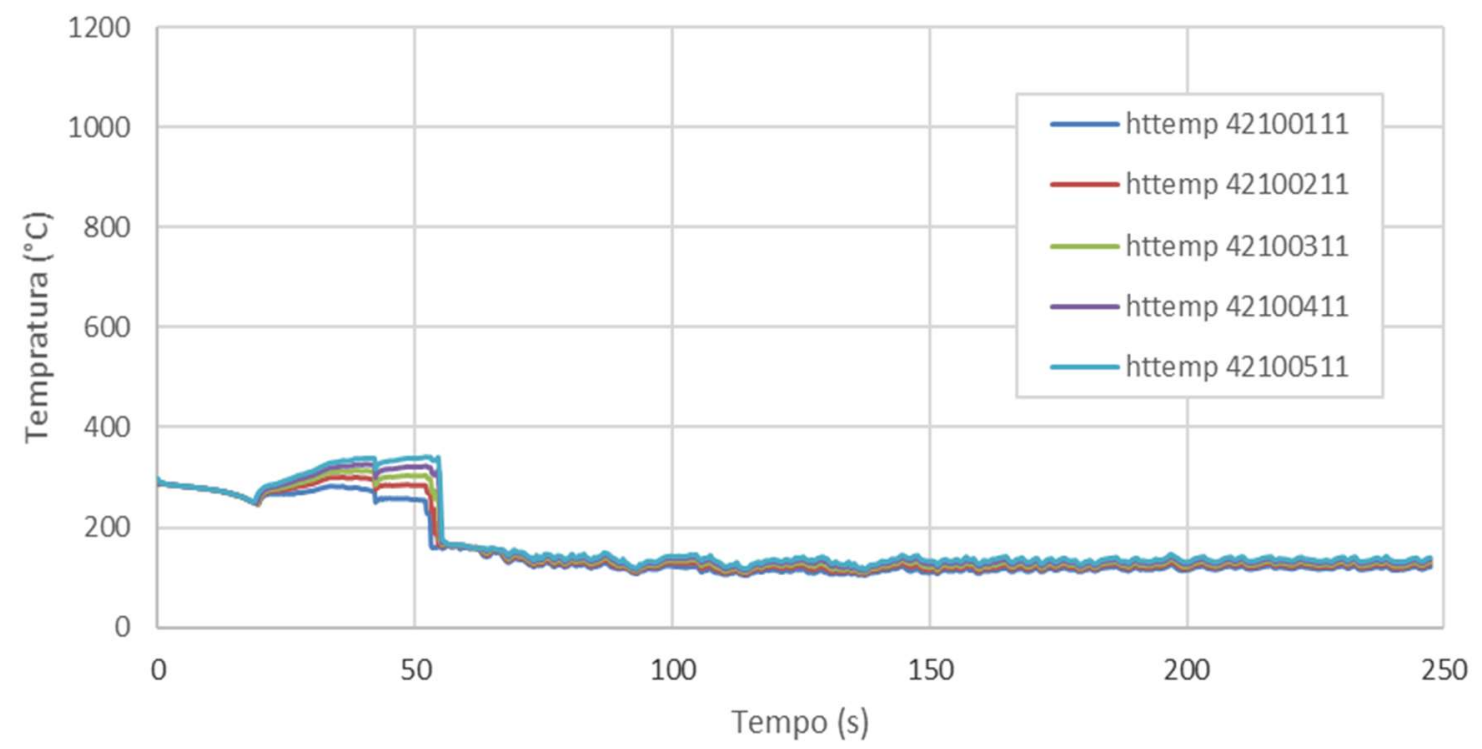

FIGURA C13 - Evolução temporal da temperatura do encamisamento na parte inferior da vareta mais realista do núcleo - LBLOCA-PQ com RELAP5 (COCOSYS)

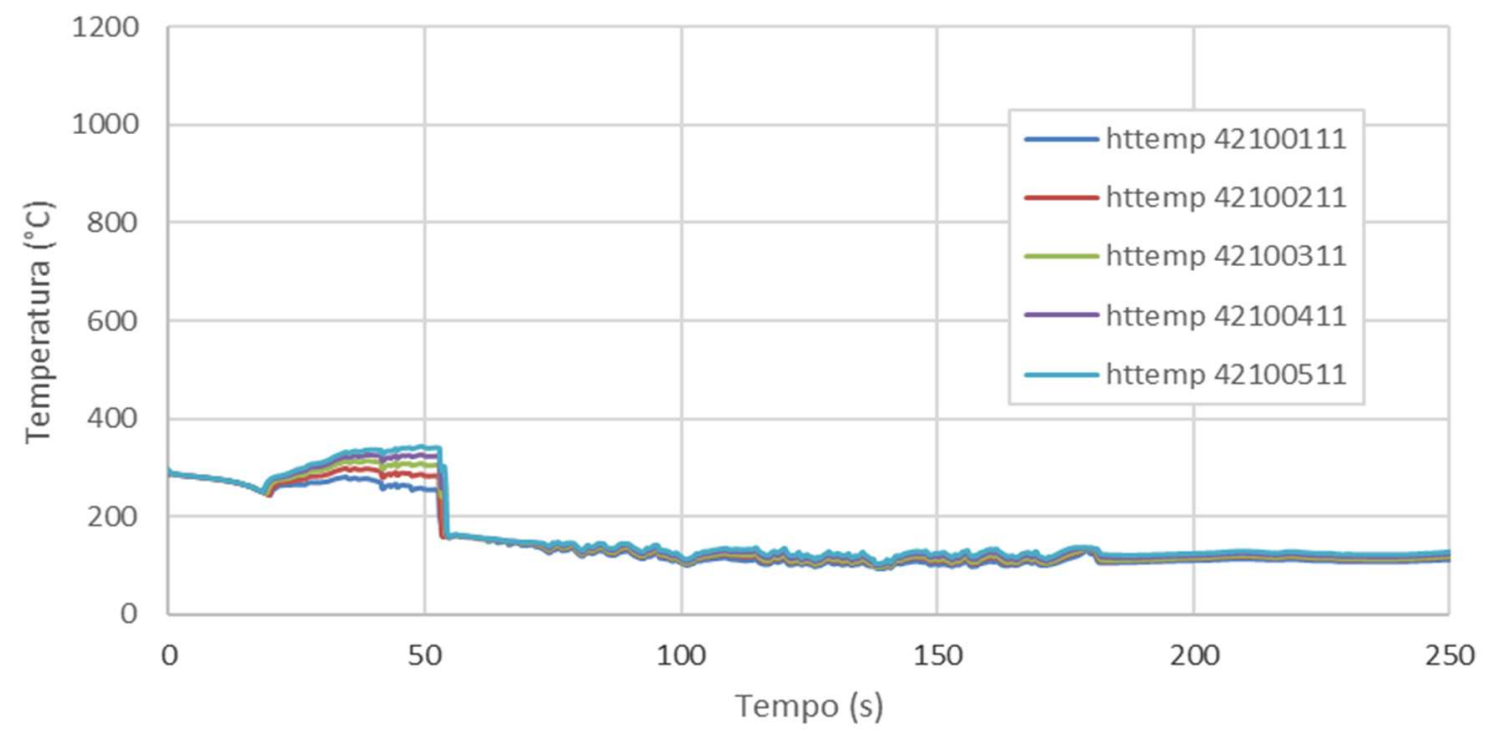

FIGURA C14 - Evolução temporal da temperatura do encamisamento na parte inferior da vareta mais realista do núcleo - LBLOCA-PQ com RELAP5 (RELAP5) 


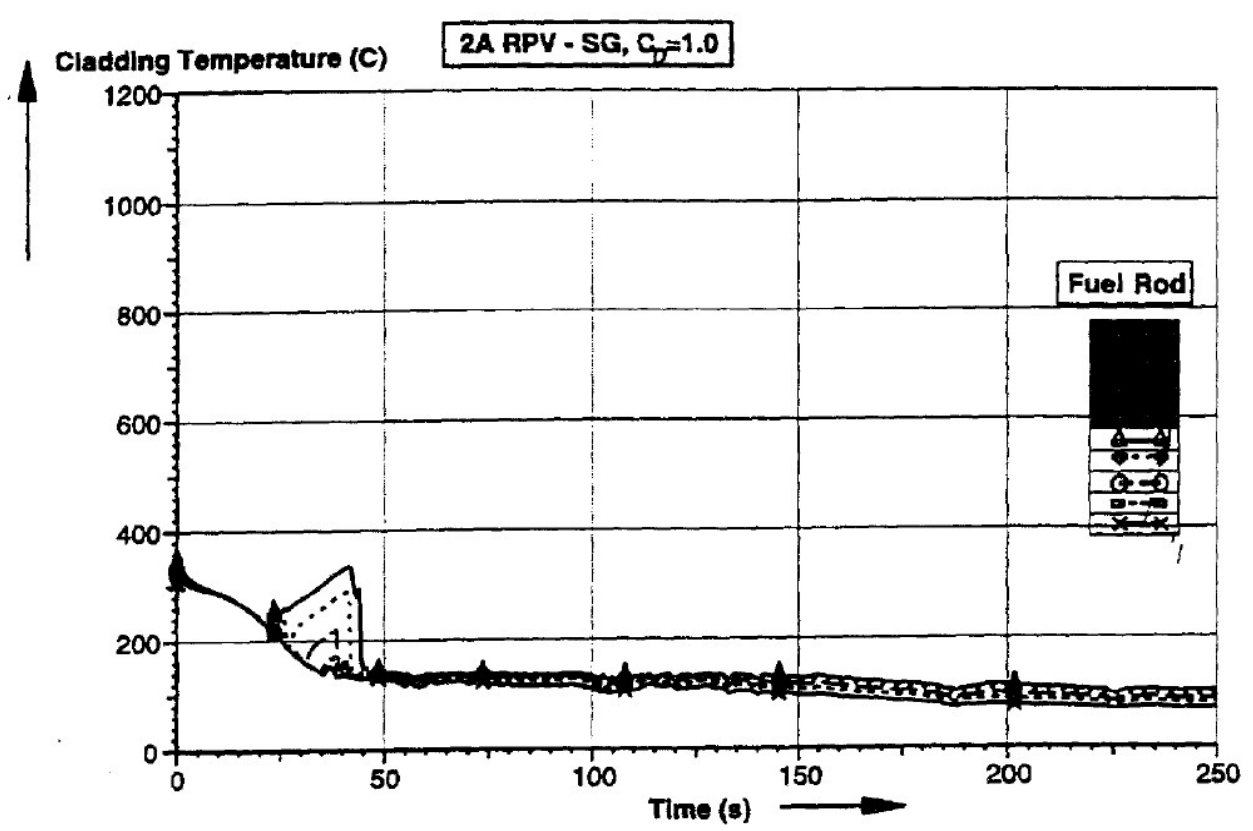

FIGURA C15 - Evolução temporal da temperatura do encamisamento na parte inferior da vareta mais realista do núcleo - LBLOCA-PQ (RFAS/A2)

Finalmente, nas FIG. C16 e C17, são apresentadas as distribuições de temperaturas do encamisamento para a parte superior da vareta mais realista do reator Angra 2 e para a mesma ruptura (LBLOCA-PQ). Assim como demonstrado para a região inferior, pode-se observar que, para cada uma das simulações, o pico possui valor de temperatura bem próximo ao que consta no RFAS/A2 (FIG. C18), além do fato de ocorrerem no mesmo intervalo de tempo. As temperaturas também se estabilizam em $130^{\circ} \mathrm{C}$, aproximadamente, tanto para as simulações da planta inteira com condições de contorno fornecidas pelo COCOSYS e RELAP5 quanto para o RFAS/A2. 


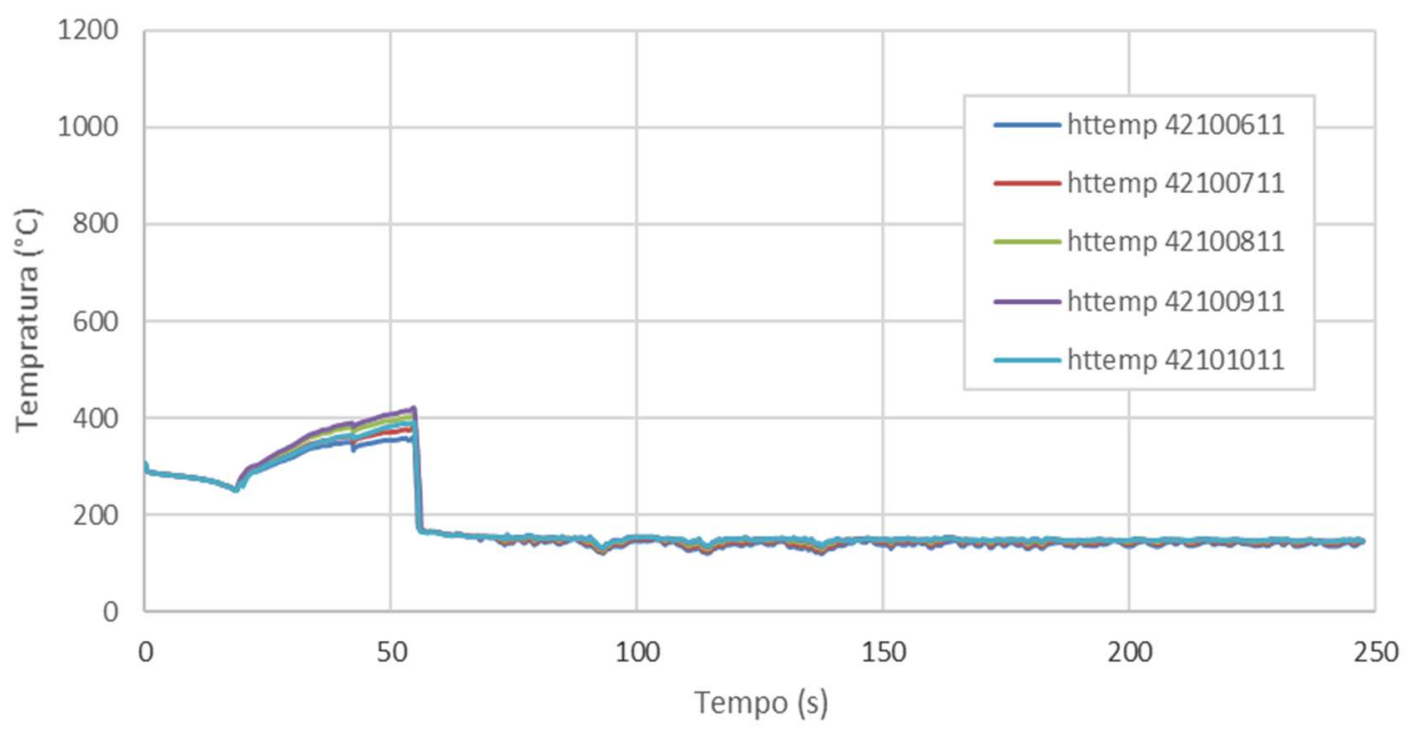

FIGURA C16 - Evolução temporal da temperatura do encamisamento na parte superior da vareta mais realista do núcleo - LBLOCA-PQ com RELAP5 (COCOSYS)

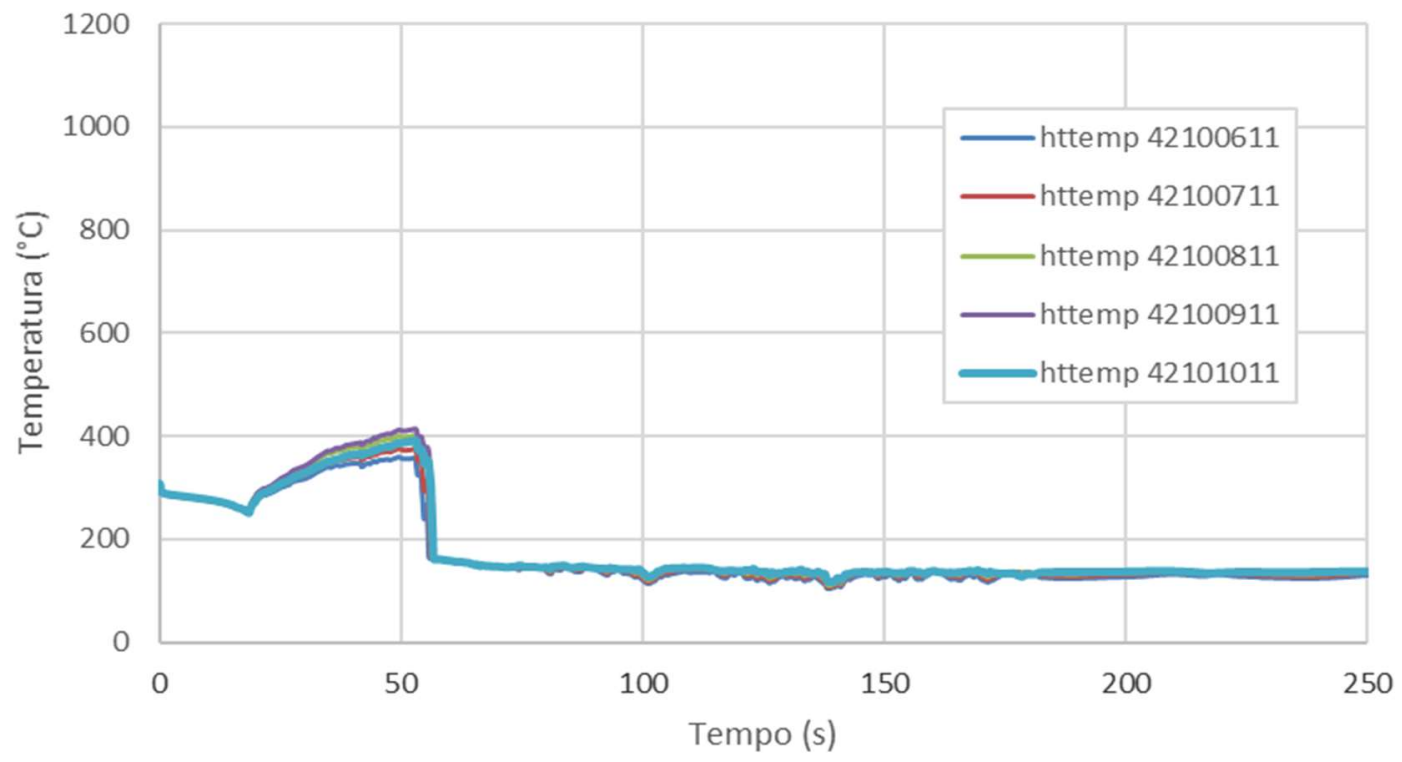

FIGURA C17 - Evolução temporal da temperatura do encamisamento na parte superior da vareta mais realista do núcleo - LBLOCA-PQ com RELAP5 (RELAP5) 


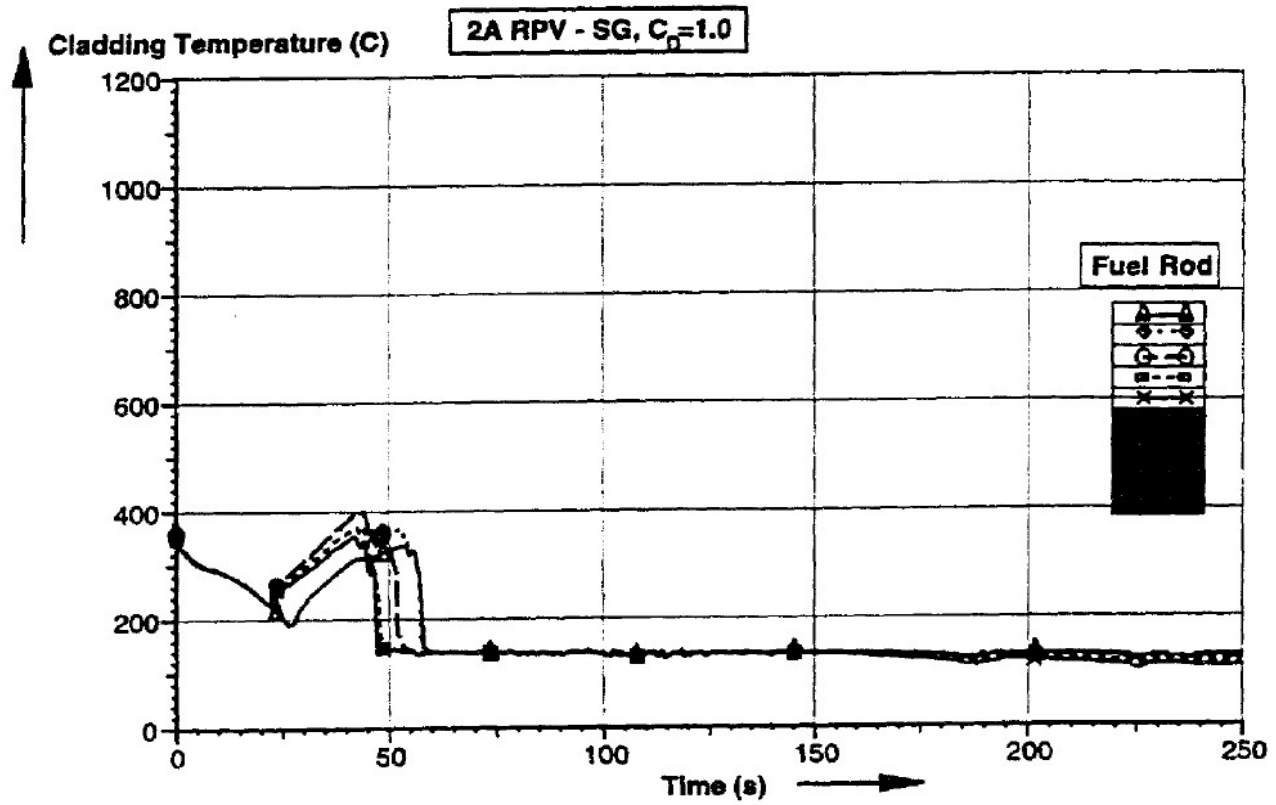

FIGURA C18 - Evolução temporal da temperatura do encamisamento na parte superior da vareta mais realista do núcleo - LBLOCA-PQ (RFAS/A2) 


\section{ANEXO A - Propriedades do Aço Austenítico WSTE 51}

A composição do aço que constitui a contenção, o aço austenítico WStE 51 , está detalhada na TAB. AA1.

TABELA AA1 - Composição química do Aço.

\begin{tabular}{c|cccccccc}
\hline AÇO & $\% \mathrm{C}$ & $\% \mathrm{Mn}$ & $\% \mathrm{P}$ & $\% \mathbf{S}$ & $\% \mathrm{Si}$ & $\% \mathrm{Ni}$ & $\% \mathrm{~V}$ & $\% \mathrm{Mo}$ \\
\hline WSTE51 & 0,20 & $1,20-$ & $<=0,035$ & $<=0,035$ & $0,10-$ & $<=0,50-$ & $0,10-$ & --- \\
& & 1,70 & & & 0,50 & 0,80 & 0,22 & \\
\hline
\end{tabular}

A condutividade térmica (TAB. AA2) e calores específicos (TAB. AA3) do aço em relação à temperatura definem as propriedades de troca de calor da estrutura inseridas no RELAP5.

TABELA AA2 - Condutividade térmica do Aço.

\begin{tabular}{c|cccccccccc}
\hline $\mathbf{T}(\mathrm{K})$ & $\mathbf{2 7 3}$ & $\mathbf{3 7 3}$ & $\mathbf{4 7 3}$ & $\mathbf{5 7 3}$ & $\mathbf{6 7 3}$ & $\mathbf{7 7 3}$ & $\mathbf{8 7 3}$ & $\mathbf{9 7 3}$ & $\mathbf{1 0 7 3}$ & $\mathbf{1 2 7 3}$ \\
\hline $\mathbf{C ~ ( W / ~} \mathbf{m ~ K})$ & 46 & 45,8 & 45 & 42,6 & 40,1 & 37,4 & 34,4 & 30,6 & 26,6 & 27,2 \\
\hline
\end{tabular}

TABELA AA3 - Calores específicos à pressão constante, Cp.

\begin{tabular}{cc}
\hline Faixa de valores de temperatura $\left({ }^{\circ} \mathrm{C}\right)$ & $\mathbf{C p ~}(\mathbf{J} / \mathbf{k g ~ K})$ \\
\hline $\mathbf{5 0 - 1 0 0}$ & 477 \\
$\mathbf{1 5 0 - 2 0 0}$ & 511 \\
$\mathbf{2 0 0 - 2 5 0}$ & 528 \\
$\mathbf{2 5 0 - 3 0 0}$ & 544 \\
$\mathbf{3 0 0 - 3 5 0}$ & 565 \\
$\mathbf{3 5 0 - 4 0 0}$ & 590 \\
$\mathbf{4 5 0 - 5 0 0}$ & 649 \\
$\mathbf{5 5 0 - 6 0 0}$ & 741 \\
$\mathbf{6 5 0 - 7 0 0}$ & 837 \\
$\mathbf{7 0 0 - 7 5 0}$ & 1449 \\
$\mathbf{7 5 0 - 8 0 0}$ & 821 \\
$\mathbf{8 5 0 - 9 0 0}$ & 536 \\
\hline
\end{tabular}

Fonte - Metals Handbook, Properties and Selection, Iron and Steels, ASM, vol. 1, pp.139-149, 9 ed., 1978. 


\section{ANEXO B - Modelagem da planta inteira}

Nas FIG. AB1 a AB3, são apresentadas as nodalizações do circuito primário/secundário do gerador de vapor e do Sistema de Resfriamento de Emergência do Núcleo (SREN), respectivamente. Nas FIG. AB4 e AB5, pode-se observar o detalhamento do vaso do reator de Angra 2 - vistas axial e radial. A descrição resumida dos componentes envolvidos nessa modelagem encontra-se na TAB. AB1.

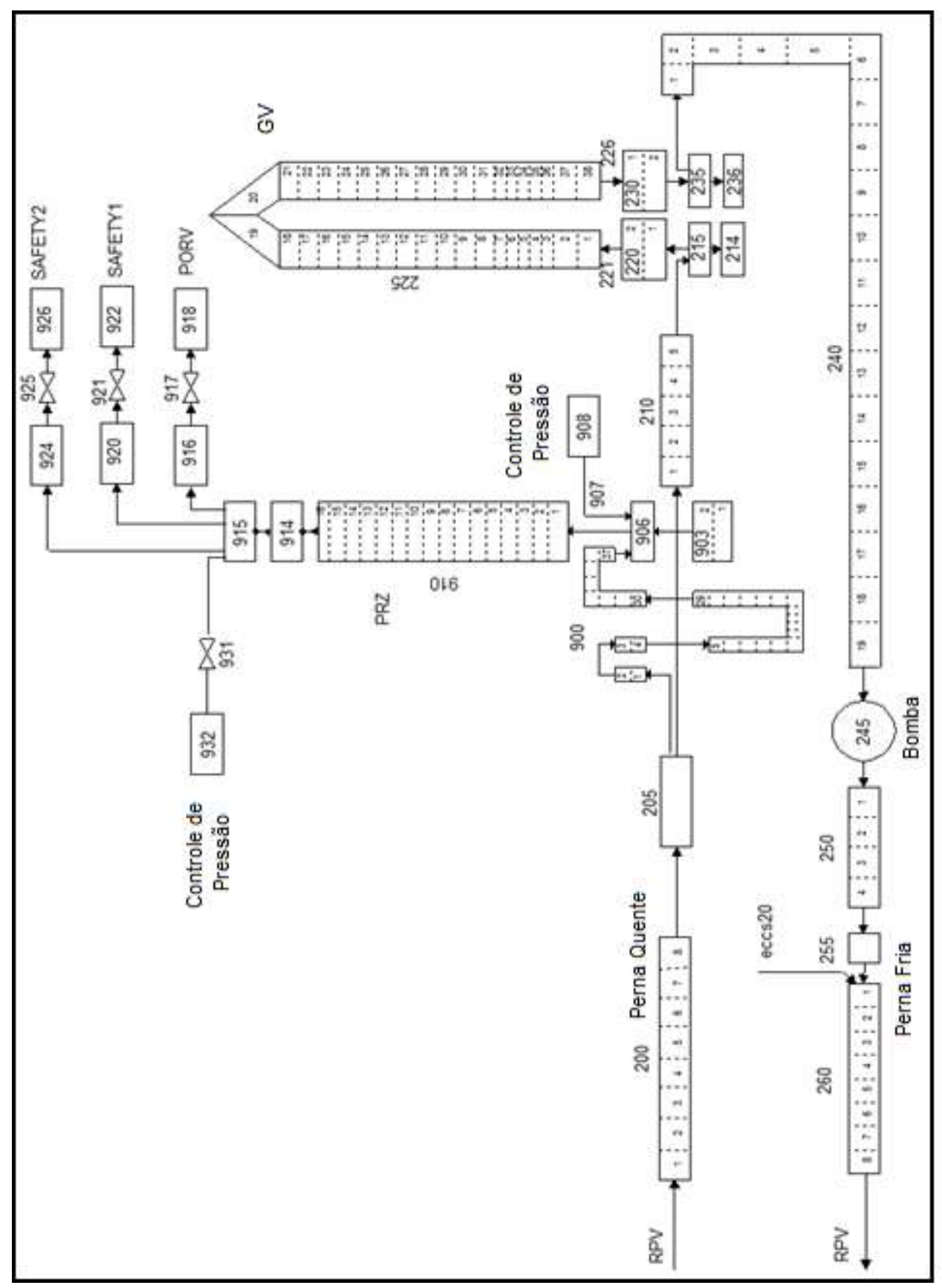

FIGURA AB1 - Nodalização do circuito primário (20) de Angra 2 


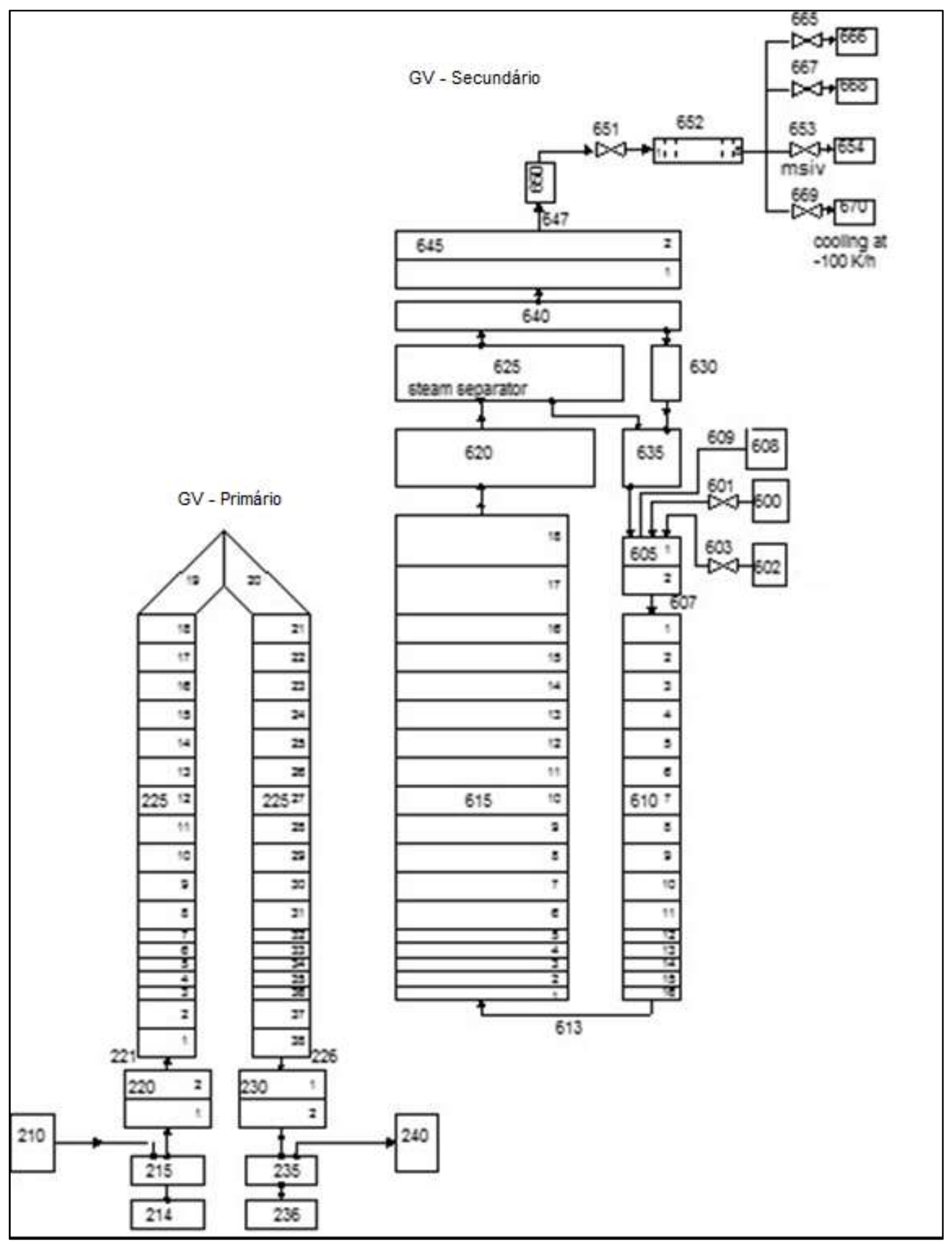

FIGURA AB2 - Nodalização do Gerador de Vapor (circuito 20) de Angra 2 


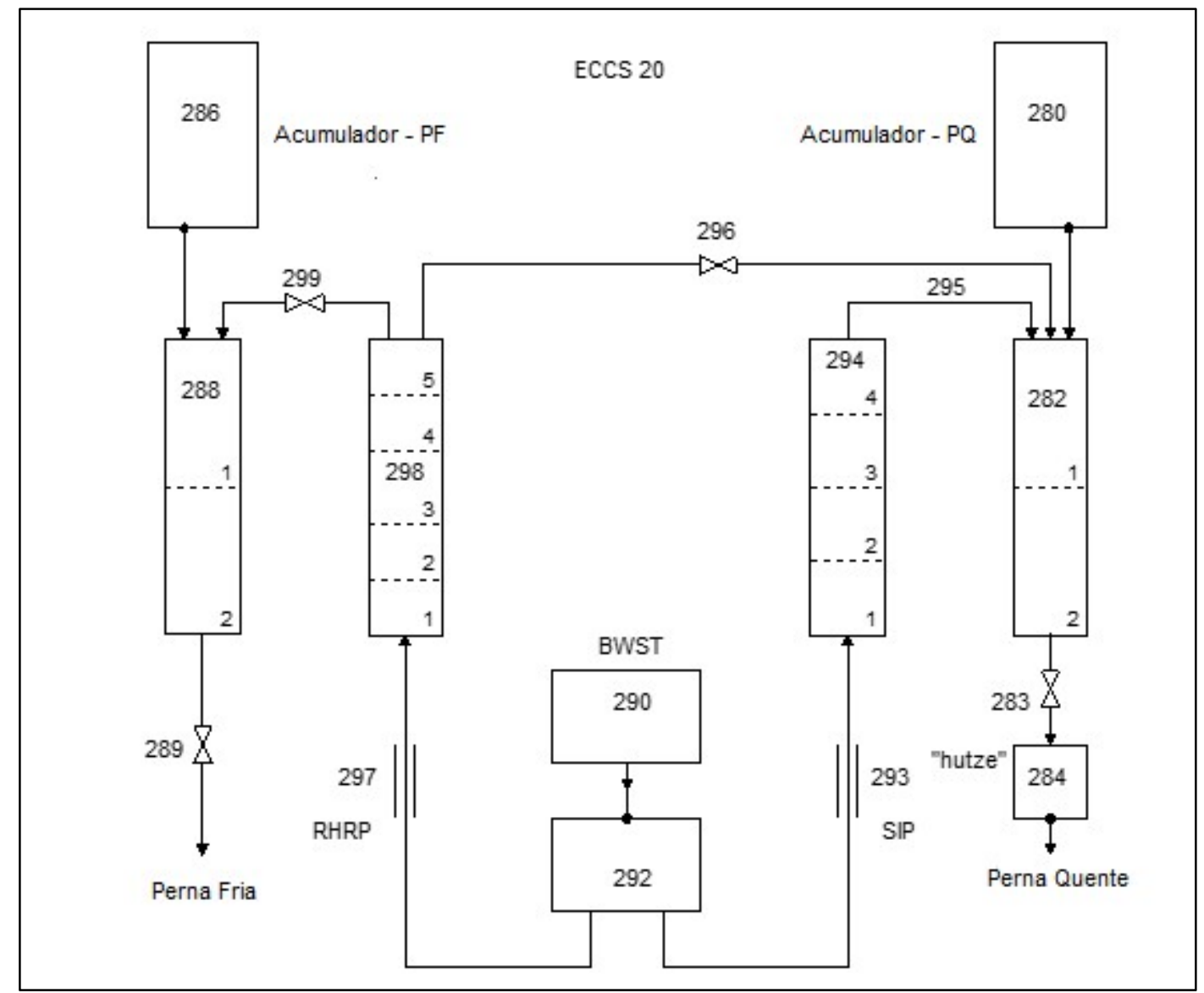

FIGURA AB3 - Nodalização do Sistema de Refrigeração de Emergência do Núcleo (circuito 20) de Angra 2 


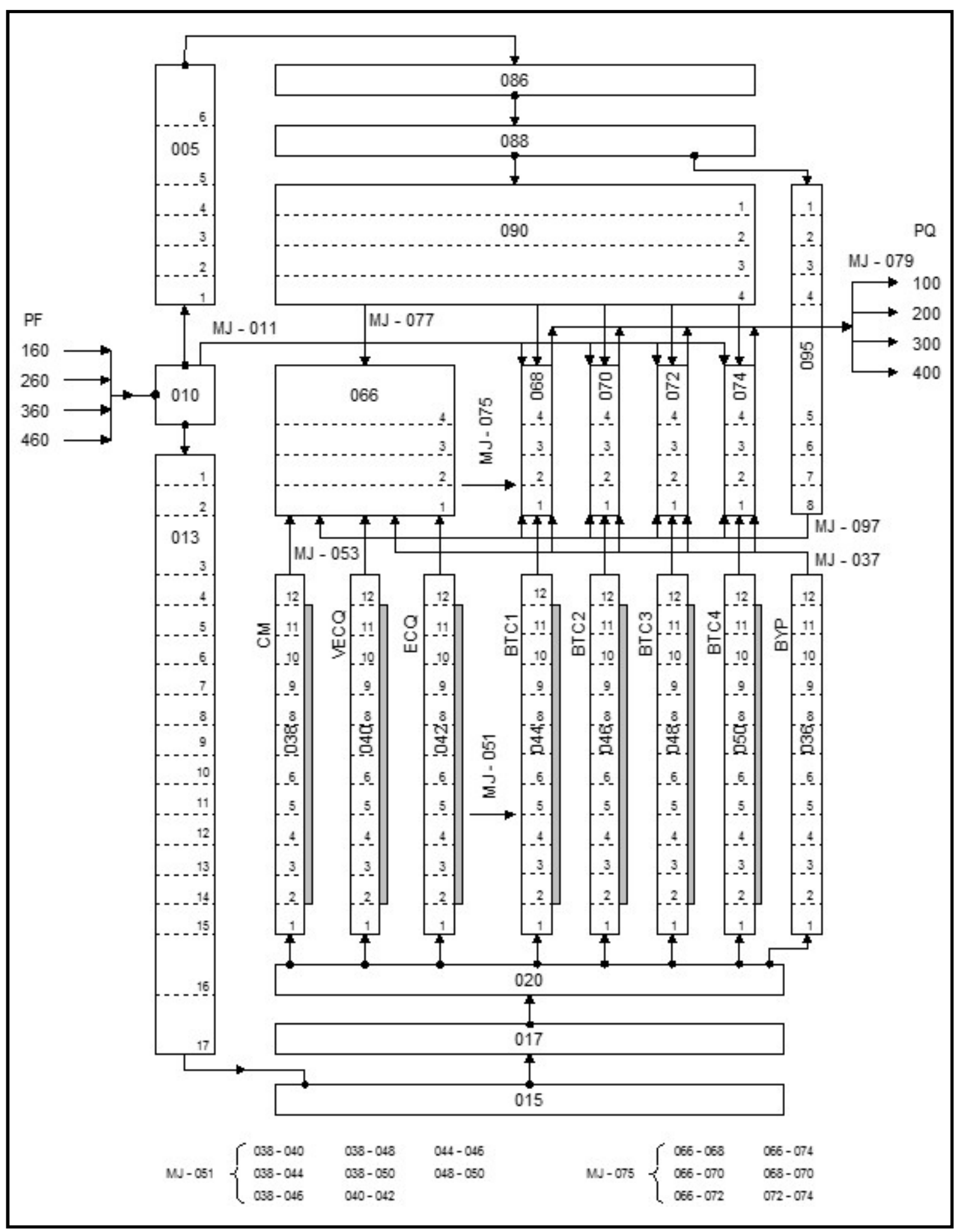

FIGURA AB4 - Esquema de nodalização do vaso de pressão de Angra 2 (axial) 


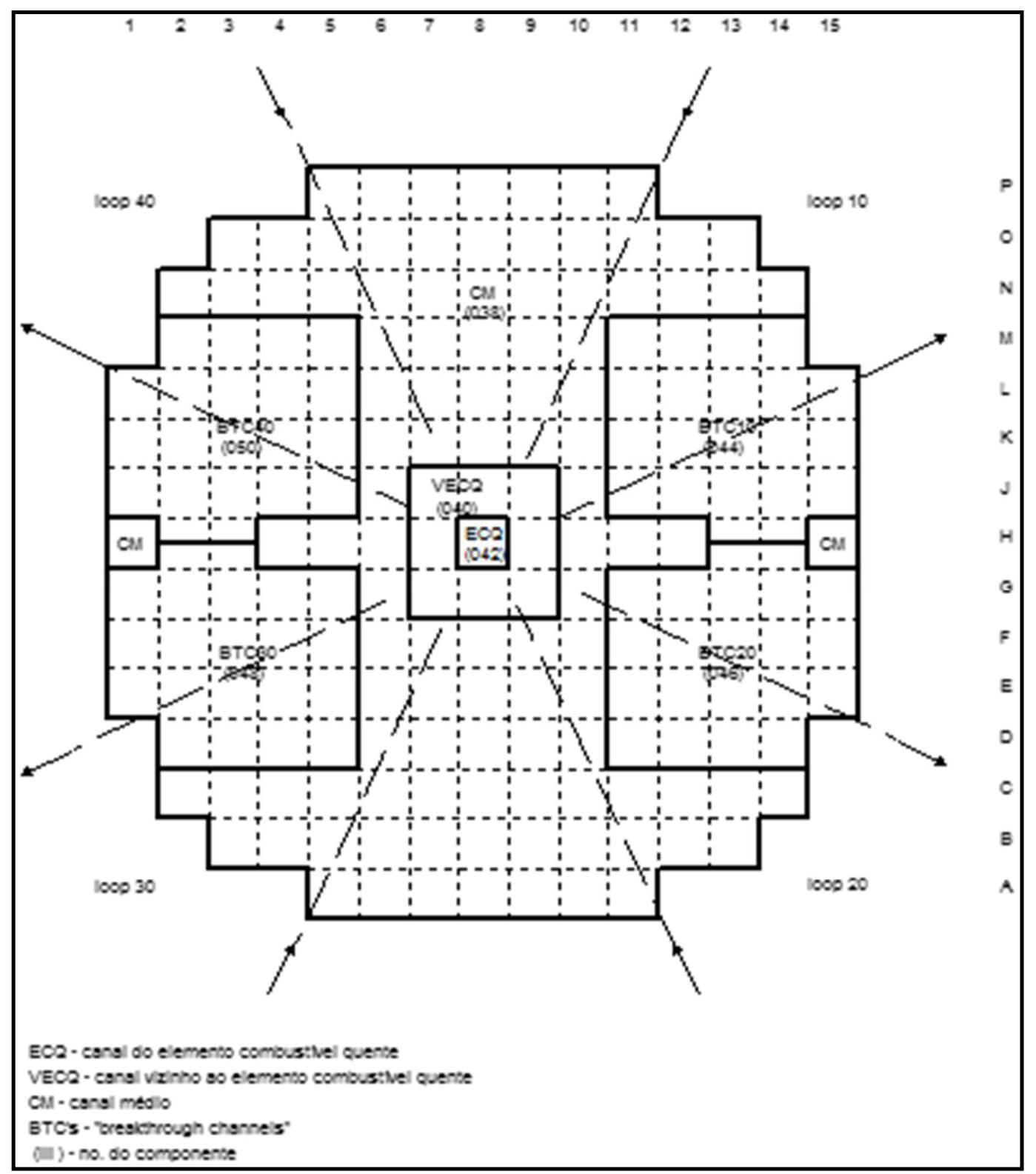

FIGURA AB5 - Nodalização do núcleo do reator Angra 2 (radial) 
TABELA AB1 - Correspondência dos componentes do código e a divisão nodal

\begin{tabular}{|c|c|c|c|c|}
\hline Trecho da Planta & \multicolumn{2}{|c|}{ Região Hidráulica } & № do componente & Tipo do componente \\
\hline \multirow{3}{*}{$\begin{array}{l}\text { Circuito 20 } \\
\text { (Circuito 10) } \\
\text { (Circuito 30) } \\
\text { (Circuito 40) }\end{array}$} & \multirow{3}{*}{ Tubulação } & $\begin{array}{c}\text { Perna Quente } \\
\\
\text { Perna Fria } \\
\text { GV(20)/Bomba(20) }\end{array}$ & $\begin{array}{c}200 \\
(100,300,400) \\
205 \\
(105,305,405) \\
210 \\
(110,310,410) \\
240 \\
(140,340,440) \\
\end{array}$ & $\begin{array}{c}\text { PIPE } \\
\text { BRANCH } \\
\text { PIPE } \\
\text { PIPE }\end{array}$ \\
\hline & & Bomba & $\begin{array}{c}245 \\
(145,345,445)\end{array}$ & PUMP \\
\hline & & $\begin{array}{c}\text { Perna Fria } \\
\text { Bomba(20)/Vaso do } \\
\text { Reator }\end{array}$ & $\begin{array}{c}250 \\
(150,350,450) \\
255 \\
(155,355,455) \\
260 \\
(160,360,460) \\
\end{array}$ & $\begin{array}{c}\text { PIPE } \\
\text { BRANCH } \\
\text { PIPE }\end{array}$ \\
\hline \multirow{3}{*}{ Pressurizador } & \multicolumn{2}{|c|}{ Linha do surto do pressurizador } & 900 & PIPE \\
\hline & \multicolumn{2}{|c|}{ Vaso do pressurizador } & $\begin{array}{l}903 \\
906 \\
910 \\
914 \\
915\end{array}$ & $\begin{array}{c}\text { PIPE } \\
\text { BRANCH } \\
\text { PIPE } \\
\text { BRANCH } \\
\text { BRANCH }\end{array}$ \\
\hline & \multicolumn{2}{|c|}{ Linha de alívio } & $\begin{array}{l}917 \\
920\end{array}$ & $\begin{array}{l}\text { VALVE } \\
\text { TMDPVOL }\end{array}$ \\
\hline Vaso do Reator & \multicolumn{2}{|c|}{ Todos os internos } & $1-99$ & PIPE E BRANCH \\
\hline $\begin{array}{l}\text { Geradores de } \\
\text { Vapor }\end{array}$ & \multicolumn{2}{|c|}{ Todos os internos } & $\begin{array}{l}500-599 \text { (circuito 10) } \\
600-699 \text { (circuito 20) } \\
700-799 \text { (circuito 30) } \\
800-899 \text { (circuito 40) }\end{array}$ & PIPE e BRANCH \\
\hline
\end{tabular}




\section{ANEXO C - Resultados da simulação da planta inteira}

Os resultados da simulação da planta inteira, utilizados como condição de contorno para a simulação das condições da contenção, são apresentados a seguir (Sabundjian, 2016).

\section{C.1 Simulação do LBLOCA-PF de Angra 2 com RELAP5}

Por meio dos cálculos realizados com o RELAP5, foram obtidos os resultados, conforme as FIG. AC1(a) a AC5(a) e FIG. AC6. Os resultados apresentados nas FIG. AC1(b) a AC5 (b) correspondem às mesmas variáveis, mas foram geradas pelo RFAS/A2.

Na FIG. AC1(a), observa-se que as pressões no circuito primário e no pressurizador caem à metade do valor original nos primeiros segundos do acidente e se estabilizam em menos 40 s, em torno de 2,3bar; enquanto que a pressão do sistema secundário sobe ligeiramente, logo após a ruptura, e se mantem praticamente constante, por volta de 67,5bar. A repentina queda da pressão era prevista, pois quando há uma grande ruptura na tubulação do primário, a despressurização é praticamente instantânea. Comparando a FIG. AC1(a) com o resultado do RFAS/A2, FIG. AC1(b), pode-se notar que a queda de pressão do sistema primário, acontece mais rapidamente com o RELAP5, de 161,1bar a 72,7 bar em 1s, do que no FSAR/A2. No entanto, o comportamento da pressão do pressurizador obtida do RFAS/A2, FIG. AC1(b), é similar ao do RELAP5, FIG. $\mathrm{AC1}(\mathrm{a})$, e se estabilizam em torno de 3bar, aproximadamente.

$\mathrm{Na}$ FIG. AC2(a), verifica-se que o primeiro pico de temperatura do encamisamento na parte inferior do elemento mais quente do reator é de $848^{\circ} \mathrm{C}$ e o segundo pico é de $594^{\circ} \mathrm{C}$. Observou-se também, que o período em que o elemento permanece aquecido até que a temperatura caia e entre em equilíbrio com a contenção é de 100s. No entanto, na FIG. AC2(b) é mostrado que o primeiro pico de temperatura está em torno de $670^{\circ} \mathrm{C}$ e o segundo pico, por volta de $570^{\circ} \mathrm{C}$ para a mesma região do núcleo analisada. Além disso, o período em que a vareta fica aquecida, até que a temperatura caia e entre em equilíbrio térmico, é bem menor, 
por volta de 50 s, enquanto que no caso do RELAP5 é de mais de $100 \mathrm{~s}$. Em ambos os casos, as temperaturas se estabilizam em $130^{\circ} \mathrm{C}$, aproximadamente. Embora tenha ocorrido uma razoável diferença no comportamento entre as duas simulações, com RELAP5 e o RFAS/A2, os valores de temperaturas atingidos nesse trabalho são superiores aos encontrados no RFAS, mas ambos os casos, ficaram bem abaixo da temperatura de fusão do zircaloy, que é de $1200^{\circ} \mathrm{C}$.

A FIG. AC3(a) demonstra que o primeiro pico de temperatura do encamisamento na parte superior do elemento mais quente do reator é de $967^{\circ} \mathrm{C}$ e o segundo pico é de $667^{\circ} \mathrm{C}$, e, embora sejam superiores aos valores da parte inferior, também estão bem abaixo do ponto de fusão do zircaloy. Neste caso, o período em que o elemento fica aquecido até entrar em equilíbrio térmico, $137^{\circ} \mathrm{C}$, é de 100s. Os picos de temperatura alcançados no RFAS/A2 no mesmo ponto, além de serem menores - primeiro pico $780^{\circ} \mathrm{C}$ e o segundo de $920^{\circ} \mathrm{C}$ - o período em que o elemento permanece quente é um pouco superior do que no da parte inferior do elemento mais quente, por volta de 75s, conforme FIG. AC3(b). Além disso, no RFAS/A2 o maior pico de temperatura ocorre na fase de remolhamento, enquanto que no caso simulado com o RELAP5, o pico maior de temperatura ocorre na fase de despressurização.

A FIG. AC4(a) demonstra que as vazões mássicas nas rupturas, uma pelo lado da bomba, válvulas 951, e a e outra pelo lado do vaso de pressão, válvula 952, se diferem. O pico de vazão da ruptura pelo lado do vaso é superior em relação ao pico do lado da bomba, $30,7 \times 10^{3} \mathrm{~kg} / \mathrm{s}$ e $24 \times 10^{3} \mathrm{~kg} / \mathrm{s}$, respectivamente. Os valores correspondentes do RFAS/A2, FIG. AC4(b), tem o mesmo comportamento, ou seja, o pico maior também é pela ruptura do lado do vaso de pressão, $27 \times 10^{3} \mathrm{~kg} / \mathrm{s}$, mas o pico de vazão da quebra pelo lado da bomba é bem menor, por volta de $13 \times 10^{3} \mathrm{~kg} / \mathrm{s}$. Em ambas as curvas da FIG. AC.4(a) nota-se que, elas se aproximam aos 10s, enquanto que na FIG. AC4(b), essa diferença é considerável, e só ficam próximas após 30s do início do acidente. Por outro lado, a vazão mássica na válvula 952, FIG.

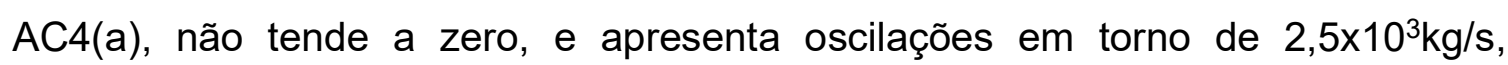
mostrando que ainda há fluido refrigerante no núcleo. Por outro lado, para o RFAS/A2, FIG. AC4(b), ambas as vazões mássicas tendem a zero. 
A pressão na contenção calculada com o RELAP5, FIG. AC5(a), tem o valor máximo de 2,39bar aos 36,3 s e se estabiliza em torno de 2,33bar. A FIG. AC5(b) mostra que a pressão na contenção obtida pelo RFAS/A2 tem um pico de 3,2 bar em 25 s e entra em equilíbrio térmico com o primário por volta de 2 bar.

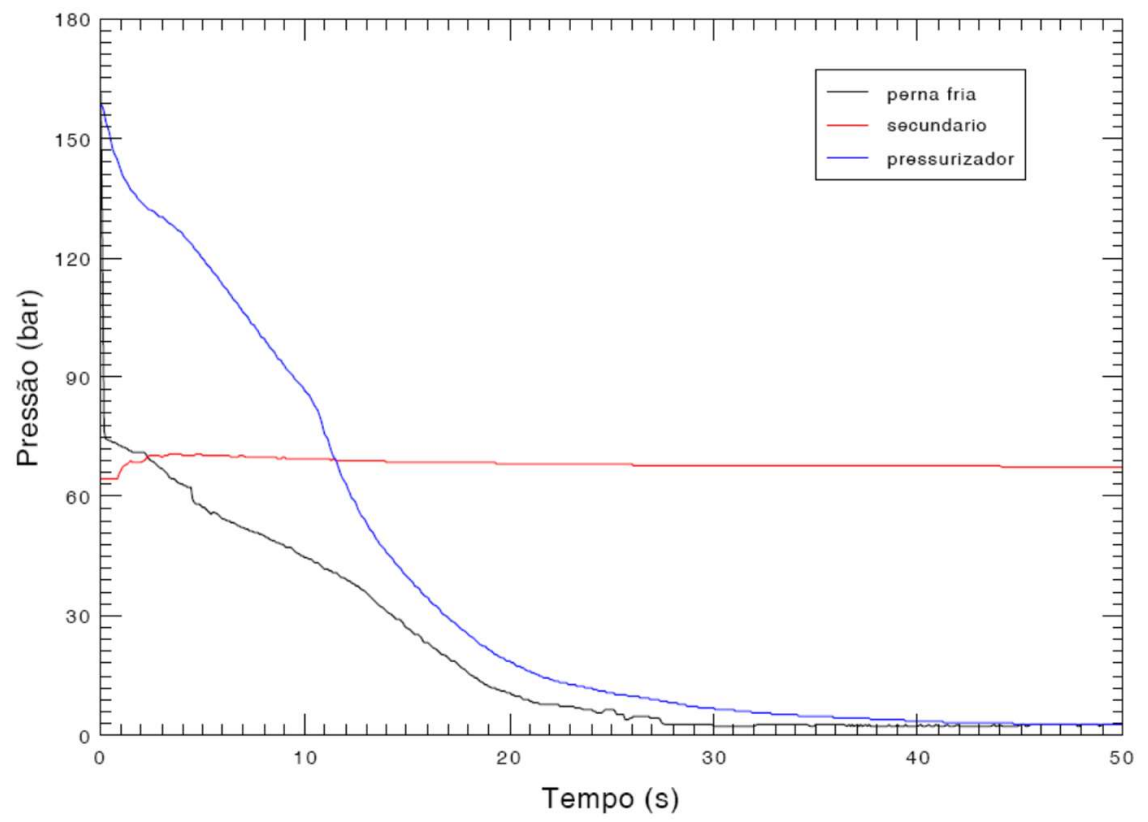

FIGURA AC1(a) - Pressões no lado primário, secundário e no pressurizador LBLOCA-PF com RELAP5 


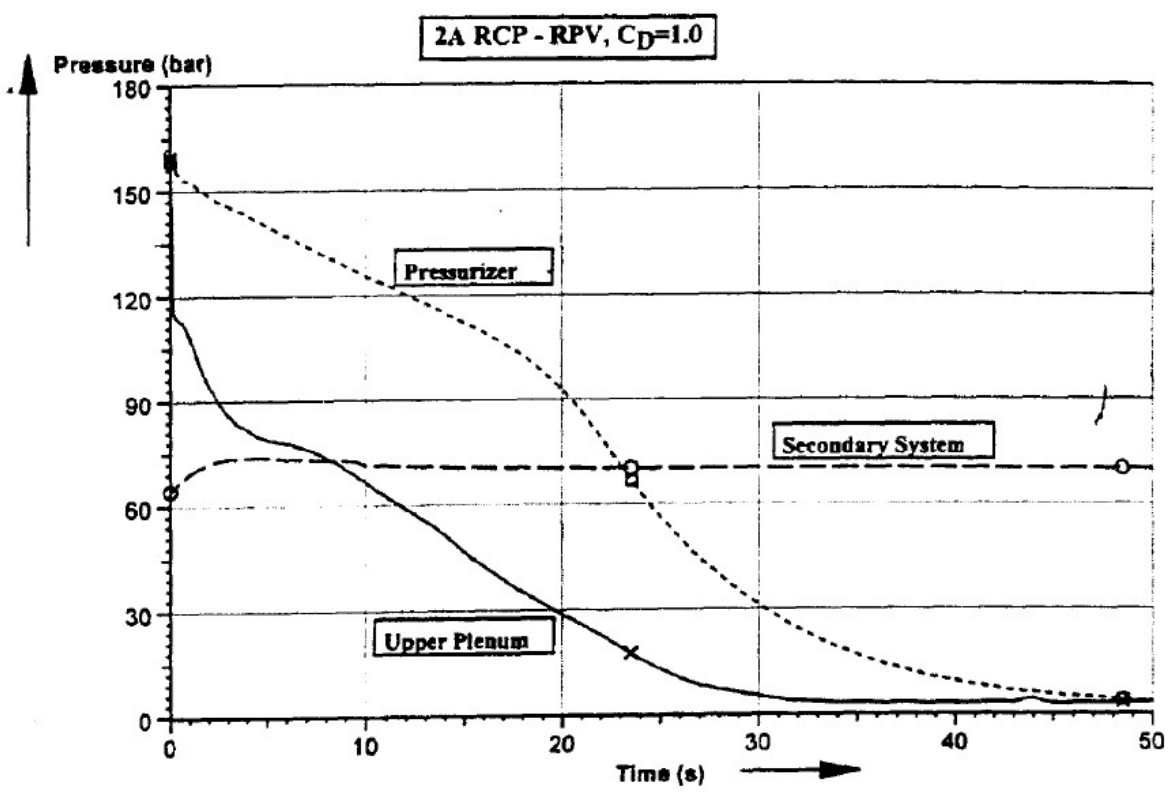

FIGURA AC1(b) - Pressões no lado primário, secundário e no pressurizador LBLOCA-PF do RFAS/A2

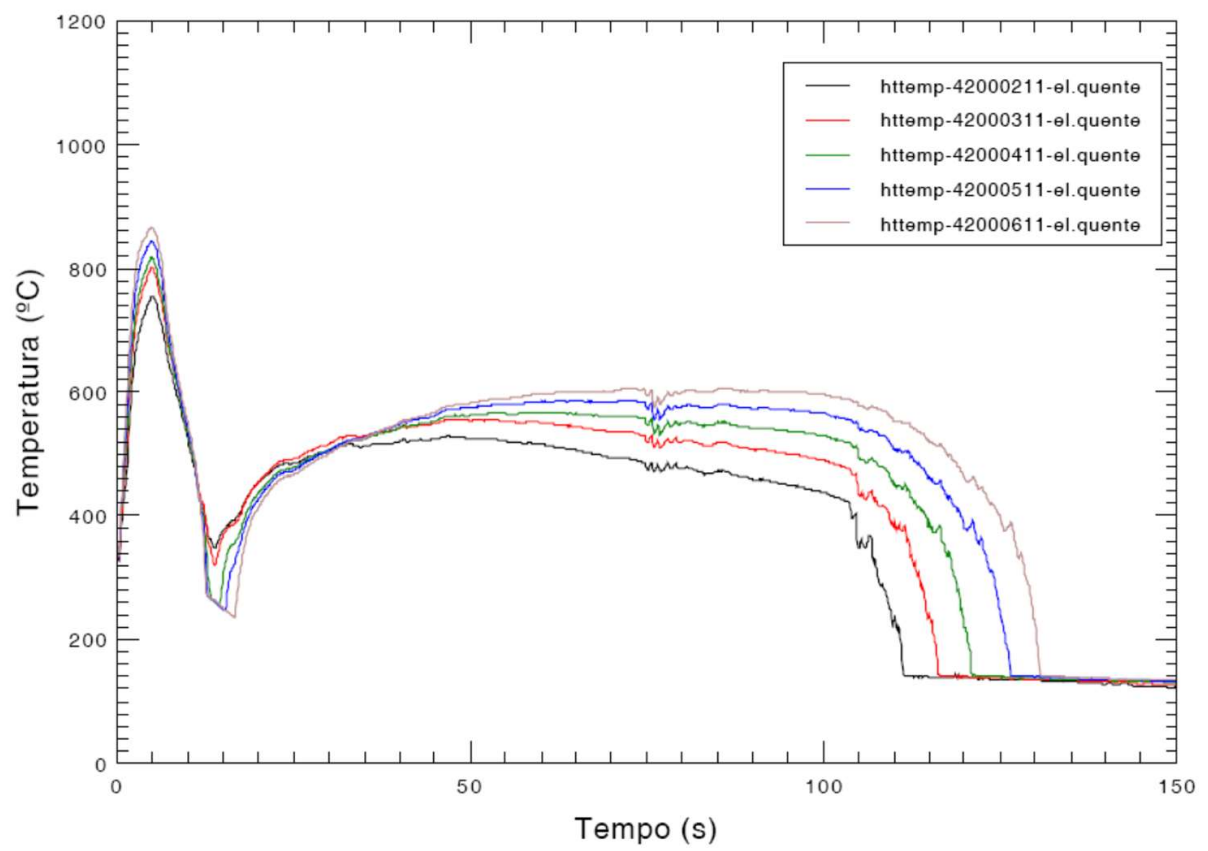

FIGURA AC2(a) - Primeiro e segundo picos de temperatura na parte inferior do elemento mais quente do reator Angra 2 - LBLOCA-PF com RELAP5 


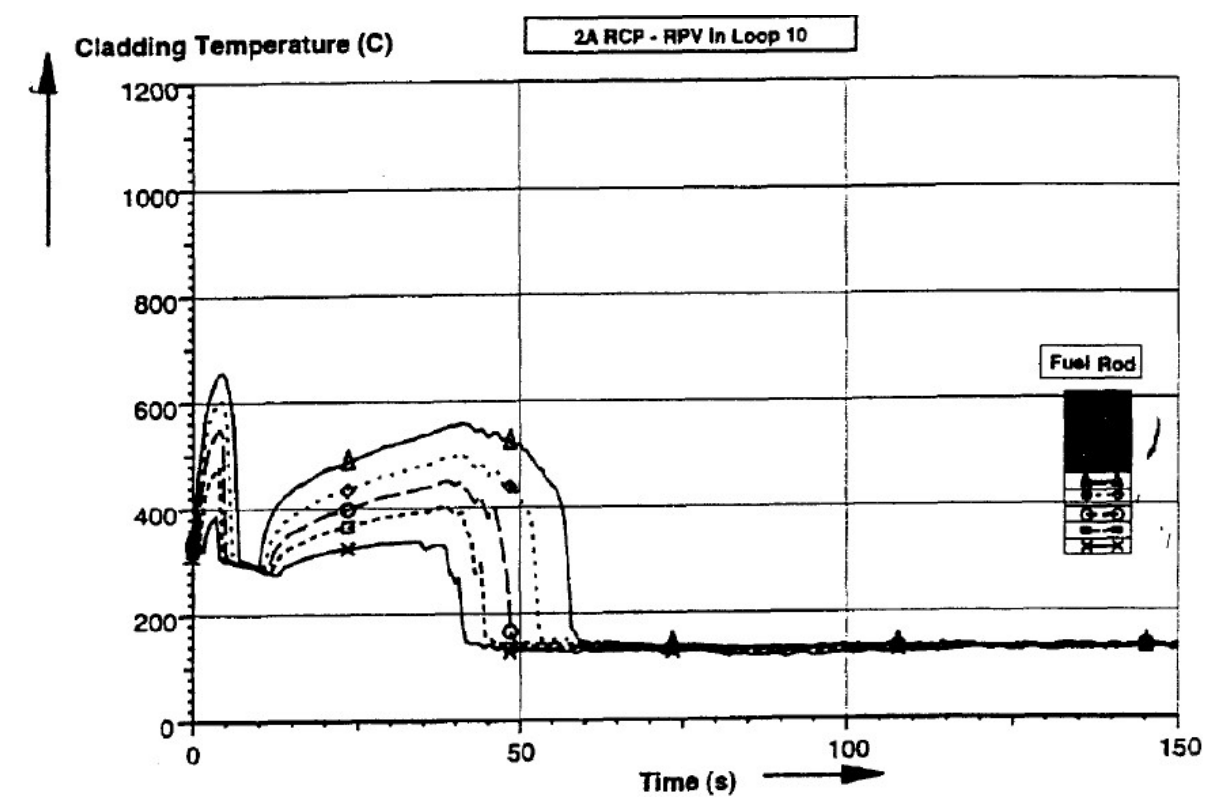

FIGURA AC2(b) - Primeiro e segundo picos de temperatura do encamisamento na parte inferior do elemento mais quente do reator Angra 2 - LBLOCA-PF do RFAS/A2

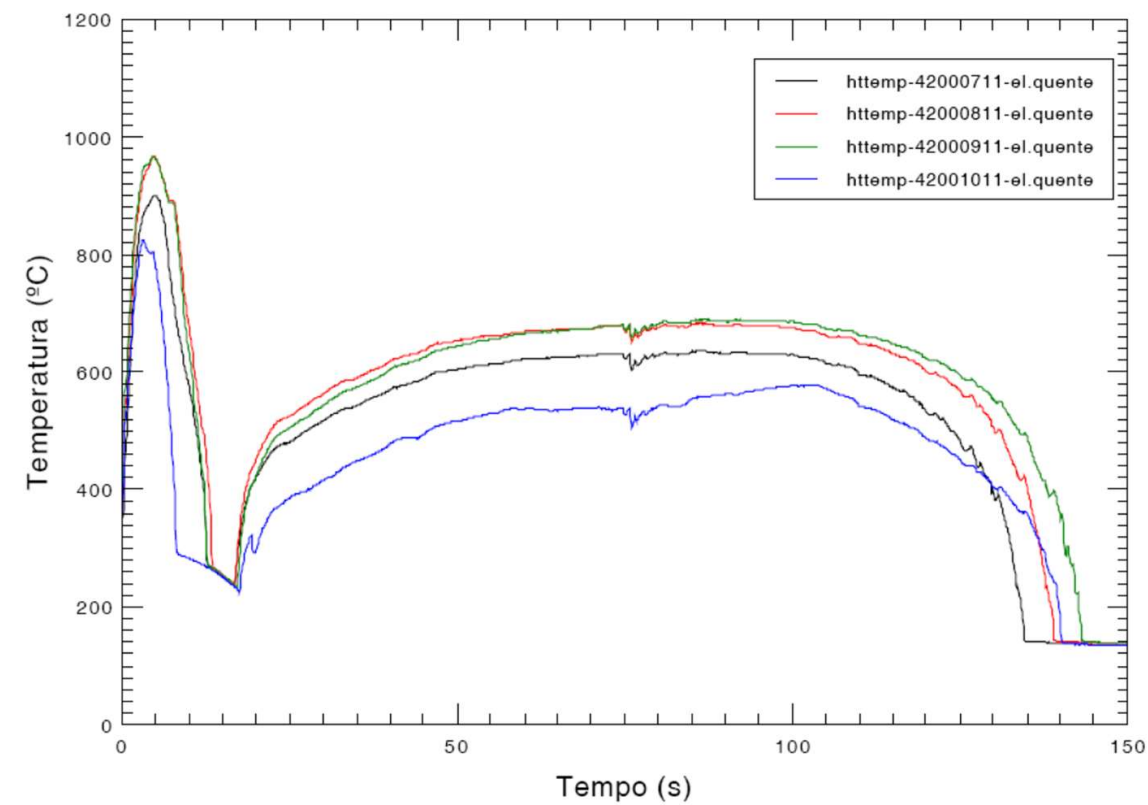

FIGURA AC3(a) - Primeiro e segundo picos da temperatura do encamisamento na parte superior do elemento mais quente do reator Angra 2 - LBLOCA-PF com RELAP5 


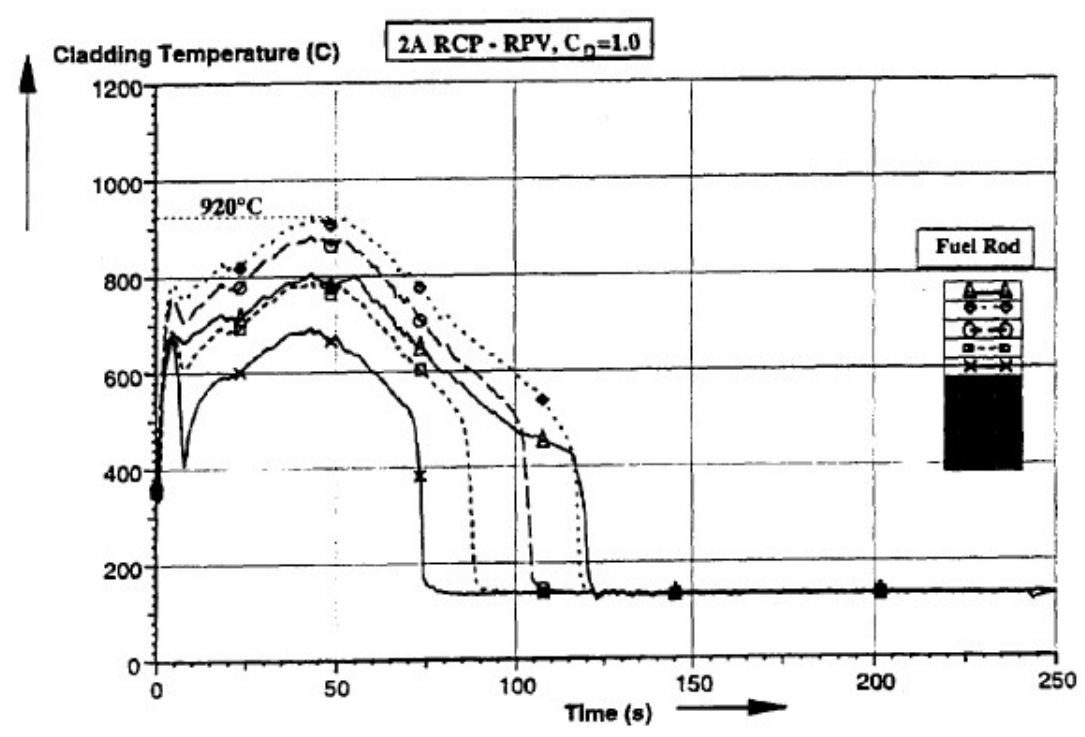

FIGURA AC3(b) - Primeiro e segundo pico de temperatura na do encamisamento parte superior do elemento mais quente do reator Angra 2 - LBLOCA-PF do RFAS/A2

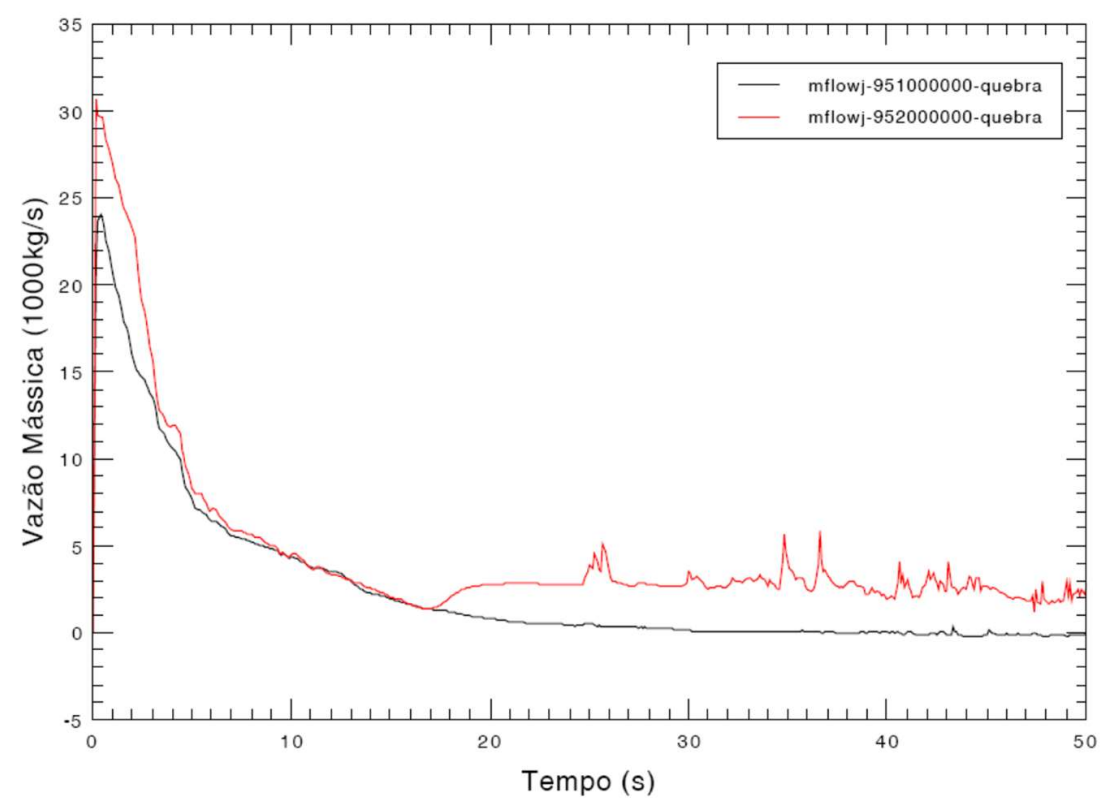

FIGURA AC4(a) - Vazão mássica na ruptura da tubulação do primário de Angra 2 - LBLOCA-PF com RELAP5 


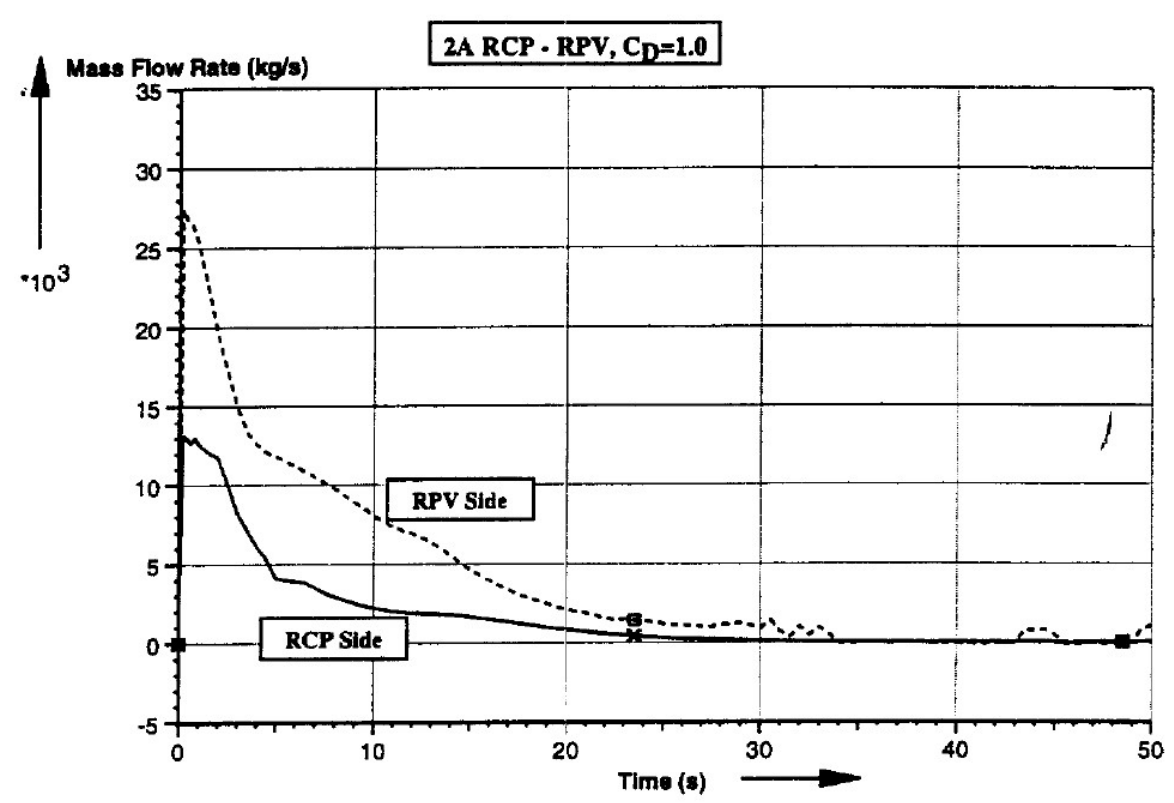

FIGURA AC4(b) - Vazão mássica na ruptura da tubulação do primário de Angra 2 - LBLOCA-PF do RFAS/A2

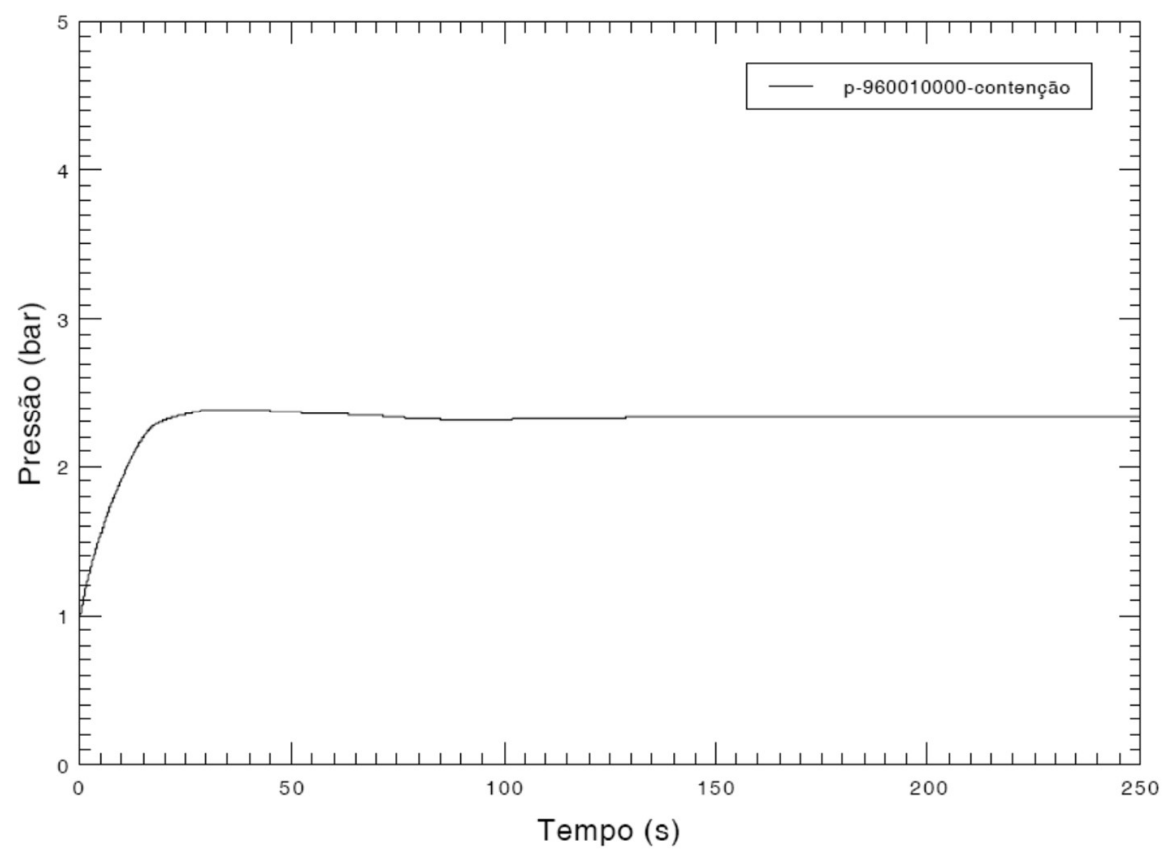

FIGURA AC5(a) - Pressão na contenção de Angra 2 - LBLOCA-PF com RELAP5 


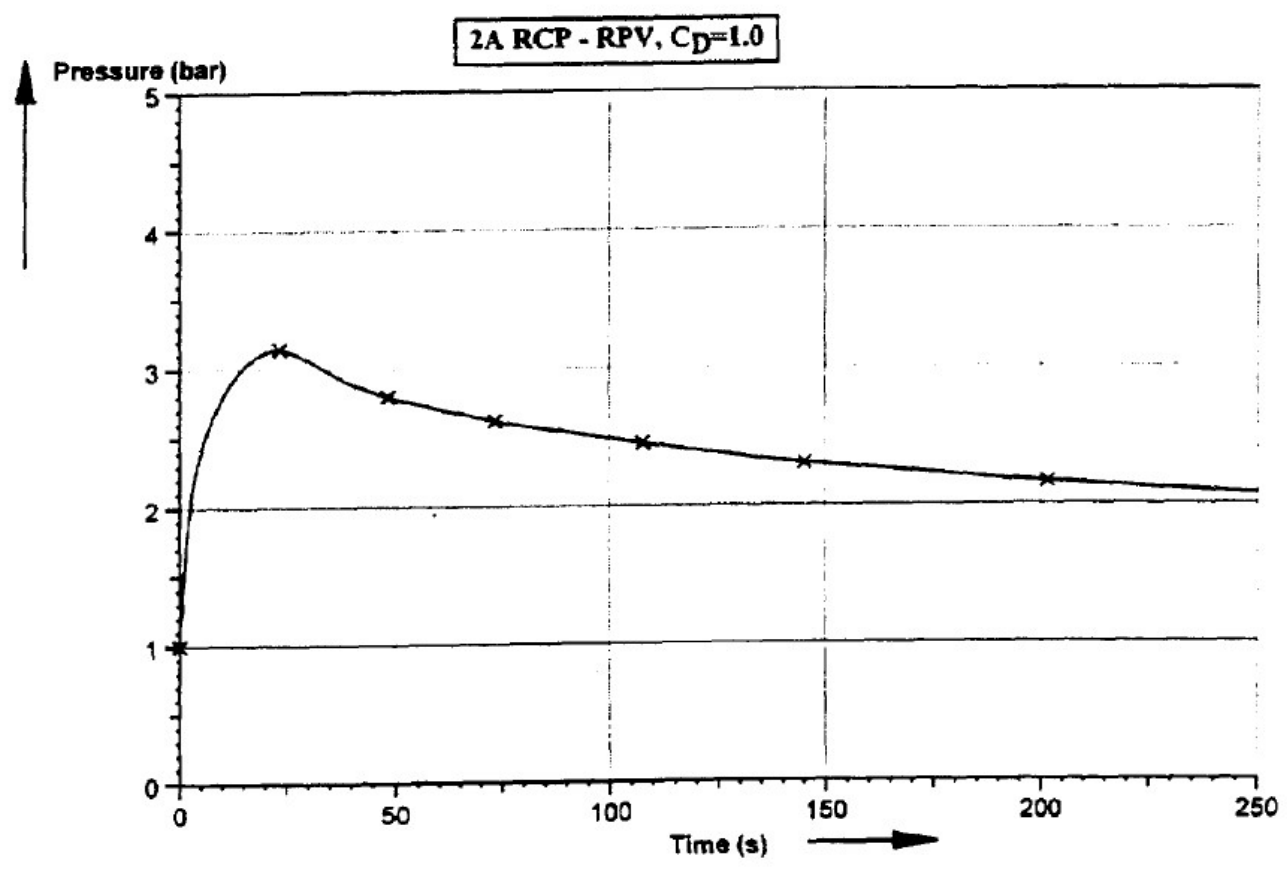

FIGURA AC5(b) - Pressão na contenção de Angra 2 - LBLOCA-PF do RFAS/A2

A FIG. AC6 apresenta as temperaturas do líquido e do vapor dentro da contenção. Ambas as temperaturas estão em $34^{\circ} \mathrm{C}$ no instante da ruptura, pois se encontravam em regime permanente, e sobem rapidamente até $104^{\circ} \mathrm{C}$, em $20 \mathrm{~s}$, e se estabilizam em torno deste valor. 


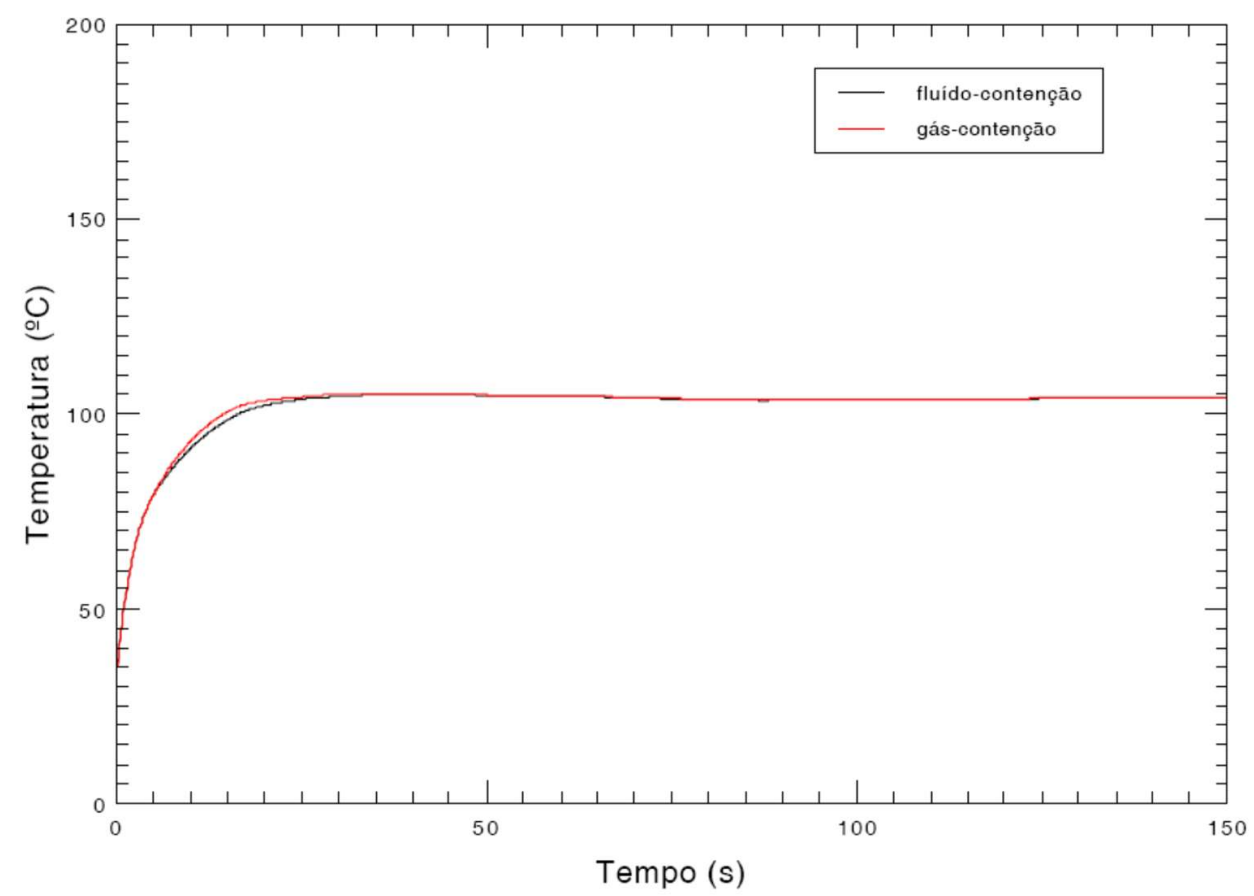

FIGURA AC6 - Temperatura na contenção de Angra 2 - LBLOCA-PF com RELAP5

\section{C.2 Simulação do LBLOCA-PI de Angra 2 com RELAP5}

Por meio dos cálculos realizados com o RELAP5, foram obtidos os seguintes resultados, conforme FIG. AC7(a) a $A C 11(a)$ e a FIG. AC12. São apresentadas também as $\mathrm{FIG}$. $\mathrm{AC7}$ (b) a $\mathrm{AC} 11(\mathrm{~b})$, que correspondem às mesmas variáveis, mas que foram geradas pelo RFAS/A2.

$\mathrm{Na}$ FIG. AC7(a), observa-se que as pressões no primário e no pressurizador caem à metade do valor original nos primeiros segundos do acidente e se estabilizam em menos 50 s, em torno de 3bar; enquanto que a pressão do sistema secundário sobe ligeiramente logo após a ruptura e se mantém praticamente constante, por volta de 70 bar. A repentina queda da pressão era prevista, pois quando há uma grande ruptura na tubulação do primário, a despressurização é praticamente instantânea. Comparando a FIG. AC7(a) com o 
resultado do RFAS/A2, FIG. AC7(b), pode-se notar que a queda de pressão do sistema primário é mais rápida com o RELAP5, de 161,1 a 72,7bar em 9s, sendo que no FSAR/A2, essa atinge este valor após 15s. No entanto, o comportamento da pressão do pressurizador obtida do RFAS/A2, FIG. AC7(b), é similar ao do RELAP5, FIG. AC1(a), e se estabiliza em torno de 70bar, aproximadamente.

$\mathrm{Na}$ FIG. AC8(a), verifica-se que o primeiro pico de temperatura do encamisamento na parte inferior do elemento mais quente do reator é de $347^{\circ} \mathrm{C}$ e o segundo pico é de $577^{\circ} \mathrm{C}$. Observou-se, também, que o período em que o elemento permanece aquecido até que a temperatura caia e entre em equilíbrio com a contenção é de 100s. A FIG. AC8(b) demonstra que o primeiro pico de temperatura está em torno de $380^{\circ} \mathrm{C}$ e o segundo pico por volta de $480^{\circ} \mathrm{C}$ para a mesma região do núcleo analisada. Além disso, o período em que a vareta fica aquecida, até que a temperatura caia e entre em equilíbrio térmico, é bem menor, por volta de $50 \mathrm{~s}$. Em ambos os casos, a temperatura se estabiliza em $140^{\circ} \mathrm{C}$, aproximadamente. Embora tenha ocorrido uma razoável diferença no comportamento entre as duas simulações, com RELAP5 e RFAS/A2, os valores de temperaturas atingidos nesse trabalho são superiores aos encontrados no RFAS, mas ambos ficaram bem abaixo da temperatura de fusão do zircaloy que é de $1200^{\circ} \mathrm{C}$.

A FIG. AC9(a) demonstra que o primeiro pico de temperatura do encamisamento na parte superior do elemento mais quente do reator é de $614^{\circ} \mathrm{C} \mathrm{e}$ o segundo pico é de $723^{\circ} \mathrm{C}$, e, embora sejam superiores aos valores da parte inferior, também estão bem abaixo do ponto de fusão do zircaloy. Neste caso, o período em que o elemento fica aquecido até entrar em equilíbrio térmico, $140^{\circ} \mathrm{C}$, é de 140s. Os picos de temperatura alcançados no RFAS/A2 no mesmo ponto, além de serem menores - primeiro pico $570^{\circ} \mathrm{C}$ e o segundo de $590^{\circ} \mathrm{C}$ - o período em que o elemento permanece quente é um pouco superior do que no da parte inferior do elemento mais quente, por volta de 100s, conforme FIG. AC9(b). Além disso, no RFAS/A2 o maior pico de temperatura ocorre na fase de remolhamento e o mesmo acontece com os resultados obtidos com o RELAP5.

Na FIG. AC10(a), verifica-se que as vazões mássicas nas rupturas, uma pelo lado do gerador de vapor, válvulas 951, e a e outra, pelo lado da bomba, válvula 
952, se diferem. O pico de vazão da ruptura pelo lado do gerador de vapor é superior em relação ao pico do lado da bomba, $16,7 \times 10^{3} \mathrm{~kg} / \mathrm{s}$ e $9,3 \times 10^{3} \mathrm{~kg} / \mathrm{s}$, respectivamente. Os valores correspondentes do RFAS/A2, FIG. AC10(b), têm o mesmo comportamento, ou seja, o pico maior também é pela ruptura do lado do gerador de vapor, $19 \times 10^{3} \mathrm{~kg} / \mathrm{s}$., mas o pico de vazão da quebra pelo lado da bomba é bem menor, por volta de $9 \times 10^{3} \mathrm{~kg} / \mathrm{s}$. Por outro lado, a vazão mássica na válvula 952, FIG.

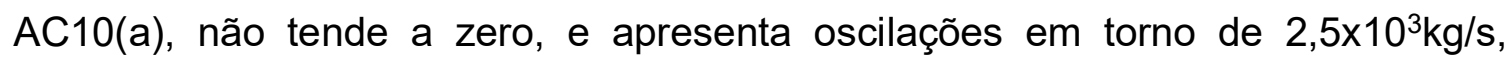
mostrando que ainda há fluido refrigerante no núcleo.

A pressão na contenção, calculada com o RELAP5, FIG. AC11(a), tem o valor máximo de 2,4bar aos $41 \mathrm{~s}$ e se estabiliza em torno de 2,3bar. A FIG. AC11(b) mostra que a pressão na contenção, obtida pelo RFAS/A2, tem um pico de 3,2bar em 25s e entra em equilíbrio térmico com o primário por volta de 2,2bar.

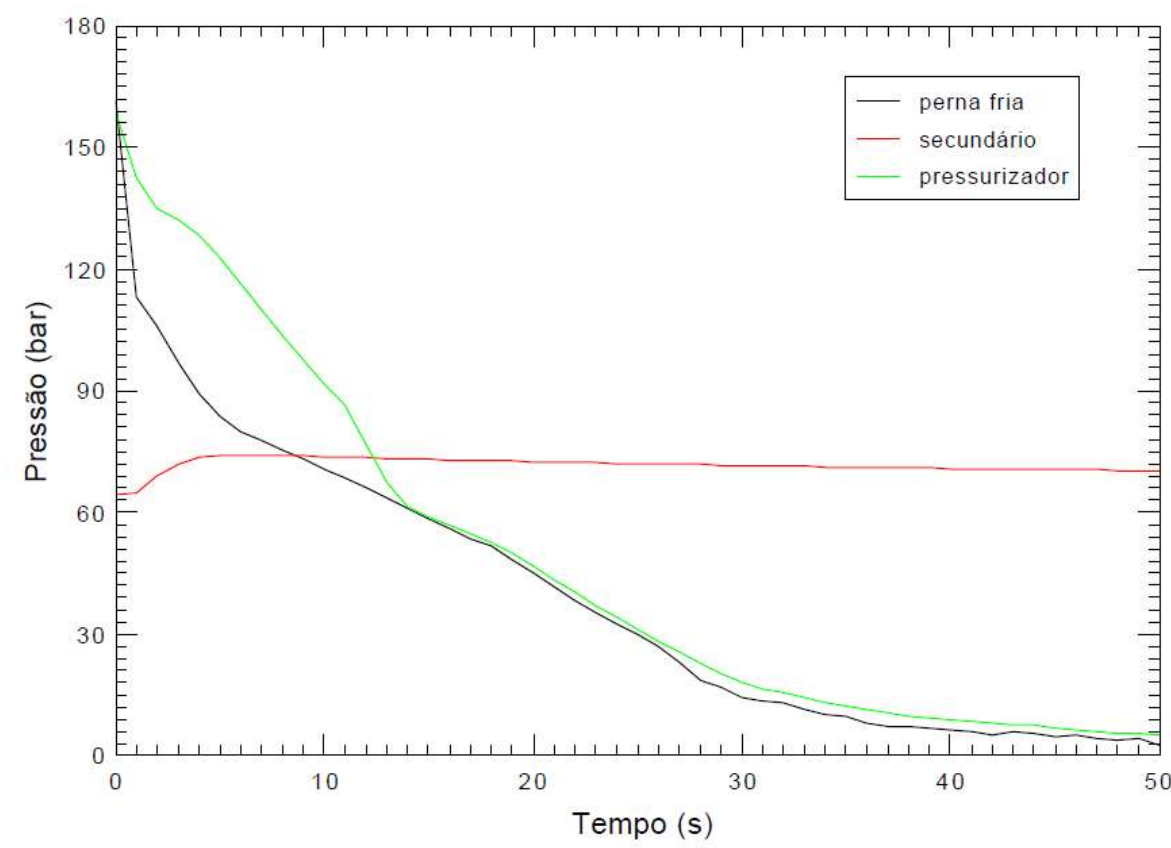

FIGURA AC7(a) - Pressões no lado primário, secundário e no pressurizador LBLOCA-PI com RELAP5 


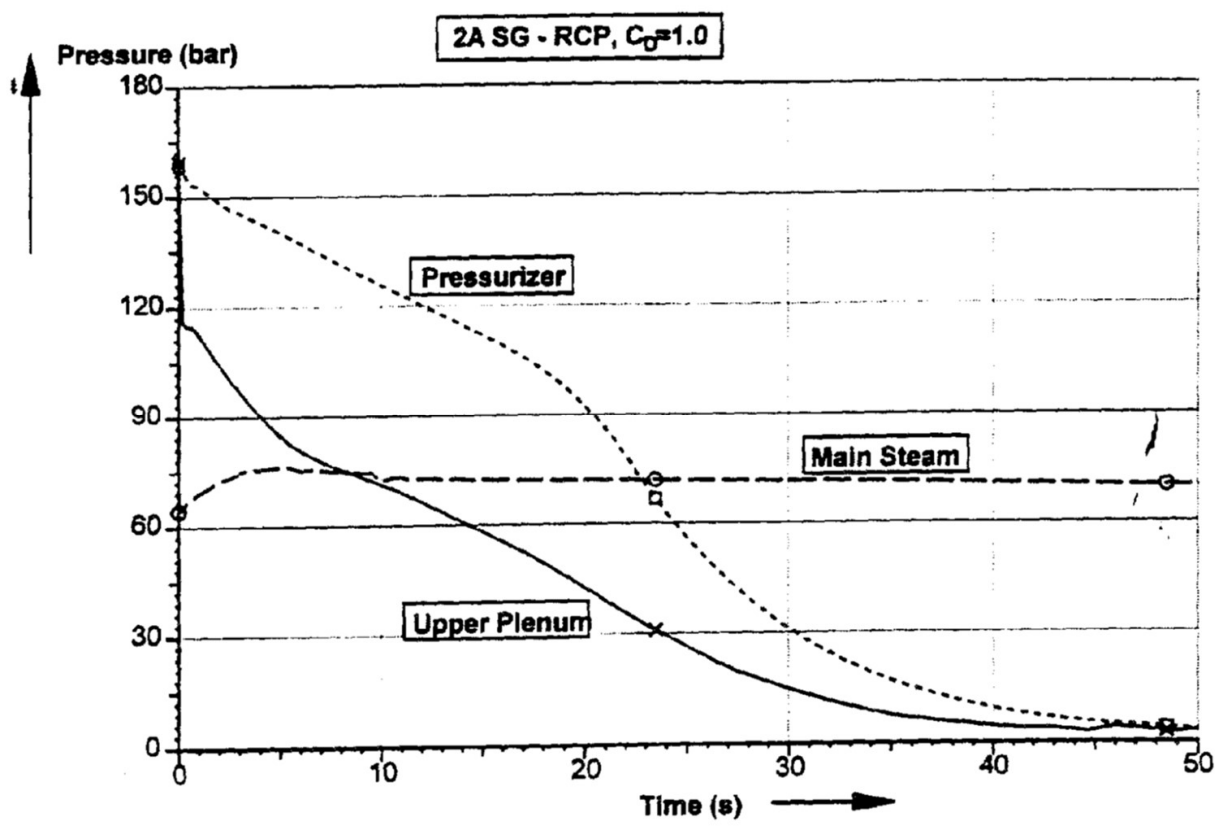

FIGURA AC7(b) - Pressões no lado primário, secundário e no pressurizador LBLOCA-PI do RFAS/A2

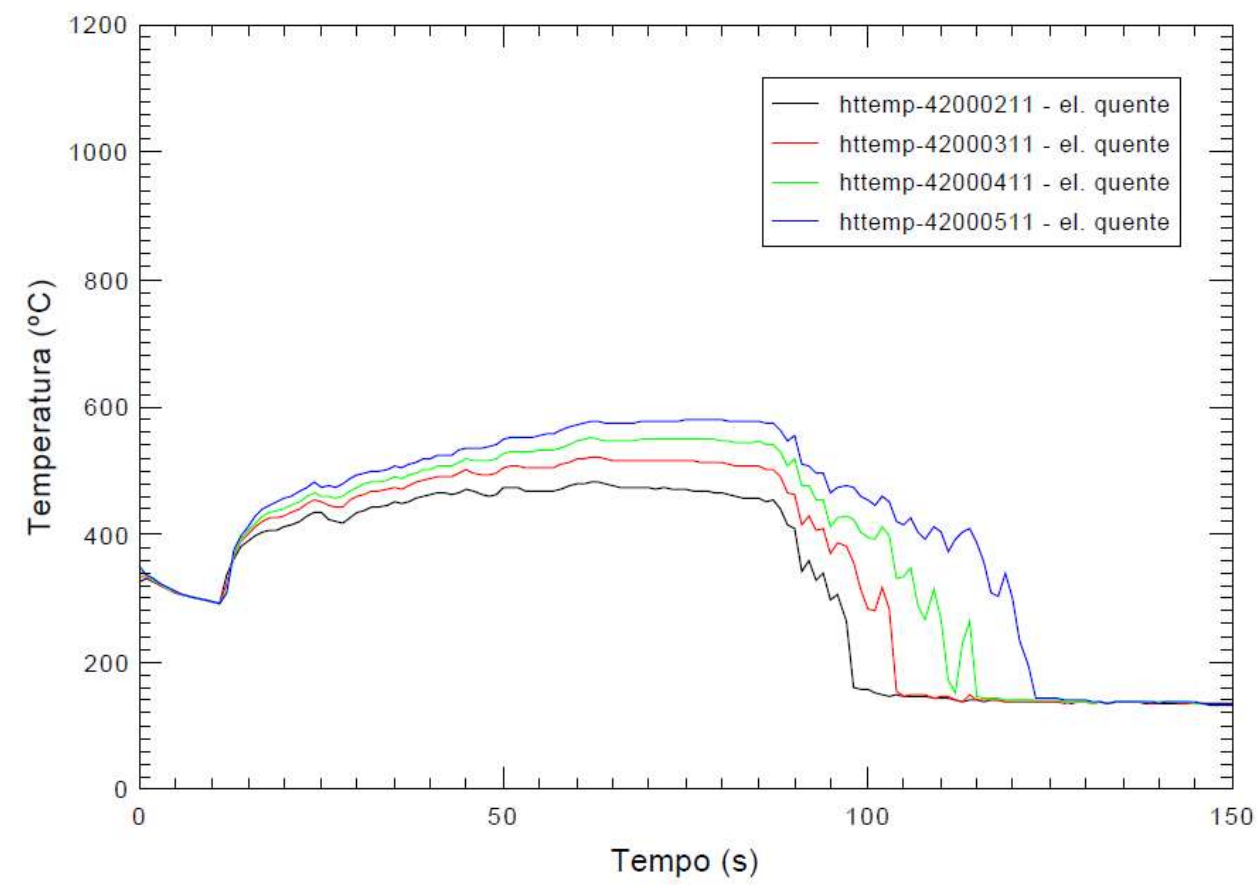

FIGURA AC8(a) - Primeiro e segundo picos de temperatura na parte inferior do elemento mais quente do reator Angra 2 - LBLOCA-PI com RELAP5 


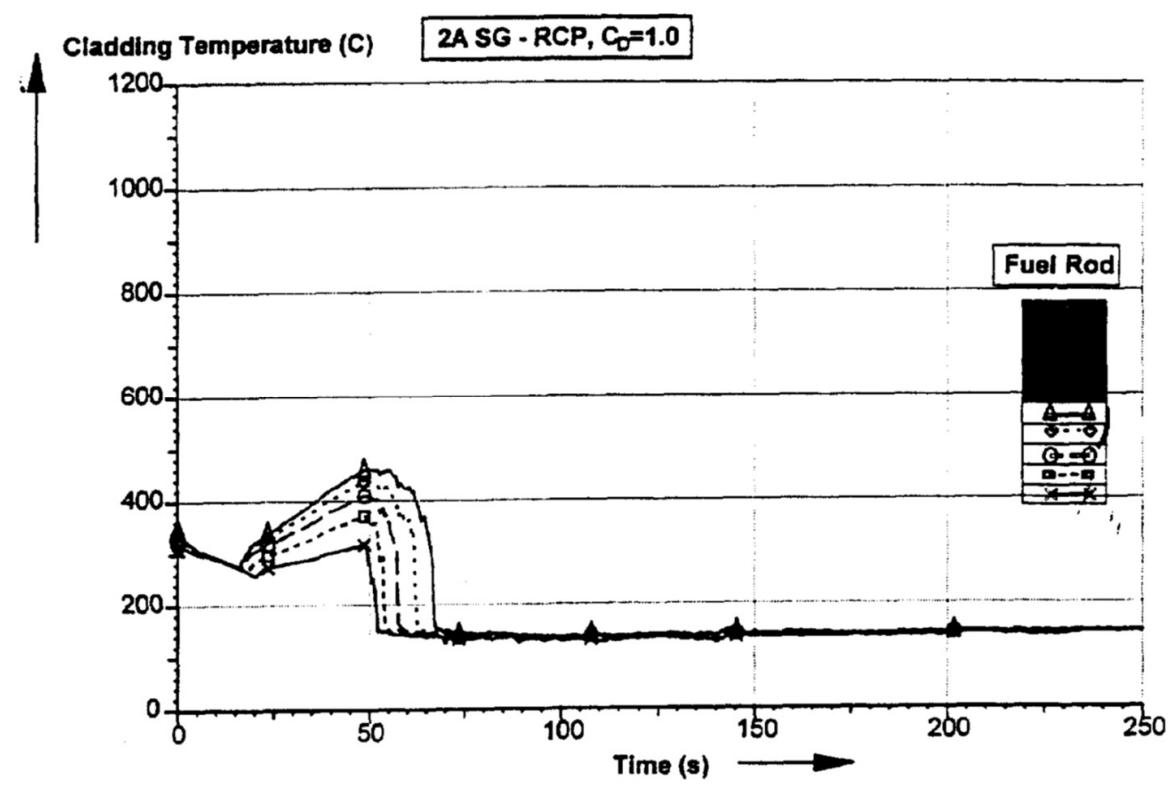

FIGURA AC8(b) - Primeiro e segundo picos de temperatura na parte inferior do elemento mais quente do reator Angra 2 - LBLOCA-PI do RFSA/A2

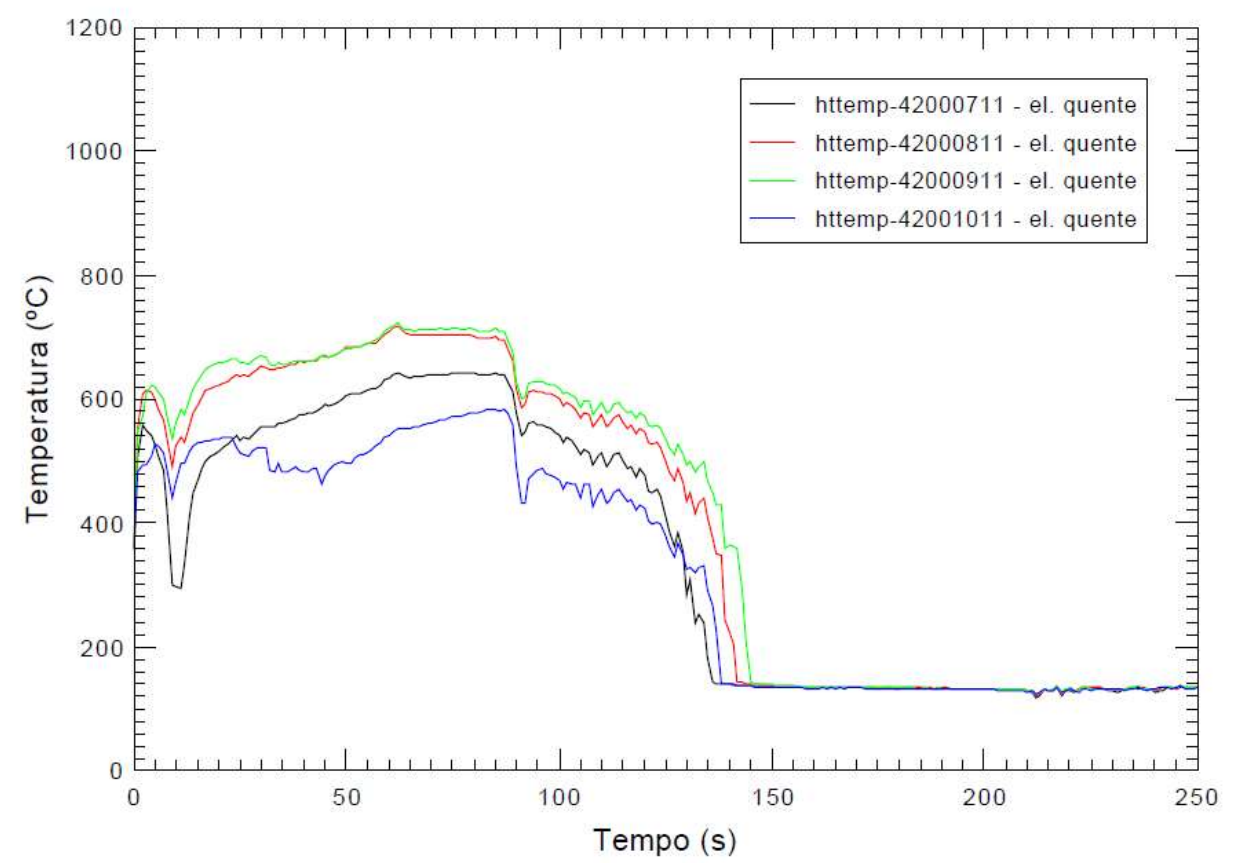

FIGURA AC9(a) - Primeiro e segundo picos da temperatura do encamisamento na parte superior do elemento mais quente do reator Angra 2 - LBLOCA-PI com RELAP5 


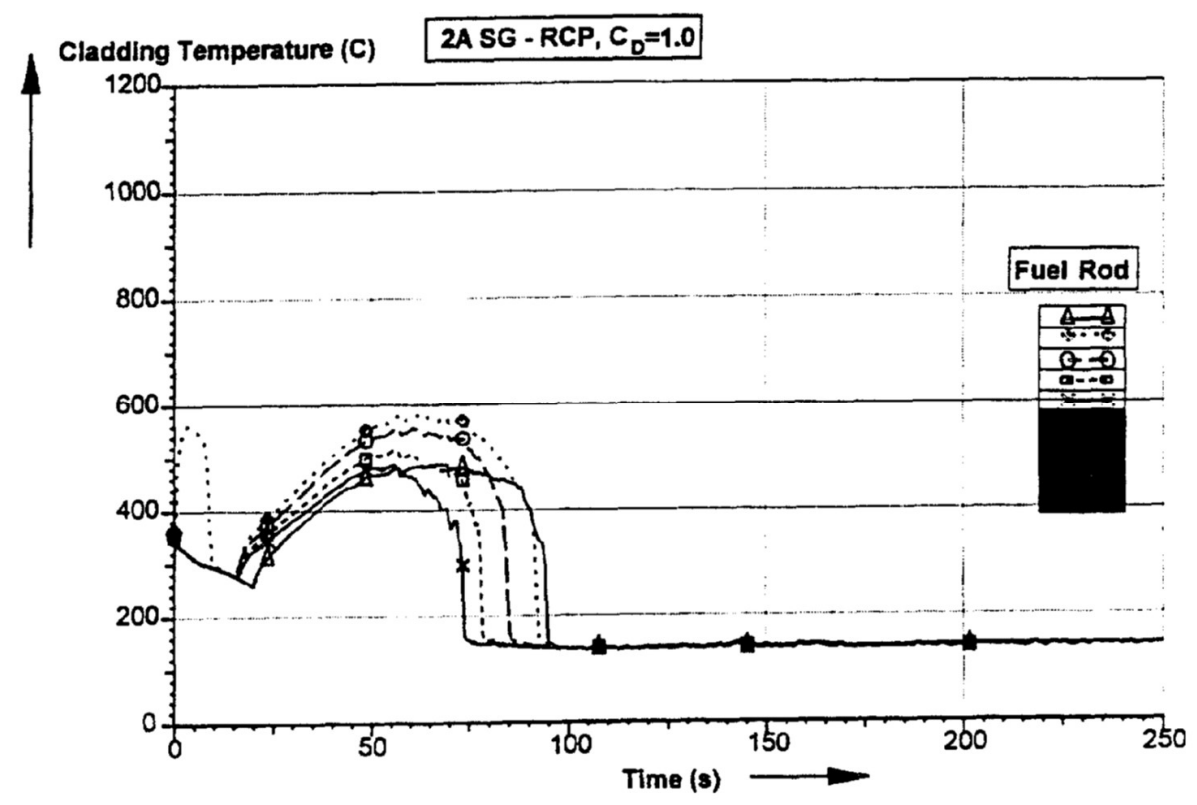

FIGURA AC9(b) - Primeiro e segundo picos da temperatura do encamisamento na parte superior do elemento mais quente do reator Angra 2 - LBLOCA-PI do RFAS/A2

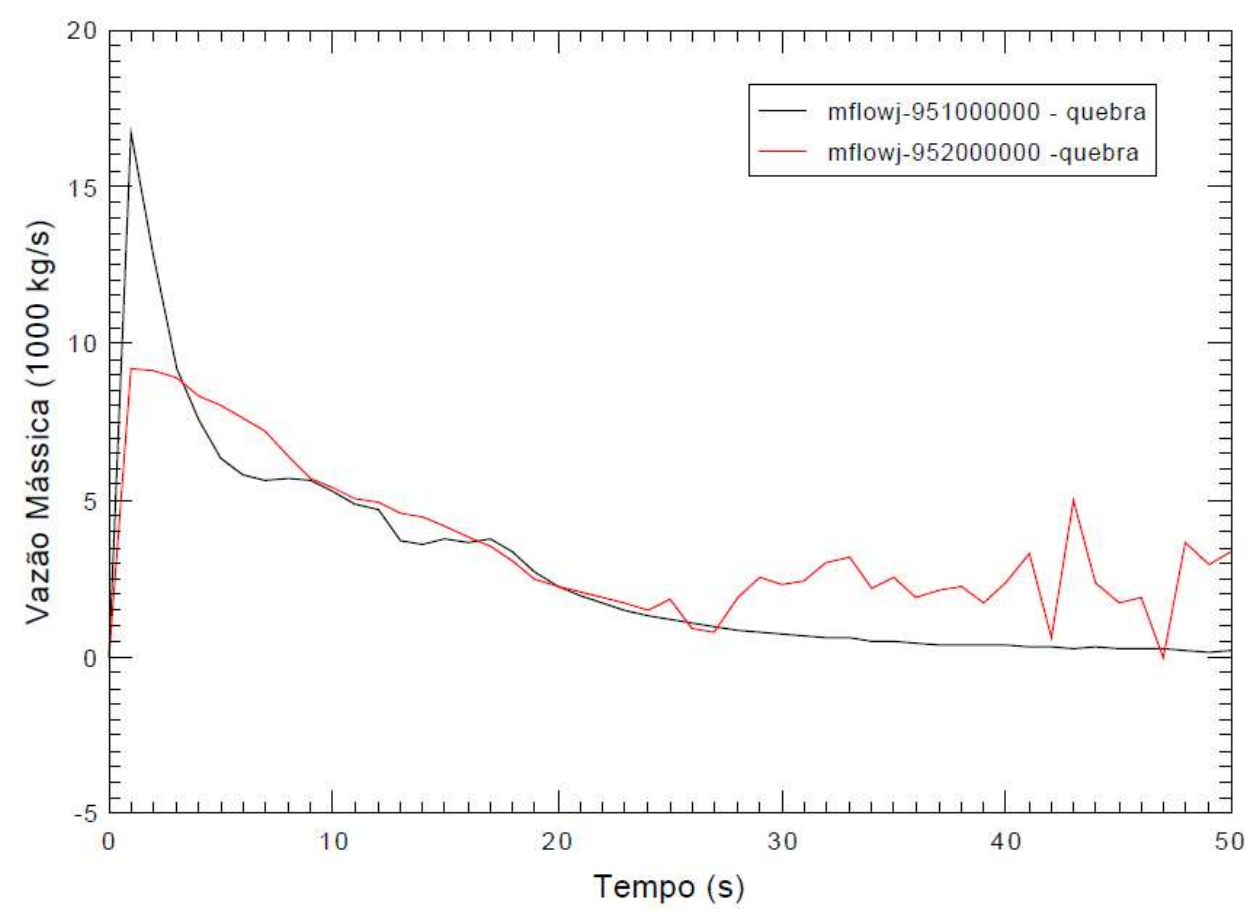

FIGURA AC10(a) - Vazão mássica na ruptura da tubulação do primário de Angra2LBLOCA-PI com RELAP5 


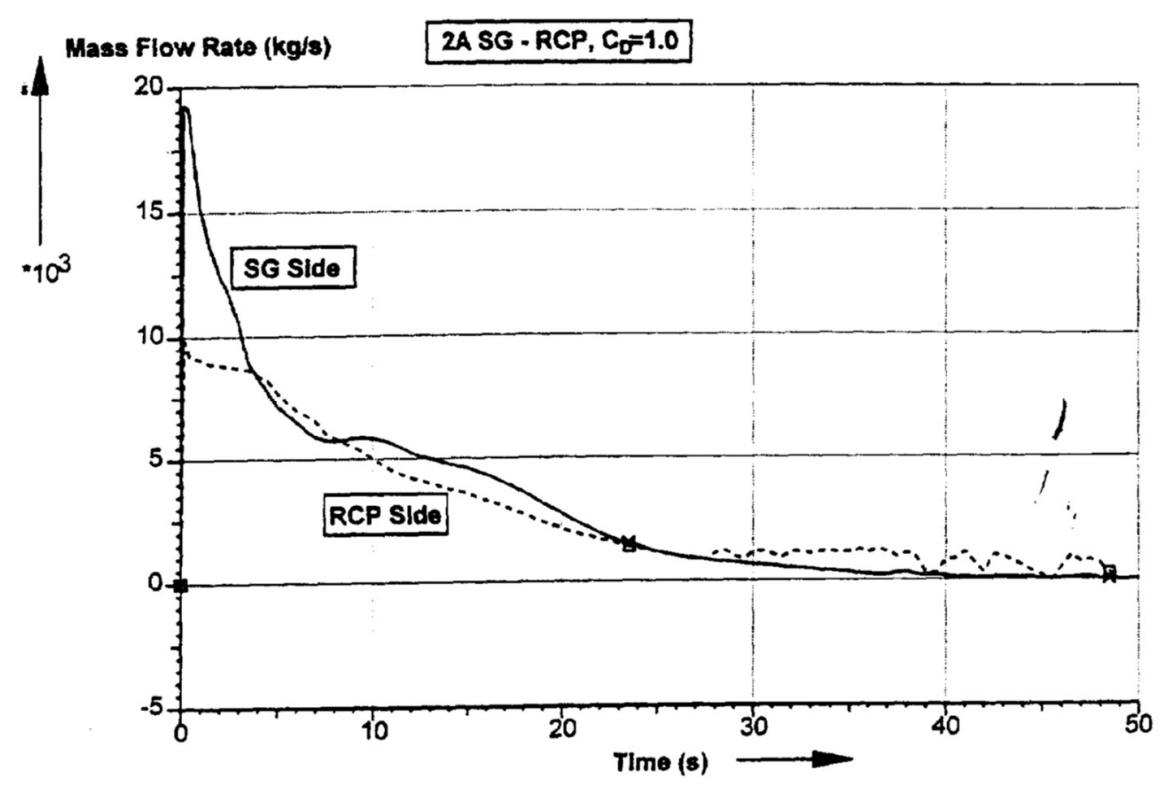

FIGURA AC10(b) - Vazão mássica na ruptura da tubulação do primário de Angra 2LBLOCA-PI do RFAS/A2

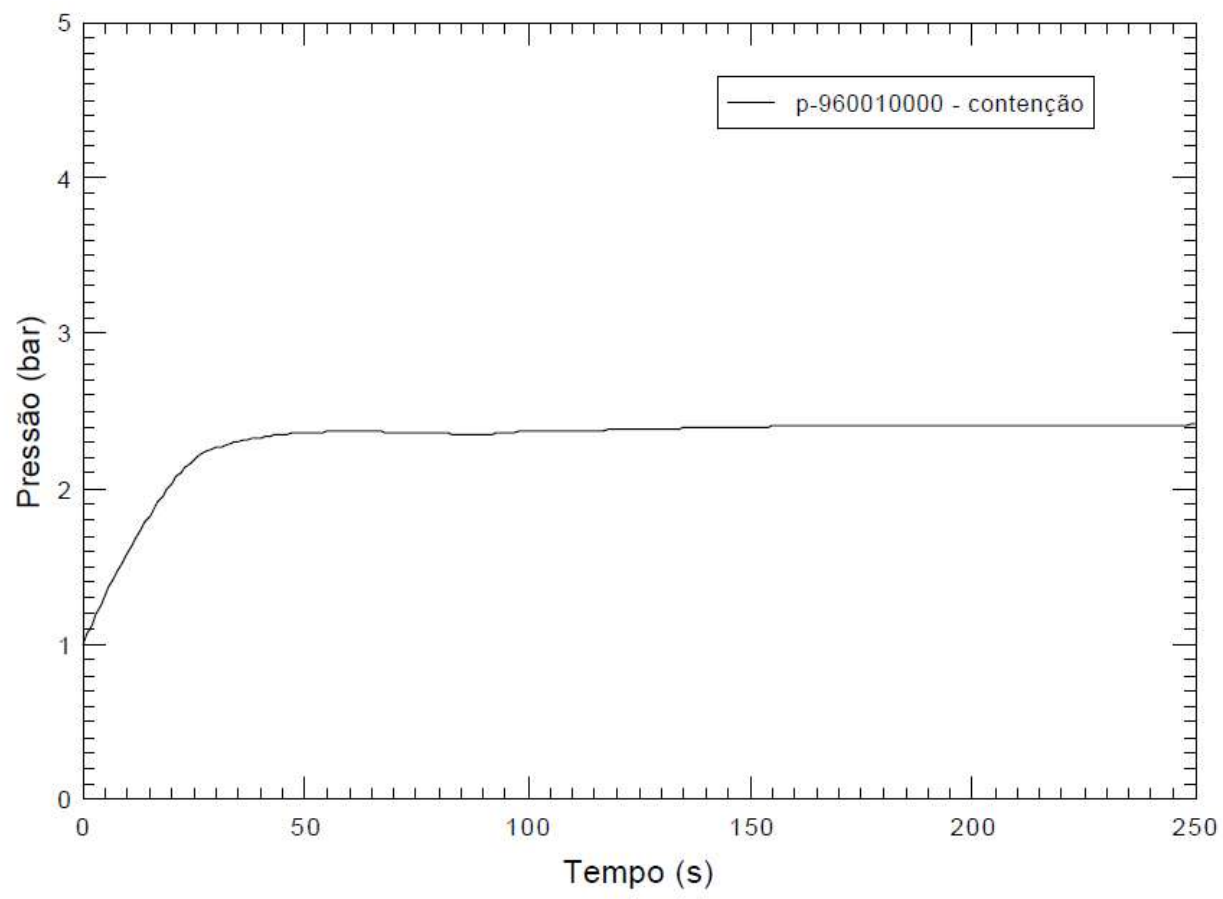

FIGURA AC11(a) - Pressão na contenção de Angra 2 - LBLOCA-PI com RELAP5 


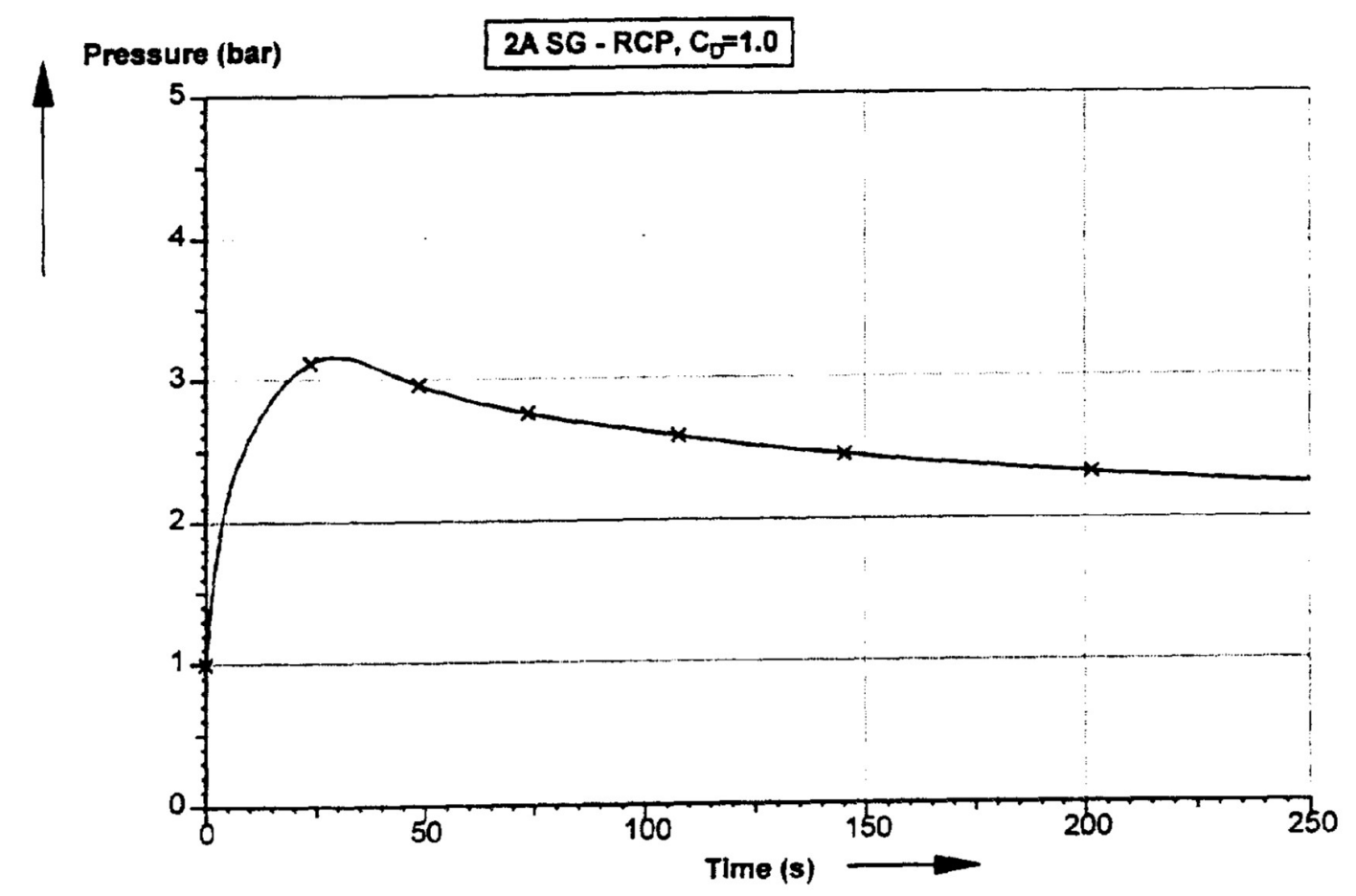

FIGURA AC11(b) - Pressão na contenção de Angra 2 - LBLOCA-PI do RFAS/A2

A FIG. AC12 apresenta as temperaturas do líquido e do vapor dentro da contenção. Ambas as temperaturas estão em $34^{\circ} \mathrm{C}$ no instante da ruptura, pois se encontravam em regime permanente; sobem rapidamente até $104^{\circ} \mathrm{C}$, em $20 \mathrm{~s}$, e se estabilizam em torno deste valor. 


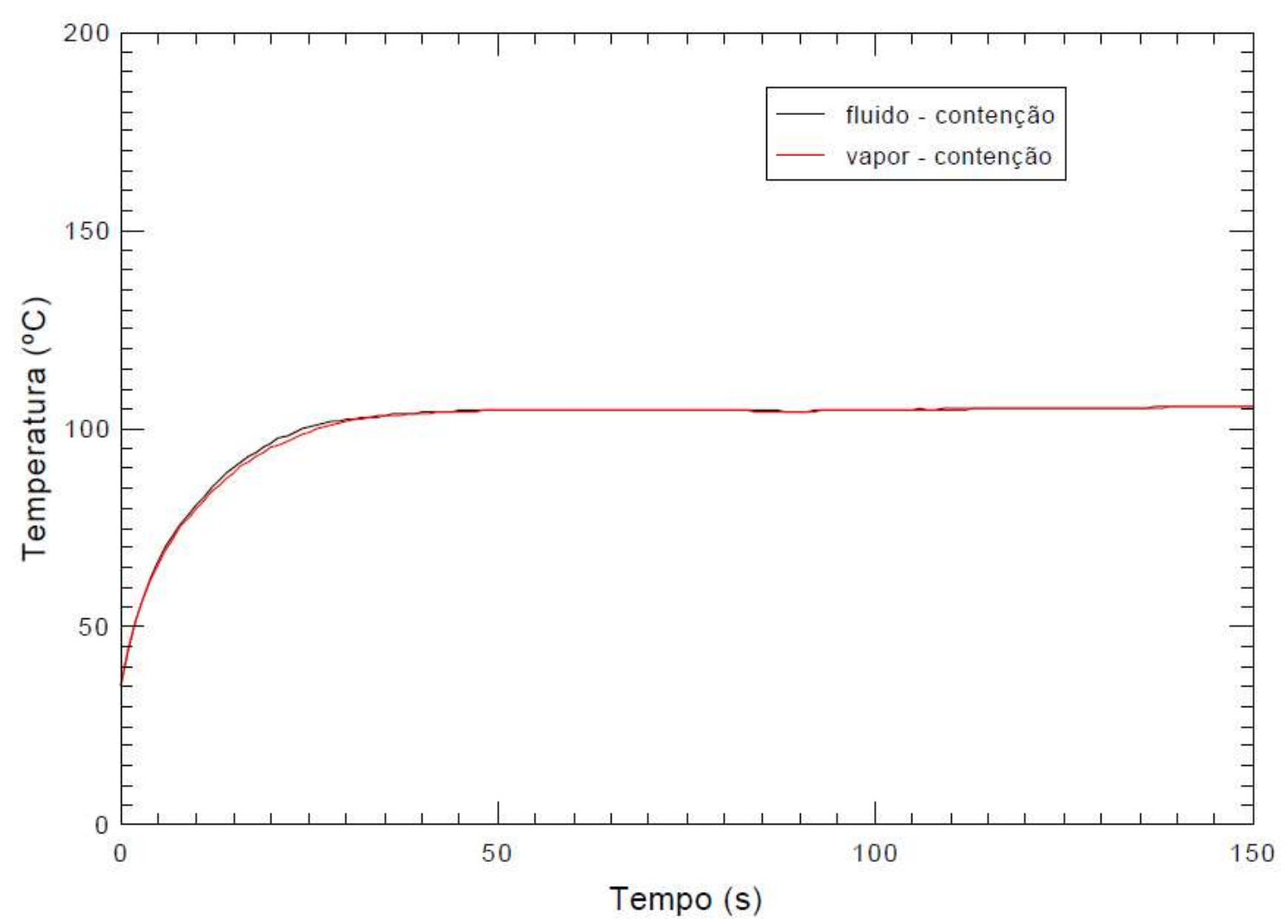

FIGURA AC12 - Temperatura na contenção de Angra 2 - LBLOCA-PQ com RELAP5

\section{C.3 Simulação do LBLOCA-PQ de Angra 2 com RELAP5}

Os resultados obtidos por meio da simulação realizada com o código RELAP5 podem ser vistos por meio das FIG. AC13(a) a AC17(a) e a FIG. AC18, e as variáveis correspondentes do RFAS/A2 são apresentadas nas FIG. AC13(b) a AC17(b).

Na FIG. AC13(a) são mostradas as pressões na perna quente do circuito primário, no circuito secundário e no pressurizador; cujos valores em regime permanente são: 158bar, 64,5bar, e 158,4bar, respectivamente. Os resultados obtidos nessa simulação apresentam o mesmo comportamento e têm valores próximos aos do RFAS/A2, FIG. AC13(b). Nota-se, por meio da FIG. AC13(a), que as quedas das pressões no sistema primário e no pressurizador 
são mais acentuadas em comparação às da FIG. AC13(b), ou seja, as pressões obtidas pelo RELAP5 atingem as estabilizações em torno de 2,5bar, com mais de 10s de antecedência, quando comparadas com as do RFAS/A2. Contudo, a pressão do sistema secundário, obtida pelo RELAP5, tem um comportamento muito semelhante à do RFAS/A2, sendo que elas se estabilizam em torno de 65,6bar e 68bar, respectivamente.

Por meio da FIG. AC14(a), observa-se que o primeiro pico de temperatura do encamisamento na parte inferior do elemento mais quente do núcleo do reator é de $355^{\circ} \mathrm{C}$ e o segundo pico é de $521^{\circ} \mathrm{C}$. As temperaturas obtidas pelo RFAS/A2, FIG. AC14(b), são menores que as do RELAP5, ou seja, o primeiro pico está em torno de $356^{\circ} \mathrm{C}$ e o segundo pico por volta de $300^{\circ} \mathrm{C}$. Em ambas as figuras, as temperaturas tendem a se estabilizar no instante de 250 s e variam entre 107 e $125^{\circ} \mathrm{C}$, segundo a FIG. AC14(a). Conforme demonstrado na FIG. AC14(b), no entanto, as temperaturas se estabilizam em valores menores, entre $67^{\circ} \mathrm{C}$ e $103^{\circ} \mathrm{C}$. Na simulação com o RELAP5, o período em que o elemento permanece quente até se estabilizar é de 60s, FIG. AC14(a), enquanto que no RFAS/A2 este tempo é bem menor, em torno de 40s, conforme a FIG. AC14(b).

Observa-se pela FIG. AC15(a), simulado com RELAP5, que o primeiro pico da temperatura do encamisamento na parte superior do elemento mais quente do núcleo do reator é de $554^{\circ} \mathrm{C}$ e o segundo pico é de $679^{\circ} \mathrm{C}$, este último no instante $\mathrm{t}=40 \mathrm{~s}$. Ambas as temperaturas se estabilizam em torno de $130^{\circ} \mathrm{C}$. As temperaturas obtidas pelo RFAS/A2, FIG. AC15(b), são as seguintes: o primeiro pico é de $400^{\circ} \mathrm{C}$ e o segundo está em torno de $360^{\circ} \mathrm{C}$, e tendem a entrar em equilíbrio entre $110^{\circ} \mathrm{C}$ e $130^{\circ} \mathrm{C}$. Na simulação com o RELAP5, FIG. AC15(a), o período em que o elemento permanece quente é um pouco superior do que no da parte inferior do elemento, por volta de 70s. No caso do RFAS/A2, este período permanece o mesmo ao longo de todo o elemento mais quente, por volta de 40s, FIG. AC15(b).

As vazões mássicas obtidas durante a simulação do acidente proposto com o RELAP5, FIG. AC16(a), ou seja, pela ruptura do lado do vaso de pressão, válvula 951, é maior do que a vazão pelo lado do gerador de vapor, válvula 952, contudo, ambas as vazões tendem a se estabilizar em torno de $0,3 \times 10^{3} \mathrm{~kg} / \mathrm{s}$. Os 
valores máximos atingidos para cada uma das válvulas, 951 e 952, são de $9,4 \times 10^{3} \mathrm{~kg} / \mathrm{s}$ e $12,7 \times 10^{3} \mathrm{~kg} / \mathrm{s}$, respectivamente. Por outro lado, as vazões mássicas nos mesmos pontos de ruptura, segundo o RFAS/A2, FIG. AC16(b), têm valores máximos de $12,5 \times 10^{3} \mathrm{~kg} / \mathrm{s}$, pelo lado do gerador de vapor; e de $15,5 \times 10^{3} \mathrm{~kg} / \mathrm{s}$, pelo lado do vaso. Verifica-se que as vazões mássicas do RFAS/A2 decrescem mais lentamente, quando comparadas as do RELAP5 para a simulação proposta.

A pressão na contenção obtida pelo RELAP5, FIG AC17(a), se estabiliza em torno de 2,7bar, enquanto que no RFAS/A2, FIG AC17I(b), observa-se um pico por volta de 3,3bar aos $24 \mathrm{~s}$, aproximadamente. A pressão na contenção para o RFAS/A2 se estabiliza ao longo do tempo em torno de 2bar. Neste caso, a pressão na contenção obtida com o RELAP5 se estabelece em valores superiores aos do RFAS/A2.

Na FIG. AC18, verifica-se que as temperaturas do líquido e do vapor na contenção, que durante o regime permanente estão em $35^{\circ} \mathrm{C}$, no instante da ruptura, sobem rapidamente nos primeiros $25 \mathrm{~s}$ e se estabilizam em torno de $105^{\circ} \mathrm{C}$.

As temperaturas do encamisamento da vareta mais realista do núcleo de Angra 2, obtidas por meio da simulação do LBLOCA - PF e PQ - com o código best estimate RELAP5, é um dos principais fatores para manter a integridade da planta; no entanto, elas superestimaram as do RFAS/A2. 


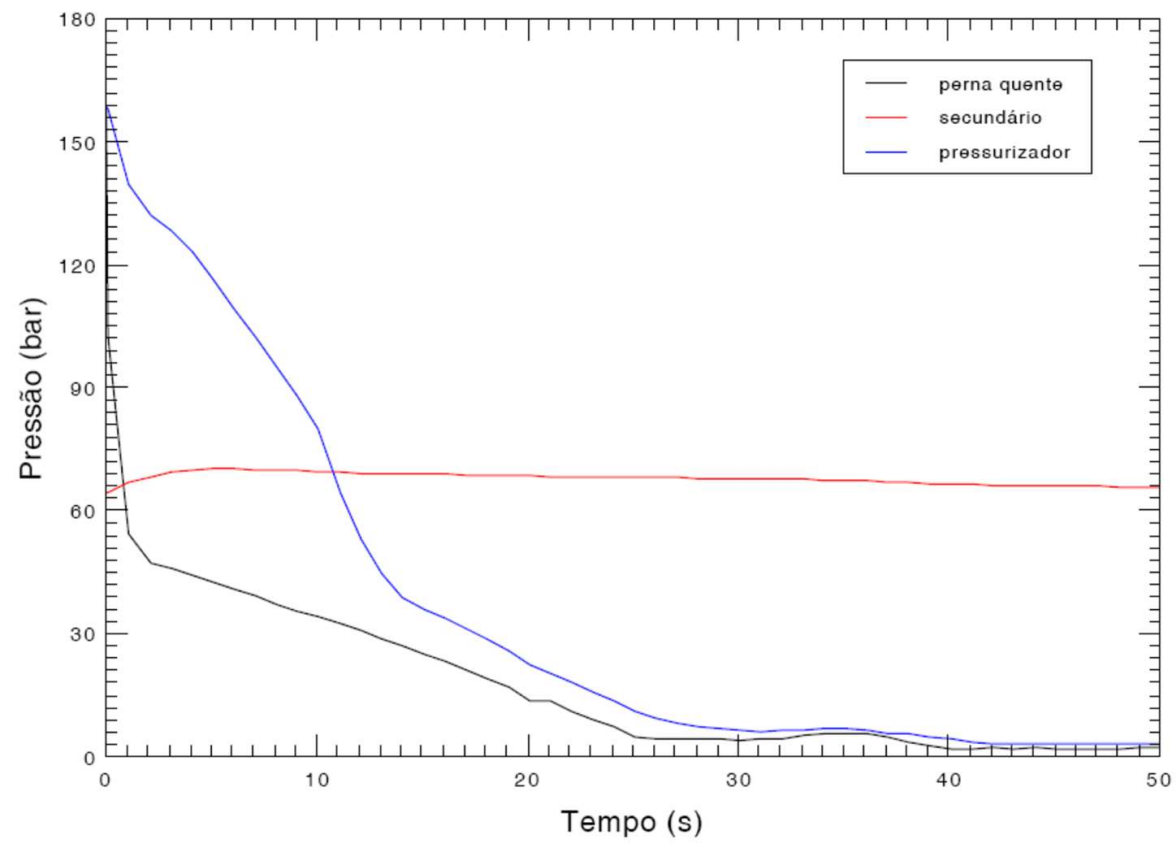

FIGURA AC13(a) - Pressões no lado primário, secundário e no pressurizador LBLOCA-PQ com RELAP5

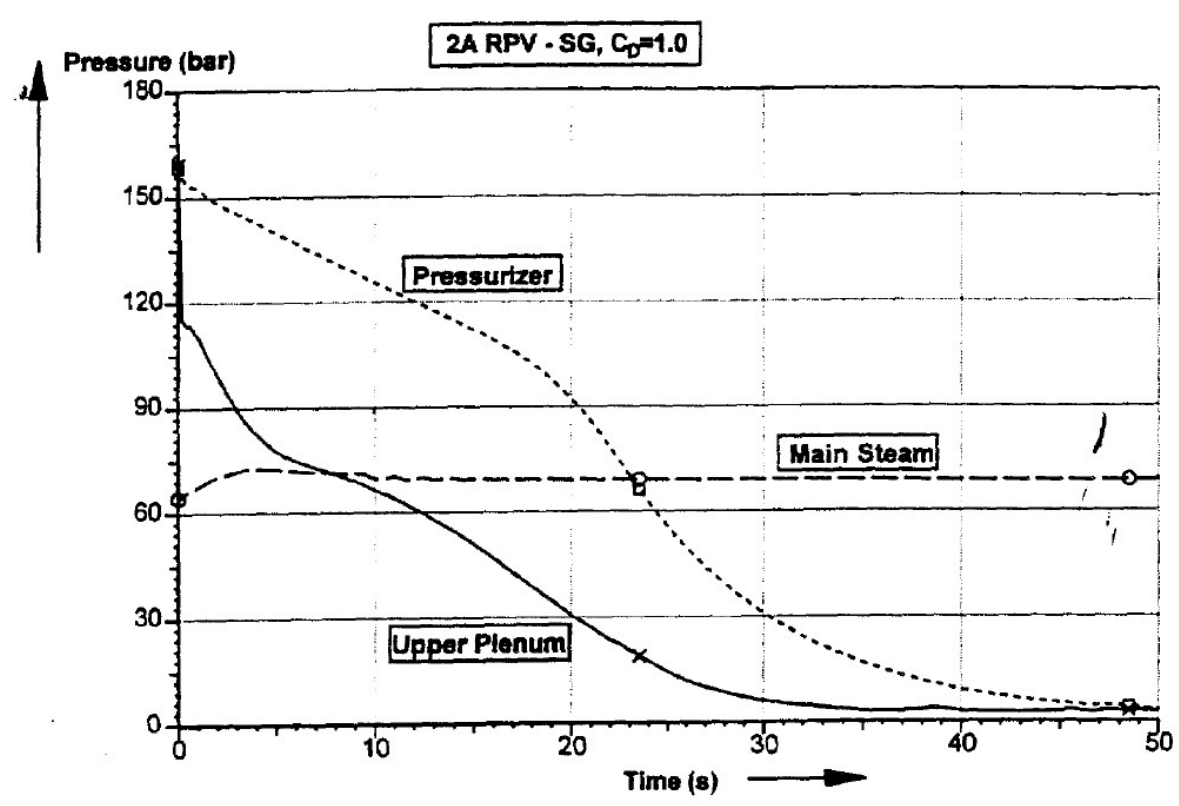

FIGURA AC13(b) - Pressões no lado primário, secundário e no pressurizador LBLOCA-PQ do RFAS/A2 


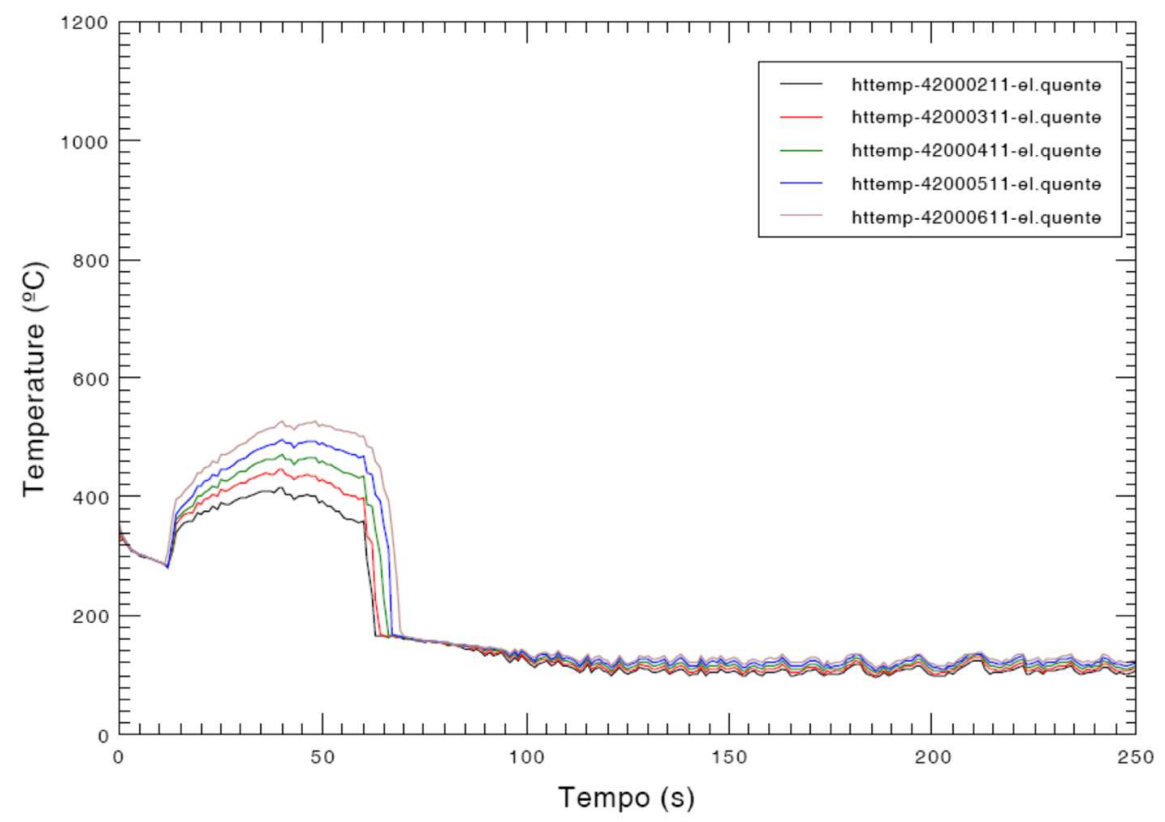

FIGURA AC14(a) - Primeiro e segundo picos de temperatura do encamisamento na parte inferior do elemento mais quente do reator Angra 2 - LBLOCA-PQ com

\section{RELAP5}

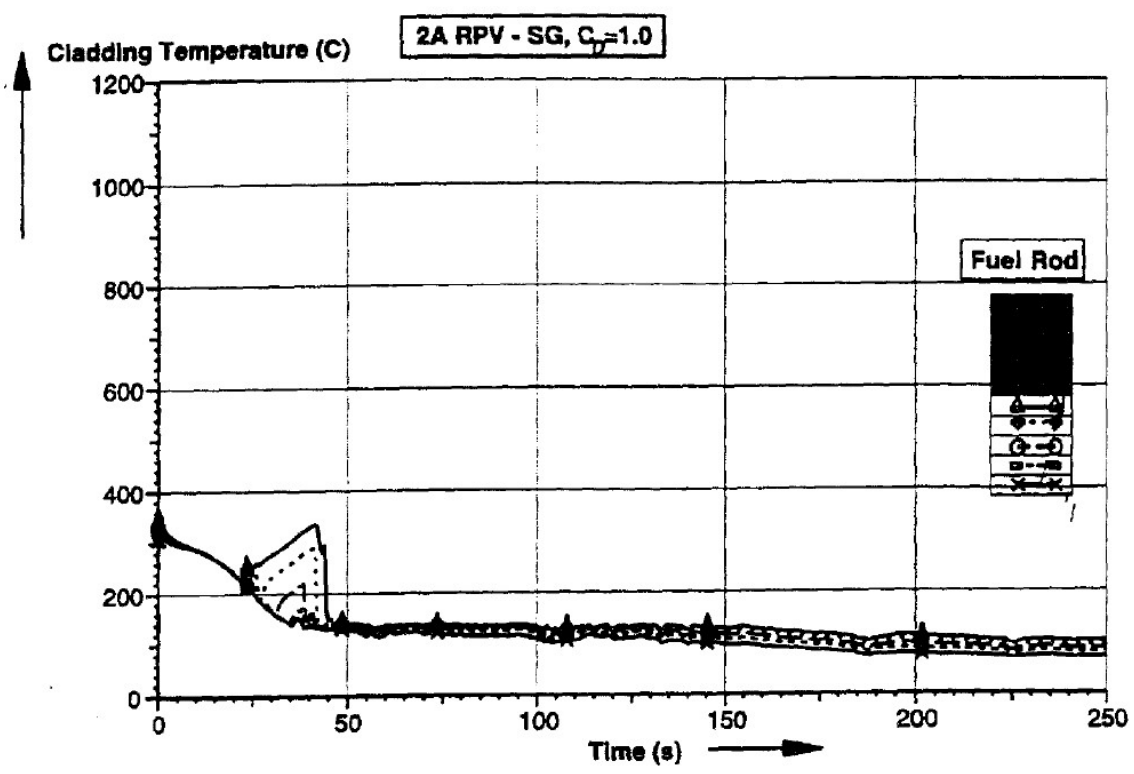

FIGURA AC14(b) - Primeiro e segundo picos de temperatura do encamisamento na parte inferior do elemento mais quente do reator Angra 2 - LBLOCA-PQ do RFAS/A2 


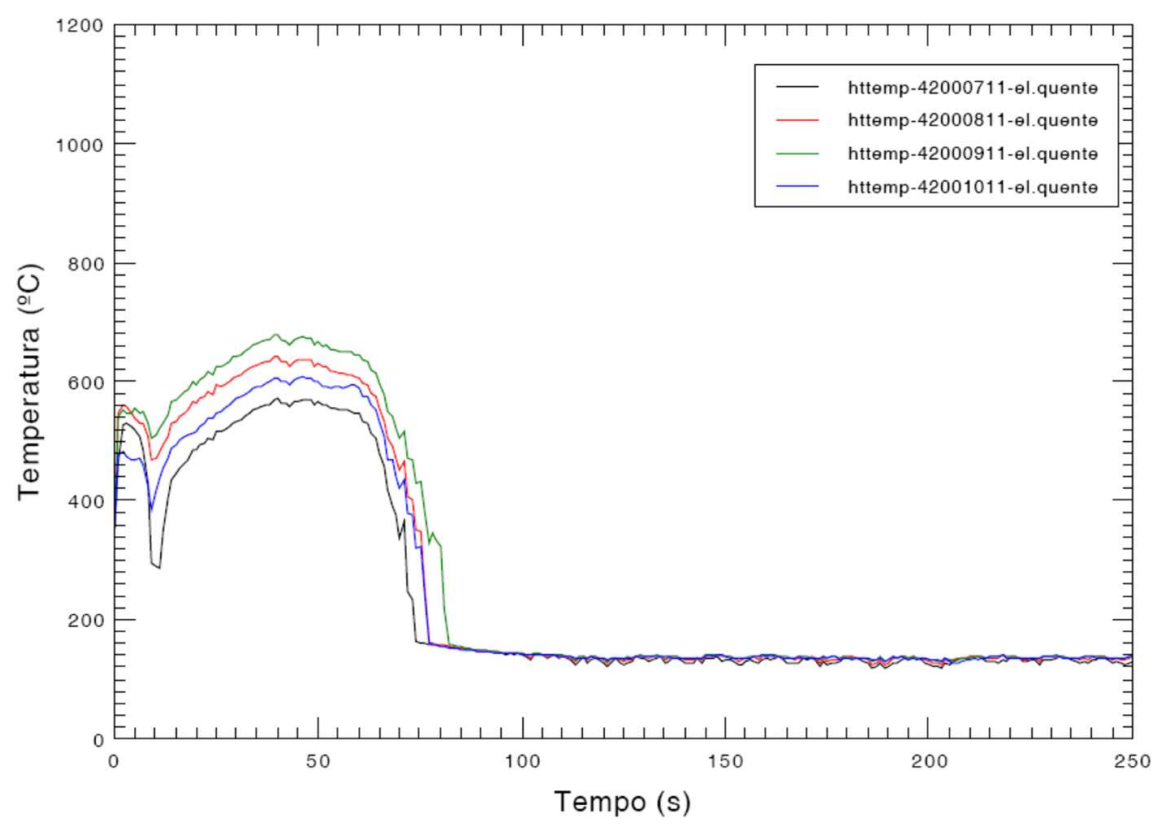

FIGURA AC15(a) - Primeiro e segundo picos de temperatura do encamisamento na parte superior do elemento mais quente do reator Angra 2 - LBLOCA-PQ com RELAP5

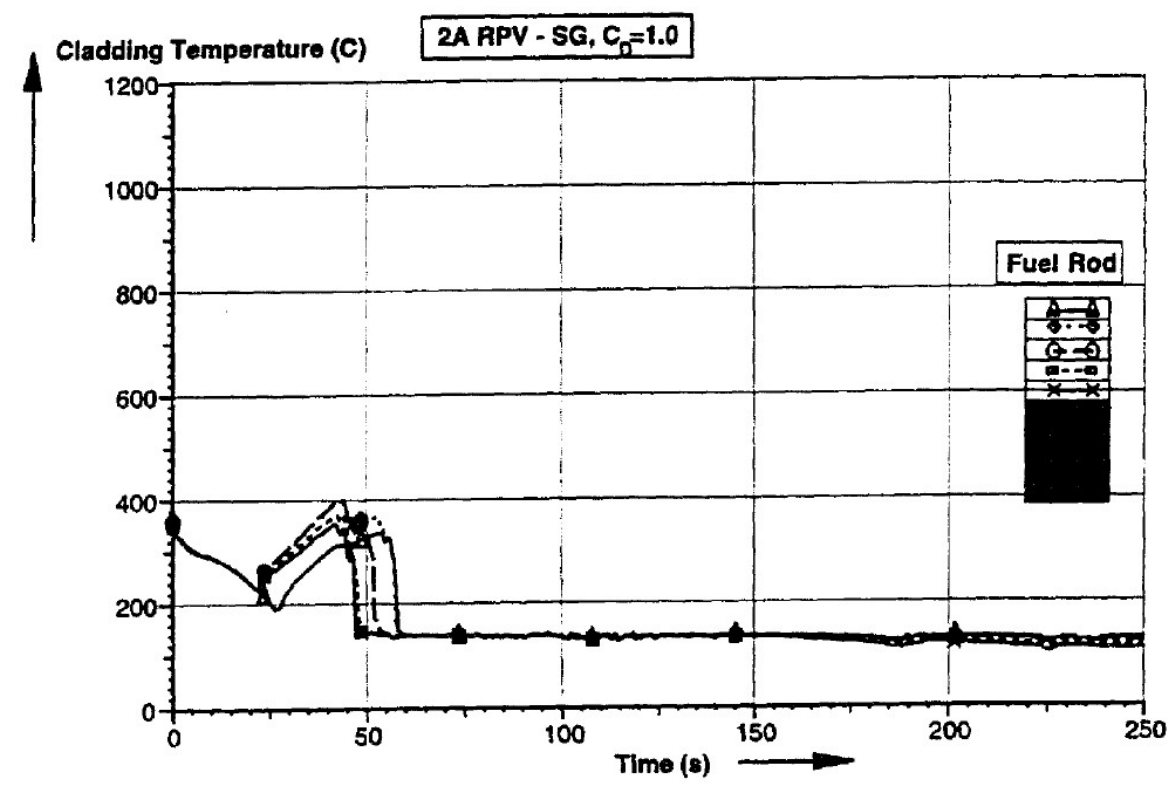

FIGURA AC15(b) - Primeiro e segundo picos de temperatura do encamisamento na parte superior do elemento mais quente do reator Angra 2 - LBLOCA-PQ do RFAS/A2 


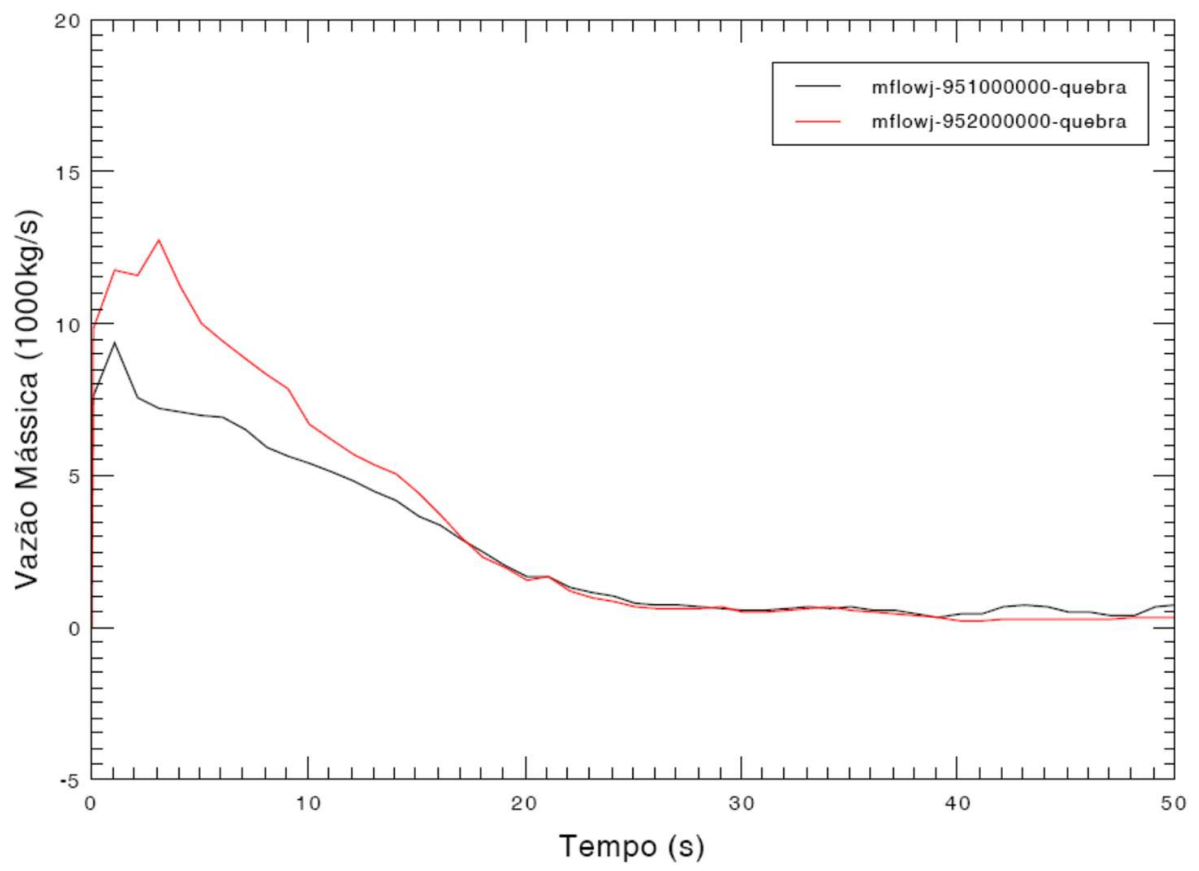

FIGURA AC16(a) - Vazão mássica na ruptura da tubulação do primário de Angra 2 - LBLOCA-PQ com RELAP5

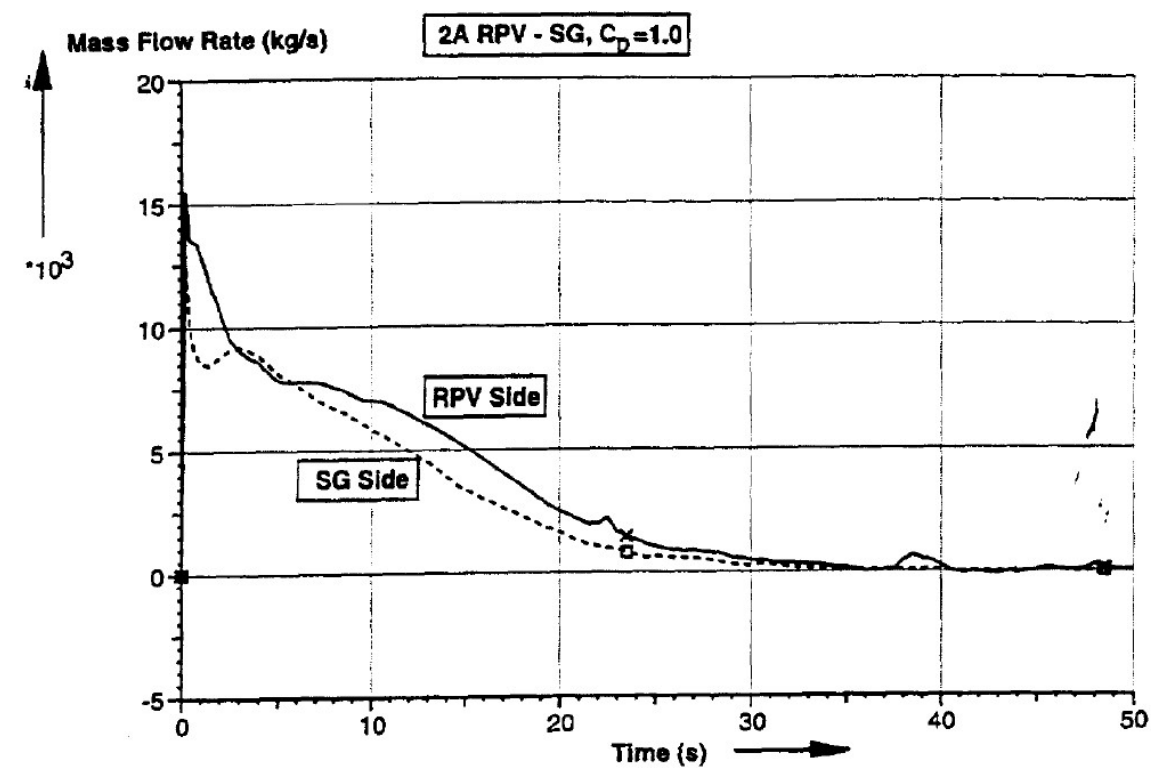

FIGURA AC16(b) - Vazão mássica na ruptura da tubulação do primário de Angra 2 - LBLOCA-PQ do RFAS/A2 


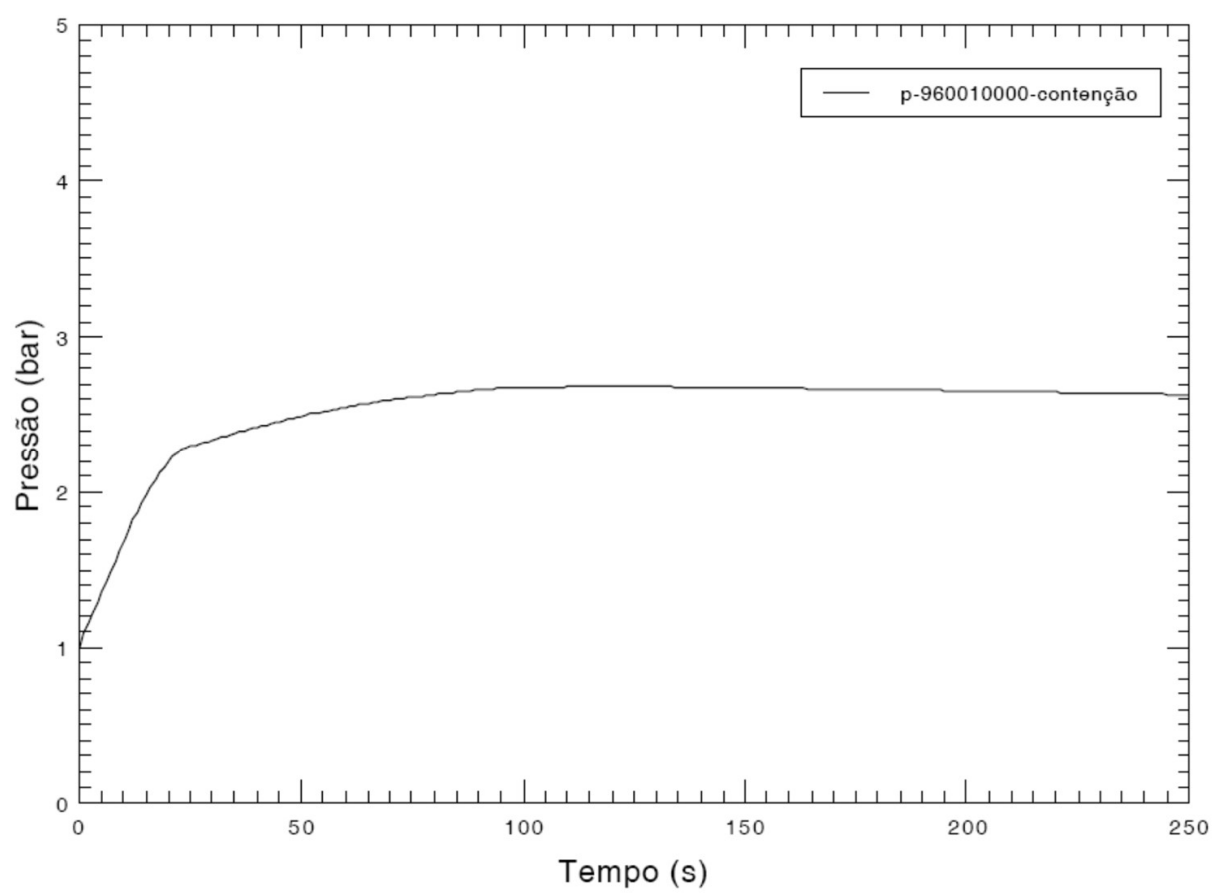

FIGURA AC17(a) - Pressão na contenção de Angra 2 - LBLOCA-PQ com RELAP5

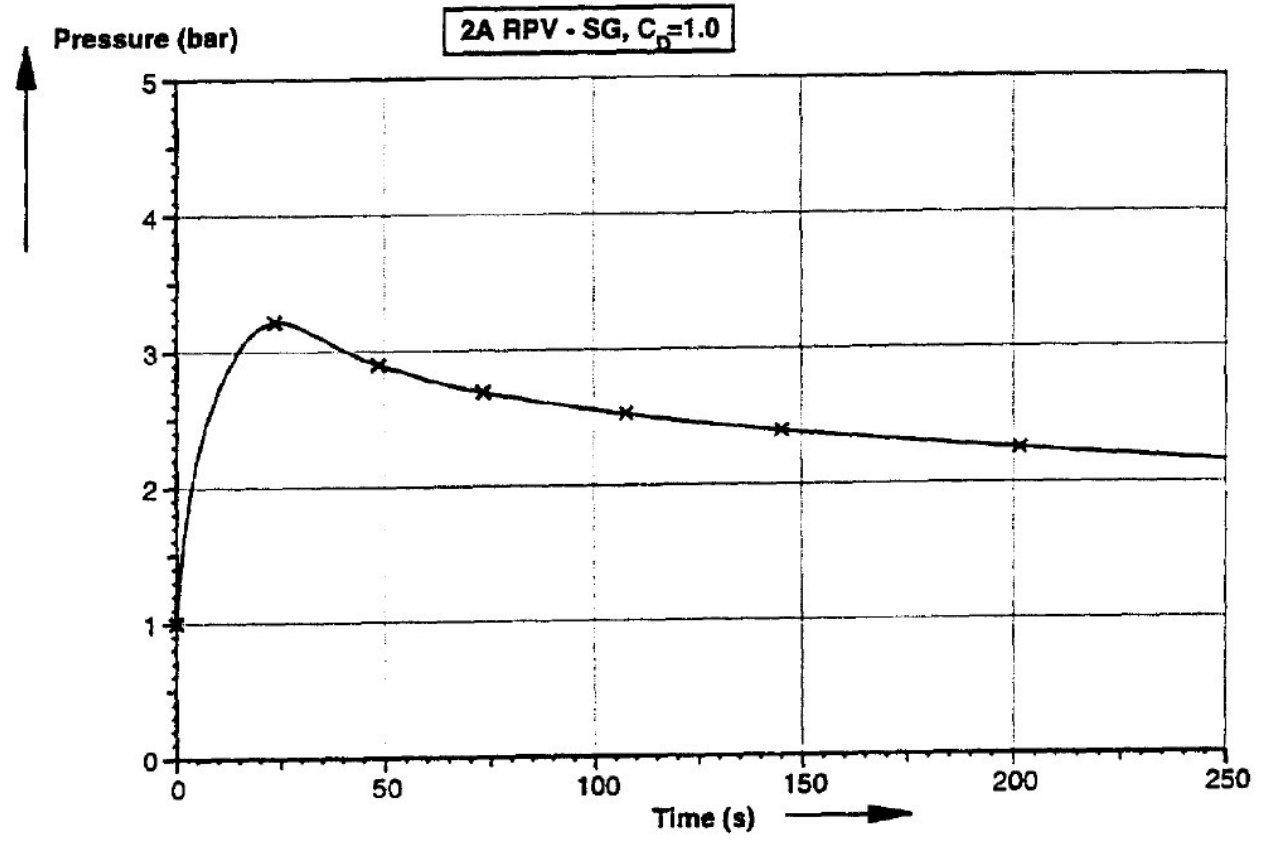

FIGURA AC17(b) - Pressão na contenção de Angra 2 - LBLOCA-PQ do RFAS/A2 


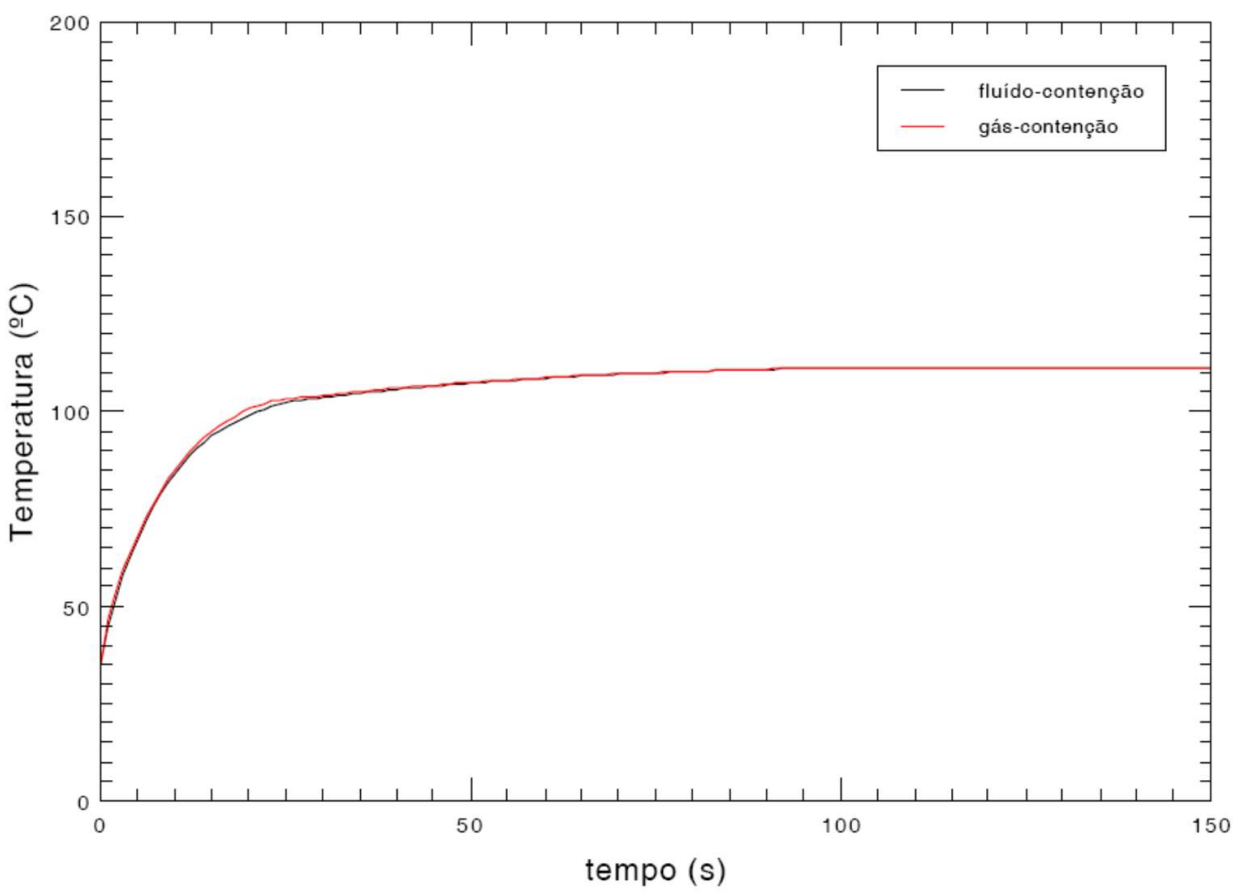

FIGURA AC18- Temperatura na contenção de Angra 2 - LBLOCA-PQ com RELAP5 


\section{REFERÊNCIAS BIBLIOGRÁFICAS}

ANDRADE, D. A.;SABUNDJIAN, G.Technical information-

PSE.CENT.DPD.008.01-INFT.001.00IRIS, IPEN Internal Document, April 2003.

BASTOS, W. S. An introduction to IV-generation fast reactors. In: :

INTERNATIONAL NUCLEAR ATLANTIC CONFERENCE - 13th Brazilian national meeting on reactor physics and thermal hydraulics, 6th Brazilian national meeting on nuclear applications, 2002, Rio de Janeiro, Brazil, Proceedings... Rio de Janeiro,2002, p.3080.

BENJAMIN, A. S. Program plan for the investigation of vent-filtered containment conceptual designs for light water reactors. Sandia National Labs., Albuquerque, New Mexico, USA, 1979 (No. NUREG/CR1029; SAND-79-1088).

CARELLI, M. D. et al. ICONE11-36564 - The design and safety features of the IRIS reactor. In: INTERNATIONAL CONFERENCE ON NUCLEAR ENGINEERING. Book of abstracts: ICONE. 一般社団法人日本機械学会, April 20-23, 2003, Tokyo, Japan, Proceedings...Tokyo, 2003, p. 198.

$\mathrm{CHIN}, \mathrm{Y}$. et al. Containment Code Validation Matrix. Organisation for Economic Co-Operation and Development, 2014.

D'AURIA, F. et al. UMAE Application: Contribution to the OECD/CSNI UMS Vol. 2, Uncertainty Methods Study for Advanced Best Estimate Thermal Hydraulic Code Applications, v.. 2, NEA/CSNI/R(97)35, França, 1998.

D'AURIA, F. et al. The Best Estimate Plus Uncertainty (BEPU) Approach in Licensing of Current Nuclear Reactors. Nuclear Engineering and Design, v. 248, p. 317-328, 2012.

DOE, U. S. et al. A technology roadmap for generation IV nuclear energy systems. In: Nuclear Energy Research Advisory Committee and the Generation IV International Forum, 2002.

DUNCAN, F.; HOLL, J. M.; Shippingport: the nation's first atomic power station - U.S. Department of the Interior, Philadelphia, Pennsylvania - HAER $N^{\circ} \mathrm{PA}-81-1983$.

ENERGY, CANDU; Enhanced CANDU 6® Technical Summary. tech. rep., Candu Energy, Mississauga, ON, 2012. 
ELETRONUCLEAR, Final Safety Analysis Report - Central Nuclear Almirante Álvaro Alberto - Unit 2, ELETRONUCLEAR S. A., Doc. Ident. MA/2-0809.2/060000, Rev. 10, 2010

FIORI, F. Application of Best Estimate Plus Uncertainty methods in licensing of Water Cooled Reactors. Universidade de Pisa. Tese de Mestrado. 2009.

GEIST, Al. PVM: Parallel virtual machine: a users' guide and tutorial for networked parallel computing. MIT press, 1994.

GOLDBERG, S. M.; ROSNER, R. Nuclear reactors: generation to generation. Bulletin of the American Academy, v. 1, 2011.

GRIMSTON, M C.; BECK, P. An enquiry into the future of civil nuclear energy. Nuclear energy, v. 39, n. 6, p. 331-337, 2000.

GRUPO DE TRABALHO. Simulação de Angra 2 com o Código Relap5/Mod3. 2.2 Gamma. Sessão Técnica Especial. XII Encontro Nacional de Física de Reatores e Termohidráulica, Rio de Janeiro, RJ, p. 15-20, 2000.

INTERNATIONAL ATOMIC ENERGY AGENCY. The Chernobyl Accident: Updating of INSAG-1. 75-INSAG-7, Safety Series.Vienna: IAEA, 1992

INTERNATIONAL ATOMIC ENERGY AGENCY. One decade after Chernobyl : Summing up the Consequences of the Accident. Vienna: IAEA, 1996.

INTERNATIONAL ATOMIC ENERGY AGENCY. Incorporation of advanced accident analysis methodology into safety analysis reports (IAEA-TECDOC--1351). Vienna: IAEA, 2003.

INTERNATIONAL ATOMIC ENERGY AGENCY. Design Of Reactor Containment Systems For Nuclear Power Plants (No. NS-G-1.10). Vienna: IAEA, 2004.

INTERNATIONAL ATOMIC ENERGY AGENCY. Fundamental Safety Principles. Safety standards series No. SF-1. Vienna: IAEA, 2006.

INTERNATIONAL ATOMIC ENERGY AGENCY. 6 th Review Meeting of the Contracting Parties to the Convention on Nuclear Safety. Summary Report, CNS/6RM/2014/11_Final (2014).

INTERNATIONAL ATOMIC ENERGY AGENCY. The Fukushima Daiichi Accident - Description and context of the Accident, Vol.1, Vienna: IAEA, Agosto de 2015. 
JENSEN, S. E.; NONBOL, E. Description of the Magnox Type of Gas Cooled Reactor (MAGNOX). Riso National Laboratory Roskilde, Denmark NKS/RAK-2(97)TR-C5 - ISBN 87-7893-050-2 - 1988

KINLY III, D. Chernobyl's legacy: Health, environmental and socioeconomic impacts and recommendations to the Governments of Belarus, the Russian Federation and Ukraine. The Chernobyl Forum 2003-2005. Second revised version. 2006.

KLEIN-HESSLING, W.; ARNDT, S.; WEBER, G. COCOSYS User Manual. Reference Manual, Implementation Manual, GRS-P-3/1, v. 3, n. 2, 2000.

KORTOV ,V.; USTYANTSEV ,Y. Chernobyl Accidents: Causes, consequences and problems of radiation measurements v. 55, pp 12-16 In: 7th International Workshop on lonizing Radiation Monitoring, August 2013.

KOSS, M., Software for Uncertainty and Sensitivity Analyses - SUSA, version 4.0. GRS, January 2015.

MARQUES, J. G. Safety of Nuclear Fission Reactors: Learning from Accidents. Nuclear Energy Encyclopedia: Science, Technology and Applications, 1st ed., Jay H. Lehr and Thomas B. Kingery Steven B. Krivit, Ed.: John Wiley \& Sons, Inc., 2011.

MATZIE, R. A.; RITTERBUSCH, S. E. SYSTEM 80+ ${ }^{\text {TM }}$ Standard PlantDesign and Operations Overview. Evolutionary water cooled reactors: Strategic issues, technologies and economic viability, p. 430, 1999.

MICAELLY, J. ; BESTUIB, D. CATHARE, the New Improved French Thermal Hydraulic Code for Safety Reactor Studies, In: INTERNATIONAL ENS/ANS CONFERENCE ON THERMAL REACTOR SAFETY, October 2-7, 1988, Avignon, France, Proceedings... Avignon

MURATA, K. K. et al. Code manual for CONTAIN 2.0: a computer code for nuclear reactor containment analysis. Sandia National Laboratories, Albuquerque, New Mexico, USA, 1997.

NASCIMENTO, J. A; ONO, S.; GUIMARÃES, L. N. F. Reator Nuclear Rápido de Altíssima Temperatura para Produção de Hidrogênio no Brasil.

Disponível em:

<http://www.iaea.org/inis/collection/NCLCollectionStore/_Public/40/030/4003 0770.pdf> Acessado em: 02-05-16. 
NONBOL, E. Description of the Advanced Gas Cooled Type of Reactor (AGR). Riso National Laboratory Roskilde, Denmark - NKS/RAK2(96)TR-C2 - November 1996.

NOORI-KALKHORAN, O. et al. Analysis of thermal-hydraulic parameters of WWER-1000 containment in a large break LOCA. Annals of Nuclear Energy, v. 68, p. 101-111, 2014.

OLIVEIRA, L. F. S. Um sumário de acidente de Three Mile Island: do instante Zero às lições para o futuro. Vienna, Austria, IAEA, 1982.

RAGHEB, M. Containment Structures. Probabilistic, Possibilistic and Deterministic Safety Analysis. Nuclear Applications. Disponível em <https://netfiles.uiuc.edu/mragheb /www/NPRE>, v.20457, 2011.

RAHU, M. Health effects of the Chernobyl accident: fears, rumours and the truth. European Journal of Cancer, v. 39, n. 3, p. 295-299, 2003.

RICKARD, N. D. COCO: A computer program for seismic analysis of a single column of the HTGR core. General Atomic Co., 1978.

SABUNDJIAN, G. Simulação dos Acidentes básicos de projeto, LBLOCAs, em Angra 2 com o Código RELAP5. Relatório Técnico- PSE-DRS-011-00 RELT-002-00, IPEN Documento Interno, Julho 2016.

SAGI, G., A Post Accident Safety Analysis Report of the Fukushima Accident - Future Direction of Evacuation: Lessons Learned, In: 21st INTERNATIONAL CONFERENCE ON NUCLEAR ENGINEERING, ICONE21-16526, 2013.

SCHULZ, Terry L. Westinghouse AP1000 advanced passive plant. Nuclear Engineering and Design, v. 236, n. 14, p. 1547-1557, 2006.

SILVA, D.E. et al. Analysis of the behaviour of pressure and temperature of the containment of a PWR reactor, submitted to a postulated loss-ofcoolant accident (CNEN-DR--85/79). Brazil, 1979.

SPORE, J.W. et al.; TRAC-PF1/MOD2 Code Manual, Volume 1, Theory Manual, NUREG/CR-5673, LA-12031-M, 1993

STRUPCZEWSKI, A. Accident risks in nuclear-power plants. Applied Energy, v. 75, n. 1, p. 79-86, 2003.

TEPCO, Tokyo Electric Power Company, Inc.; "Fukushima Nuclear Accident Analysis Report" June 20, 2012. 
The RELAP5 Development Team. RELAP5/MOD3 Code Manual, Code Structure, System Models, and Solution Methods, Idaho National Engineering Laboratory, NUREG/CR-5535, INEL-95/0174, Volume 1, 1999.

USNRC - United States Nuclear Regulatory Commission. 10 CFR 50.46 Acceptance criteria for emergency core cooling systems for light-water nuclear power reactors, 1974

USNRC, US Nuclear Regulatory Commission. Three Mile Island: A report to the commissioners and to the public, Vol. 1, Washington, D.C. (Janeiro 1980).

USNRC LICENSING OF PRODUCTION AND UTILIZATION FACILITIES, Code of Federal Regulations, Title, v. 10, 1980.

USNRC; US Nuclear Regulatory Commission. Severe accident risks: as assessment for five U.S. nuclear plants, NUREG-1150, Final Report (December. 1990).

USNRC, US Nuclear Regulatory Commission. History, March 30, 2016 disponível em <http://www.nrc.gov/about-nrc/emergpreparedness/history.html> Acessado em: 02-01-17.

Westinghouse Electric Company Lcc. IRIS Plant Description Document. Westinghouse Proprietary Class 2 - WCAP 16062 - P. March 21, Pittsburgh, 2003.

WOLFER, K. et al. The GRS Thermal Hydraulic System Code ATHLET for PWR and BWR Analysis, In: 3RD INT. TOPICAL MEETING ON NUCLEAR POWER PLANT THERMAL HYDRAULICS AND OPERATION, November 14-17, 1988, Seoul, Korea, Proceedings... Seoul. 